\title{
Fatigue and Fracture Library for the Inspection, Evaluation, and Repair of Vehicular Steel Bridges
}

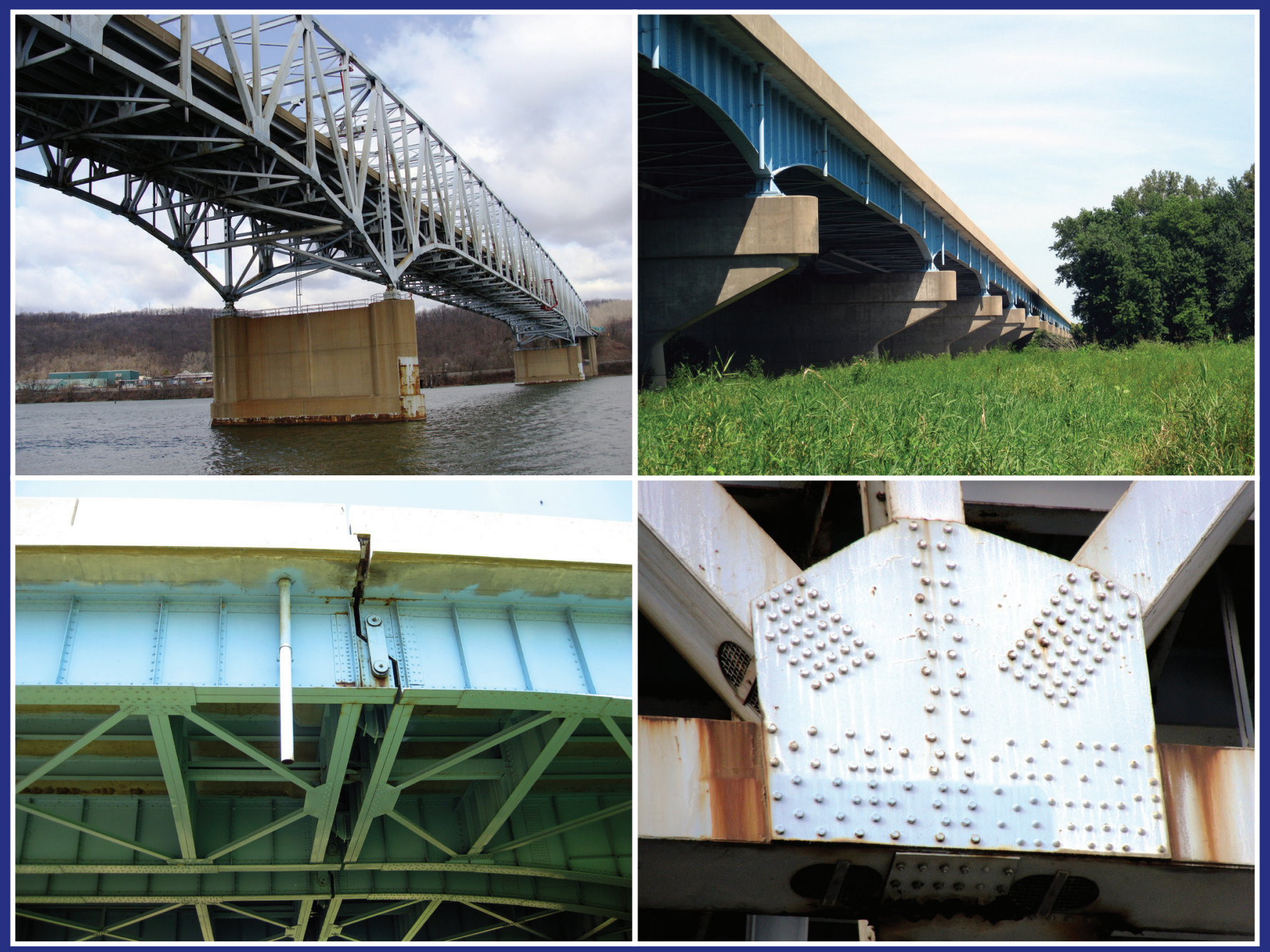

Phil Fish, Curtis Schroeder, Robert J. Connor, Phil Sauser

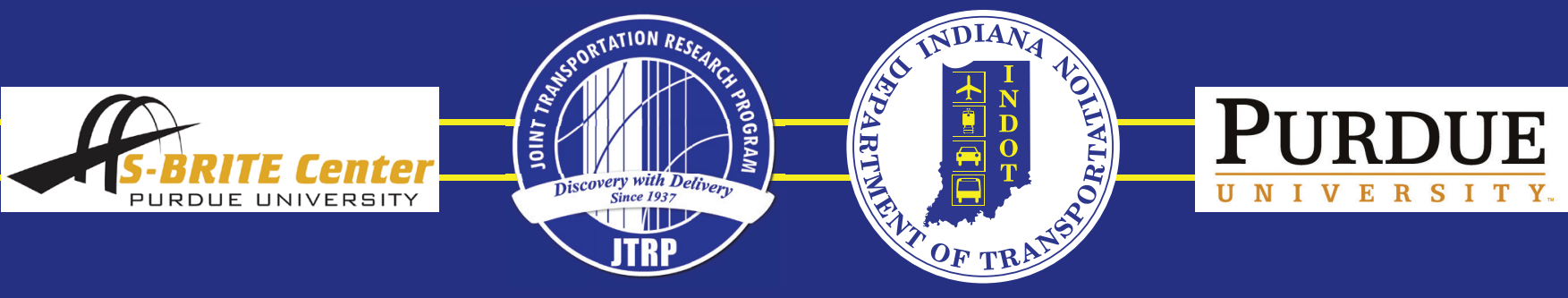




\section{RECOMMENDED CITATION}

Fish, P., Schroeder, C., Connor, R. J., \& Sauser, P. (2015). Fatigue and fracture library for the inspection, evaluation, and repair of vehicular steel bridges. West Lafayette, IN: Purdue University. http://dx.doi.org/10.5703 $/ 1288284315520$

\section{AUTHORS}

\section{Phil Fish}

Fish \& Associates, Inc.

\section{Curtis Schroeder}

Fish \& Associates, Inc.

\section{Robert J. Connor}

Purdue University

\section{Phil Sauser}

United States Army Corps of Engineers

\section{ACKNOWLEDGMENTS}

The purpose of this document is to inform and to educate engineers in the fundamentals of fatigue and fracture, particularly as it relates to existing steel bridges, and to provide guidance on the evaluation of these bridges to determine their suitability for given conditions and use and on the implementation of repairs. The information used in this document is based on a review of published literature and the review and input of experts in the field of fatigue and fracture.

Thanks must be given to the following individuals for their technical review and input:

Mark Bowman-Purdue University

Barry Brecto-FHWA

Thomas Drda-FHWA

Thomas Everett-FHWA

Dennis Mertz-University of Delaware

Gary Moss-FHWA

John Thiel-FHWA

Bill Wright—Virginia Polytechnic Institute and State University

\section{NOTICE}

The contents of this document reflect the views of the authors, who are responsible for the facts and the accuracy of the data presented herein. The contents do not necessarily reflect the official views and policies of the US Army Corps of Engineers. The report does not constitute a standard, specification or regulation.

\section{COPYRIGHT}

Copyright 2015 by Purdue University. All rights reserved.

Print ISBN: 978-1-62260-328-2

ePUB ISBN: 978-1-62260-329-9 
1. FATIGUE AND FRACTURE FUNDAMENTALS $\ldots \ldots \ldots \ldots \ldots \ldots \ldots \ldots \ldots \ldots \ldots \ldots$

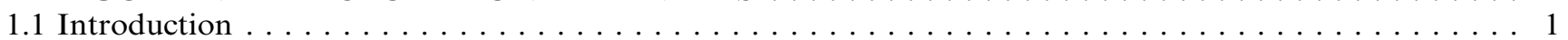

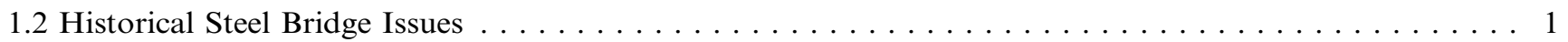

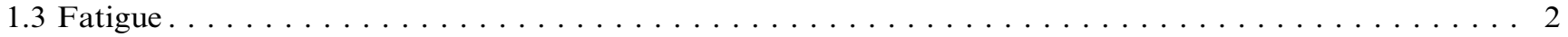

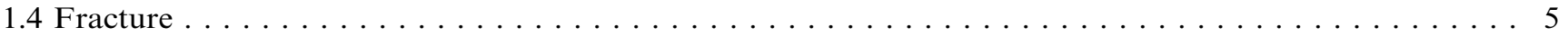

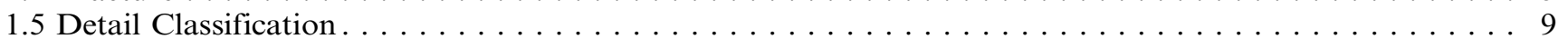

1.6 Considerations for Evaluating Existing Structures. $\ldots \ldots \ldots \ldots \ldots \ldots \ldots \ldots \ldots \ldots \ldots \ldots \ldots \ldots$

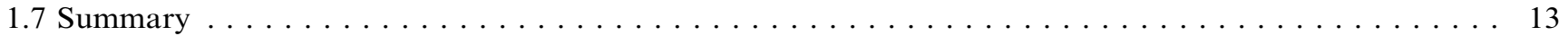

2. FATIGUE AND FRACTURE DETAIL LIBRARY $\ldots \ldots \ldots \ldots \ldots \ldots \ldots \ldots \ldots \ldots \ldots \ldots \ldots \ldots$

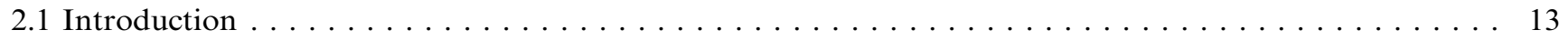

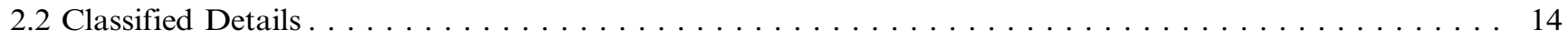

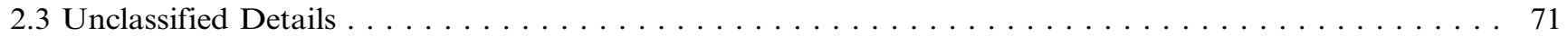

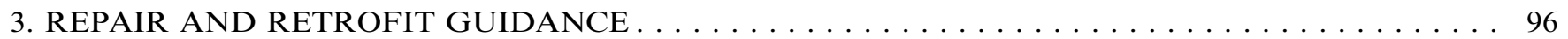

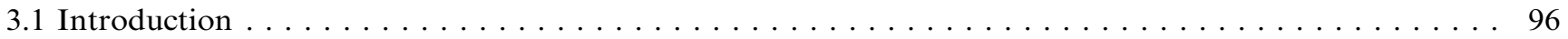

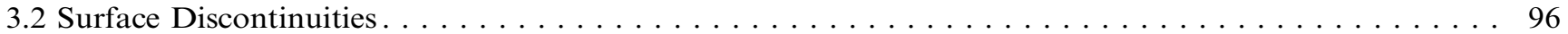

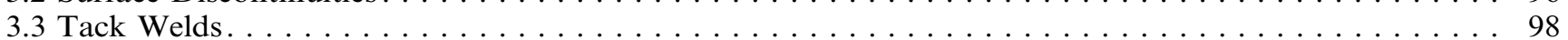

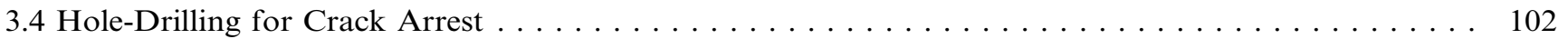

3.5 Weld Toe Improvement Techniques . . . . . . . . . . . . . . . . . . . . . . . . . . . 103

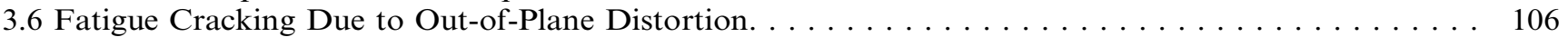

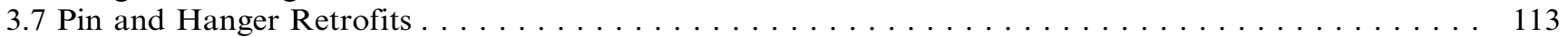

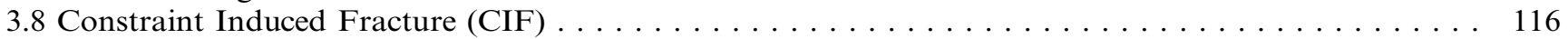

3.9 Cover Plate Repair . . . . . . . . . . . . . . . . . . . . . . . . . . . . . . . . . 120

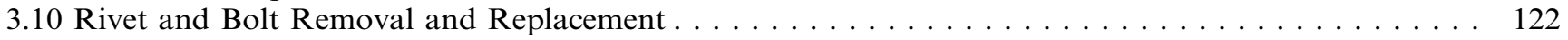

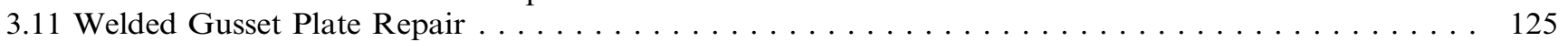

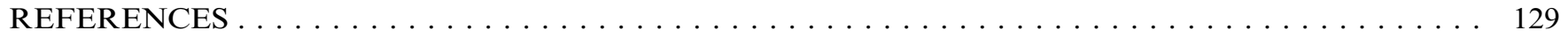




\section{LIST OF FIGURES}

Figure

Figure 1.1 Stress-range cycles

Figure 1.2 S-N plot, AASHTO detail category D

Figure 1.3 (Left) ductile fracture; (right) brittle fracture

Figure 1.4 Stress concentrations in a web plate at edges of a welded detail

Figure 1.5 Material toughness

Figure 1.6 Charpy impact test apparatus

Figure 1.7 Sample Charpy energy transition curve

Figure 1.8 Brittle and ductile fracture of CVN specimens

Figure 1.9 Temperature shift

Figure 1.10 Distortion-induced cracking

Figure 3.1 Typical die grinder and stone wheels

Figure 3.2 Typical flapper-type paper grit sanding/polishing wheels

Figure 3.3 Intermittent welds used to attach a transverse stiffener

Figure 3.4 Tack weld with $100 \%$ throat crack

Figure 3.5 Tack weld with partial throat crack

Figure 3.6 Toe crack at tack weld

Figure 3.7 Tack weld cracking from pack rust

Figure 3.8 Crack arrest holes installed in a high-mast lighting tower

Figure 3.10 Sample peening detail

Figure 3.11 Web gap cracking at a diaphragm connection plate

Figure 3.12 Detailing considerations to prevent web gap cracking (left) at transverse connection plate; (right) at gusset plate

Figure 3.13 Crack arrest holes drilled at a transverse connection plate attached to a diaphragm

Figure 3.15 Mock-up of WT connection plate retrofit concept

Figure 3.17 Web softening technique

Figure 3.18 Schematic of typical large diameter hole retrofit

Figure 3.19 Implementation of large hole retrofit

Figure 3.20 Photo of typical pin and hanger assembly

Figure 3.21 Exploded view of typical pin and hanger assembly

Figure 3.22 Examination of failed hanger bar

Figure 3.23 Catcher system on a typical pin and hanger bridge

Figure 3.24 Rod-and-saddle system on a typical pin and hanger bridge

Figure 3.25 Complete girder splice installed to replace a pin and hanger connection in a two-girder bridge

Figure 3.27 Incomplete fusion in weld of transverse splice in longitudinal stiffener 
Figure 3.30 Hole-drilling process at gusset detail with difficult access

Figure 3.31 Retrofit hole (prior to finish grinding)

Figure 3.32 Close-up of retrofit hole with finished ground surface

Figure 3.33 Cover plate with weld at termination

Figure 3.34 Cover plate without weld at termination

Figure 3.35 Plan view of bolted cover plate retrofit (without splice plate)

Figure 3.36 Elevation view of bolted cover plate retrofit

Figure 3.37 Pack rust in mechanically fastened connections

Figure 3.38 Rivet head removal using rivet buster

Figure 3.39 Driving rivet out of connection plates using rivet buster

Figure 3.40 Drilling out center of rivet

Figure 3.41 Damaged surface after rivet removal around hole

Figure 3.42 Constraint-induced fracture in gusset plate connection

Figure 3.43 Cracking in flange of channel (gusset plate) and girder

Figure 3.44 Cracking in girder flange

Figure 3.45 Bolted splice gusset plate repair

Figure 3.46 Bolted connection angle gusset plate repair 


\section{GLOSSARY OF TERMS AND ABBREVIATIONS}

\begin{tabular}{|c|c|}
\hline AASHTO & American Association of State Highway Transportation Officials \\
\hline AISC & American Institute of Steel Construction \\
\hline ASTM & American Society of Testing Materials \\
\hline AWS & American Welding Society \\
\hline CAFL & Constant Amplitude Fatigue Life \\
\hline CAFT & Constant Amplitude Fatigue Threshold \\
\hline CIF & Constraint Induced Fracture \\
\hline CVN & Charpy V-Notch Test \\
\hline DTD & Damage Tolerant Design \\
\hline ET & Eddy Current Testing \\
\hline FCM & Fracture Critical Member \\
\hline FCP & Fracture Control Plan \\
\hline FFS & Fitness for Service \\
\hline HAZ & Heat Affected Zone \\
\hline HPS & High Performance Steel \\
\hline HS Bolt & High Strength Bolt \\
\hline Intermittent Welds & Evenly spaced short structural welds used to permanently attach components \\
\hline LAST & Lowest Anticipated Service Temperature \\
\hline LRFD & Load and Resistance Factor Design \\
\hline MT & Magnetic Particle Testing \\
\hline NCHRP & National Cooperative Highway Research Program \\
\hline NDT & Non-destructive Testing \\
\hline PT & Dye Penetrant Testing \\
\hline RCSC & Research Council on Structural Connections \\
\hline Repair & $\begin{array}{l}\text { A maintenance action to correct a localized deficiency and extend the life of an element or } \\
\text { component }\end{array}$ \\
\hline Retrofit & $\begin{array}{l}\text { Replacement of an element or component or the repair of a significant portion of an element } \\
\text { or component to significantly improve the condition of the element or component. }\end{array}$ \\
\hline RT & Radiographic Testing \\
\hline Tack Welds & Welds used to hold components together during fabrication \\
\hline UIT & Ultrasonic Impact Treatment \\
\hline USACE & United States Army Corps of Engineers \\
\hline UT & Ultrasonic Testing \\
\hline
\end{tabular}




\section{FATIGUE AND FRACTURE FUNDAMENTALS}

\subsection{Introduction}

Of all the limit states that affect the performance of steel bridges, fatigue and fracture are often misunderstood when it comes to design, inspection, and repair/ retrofit. Although there is a wealth of research and case studies of failures in the literature, few civil engineering programs offer any courses that spend more than a lecture or two on these topics. There are even fewer courses or credible reference manuals available on the repair and retrofit of steel bridges that are in service. Hence, owners often are left to develop an original design when it comes to repair or retrofit. In some cases, the repair or retrofit selected is found to make the condition worse due to a lack of understanding of the problem, lack of available reference materials, and/or lack of experienced personnel.

Though often thought of as secondary design considerations, fatigue and fracture have been found to be critical for steel bridges. Without adequate design and inspection, fatigue cracks may initiate in primary load-carrying elements and then propagate, leading to conditions for fracture. Through relatively simple detailing rules developed through research and experience along with knowledge of the primary factors influencing fatigue and fracture, modern (post-1985) steel bridges have demonstrated excellent fatigue and fracture performance in the field.

This chapter begins by explaining the historical changes to the design of steel bridges to resolve fatigue and fracture issues. The critical factors which influence the initiation and propagation of fatigue and fracture damage are then discussed along with the design and detailing rules to avoid these damage modes. Finally, this chapter closes with a discussion on the evaluation of existing structures for their susceptibility to the initiation of fatigue cracking or fracture.

\subsection{Historical Steel Bridge Issues}

Before the advent of modern (post-1985) bridge design specifications which account for influences such as fracture toughness and redundancy, little attention was given to detailing practices to prevent distortional effects at welded details. As a result, bridges were often designed with details prone to fatigue and fracture. Prior to 1965, the then AASHO Specifications for Highway Bridges had no provisions for fatigue design. Between 1965 and 1974, only modest provisions were contained in the specifications. In 1974, the modern fatigue design provisions which utilize the nominal stress approach developed by Fisher (Connor, Dexter, \& Mahmoud, 2005) were introduced. The current AASHTO LRFD Specifications utilize the same basic approach incorporated in 1974, but many improvements have been made.

Although the provisions introduced in 1974 effectively solved most of the fatigue issues that traditionally resulted from primary live load stresses (i.e., those calculated in basic structural analysis; P/A or Mc/I), the provisions did not adequately address cracking due to secondary stresses (i.e., out-of-plane distortion fatigue). The most common of which is out-of-plane distortion cracking observed within the web gap where cross frames are attached to transverse connection plates not welded to the tension flange. Provisions were added to the AASHTO specifications in 1985 to ensure that through proper detailing, secondary distortional stresses would be minimized or eliminated. This was a substantial advance in practice, most fatigue problems that have been documented can be attributed in some way to distortional effects.

In the 1970s, following the collapse of the Point Pleasant Bridge, issues related to redundancy were addressed as an important design consideration for the first time. Because of a few noteworthy fractures in nonredundant members, more stringent requirements were placed on bridges classified as "Fracture Critical." Some of these more stringent requirements introduced with the AASHTO/AWS Fracture Control Plan (FCP) included reduced allowable fatigue stress ranges, more stringent material Charpy V-Notch (CVN) requirements (a measure of fracture toughness), more rigorous shop inspection, and the federal requirement for arms-length visual inspection every 24 months for members classified as fracture critical. This enhanced inspection requirement resulted in significantly increased costs, due to both access and time, because of the need to place inspectors close to the Fracture Critical Members (FCMs). This quickly played a factor in virtually eliminating new nonredundant bridge designs nationwide.

It is worth noting that, prior to 1970 , there were neither toughness requirements for bridge steels nor any required field inspections. Minimum CVN requirements were not specified in bridge steels until 1974 and then later further refined in 1978 with the AASHTO "Guide Specifications for Fracture Critical NonRedundant Steel Bridge Members" requirements. Before these and additional requirements were adopted by AASHTO, the fracture toughness of the material was largely unknown. As the industry progressed toward higher strength steels with often lower fracture toughness while subject to higher stresses, small flaws and cracks were more likely to lead to brittle fracture of structural members. These flaws and cracks can be hard to find during an in-service inspection, and it was recognized that minimum $\mathrm{CVN}$ requirements were needed. With the introduction of the AASHTO/AWS Fracture Control Plan in 1978, significant improvements were implemented through increased CVN requirements, fabrication control processes, welder qualifications, and requirements for shop inspection. Thus, bridges fabricated prior to the introduction of the FCP criteria are generally assumed to be at higher risk for fracture failure than those fabricated since the implementation of the FCP criteria.

Today, with the use of modern fatigue provisions, the FCP, improved materials, and inspection, the fatigue and fracture limit states are well controlled 
and fatigue cracking in modern bridges (post-1985) is rare. There is also active research in the areas of fracture mechanics, damage tolerant design (DTD), and fracture arrest toughness to take advantage of the superior toughness offered by the new High Performance Steel (HPS) grades. Specifically, in their application to members traditionally classified as fracture critical. Modern steel bridges and those that will be built in the future have continued to be more reliable and robust than their predecessors.

\subsection{Fatigue}

\section{A. Introduction}

Fatigue is the initiation and/or propagation of cracks due to a repeated variation of normal stress [in a member] with a tensile component (AASHTO, 2012). Fatigue is the process by which a material is weakened under repeated (cyclic) loading due to localized damage (i.e., cracks). The damage is cumulative over time as the cracks grow or propagate because of the cyclic loading. The stresses created by fatigue loading are generally within the elastic range of the material. Under most conditions, cracks will continue to grow under each loading cycle until a limiting (critical) crack size is attained. If cyclic loading of the member stops, the crack growth will also stop. There are three stages of fatigue: initiation, propagation, and fracture. A time-lapse video of crack growth taken at an out-of-plane distortion crack observed during a laboratory test can be viewed at http:// dx.doi.org/10.4231/R7W9573Z.

Initiation. In fabricated structural steel, fatigue cracks begin at points of stress concentration. Stress concentrations are caused by the welded detail geometry, abnormalities, or discontinuities within the member. The abnormalities can be due to a material discontinuity, a discontinuity introduced during fabrication (e.g., from welding processes), or a discontinuity due to some external action such as a notch or gouge. Crack initiation is highly dependent on construction quality. The size of the initial discontinuity varies, and in fact may be well within acceptable limits per AWS or other specifications. It can take considerable time to initiate finite size cracks from a welded detail or abnormality and the initiation phase can consume up to $90 \%$ of the cyclic life from initiation to the point just prior to fracture. Microscopic crack growth during this stage is largely independent of material properties.

Propagation. Once a crack has initiated, it will propagate or grow under repeated load cycles. The onset of the propagation stage typically is not well defined and may begin prior to detection of a crack by visual inspection or nondestructive testing. Once the crack is detectable, the growth rate can usually be safely monitored, in most cases, using fracture mechanics principles. Generally, fatigue cracks exhibit slow and stable crack growth over an extended period of time, often many years. In such cases, the crack will continue to propagate until it reaches a critical size. Cracks can extend rapidly in the propagation phase if they are not detected before they are near the critical crack size. Within the propagation phase, fatigue crack growth rate is dependent on material properties such as the material composition, microstructure, and toughness, which may be affected or altered by heat treatment. Tensile residual stresses from welding may also contribute to crack propagation. Fatigue cracks mainly grow perpendicular to the primary tensile stresses in the member. The "fracture toughness" is an important material property in the latter stages of crack propagation as the crack approaches what is referred to as the critical crack length and results in a brittle or ductile fracture.

Fracture. Fracture is defined as the occurrence of nearly instantaneous, rapid crack extension that may result in complete separation of a member. Fracture occurs when a crack reaches its critical size. This unstable crack growth occurs when a combination of specific factors including fracture toughness, state of stress (including residual stresses), temperature, loading rate, crack length, and constraint. There are three types of fracture: brittle, transitional, and ductile. Though often preceded by fatigue, fracture can also occur independently of fatigue, as discussed further in the next section.

\section{B. Introduction to the Nominal Stress Approach of Fatigue Evaluation}

Bridges in the United States are designed for fatigue using the AASHTO LRFD Specifications, which employs a "nominal stress" approach to the evaluation of the fatigue crack growth. Three primary factors affect the fatigue life of bridge details: (1) the magnitude of the stress ranges in the detail, (2) the number of applied stress cycles, and (3) the orientation and configuration of the structural detail.

Stress range. Stress range is generally the result of live loads only and is equal to the difference between the minimum and maximum applied stresses produced by a load cycle. Although temperature and wind can also introduce cyclic stresses, their contribution to the overall fatigue damage (as compared to that produced by traffic) is generally negligible. The stress range may be entirely in tension, entirely in compression, or have both a tension and compression component. A fatigue crack will only propagate under net tensile stress. Hence, any component that is subjected to a stress cycle that produces any net tensile stress (after accounting for compressive or tensile dead load stresses) must be designed for fatigue. Tensile residual stresses from welding are not considered in the determination of tensile net stress for fatigue analysis since residual stresses are already accounted for in the fatigue resistance curves. Cracking within a compression member, due solely to high tensile residual stresses, would not propagate beyond the weld heat affected zone (HAZ). The orientation of the stress field in relation to the crack flaw direction is important 
for fatigue propagation. Crack propagation will only occur at cracks where a perpendicular tensile stress is applied to the crack tip.

In everyday operation, bridge structures undergo load cycles of varying stress ranges produced by the changing traffic loading conditions, or also known as the "variable amplitude loading spectrum." While each load cycle induces damage in the member and contributes to crack growth, load cycles with greater stress ranges will induce more damage than smaller stress ranges. In design for fatigue, a single stress range is used and must represent an effective loading condition which accounts for the equivalent "damage" induced by all of these variable live load stresses produced over the life of the bridge. This is represented by a modified design truck to produce a fatigue loading model for calculation of the equivalent stress range. This fatigue loading model has a given load and axle spacing and simplifies the design for the fatigue limit states.

Number of stress-range cycles. A stress-range cycle is generally defined as a complete oscillation of the peak to peak amplitude cycle of stress. Although a typical truck may produce one primary stress-range cycle in the main load carrying member, secondary members such as stringers and floor beams may be subjected to multiple stress-range cycles from a single truck. Small, secondary stress-range cycles are often produced by free vibration after the passing of the vehicle. Therefore, the determination of the number of stress-range cycles at a given stress-range value is critical in determining the cumulative damage and crack growth that may eventually lead to cracking. The stress-range cycles caused by actual truck loading is converted to an equivalent constant-amplitude fatigue loading for evaluation and testing. Figure 1.1 shows a sample conversion of a complex stress cycle with secondary peaks to three constantamplitude stress-cycles.

Detail category. In the AASHTO LRFD Specifications (2012), different details are grouped into categories having similar fatigue resistance. Each is referred to as a "detail category" and is assigned letters A through $E^{\prime}$. Each of these categories defines a level of fatigue resistance expressed as a function of applied stress range and number of stress cycles. The AASHTO LRFD Specifications include eight fatigue categories listed in order of decreasing fatigue resistance: $\mathrm{A}, \mathrm{B}$, $\mathrm{B}^{\prime}, \mathrm{C}, \mathrm{C}^{\prime}, \mathrm{D}, \mathrm{E}, \mathrm{E}^{\prime}$. Additional information on the AASHTO LRFD Speciation fatigue categories is contained in Section D.

The detail categories are incorporated in design by using stress range vs. number of cycle (S-N) curves for a specific detail category where $S$ is the nominal stress range and $N$ is the number of loading cycles until visual detection of a crack. Based on extensive research, empirical evidence, and some engineering judgment, each detail category has been assigned a nominal fatigue resistance by AASHTO in the form of a design curve with a diminishing allowable stress-range as the number of cycles increases. Each detail category also has a corresponding stress range limit below which no fatigue damage is theoretically expected to occur (i.e., infinite life). This limit is referred to as either the ConstantAmplitude Fatigue Limit (CAFL) or ConstantAmplitude Fatigue Threshold (CAFT) and provides a target stress range to be used in design if an infinite life detail is indicated. Both the terms CAFL and CAFT refer to the same limit and may be used interchangeably in contemporary literature. The most recent versions of the AASHTO LRFD Specifications introduce different terminology for their fatigue design methodology, the nominal stress range $\mathrm{S}=(\Delta \mathrm{F})_{\mathrm{n}}$ and the constant amplitude fatigue limit $\mathrm{CAFL}=(\Delta \mathrm{F})_{\mathrm{TH}}$.

Individual $\mathrm{S}-\mathrm{N}$ curves are constructed in two parts: a sloping portion and a horizontal portion. A sample $\mathrm{S}-\mathrm{N}$ curve is shown in Figure 1.2.

- A similar relationship is used to define the sloping portion for all the detail categories with the only difference being the y-intercept (Detail Constant $A$ ) the detail constant "A" as shown in the equation below of each line. Therefore, the sloping portions of all the $\mathrm{S}-\mathrm{N}$ curves are parallel. However, each detail category has a different acceptable stress range for the same number of cycles. Higher fatigue resistant details (e.g., Category A) permit the highest acceptable stress ranges and hence have the greatest fatigue resistance.

$S=\left(\frac{A}{N}\right)^{1 / 3}$ where $A$ is the y-intercept or detail constant.

- The horizontal portion of the curve represents the CAFL of the detail. The CAFL is different for the individual detail categories with the more fatigue resistant details allowing higher fatigue limits.
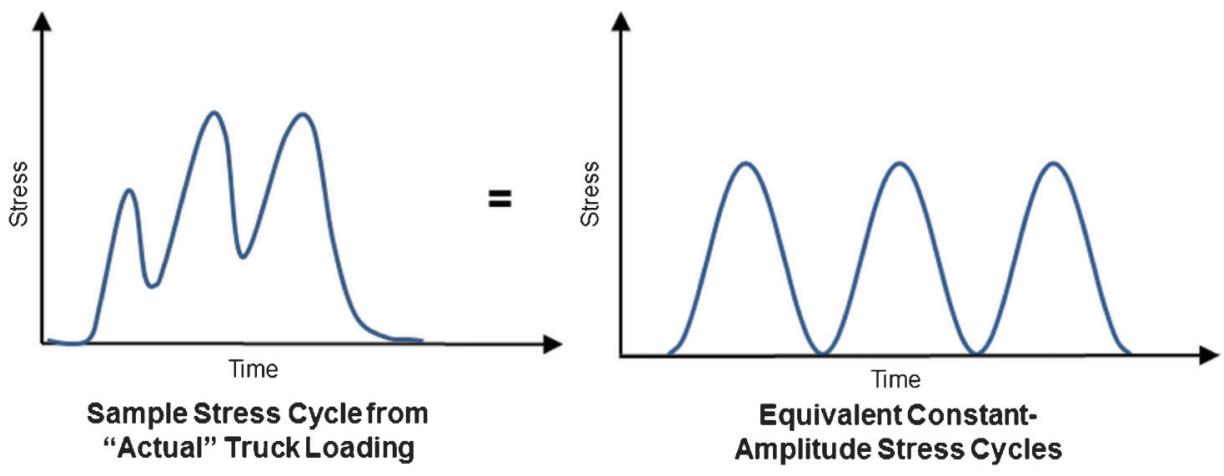

Figure 1.1 Stress-range cycles. 


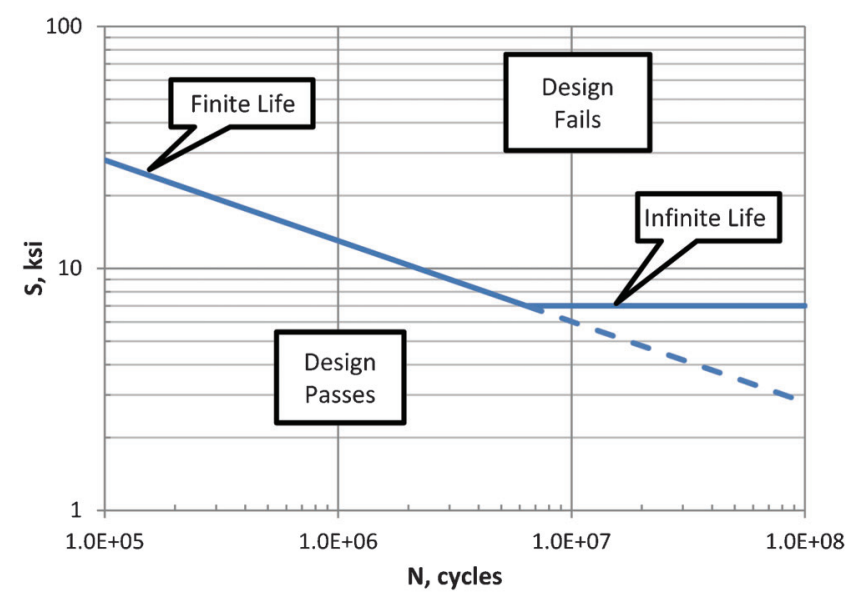

Figure 1.2 S-N plot, AASHTO detail category D.

Two design conditions exist, Finite Life, using the sloping portion of the $\mathrm{S}-\mathrm{N}$ curve, and Infinite Life, using the CAFL or horizontal portion of the curves. If all of the variable amplitude stress range cycles in a spectrum are kept below the CAFL, infinite life of the detail is assumed. Design using the finite life approach requires that an accurate estimate of the stress range and the number of design cycles that will be applied during the life of the structure be available because the equation for the nominal fatigue resistance includes a cubed exponent and small changes in these variables may greatly affect acceptability. If such data are available, they may be used to establish an effective stress range which, along with the number of cycles, may be compared to the S-N curve for that particular detail. The detail is then checked to determine if it meets the required life. Designing for infinite life requires that only the maximum stress range anticipated be known and compared to the CAFL of the detail to ensure that all stress range cycles will remain below the CAFL.

The S-N curves were developed through full-scale testing of various details through research sponsored by the National Cooperative Highway Research Program (NCHRP) and other organizations. For more information, see Fisher, Albrecht, Yen, Klingerman, and McNamee (1974) and Schilling, Klippstein, Barsom, and Blake (1978). Nearly all tests were conducted by applying a constant-amplitude stress range, as shown in Figure 1.2 (no variation in stress cycles during the test) to a detail and counting the number of cycles applied until failure, defined as the first visible detection of a crack. Because the specimens in these testing programs were full-scale, the effects of the stress concentrations, discontinuities, and residual stresses that occur in the details are accounted for in the development of the S-N curves. However, the variability of these factors, such as differences in the local weld toe geometry, result in considerable scatter in the test data. It is not uncommon to observe an order of magnitude scatter in data for specimens run at the same stress range. Because the specimens used to develop the AASHTO LRFD Specifications detail categories incorporated all of these variables, the data are representative of the details found in real steel bridges. By taking this approach when developing the design curves, simple calculations of the stress range using basic structural analysis equations (i.e., $\mathrm{Mc} / \mathrm{I}$ and $\mathrm{P} / \mathrm{A}$ ) are implemented during a design instead of requiring the use of complex modeling such as finite element analysis.

The full-scale fatigue tests used to develop the nominal stress approach described above revealed several interesting aspects of fatigue cracking in steel structures that are worth noting:

- The strength and type of steel had only a negligible effect on the fatigue resistance of a particular detail.

- Although the welding quality can affect the fatigue resistance of a detail, the type of welding process did not typically affect the fatigue resistance.

- Due to the high tensile residual stresses resulting from welded fabrication, the dead load had little effect on the loading of a detail. Therefore, the constant-amplitude fatigue loading could represent the live-load stress range without a major influence from the mean stress.

A brief description of the AASHTO detail categories are described below. For a more detailed description of the specific AASHTO nominal stress approach for fatigue design and the determination of the load and number of cycles to be used in the design, see NCHRP Synthesis 354 (Connor et al., 2005).

\section{Influence of Discontinuities}

Steel bridge elements commonly contain many discontinuities due to both material and fabrication anomalies. Material discontinuities can occur from the rolling of steel members and can include conditions such as segregation of the microstructure, delaminations, or imperfections. Fabrication discontinuities can occur from a variety of processes including handling of the material, drilling of holes, or cutting of material; but the most common source of fabrication discontinuities is welding. Welded details are especially susceptible to internal discontinuities, which are usually larger than those that occur due to rolling of steel shapes and plates.

Fatigue cracks often initiate at structural connections, abrupt dimensional changes, and surface or internal discontinuities due to the stress concentrations and sharp, "crack-like" geometric conditions at these locations. Locations where tensile stress is applied perpendicular to the sharp geometric conditions are especially vulnerable.

\section{Influence of Residual Stresses}

When components are welded, tensile residual stresses are created at or near the welds due to differential shrinkage. These stresses often approach or reach the yield stress of the lower strength material in the connection, often the steel base metal, and increase the likelihood of fatigue cracks, particularly where internal discontinuities exist. 
Because the residual stresses are tensile and of a large magnitude, a nominal compressive stress applied to a location at or near a weld will only reduce the magnitude of the tensile residual stress but not eliminate them. Therefore, a detail which would appear to be subjected to nominal compression cyclic stresses under live load can actually be undergoing tensile stress cycles due to the presence of the tensile residual stresses. Because of this phenomenon, fatigue cracks can develop in welded details in the compressive regions of the member, although these cracks often stop growing once the crack tip extends outside of the relatively small tensile residual stress zone.

\subsection{Fracture}

\section{A. Introduction}

Fracture can be defined as an instability or rapid extension of a crack under tension leading to either complete or partial separation of a member. Fracture occurs when the defect or crack, no matter how small, becomes unstable under a set of conditions and propagates. The maximum crack size that can be tolerated for a given applied stress, temperature, and fracture toughness is referred to as the Critical Crack Size and can be estimated using fracture mechanics.

\section{B. Types of Fracture}

Fractures are generally classified into three types: ductile fracture, brittle fracture, or transitional fracture. Representative photographs of brittle and ductile fracture on tension test specimens are shown in Figure 1.3.

- Brittle fracture is characterized by presence of very little ductility or plasticity adjacent to the crack tip, much like a piece of glass breaking. The fracture surface generally appears flat, with little or no plastic deformation, and is rough to the touch, similar to 60 to 80 grit sandpaper. A video showing brittle fracture that occurred during a laboratory test can be viewed at http://dx.doi.org/10.4231/R78K7710.

- Ductile fractures are preceded by extensive plastic deformation and are generally very jagged. A ductile fracture is preceded by yielding and necking deformation of the member, which may provide warning of the failure, whereas a brittle fracture can occur suddenly and without any warning.

- A transitional fracture, just as the name implies, possesses characteristics of both ductile and brittle fractures.

Fracture from fatigue cracks in bridges is typically brittle in nature. For other types of fracture, material

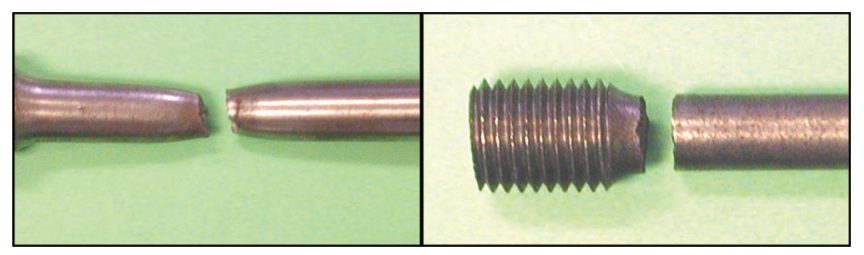

Figure 1.3 (Left) ductile fracture; (right) brittle fracture. properties of a steel member or connecting weld will determine the specific nature of the failure mechanism, with fracture toughness and temperature as the governing factors.

Unlike fatigue where there is a slow growth of cracks under repeated loading over time, brittle fracture is characterized by cracking that propagates at an extremely high velocity, up to $7,000 \mathrm{ft} / \mathrm{s}$ (the speed of sound is roughly $1,100 \mathrm{ft} / \mathrm{s}$ ).

\section{Critical Factors}

Fracture should be a consideration in bridges during the latter stages of fatigue crack propagation and in any bridges susceptible to other critical factors that affect the onset of fracture, regardless of whether any prior fatigue cracking has occurred. These critical factors are listed as follows: constraint, rate of loading, temperature, stress, discontinuity size, and fracture toughness. These parameters are described in greater detail below. Although fracture of a single member may be tolerated in redundant designs, fracture cannot be tolerated in the design and evaluation of the elements of the structure referred to as "Fracture Critical Members" (FCMs). A formal definition of "Fracture Critical Members" is fully discussed in the following sections.

Constraint. Constraint can occur at intersecting welds, large weldments, or thick members. Constraint limits the ability of a member to deform and yield (due to Poisson's effect) under load. Since the constraint prevents the material from yielding in the classic sense, local stresses can therefore increase well beyond the nominal yield strength of the steel. This increases the vulnerability to brittle fracture. Minimizing constraint through proper detailing is an effective way of lowering the likelihood of brittle fracture.

Brittle fracture due to restraint is now recognized as "Constraint-induced Fracture" (CIF). If the level of local constraint is such that local yielding is prevented and the localized stresses exceed the yield strength, brittle fracture may occur suddenly without any visual warning such as fatigue cracking or excessive deformation. From the AASHTO LRFD Bridge Design Specification, $6^{\text {th }}$ ed. (2013), constraint-induced fracture is a form of brittle fracture that "can occur without any perceptible fatigue crack growth and, more importantly, without any warning."

Highly constrained details should be avoided, as much as possible, to minimize CIF. This can be achieved by employing relatively simple techniques: provide copes to eliminate intersecting welds; avoid intersecting members by providing relief (e.g., copes); avoid large weldments by minimizing weld size, using bolted connections, or reconfiguring the joint. Avoid the combination of restrained thick members and heavy welds when possible by using built up members or higher strength steels. Later sections of this document will provide additional details on avoiding constraint to reduce the potential for fracture. For more information on CIF, see 
Mahmoud, Connor, and Fisher (2005) and Connor, Kaufmann, Fisher, and Wright (2007).

Loading rate. The speed of the application of live load to a structural element is the loading rate. The influence of loading rate on fracture initiation is directly related to the strain rate experienced by the material; the higher the strain or loading rate, the greater the potential for fracture. For typical bridges, the loading rates from traffic are usually low $(0.2$ to $1.0 \mathrm{sec})$. Therefore, these structures are often considered a quasistatically loaded structure. However, higher load rate events occur in some cases, such as when a bridge member is struck by an over-height vehicle. This can be considered a dynamic loading rate. The effect of loading rate is usually considered as an adjustment to the fracture resistance of the material rather than by explicitly considering strain rate in the analysis.

Temperature. Temperature has an inverse relationship to a material's resistance to fracture. As a result, the lower the temperature, the higher the potential for fracture. Temperature cannot typically be controlled in the design process but must be accounted for by properly specifying materials which possess sufficient fracture toughness at the Lowest Anticipated Service Temperature (LAST) (see section on toughness below).

Stress. As applied to a discussion of fracture, stress is the maximum design or actual (measured) nominal stress in a member (e.g., due to standard structural analysis equations; P/A, Mc/I) without any localized stress concentration effects. In fracture mechanics, this is referred to as the far-field stress. Stress has a direct relationship to fracture; the higher the nominal member stress, the higher the potential for fracture. Stress can be controlled through member sizing, detailing, and load distribution. Localized stress increases, such as from section loss due to fatigue crack growth or corrosion, will also increase the risk of fracture. These are not directly calculated, but are accounted for when stress concentration factors are calculated for a given detail or flaw. Localized stress increases caused by discontinuities which will increase the likelihood of fracture are discussed below.

Discontinuity. A discontinuity includes any disruption of the uniform flow of stress such as material imperfections, fabrication errors, and geometrical changes. Discontinuities result in a localized increase in stress or a stress concentration. For example, a straight rectangular bar that is uniaxially loaded and has no discontinuities will have a uniform stress distribution across the member. Introducing a small hole in the middle of the bar interrupts this uniform flow of stress, creating stress concentrations at the edges of the hole. Depending on the size of the hole and other factors, the stress amplification at the edge of the hole can be up to three times greater than the nominal (P/A) stress in the member. Figure 1.4 shows the stress concentrations in a web plate at the edge of a welded lateral gusset plate and at a cope hole at the intersection of a vertical stiffener.

Discontinuities can also be the result of a material imperfection or detail geometry due to disruptions in the flow of stress. Material imperfections are inherent in the manufacturing processes but can be controlled through use of accepted manufacturing standards. Geometrical changes include changes to the member geometry (e.g., addition of bolt holes or attachments). Abrupt changes in geometry result in higher disruption of stress flow and a corresponding increase in stress concentrations. Discontinuities can be controlled in design through proper specification of materials and

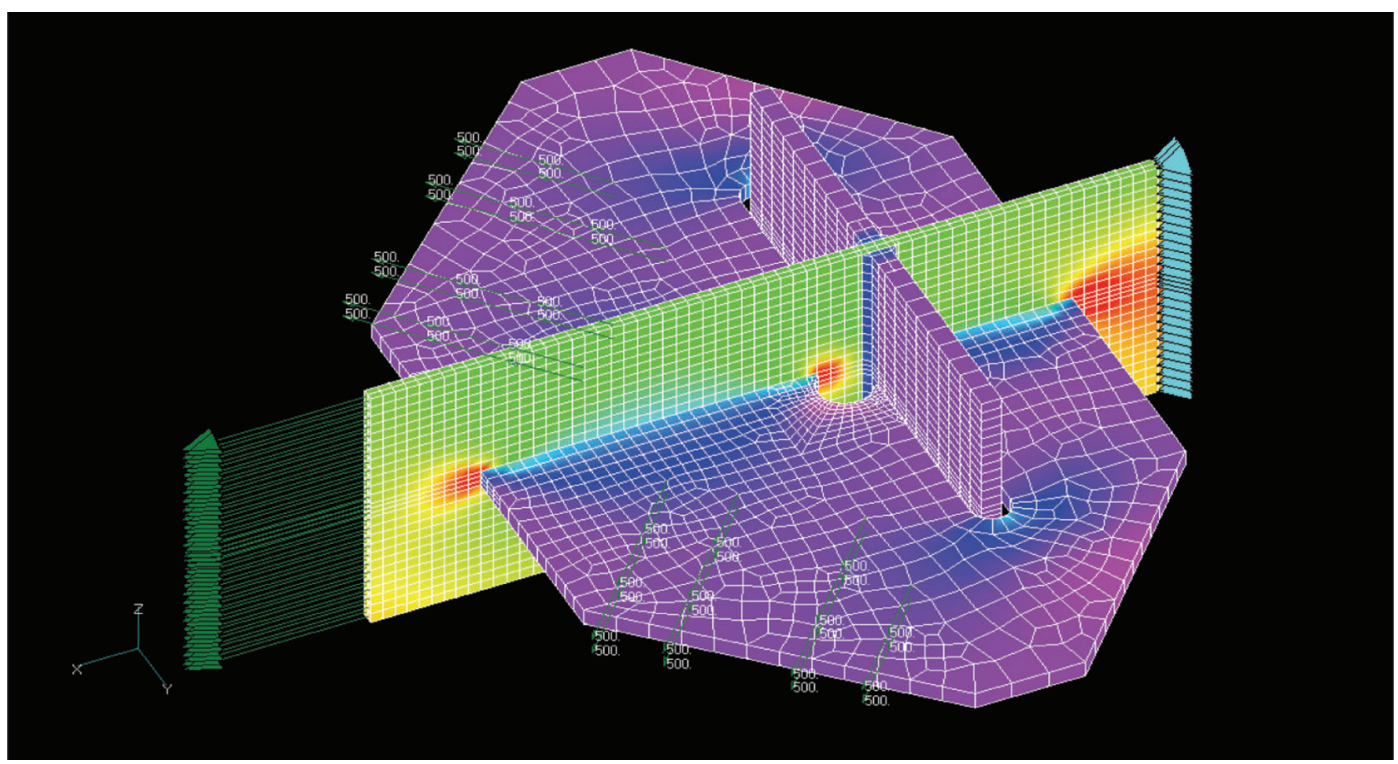

Figure 1.4 Stress concentrations in a web plate at edges of a welded detail. 
fabrication practices, and through detailing that minimizes stress concentrations and disruptions to stress flow.

Material properties. The primary material property affecting resistance to fracture is fracture toughness, although strength, ductility, and corrosion damage also can have an effect. Toughness measures a material's ability to resist fracture from cracks under load. Unlike fatigue, where the crack growth is mainly independent of material properties, fracture initiation and the fracture types are highly influenced by material properties. Materials with greater toughness can tolerate larger cracks under a given set of conditions than those with lower toughness and therefore offer increased resistance to fracture. The yield and tensile strength has an indirect influence on fracture initiation since higher strength materials can develop higher stress at crack tips.

\section{Toughness}

Toughness is a measure of the ability of a material to absorb energy and resist crack propagation and can be defined in terms of material toughness or fracture toughness.

Material toughness is defined as the ability of a material to absorb energy up to failure. Material toughness involves both strength and ductility, and material toughness is often evaluated by the area under the stressstrain curve in a tensile test. The units of material toughness are energy per volume of material. In Figure 1.5, the stress-strain curve for two different carbon steels is shown. The high carbon steel has the higher strength but is not very ductile and has a lower material toughness. The low carbon steel has lower strength but is more ductile with greater material toughness. Material toughness can be used to identify the brittle nature of a material. In this example, the higher strength material can be expected to behave in a brittle manner, as depicted in the brittle fracture example of Figure 1.3.

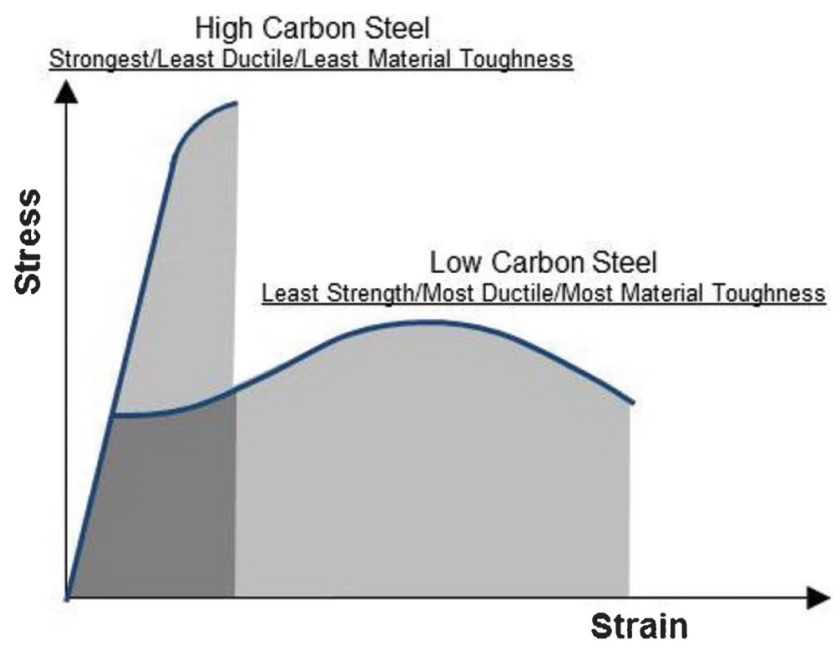

Figure 1.5 Material toughness.
Fracture toughness is the ability of a material containing a crack or other discontinuity to absorb energy while resisting fracture. Materials that absorb greater amounts of energy at a crack tip of similar size and shape will have greater fracture (or CVN notch) toughness. The units of fracture toughness are $\mathrm{ksi} \times$ inch $^{0.5}$. The amount of energy that can be absorbed directly relates to the local plastic deformation at the crack tip prior to fracture. When the fracture toughness is low, less plastic strain can be achieved and the failure occurs in a more brittle fashion. In contrast, a material subjected to the same conditions which possesses high material fracture toughness, may undergo significant plastic deformation at the crack tip before fracture initiates, resulting in a ductile fracture. The fracture mode depends on material properties, loading rate, temperature, and constraint at the crack tip. Steels that have very low toughness can fracture in a brittle fashion in the presence of rather small discontinuities. When the toughness of a material is specified, it is the fracture toughness (as measured by the Charpy V-Notch test described below), not the material toughness, that is specified.

In the production of structural steel, the Charpy VNotch $(\mathrm{CVN})$ test is used to qualitatively infer fracture toughness as it is not a direct measure of toughness, but rather energy absorption. CVN testing is a standardized, high strain-rate test to determine how much energy a material may absorb before fracture occurs. This method, described in ASTM E23, involves a hammer apparatus which swings into a notched specimen as shown in Figure 1.6. (Videos showing CVN impact testing can be viewed at http://dx.doi.org/10.4231/R7H41PC8 and http://dx.doi.org/10.4231/R74T6G98.) As stated, although

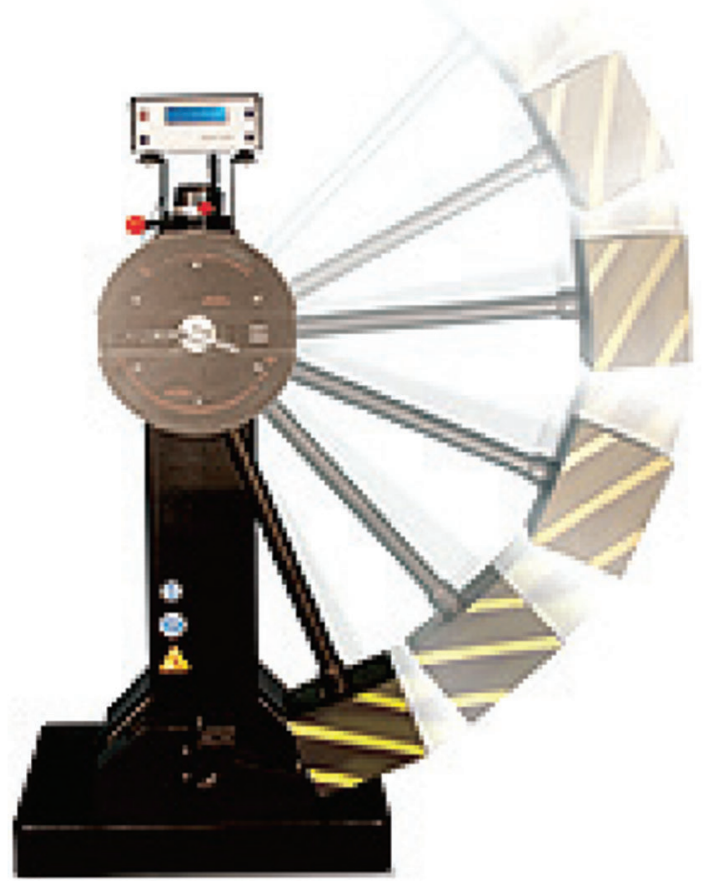

Figure 1.6 Charpy impact test apparatus (courtesy of AWS). 


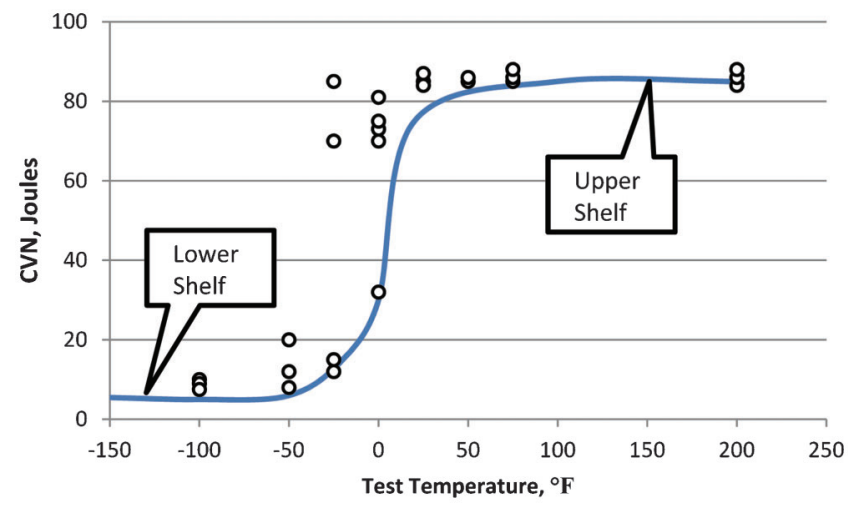

Figure 1.7 Sample Charpy energy transition curve.

the Charpy V-Notch Test is not a direct measure of fracture resistance, it can be used to infer fracture resistance using established correlations. This is similar to how hardness can be used to estimate ultimate strength.

The CVN energy for structural steel varies as a function of temperature. Figure 1.7 displays a sample CVN energy curve developed from specimens tested at different temperatures.

Going from lower to higher temperature, the steel undergoes a brittle-to-ductile transition in fracture behavior. The plot displays two shelves or regions of relatively constant toughness. The lower shelf is associated with brittle fracture and low plastic deformation of the specimens. The upper shelf is associated with ductile fracture, also called ductile tearing, along with significant plastic deformation and large shear lips on the fracture surface. A transition zone occurs between the upper and lower shelf where the fracture mode is not purely brittle or ductile. Large variability is typical in the transition zone where some specimens show brittle behavior while others show ductile behavior. For some steels, the transitional zone occurs over a short temperature range, such as the Charpy curve shown in Figure 1.7. Other steels exhibit transitional fracture over a wider temperature range resulting in a lower slope for the transition curve. Figure 1.8 shows the difference between brittle behavior (top) and ductile behavior (bottom) for two different CVN specimens.

AASHTO specifies that bridge steel and weld filler meet minimum CVN requirements at a specific testing temperature. The requirements vary depending on the lowest anticipated service temperature at the location of the bridge. However, the CVN testing temperature does not necessarily correspond to expected fracture resistance at a given temperature in bridges due to the strain rate effect. The CVN test is a dynamic impact test and the loading rate is much higher compared to bridges loaded by traffic. Since toughness is lower at higher strain rates, a temperature shift can be applied to the CVN curve to better predict fracture initiation resistance in bridges at their actual service temperatures. Therefore, the CVN testing temperature in AASHTO

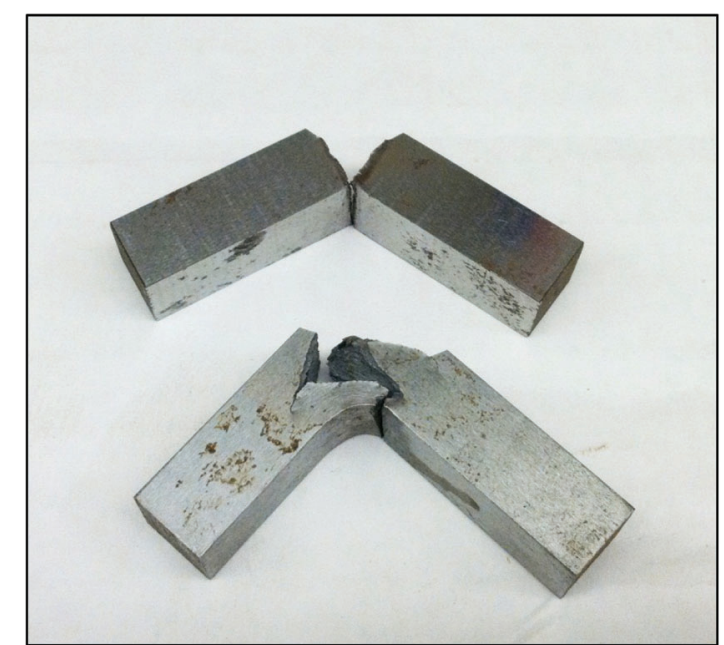

Figure 1.8 Brittle and ductile fracture of CVN specimens.

for a given temperature zone is higher than the lowest anticipated service temperature (LAST) for that zone. This effect is demonstrated in Figure 1.9 which shows how a CVN curve tested at temperatures above the LAST can be used to predict fracture resistance in bridges that operate at the LAST. The AASHTO test temperatures are based on temperature shift correlations developed by Barsom and Rolfe (1999) for bridge steels being used up to the 1970 's. The temperature shift is somewhat dependent on the steel grade and current research is showing that the new HPS steel grades may require a different approach to setting CVN test temperatures.

The Barsom and Rolfe (1999) correlation procedures can be used to estimate the material fracture toughness $\left(\mathrm{K}_{\mathrm{Ic}}\right)$ at bridge service temperatures from the CVN test data. The $\mathrm{K}_{\mathrm{Ic}}$ versus temperature curves have similar shape to the CVN versus temperature curves and therefore exhibit a similar lower shelf and transition behavior. The AASHTO fracture control philosophy is to insure that the material has sufficient $\mathrm{K}_{\mathrm{Ic}}$ toughness at the LAST to prevent lower shelf, brittle fracture. This is achieved, as long as the AASHTO minimum CVN requirements are met for materials used in bridge

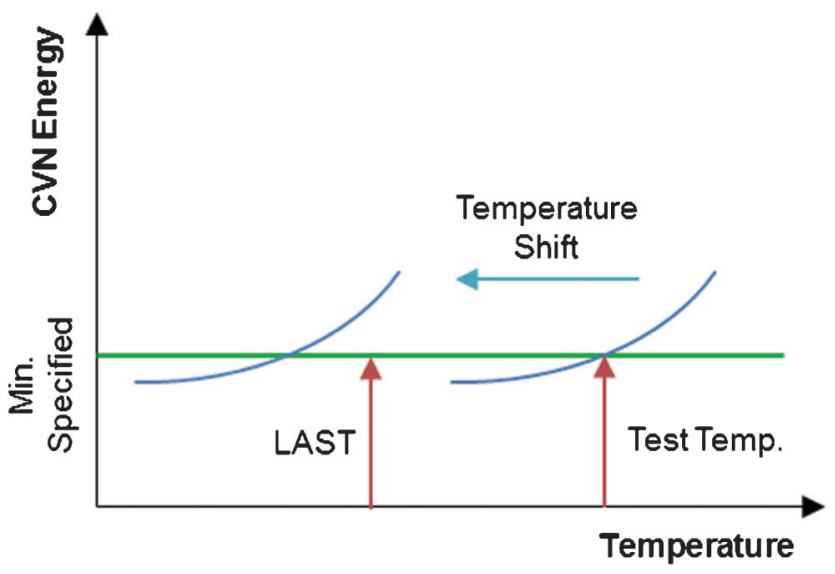

Figure 1.9 Temperature shift. 
fabrication. Fracture critical members (FCM) have separate CVN material requirements that provide a higher $\mathrm{K}_{\mathrm{Ic}}$ fracture resistance at the LAST. The FCM requirements have a combination of lower testing temperatures and higher $\mathrm{CVN}$ minimum energy requirements to meet this goal.

Generally, finer-grained steels tend to be more ductile than coarser-grained steels. In the past, some highstrength steels used in bridge fabrication have exhibited relatively low fracture toughness. Fortunately, over the past decade, high strength steels with improved finegrain microstructure, increased ductility, toughness, and weldability have been developed. For example, recentlydeveloped High Performance Steels (HPS), as governed by ASTM A709, display both high strength and fracture toughness due to modifications in the chemical composition and heat treatment during the manufacturing of these steels.

A high-strength quenched and tempered steel, commonly called "T-1 Steel," was used in bridge fabrication in the early 1960s before AASHTO adopted toughness requirements. This steel, AASHTO M270 Grade 100W (ASTM A514/A517), was utilized to increase design efficiency of members where the $100 \mathrm{ksi}$ could be utilized to advantage. Through experience, T-1 Steel has been shown to be vulnerable to hydrogen embrittlement due to welding, which may lead to premature fatigue cracking and/or brittle fracture. Hydrogen embrittlement occurs when moisture is trapped in the solidifying weld metal. The hydrogen attacks the bond between metal grains and cracks form as the trapped hydrogen diffuses out of the welds and heat affected zone.

Hydrogen cracks often occur days, weeks, or months after welding since the diffusion process is time dependent. This presents a challenge for inspection and there have been cases where bridges are in service before cracks are discovered. Hydrogen-induced cracking can be minimized or prevented by proper welding procedures, including use of clean and dry low hydrogen consumables, control of heat input and cooling rate, and use of lowest strength (undermatching) filler metal which meets the design requirements. These actions will help to limit the input of hydrogen atoms into the weld and limit the residual stress and restraint necessary to initiate cracking. The vulnerability to hydrogen cracking is somewhat proportional to steel strength. Few problems have been observed for grade 50 and lower strength structural steels.

\section{E. Fracture Critical Members}

Although various definitions of a FCM exist, they all have a similar intent. The AASHTO LRFD Specifications (2012) define FCM as a "Component in tension whose failure is expected to result in the collapse of the bridge or the inability of the bridge to perform its function." It is further explained in Article 6.6.2 as follows:
"The Engineer shall have the responsibility for determining which, if any, component is a fracture-critical member (FCM). Unless a rigorous analysis with assumed hypothetical cracked components confirms the strength and stability of the hypothetically damaged structure, the location of all FCMs shall be clearly delineated on the contract plans. The contract documents shall require that FCMs shall be fabricated according to Section 12 of the AASHTO/AWS D1.5M/D1.5 Bridge Welding Code.

Any attachment having a length in the direction of the tension stress greater than $4.0 \mathrm{in}$. that is welded to a tension area of a component of a FCM shall be considered part of the tension component and shall be considered fracturecritical.”

AASHTO/AWS D1.5 (2012) Article 12.2.2 defines FCM in Article 12.2.2 as follows:

"Fracture critical members or member components are tension members or tension components of bending members (including those subject to reversal of stress), the failure of which would be expected to result in collapse of the bridge. ... Members and components that are not subject to tensile stress under any condition of live-load shall not be defined as fracture critical.

Any attachment welded to a tension zone of a FCM member shall be considered an FCM when any dimension of the attachment exceeds $4 \mathrm{in}$. in the direction parallel to the calculated tensile stress in the FCM. Attachments designated FCM shall meet all the requirements of the [Fracture Control Plan].

All welds to FCMs shall be considered fracture critical and shall conform to the requirements of this [Fracture Control Plan]. Welds to compression members or compression areas of bending members shall not be defined as fracture critical.”

\section{F. Considerations for Design}

Design to prevent fracture is often provided through good detailing procedures to minimize geometrical discontinuities, therefore, good fatigue details often lead to good fracture resistance. The use of details with a high fatigue resistance, such as Categories A through $\mathrm{C}^{\prime}$, is preferred since these details also offer more resistance to fracture by minimizing geometrical discontinuities. As long as high constraint conditions are avoided, proper design for fatigue will often provide adequate details which, along with specifications for proper material toughness for the temperature zone and member type (FCM or non-FCM), can limit the chance for a brittle fracture. Consideration also is needed to provide details that control localized distortional stresses introduced through loading or thermal expansion.

\subsection{Detail Classification}

\section{A. AASHTO Detail Categories}

The AASHTO Specifications classify common bridge details into categories with similar fatigue resistances. 
For additional information on the development of the fatigue categories see Keating and Fisher (1986), Fisher, Frank, Hirt, and McNamee (1970), and Fisher et al. (1974). Details which have a higher fatigue resistance will have a longer fatigue life under a given stress range or a higher allowable stress range for a given life. Categories $\mathrm{A}$ through $\mathrm{C}$ and $\mathrm{C}^{\prime}$ will rarely be problematic and are commonly used in new bridge designs. History has shown that Category D, E, and E' details are more likely to have fatigue problems and should be avoided in new design, if possible. This is particularly true for details used for attaching lateral bracing or other secondary members to primary members. Forces present in the secondary members, that are often not accounted for in design, can introduce distortion and thereby reduce the fatigue resistance below what is predicted by the AASHTO detail category. Details falling into Categories D, E, and $\mathrm{E}^{\prime}$ should be highlighted during inspections for special attention. The following presents a discussion of the specific detail categories and some typical examples of each. Although some of the details included in each category are described below, a complete listing of the detail categories can be found in the AASHTO LRFD Bridge Design Specifications (2012).

Category A. Category A has the highest fatigue resistance and is the ideal condition for fatigue design. This category refers to the "base metal" or plain metal condition. The edges and the surfaces of the plates and rolled shapes must be smooth and located away from welded, riveted, and bolted connections. Although cracking is unlikely to develop in base metal, cracks could eventually develop at the edges with notches or sharp indentations introduced during handling or fabrication. Because bridge members will include details and connections with lower fatigue strength categories, base metal regions are usually not examined for fatigue cracking. It should be noted that plug welds or other repair welds should not be considered base metal even when they are ground smooth. Plug welds may contain large discontinuities where a fatigue crack can initiate. A member with re-entrant corners at copes, cuts, block-outs, and other geometrical discontinuities does not meet the requirements of Category A.

Category B. Category B includes both welded and bolted details, and are preferred details in new construction due to the high fatigue resistance provided by these connections. The following are some Category B details:

- Longitudinal continuous fillet or groove welds where the primary stresses are parallel to the weld. This category does not apply to the end of the weld where there will be a stress concentration.

- Transverse full penetration groove welds with weld soundness established by non-destructive testing (NDT) and welds ground smooth. Transition in thickness or width shall be made on a slope no greater than 12.5 or a radius not less than 2 feet.
- Welded attachments with a transition radius not less than 24 inches and weld termination ground smooth.

- Pretensioned high strength bolted connections.

- Unpainted weathering steel base metal (the surface roughness reduces the fatigue strength below Category A).

Category $\mathbf{B}^{\prime}$. Category $\mathbf{B}^{\prime}$ contains a few welded details. This category was not included in the original development of the Detail Categories. It contains details which are similar to Category B but have slightly less fatigue resistance due to the presence of larger initial discontinuities, blow holes, and root gap discontinuities. Typical details that Category $\mathrm{B}^{\prime}$ includes are:

- Longitudinally loaded full penetration welds without backing bars removed.

- Continuous partial penetration groove welds parallel to the direction of the applied stress.

- Full penetration groove welds in steels with a yield strength greater than $100 \mathrm{ksi}$.

Category C. Category $\mathrm{C}$ includes the following details:

- Member with re-entrant corners at copes, cuts, blockouts, or other geometrical discontinuities.

- Short welded attachments which are less than 2 inches long including transverse connection plates and short attachments on the flange or web that can be groove or fillet welded.

- Transverse full penetration groove welds without weld reinforcement ground smooth.

- Longitudinal groove welded attachments with the weld termination ground smooth and a transition radius between 6 and 24 inches.

- Shear studs.

Category $\mathbf{C}^{\prime}$. Category $\mathrm{C}^{\prime}$ only applies to stiffener-toweb and stiffener-to-flange fillet or groove welds on transverse stiffeners, transverse connection plates, and bearing stiffeners. Category $\mathrm{C}^{\prime}$ has slightly improved infinite life fatigue resistance over Category $\mathrm{C}$ so the CAFL was raised from $10 \mathrm{ksi}$ to $12 \mathrm{ksi}$.

Category D. Category D applies to intermediate welded attachments, welded connections with sharp transitions, non-pretensioned high strength bolted joints, and riveted members and joints. Intermediate welded attachments include groove or fillet welded attachments parallel to the direction of stress that are between 2 to 4 inches long. The length of the attachment must also be less than 12 times the thickness of the attachment. Longitudinally loaded attachments must be attached by full or partial penetration welds with weld terminations ground smooth. Transversely loaded groove welded attachments must have a transition radius between 2 and 6 inches and weld soundness established by NDT. If the plate is attached to a plate of equal thickness, the weld reinforcement may or may not be removed. If the plate is attached to a plate of unequal thickness, the weld reinforcement must be removed. 
Riveted joints are classified as Category D for new design and evaluation. However, this presumes the following:

- The rivets are sound.

- The holes were subpunched and reamed or drilled full size.

- There is no existing cracking.

- There is no significant section loss.

It is noted that some specifications, such as the Manual for Bridge Evaluation (AASHTO, 2011), indicate that riveted joints may be evaluated as Category $\mathrm{C}$ in specific instances. For example, from the MBE:

\section{Specification language in the 2nd edition of the MBE}

"Except as specified herein, the base metal at net sections of riveted connections shall be evaluated based upon the requirements of Category C, given in LRFD Design Table 6.6.1.2.3 1, instead of Category $\mathrm{D}$ as specified for new designs. The exception is for riveted members of poor physical condition, such as with missing rivets or indications of punched holes, in which case Category $\mathrm{D}$ shall be used."

\section{Associated commentary in the MBE}

"For new design, the base metal at net sections of riveted connections is specified to be Category D. This represents the first cracking of a riveted member, which is highly redundant internally. Category $\mathrm{C}$ more accurately represents cracking that has propagated to a critical size. This increase in fatigue life for evaluation purposes is appropriate due to the redundancy of riveted members."

According to the MBE, the rational for this increase in life for evaluation to category $\mathrm{C}$ is related to the inherent redundancy of built-up members. For example, in a built up I-shape, there is typically a web, two angles, and one or more cover plates. Cracking in one of these components is not deemed as critical as in a welded built-up member since there is not a direct path for crack propagation between components. Hence, a higher category is deemed to be justified by the MBE.

The authors of this document do not agree with that strategy for several reasons as listed below:

1. The data from full-scale fatigue testing demonstrates that cracking in riveted members is consistent with category D for drilled holes. Internal member redundancy is not a reason to change the category. While the consequence of the cracking may not be as high in built-up members, the likelihood of cracking is no different and best characterized by category D. Classifying these details as category $\mathrm{C}$ implies cracking will occur at a stress range and number of cycles consistent with category $\mathrm{C}$, which is not true. The actual cracking follows the category $\mathrm{D}$ curve at best.

2. The laboratory testing cited in the AASHTO MBE (2011) demonstrated that there was considerable remaining life after cracking was first observed. However, extending this observed behavior to all riveted members is questionable in the opinion of the authors as it presumes all members are proportioned similar to the specimens used in the experimental programs. Most beams are comprised of two angles that are on the order of $6 \times 6 \times 3 / 4$ and cover plates that are $5 / 8$ to $3 / 4$ inches thick and 12 to 16 inches wide. However, there are several bridges where much larger cover plates (say 1 inch thick by 24 inches wide) exist. The effects of one of these cover plates failing is much worse as the large plates comprise a significant portion of the cross section. Assuming this observation can be extended to all members and all joint types is not been justified to date.

3. Not all built-up members possess cover plates or significant internal redundancy. For example, many truss bridges utilize tension members comprised of four angles stitched together using lattice. As another example, some lighter beams only utilized angles for the flanges without any cover plates. In such cases, failure of one of the angles is more serious than in cases where there are multiple cover plates and/or other plate components in addition to the angles. Hence, the high internal redundancy presumed by the AASHTO MBE (see commentary from the MBE above) may not actually be present. The AASHTO MBE (2011) does not provide any guidance on how the members should be proportioned.

At present (2014) FHWA does not explicitly permit the use of internal member redundancy for the design or evaluation of built-up members or joints for the determination of FCM. As such, pooled fund research project TPF-5(253) Member-Level Redundancy of Built-Up Steel Members is currently underway to quantify the performance of riveted and bolted built-up members in which one component has failed. (A video of a test conducted during TPF-5(253) of a built-up member in which a brittle fracture was initiated in a cover plate but did not propagate into the remaining components can be viewed at http://dx.doi.org/10.4231/R7MS3QPZ.) Until that research is completed, the authors of this document recommend classifying riveted built-up members as Category $\mathrm{D}$ when drilled holes are used for both design and evaluation. For punched holes, Category E may be used. Alternatively, the procedures contained in the AREMA Chapter 15-Steel Structures for evaluating the fatigue resistance of riveted members provide rational guidance on this topic (AREMA, 2014).

Categories $\mathbf{E}$ and $\mathbf{E}^{\prime}$. Categories $\mathrm{E}$ and $\mathrm{E}^{\prime}$ include the details with the lowest fatigue resistance. Category $E^{\prime}$ generally applies to similar details as Category E but with thicker plates which increases the stress concentration. These details have very low CAFLs with the CAFL for Category $\mathrm{E}$ at $4.5 \mathrm{ksi}$ and Category $\mathrm{E}^{\prime}$ at $2.6 \mathrm{ksi}$. These categories include details such as:

- Ends of partial length cover plates with or without end welds. Category $\mathrm{E}$ applies for thicknesses less than 0.8 inches, otherwise Category $\mathrm{E}^{\prime}$ applies.

- Long welded attachments without a transition radius or a short radius. Category $\mathrm{E}$ applies for most welded attachments with a transition radius less than 2 inches. One exception is longitudinally loaded welded components with no transition radius where the detail category varies from Category $\mathrm{C}$ to $\mathrm{E}^{\prime}$ depending on the length and the thickness of the attachment. 
- The termination of longitudinal stiffeners attached with fillet welds may be either Category $\mathrm{E}$ or $\mathrm{E}^{\prime}$. If the longitudinal stiffener does not have any transition radius and the thickness is less than 1 inch, Category $\mathrm{E}$ applies, otherwise Category $\mathrm{E}^{\prime}$ applies. If the longitudinal stiffener has a transition radius but is less than 2 inches, Category E applies.

- Eyebars, Category E applies.

\section{B. Unclassified Details}

The AASHTO fatigue categories cover most of the common bridge details where the fatigue resistance has been established through testing. However, there are some details which have been found through experience to be fatigue and fracture prone and are not included in the AASHTO LRFD Specifications categories. These details, such as extraneous welds, undocumented tack welds, or poor quality welds, were not accounted for as "common" details since they often contain discontinuities required to initiate damage. Guidance to the repair, removal, and proper documentation of these discontinuities are given in Section IV to help control and monitor the initiation of any cracks.

Other common issues that are not covered by the fatigue categories are out-of-plane bending which leads to distortion-induced cracking. One type of distortion cracking is driven by out-of-plane bending over a small web gap as shown in Figure 1.10. (A video of an out-ofplane distortion crack observed during a laboratory test can be viewed at http://dx.doi.org/10.4231/R7125QKV.) Another example is moments introduced on longitudinal gusset plates used to attach lateral bracing members to web plates. The forces driving the distortion can be either load induced or due to differential thermal

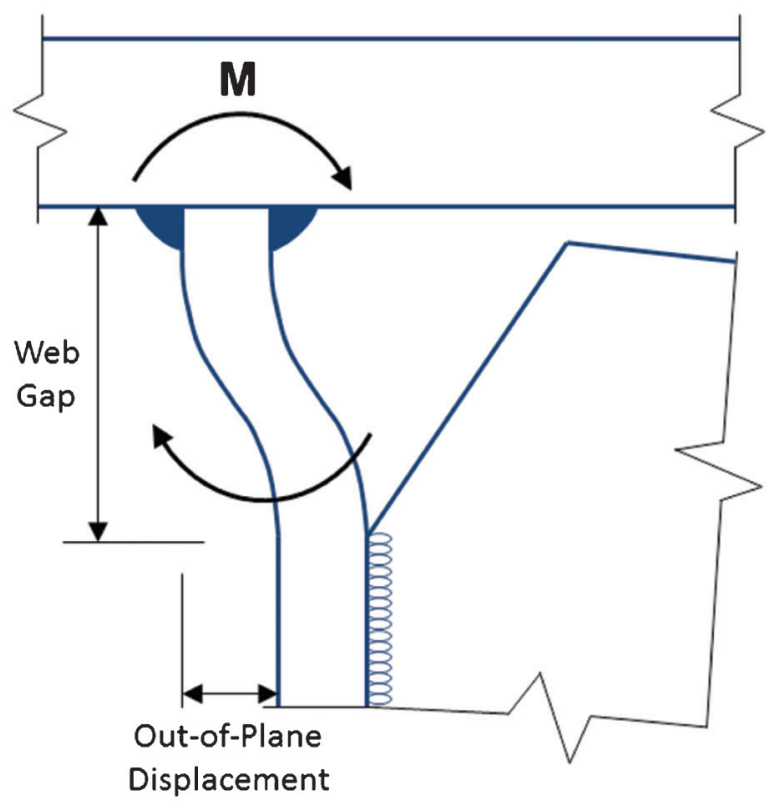

Figure 1.10 Distortion-induced cracking. expansion of bridge components. Although the current specifications contain guidance on minimizing distortion-induced cracking, many existing bridges (of pre1984 design) contain details which are susceptible to this type of cracking. Many of the fatigue cracks found in earlier vintage bridges can be attributed to failure to control distortion.

\subsection{Considerations for Evaluating Existing Structures}

\section{A. Fatigue Evaluation}

There are many differences between fatigue design of a new structure and fatigue evaluation of an existing structure. During a fatigue design, the designer is usually concerned with providing 75-100 years of life with a very low probability of cracking. During a fatigue evaluation, the designer is usually concerned with a shorter life of 10-50 years, and a higher probability of cracking may be acceptable. The fatigue design procedure using the S-N curves assumes approximately a $2.5 \%$ probability of the actual life being less than the predicted life. This is accomplished by setting the AASHTO S-N curves at two standard deviations below the mean established for the testing data. This confidence level is very important to set a reasonable factor of safety due to the variability associated with the data used to develop the AASHTO LRFD Specifications S$\mathrm{N}$ curves. During fatigue evaluation of an existing bridge, an engineer may decide to implement a fatigue resistance higher than the AASHTO design fatigue resistance to provide a less conservative estimate of remaining fatigue life. The AASHTO Manual for Bridge Evaluation (AASHTO, 2011) permits the use of one of three different fatigue resistance curves:

- The "minimum life" which is equal to the design fatigue resistance with a $2 \%$ probability of failure,

- The "mean life" which is equal to the mean expected cyclic life with a $50 \%$ probability of failure, or

- The "evaluation life" which is between the minimum and mean life with a $16 \%$ probability of failure.

Due to the large variability in the fatigue data, using the mean or evaluation resistance curve will provide a significant increase in life compared to the design curve. The increase in life using these resistance curves vary for each detail category, but it can be as much as 1.5 times the life for the evaluation curve or twice the life for the mean resistance curve for some details. The use of higher fatigue resistance is justified in many cases since the purpose of fatigue evaluation is often different than the purpose of new design. In fatigue evaluation of existing structures, the goal is often to determine the need for inspection, maintenance, and possible retrofits to extend service life. The cost of properly designing a new structure with a lower probability of fatigue is trivial compared to expensive retrofits that may be required for a structure in service.

Because of these differences, many factors need to be considered to determine if corrective actions (e.g., 
retrofitting, peening, etc.) are required to extend service life of a fatigue critical detail. Some of the important factors are the magnitude of the loading (stress range), the age of the bridge and traffic history (number of cycles), material properties, size of discontinuities, redundancy (FCM or non-FCM), history of fatigue problems, and any unique behavior that the member may undergo (i.e., out-of-plane bending). One of the most important considerations when determining what action (if any) is required is related to establishing the expected future life of the detail and assessing the risk over this period. For instance, if a bridge will be replaced within 10 years, details with a low fatigue resistance may be sufficient if it is determined that the likelihood of the occurrence of fatigue cracking is low; but if it is desired for the bridge to have 50 or more years of remaining life, these same details may need to be retrofitted (AASHTO, 2011). For more information on establishing inspection procedures and evaluation practices, see the AASHTO Manual for Bridge Evaluation.

\section{B. Fracture Evaluation}

Most bridges traditionally are not subjected to a rigorous evaluation of the potential for brittle fracture. Fracture critical members are identified and subjected to the more rigorous fracture critical inspection protocols. However, inspection only serves to detect fatigue cracks or other damage that contributes to fracture risk. Some bridges, usually those with higher importance, are subjected to more detailed evaluations that include fracture-mechanics based evaluation of details and measurement of material fracture toughness. While detailing rules and fracture toughness requirements are in place for modern bridges, for bridges built before 1978, AASHTO had not introduced the Fracture Control Plan to set the standard CVN energy requirements of FCMs. For bridges built before 2009, AASHTO did not have the necessary provisions to ensure that a proper web gap is used at intersecting welds which will resist the initiation of Constraint Induced Fracture. Thus, it is important during inspections to check for any details which could initiate CIF and to document and report all fatigue cracks in FCMs.

Fitness-for-service (FFS) may be used to check for adequate fracture resistance to an existing fatigue crack, but this process is quite complex and involves the accumulation of input data including material fracture toughness, flaw size, live load stresses, and an estimation of dead load stresses. It is important to acknowledge that fracture is driven by the total stress instead of the stress-range, especially when adding dead load through any rehabilitation or retrofit projects. In some cases FFS evaluations include evaluation of the probability of fatigue cracking and the probability of crack detection through inspection before they grow to a critical size.

\subsection{Summary}

The preceding background of the fundamentals of fatigue and fracture will allow bridge inspectors and engineers to better identify details and retrofit strategies that will mitigate fatigue and fracture damage. For fatigue, the driving forces for damage are the stress range, number of cycles, stress concentrations, and detailing discontinuities. For fracture, the driving forces for damage are constraint, rate of load application, temperature, stress, discontinuities, and toughness.

The following detail library contains numerous examples of critical elements and details which are susceptible to degradation or failure due to fatigue and fracture. This document may be used by inspectors as a guide for identifying common fatigue and fracture prone details and for developing corrective action strategies. This guide contains details both identified and included in the AASHTO specification and some common bridge conditions or details which do not have an AASHTO fatigue category. Guidance is provided on the deficiencies where inspections should be focused and where these deficiencies are commonly found. This includes locations where fatigue cracks are likely to initiate, when and where to use NDT methods and what the preferred methods are, and repair and retrofit recommendations for specific deficiencies at specific details.

A repair and retrofit guide is presented for nonstandard, noncompliant, or failed details commonly found on steel bridges. For each specific problematic type of defect or detail, an evaluation procedure for assessing the need for a repair or retrofit is provided along with considerations for performing the necessary action. This guide is based on field experience and research thus, not all possible detail and damage configurations could be presented. This guide will aid in understanding the basic principles of fatigue-resistant retrofits that have succeeded during in-service application and could be applied to a unique configuration.

\section{FATIGUE AND FRACTURE DETAIL LIBRARY}

\subsection{Introduction}

Numerous examples of bridge details are presented for the various fatigue detail categories defined in the AASHTO LRFD Bridge Design Specifications. Photos of details are shown with descriptions of the member and detail identified. Recommendations for visual inspection and NDT are provided along with possible retrofit solutions that will improve the fatigue resistance of the detail.

This library can be used by inspectors as a guide for identifying fatigue and fracture prone details. The purpose of this library is to provide inspectors with specific examples of fatigue details which are classified according to the AASHTO fatigue detail categories and examples of fatigue and fracture prone details that are not classified as AASHTO fatigue categories. The photos show a variety of examples of details encoun- 
tered in the field. The photos do not always match the illustrative examples in the AASHTO table, and thus provide better clarity in detail classification in these cases. Guidance is provided on what deficiencies to look for and where to look, including locations where fatigue cracks are likely to initiate, when and where to use NDT methods and what methods are preferred, and repair and retrofit recommendations for specific deficiencies at specific details.

This library is only a guide, and good engineering judgment must be exercised in all cases of identifying details and deficiencies and responding to conditions identified.

The descriptions of each detail are organized as follows:

- AASHTO Fatigue Detail: General condition as defined in the AASHTO Detail Categories for Load-induced Fatigue that influences fatigue resistance. The detail number from the AASHTO Fatigue Detail Categories is assigned as applicable.

- Description: Detailed description of members, attachments, connections, and loading that make up a particular category of fatigue detail. Descriptions are based on those provided in the AASHTO Detail Categories for Load-induced Fatigue, as applicable.

- Detail Category: A geometric discontinuity, joint, splice, or other welded, riveted, or bolted detail whose fatigue resistance has been defined through testing. Details with similar fatigue resistance have been grouped into categories identified by letters A through $\mathrm{E}^{\prime}$, as defined by AASHTO. Details not defined under these categories are defined as Unclassified Details and may also be identified as Fatigue or Fracture Prone. These have not been grouped under specific categories as their fatigue lives are unknown either due to lack of testing data or unpredictability of behavior.

- Visual Inspection: Identifies specific crack locations expected in the detail shown along with other deficiencies that may impact fatigue and fracture of the detail.

- NDT: Recommendations for type and location of NDT on the detail shown.

- Repair and Retrofit Recommendations: Recommendations for performing repairs or retrofits of a detail due to the presence of deficiencies or a high likelihood of the occurrence of a deficiency if prior action is not taken. For the purpose of this document, a repair is defined as a maintenance action to correct a localized deficiency and extend the life of an element or component. A retrofit is defined as the replacement of an element or component or the repair of a significant portion of an element or component to significantly improve the condition of the element or component. When it is recommended that a crack may be monitored through special inspections, these inspections should be scheduled in accordance with the Recording and Coding Guide for the Structure Inventory and Appraisal of the Nation's Bridges (Coding Guide) and agency policy.

- Repair Reference: Reference number corresponds to the repair procedure section found in the "Chapter 3: Repair and Retrofit Guidance."

- Comments: Further discussions on various inspection and repair techniques for various specific instances of the detail type. Also includes a detailed description of each photo shown and any specific considerations for that condition.

\subsection{Classified Details}

This section contains many of the most common bridge details that are included in Table 6.6.1.2.3-1Detail Categories for Load-Induced Fatigue in AASHTO (2012) LRFD (see bulleted list below). The fatigue categories have been developed for these details through extensive research to provide a quantitative procedure for fatigue design and evaluation. The Classified Details will vary largely in fatigue resistance from high resistance in Category A to very low resistance in Category $\mathrm{E}^{\prime}$. The Classified Details in this section do not necessarily have greater fatigue resistance than the Unclassified Details in the following section. Rather, the Unclassified Details either represent an in-service condition which was not accounted for during the design or represent a bridge detail which lacks the uniformity in design or extensive research to be classified with an applicable fatigue category. The bridge details included in this section are as follows:

- Base Metal

- Re-entrant Corners and Copes

- Holes Weld Access Holes

- Holes Open Holes

- Mechanically Fastened Connections Pretensioned high strength A325 and A490 bolts

- Mechanically Fastened Connections Non-pretensioned A325 and A490 bolts, rivets, and A307 bolts

- Threaded Rods or Bolts in Tension

- Fusion Welded and Fillet Welded Connectors

- Pin Connected Elements Pin \& Hanger on Beam or Girder

- Pin Connected Elements Pin \& Hanger on Truss Bridge

- Pin Connected Elements Pin Connected Cantilever Truss Eyebars

- Pin Connected Elements Pin Connected Truss Eyebars

- Pin Connected Elements Pin Uplift Bearings

- Pin Connected Elements Pin Plate Connection for Beams \& Girders

- Complete Joint Penetration Butt Welds Not Ground Flush

- Stiffeners and Transverse Connection Plates Transverse Stiffener Weld

- Stiffeners and Transverse Connection Plates Termination of Longitudinal Welds

- Longitudinal Weld (Non-Termination) Built-up Sections

- Longitudinal Weld (Non-Termination) Longitudinal Stiffeners/Cover Plates

- Welded Longitudinal Gusset Plates and TransverselyLoaded Attachments Joined by CJP (Connected with Equal Thickness Plates)

- Welded Longitudinal Gusset Plates and Transverselyloaded Attachments Joined by CJP (Connected with Unequal Thickness Plates)

- Welded Longitudinal Gusset Plates and Transverselyloaded Attachments Joined by Fillet or PJP

- Angle Members Connected by Longitudinal Fillet Welds

- Terminations of Welded Cover Plates Bolted Terminations

- Termination of Welded Cover Plates Welded Terminations 
This page intentionally left blank. 


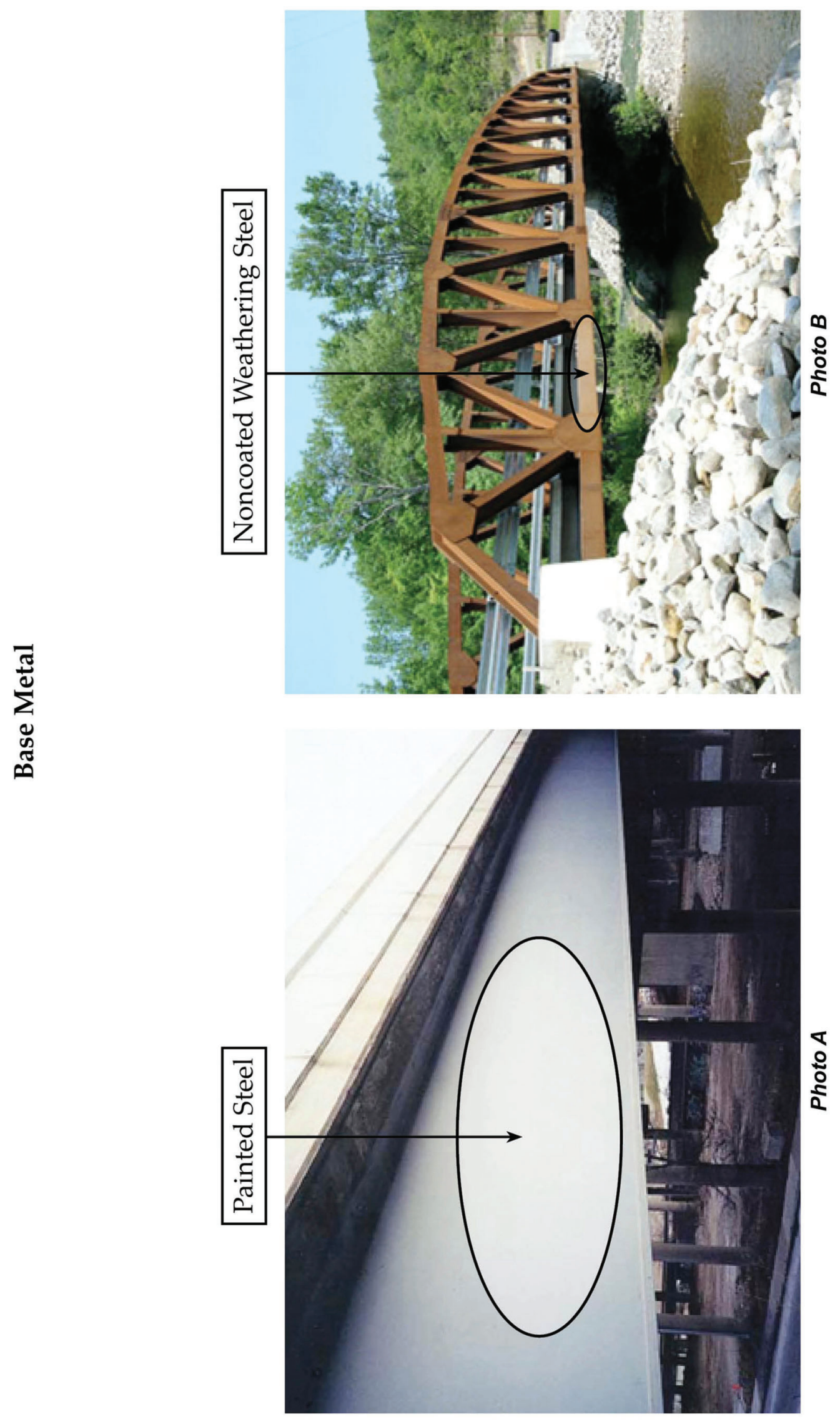




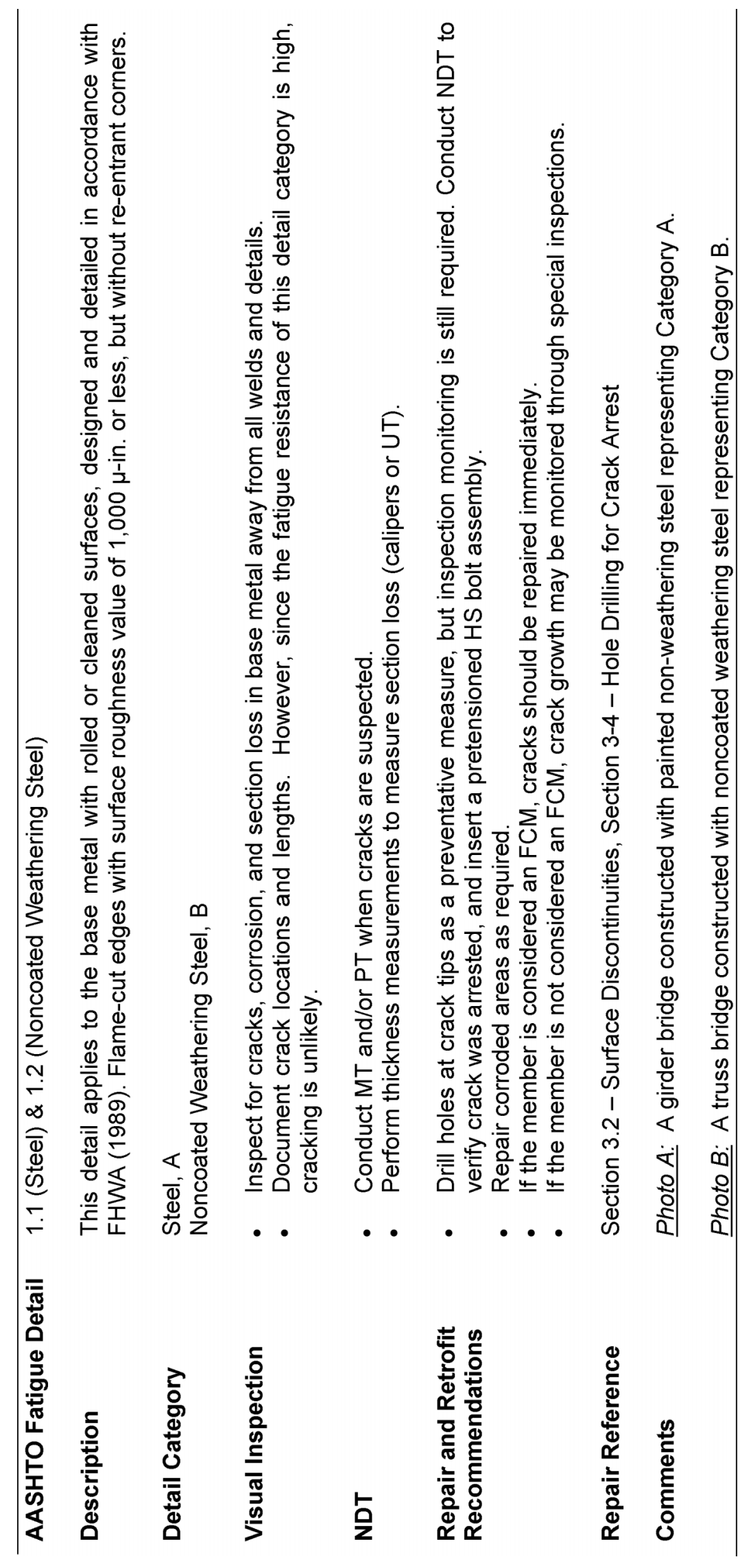




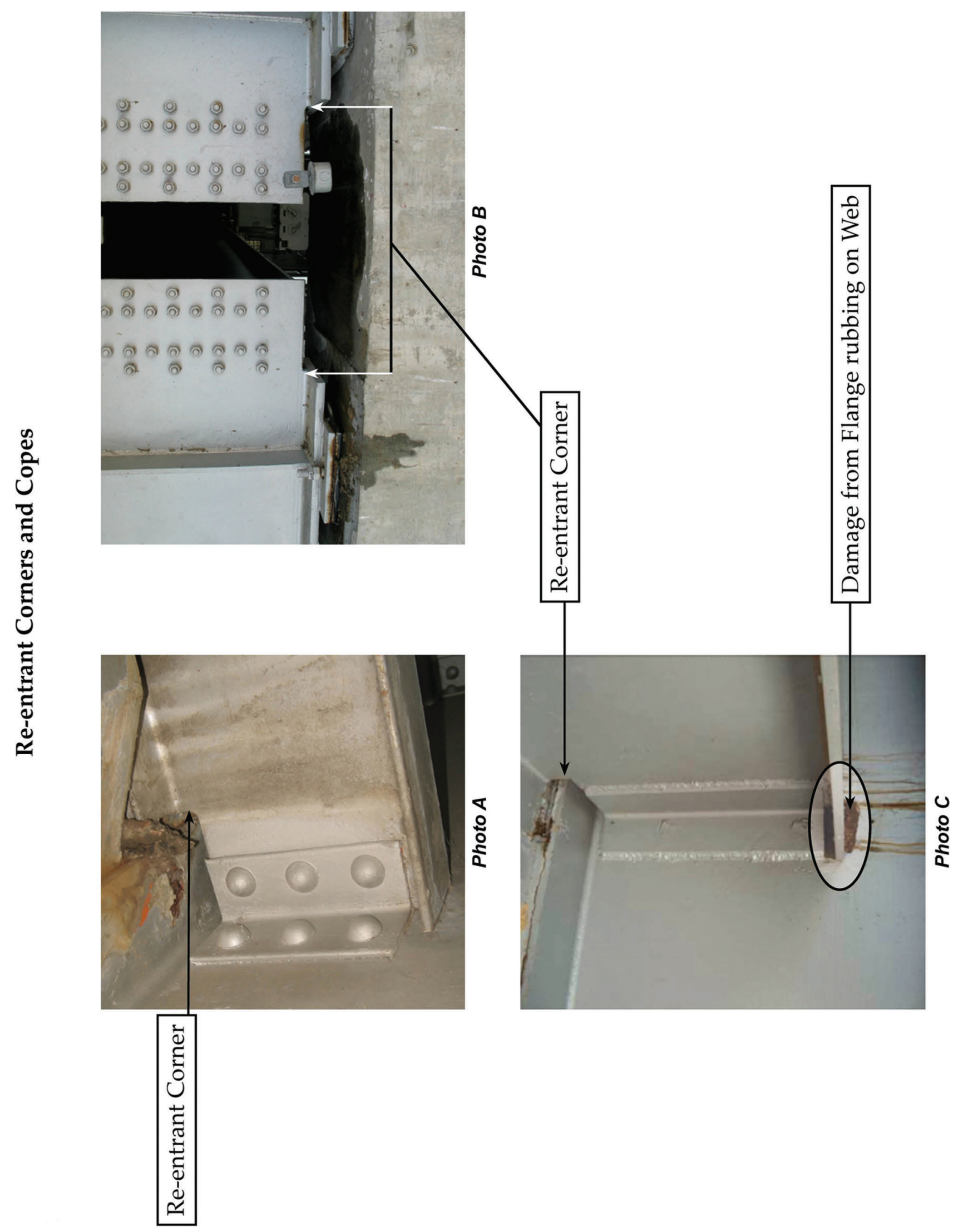




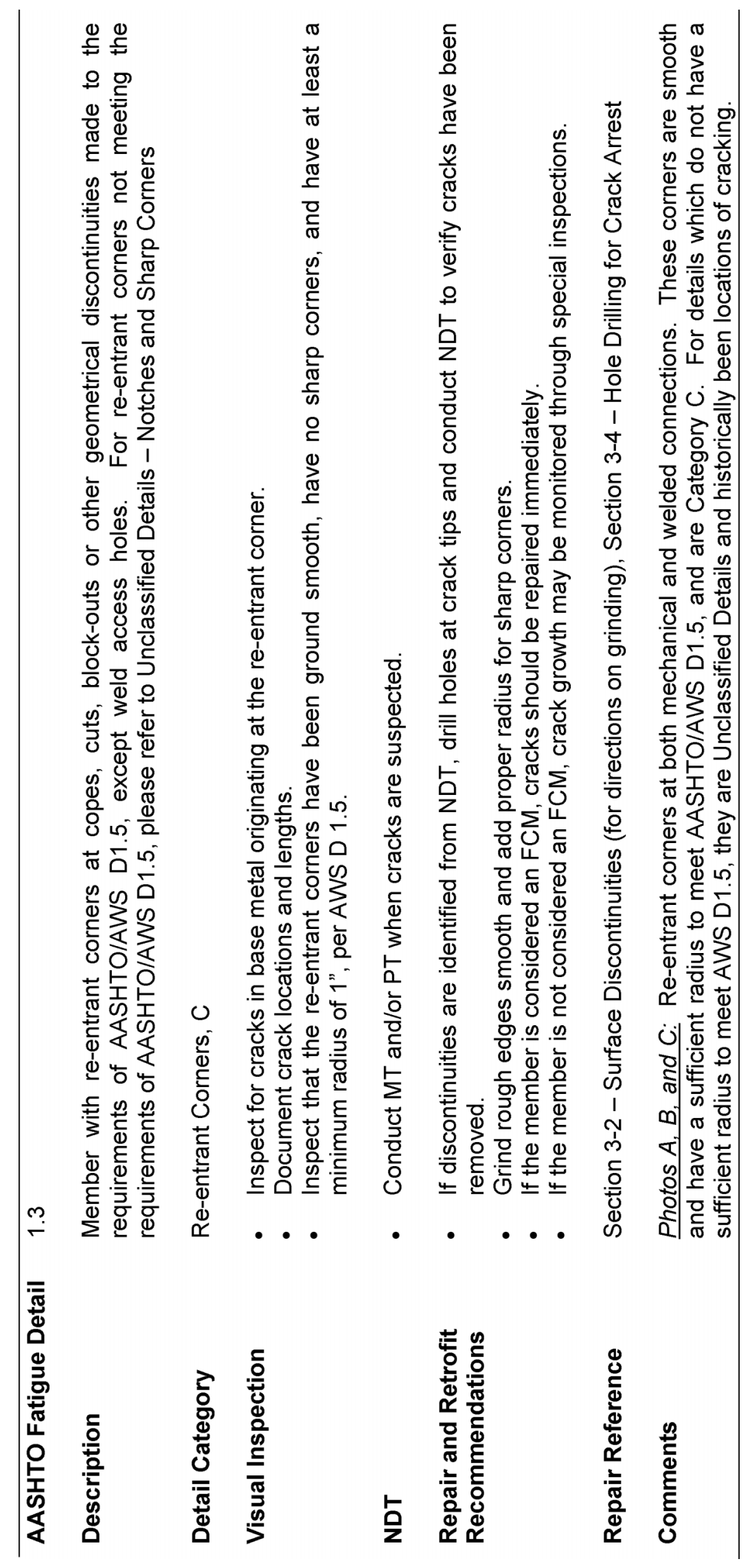




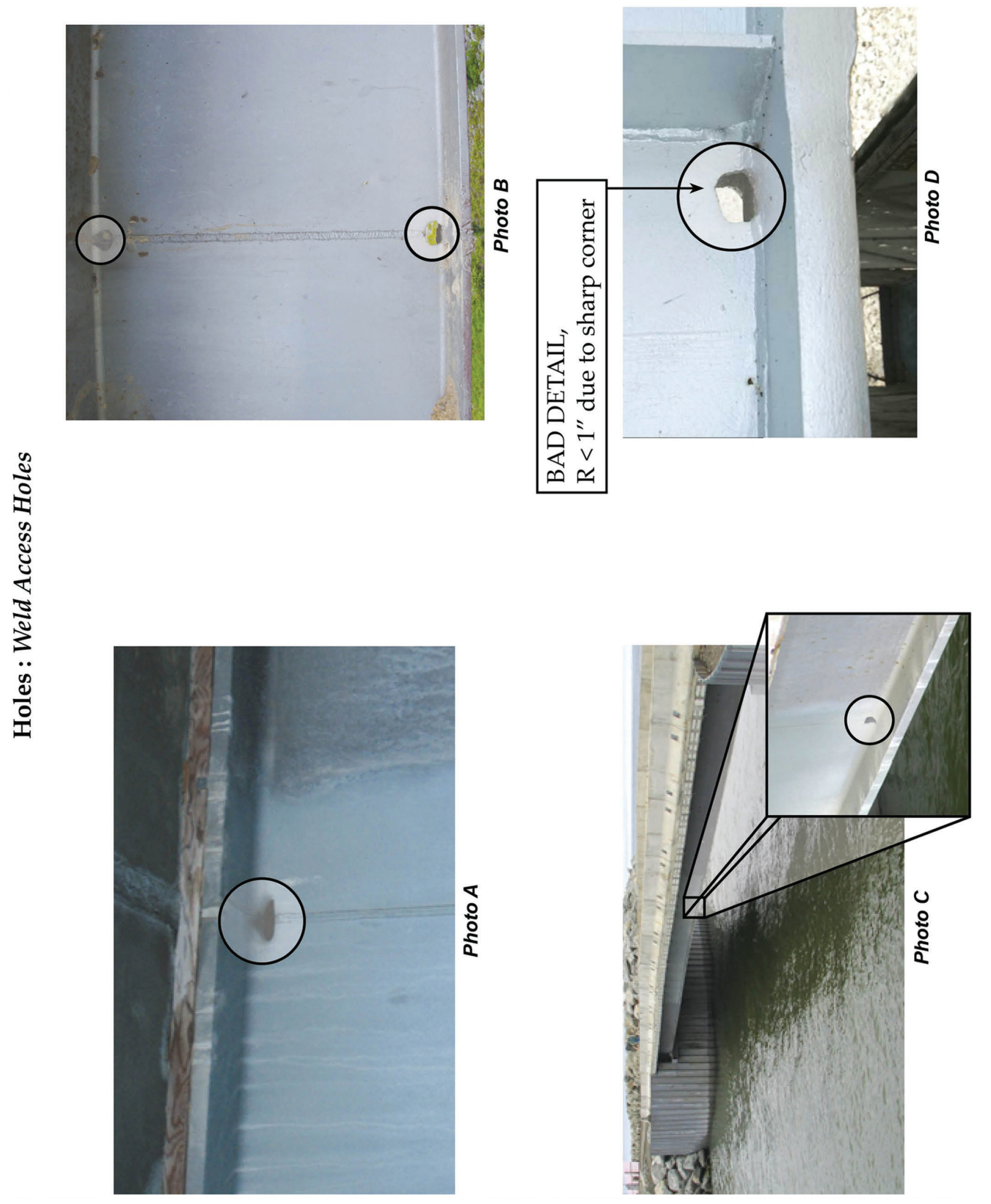




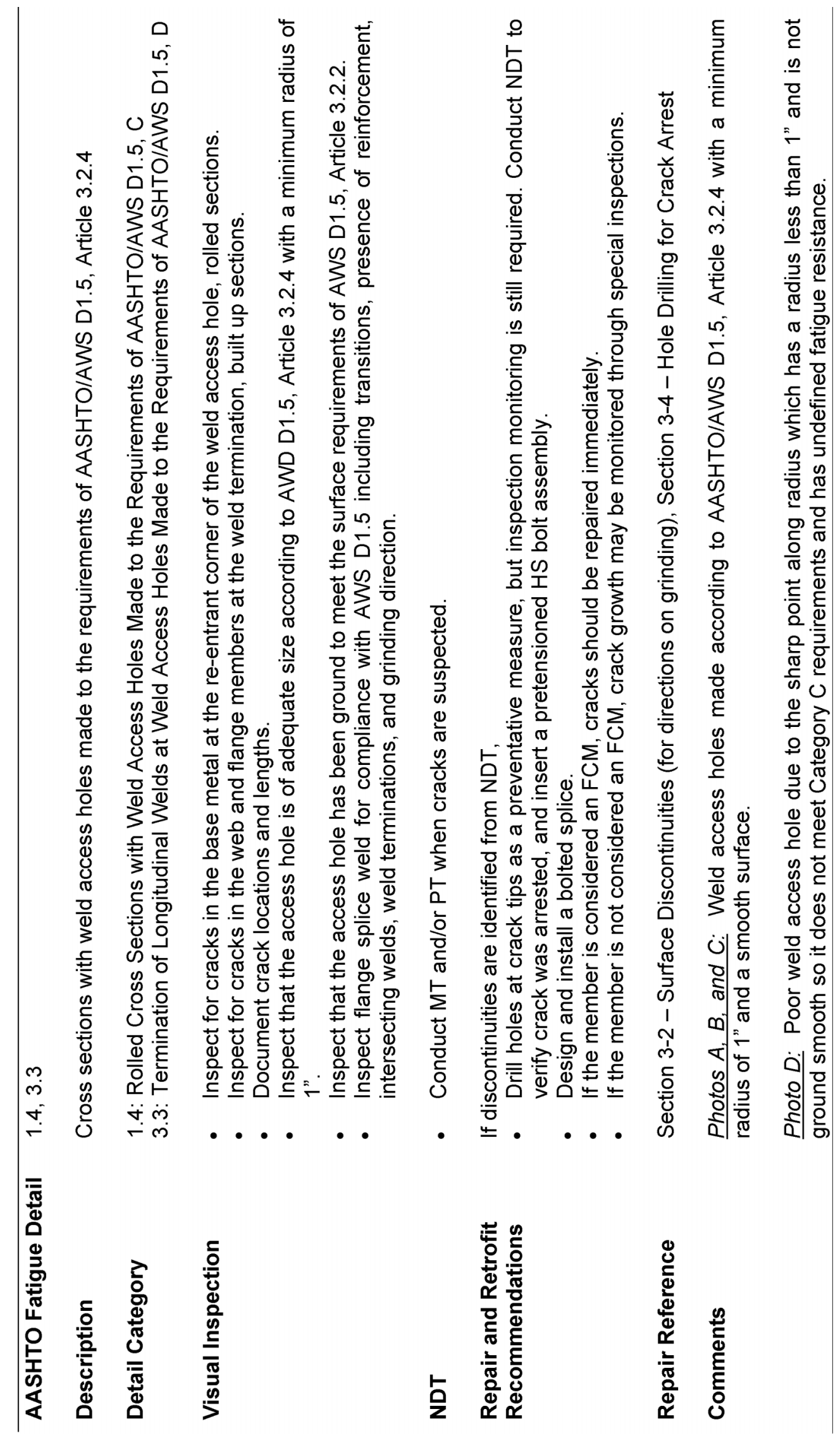




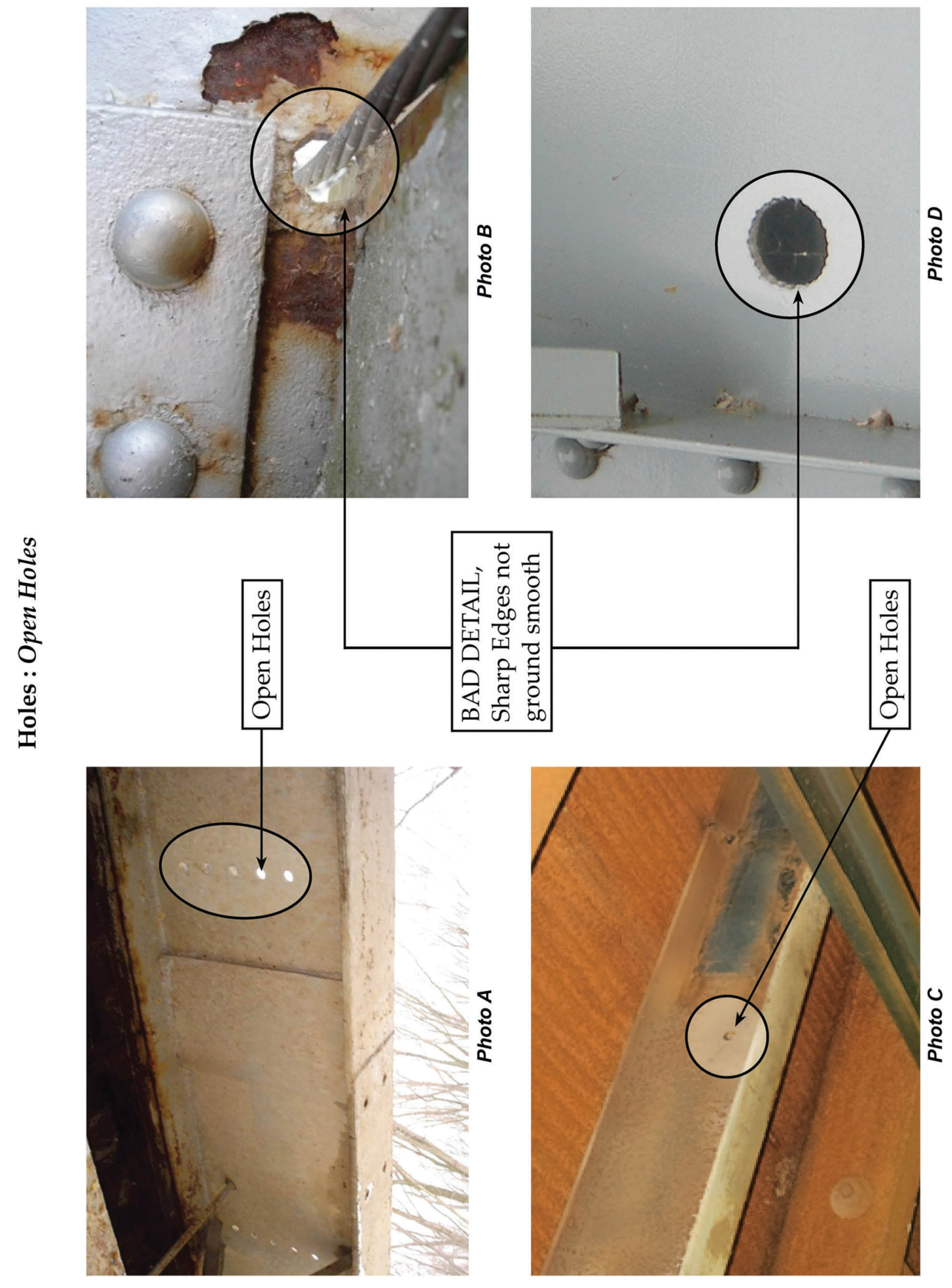




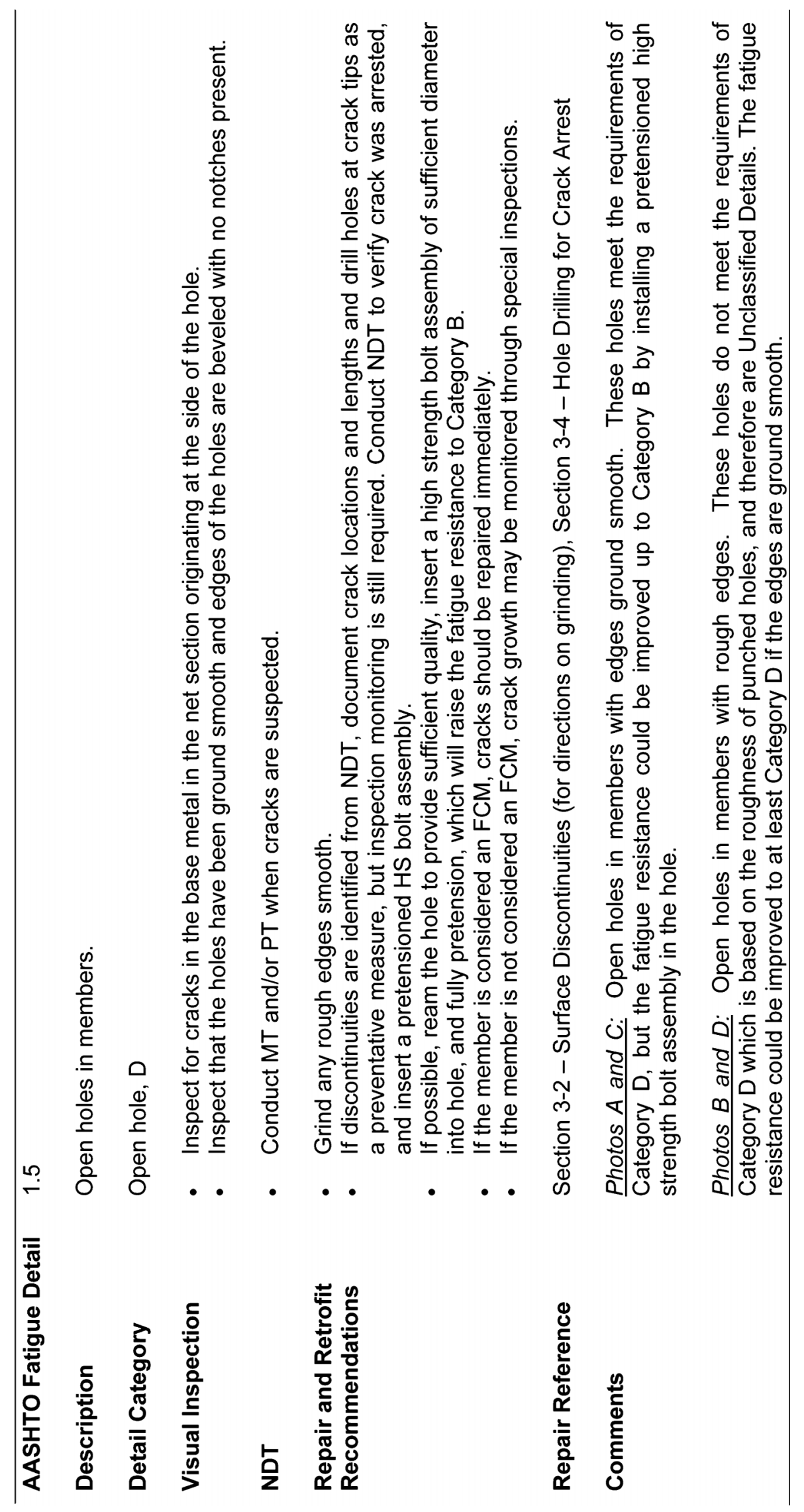



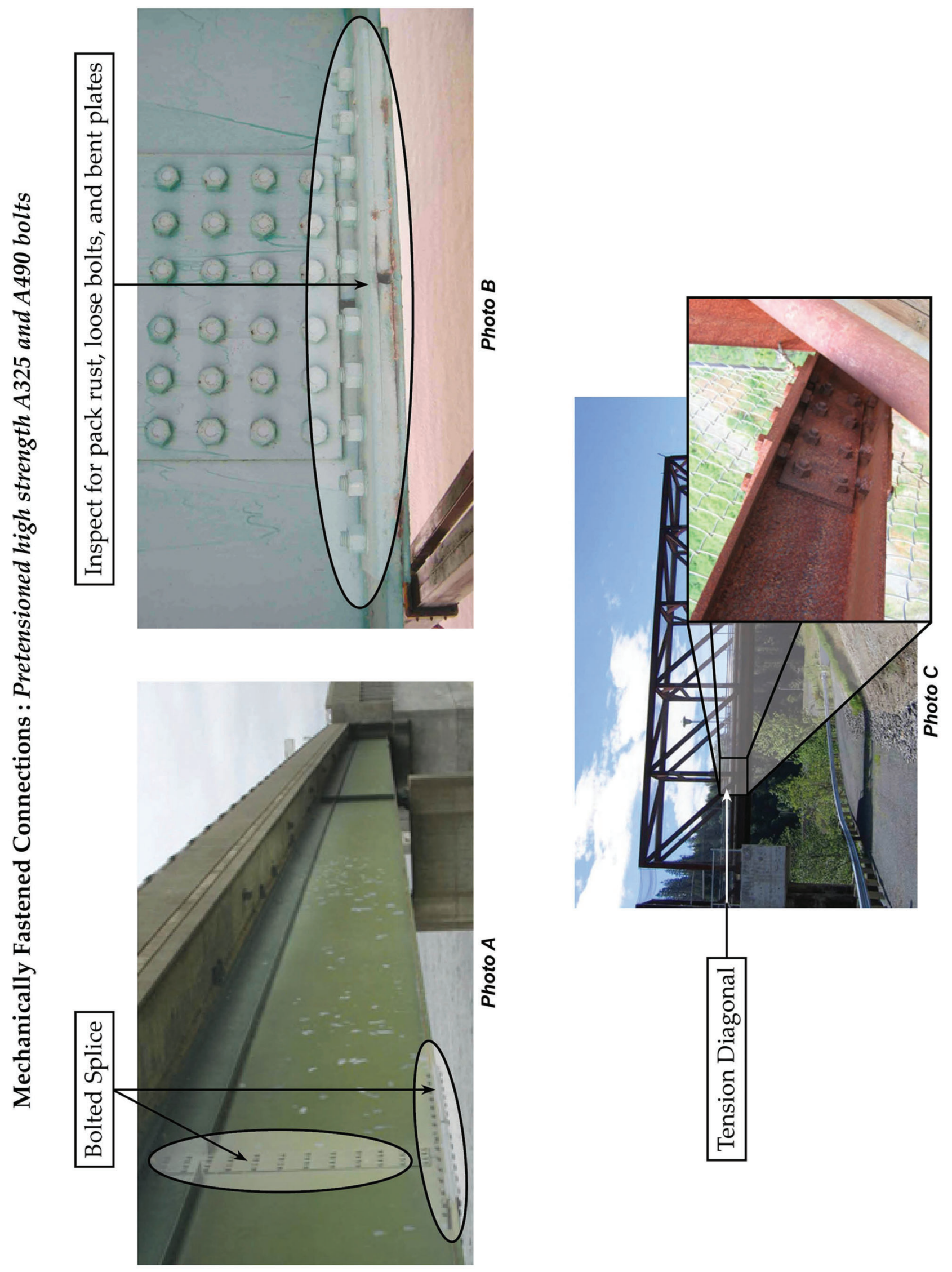


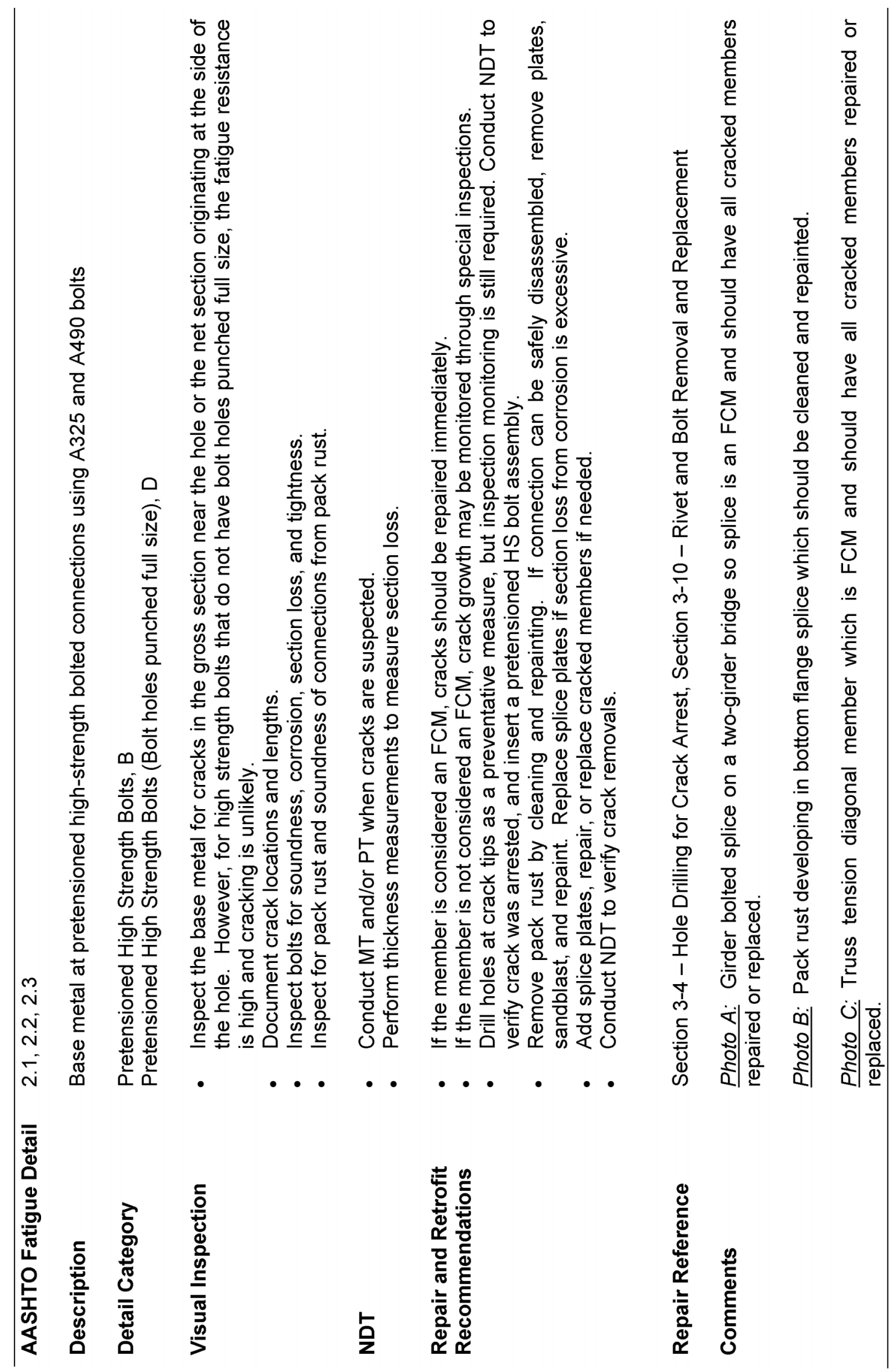




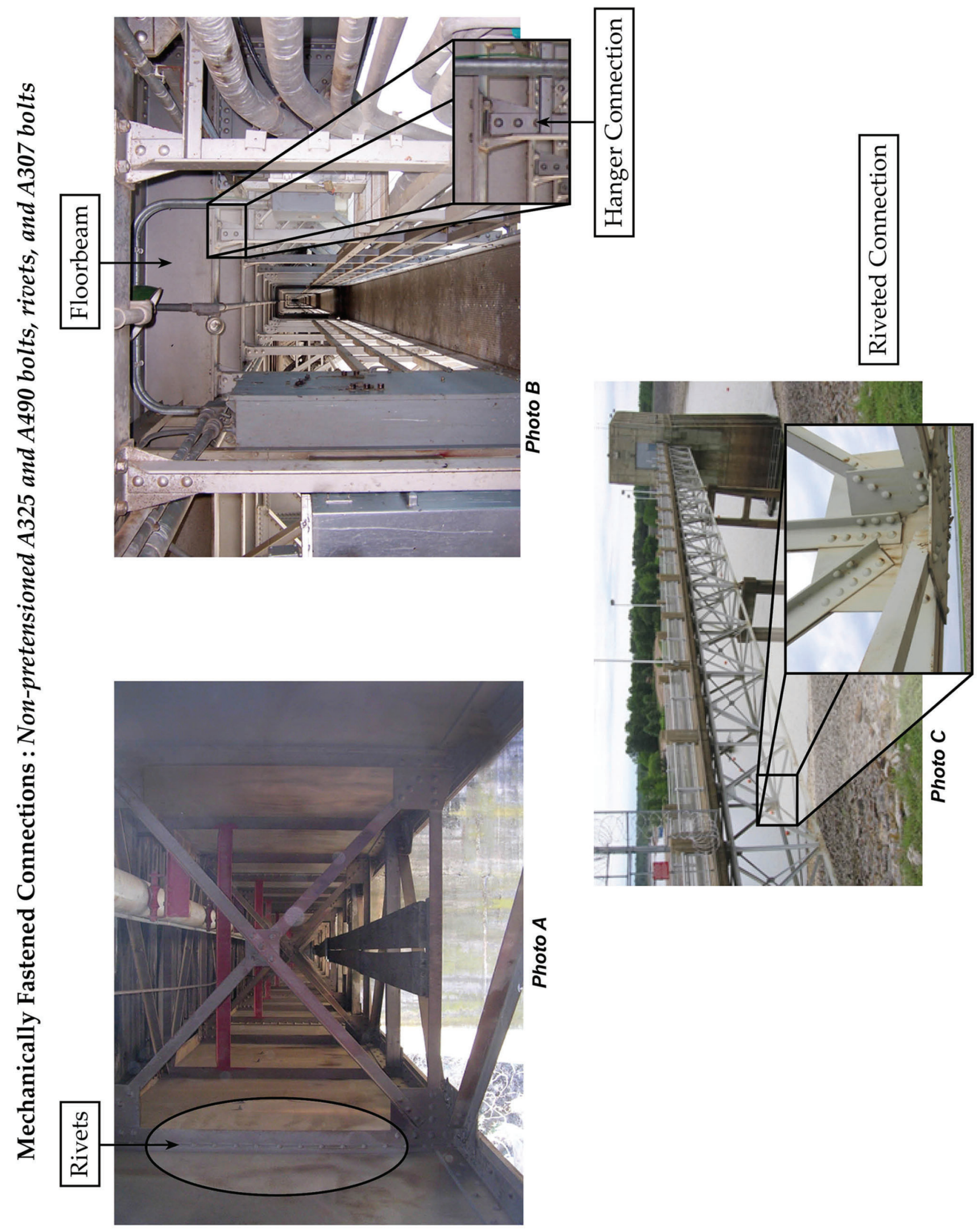




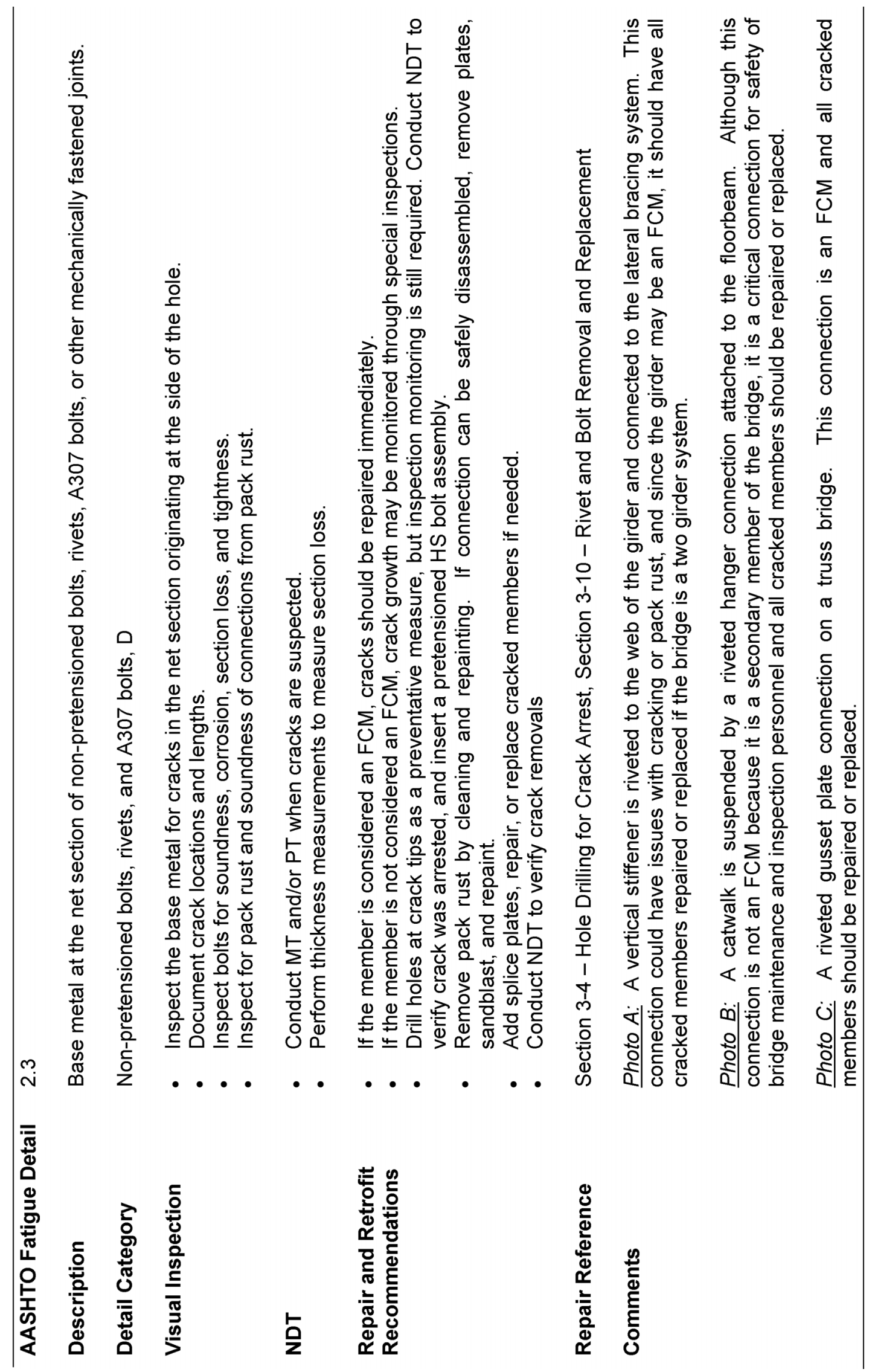


בี
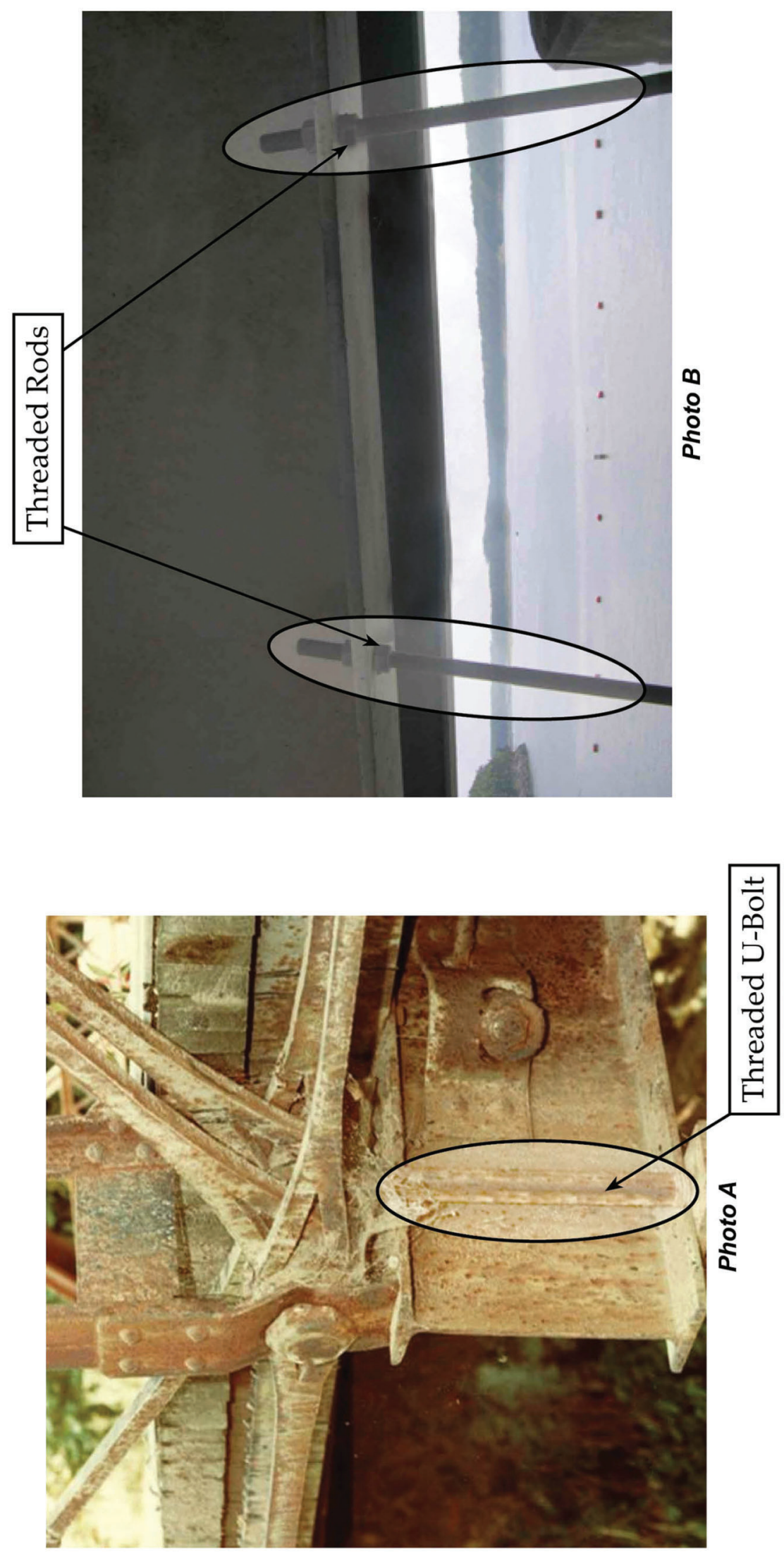


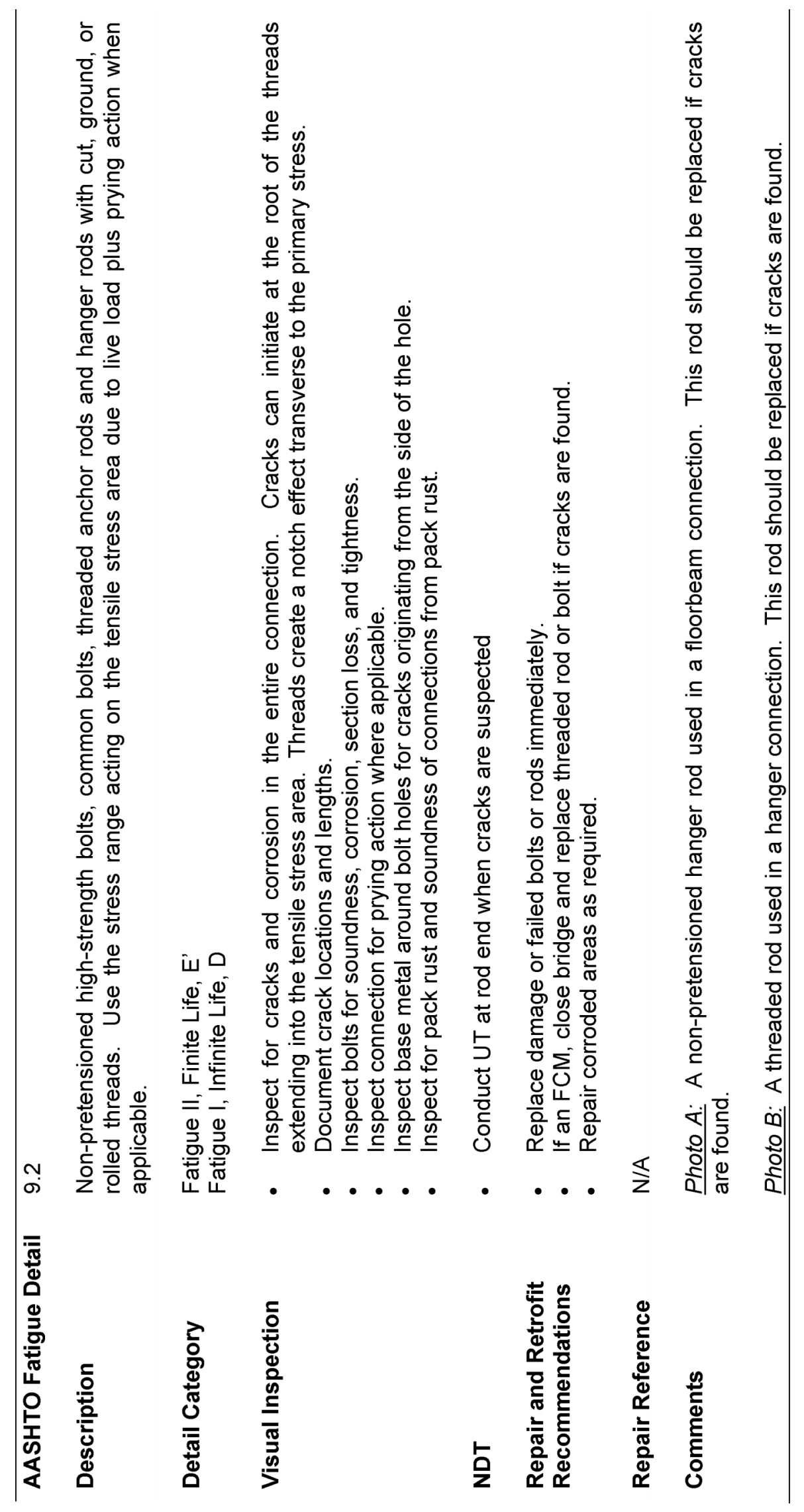




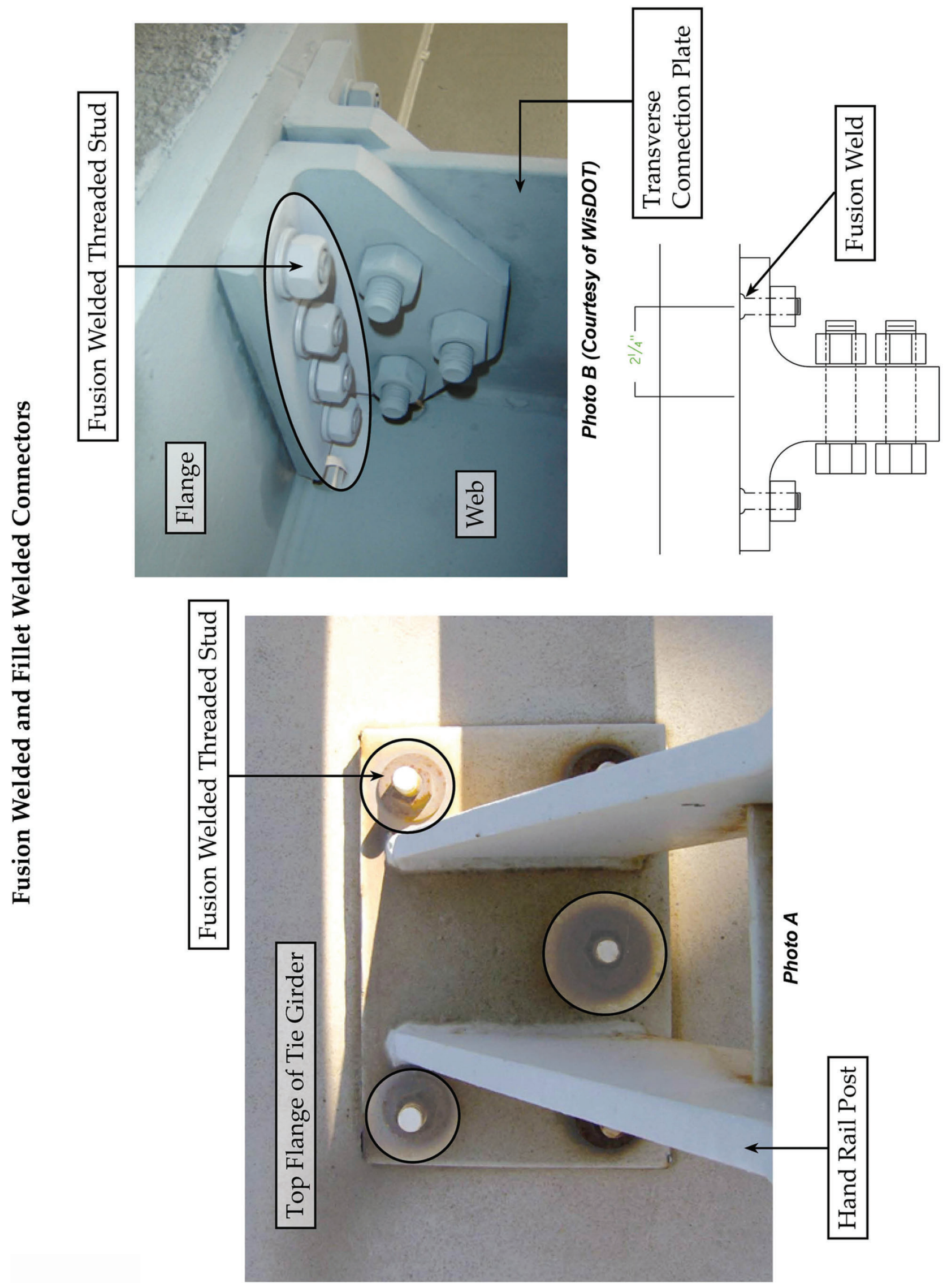




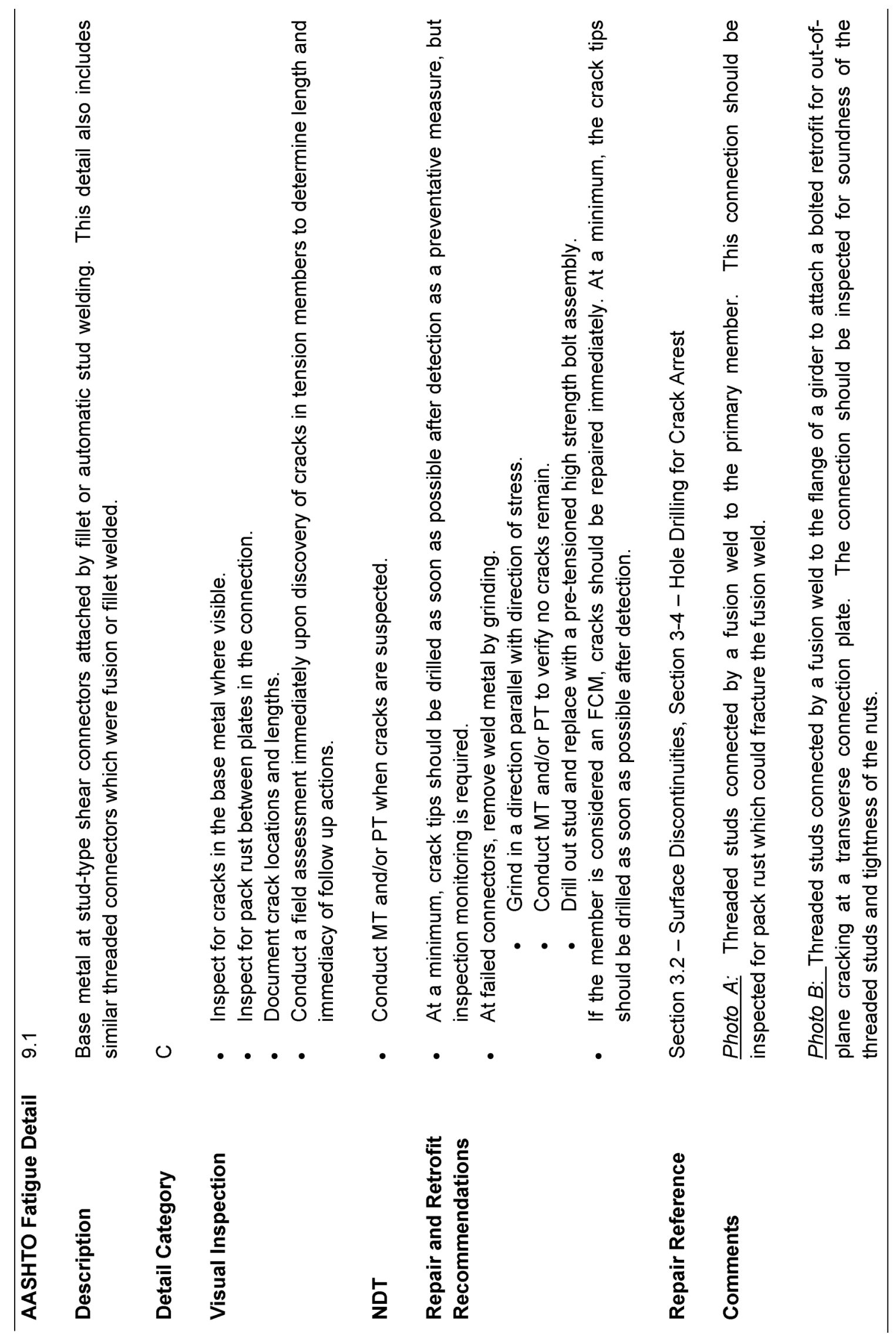




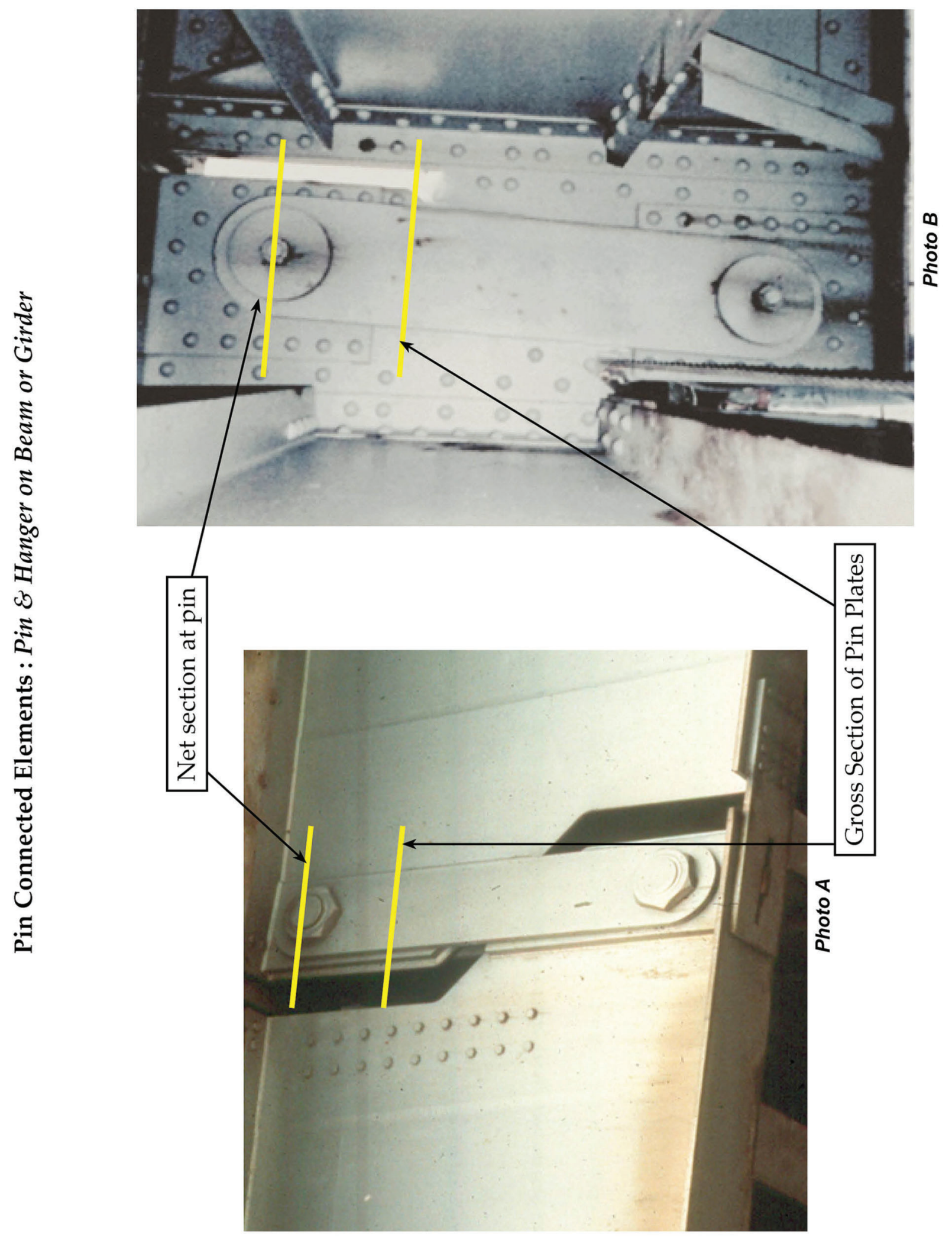




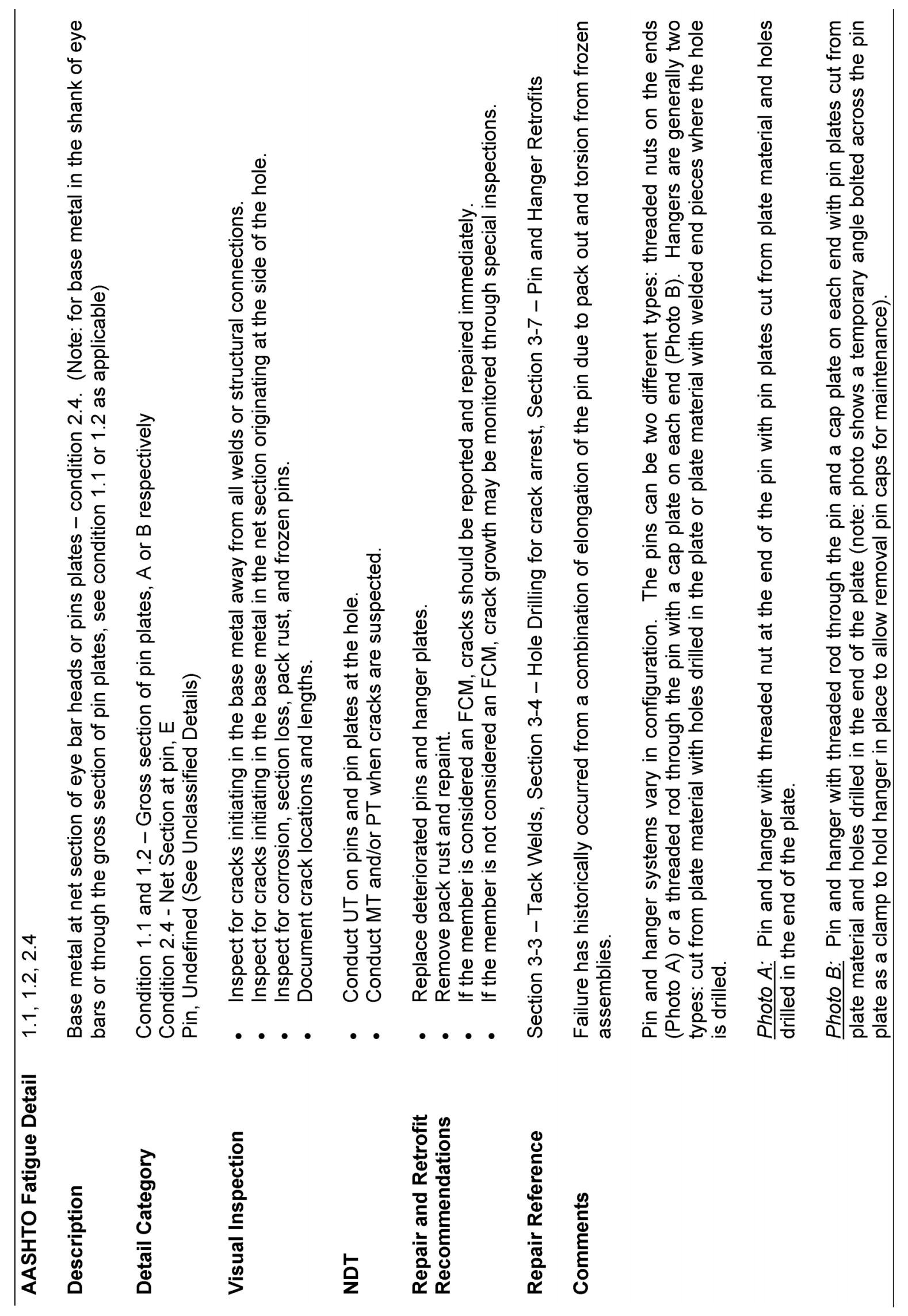




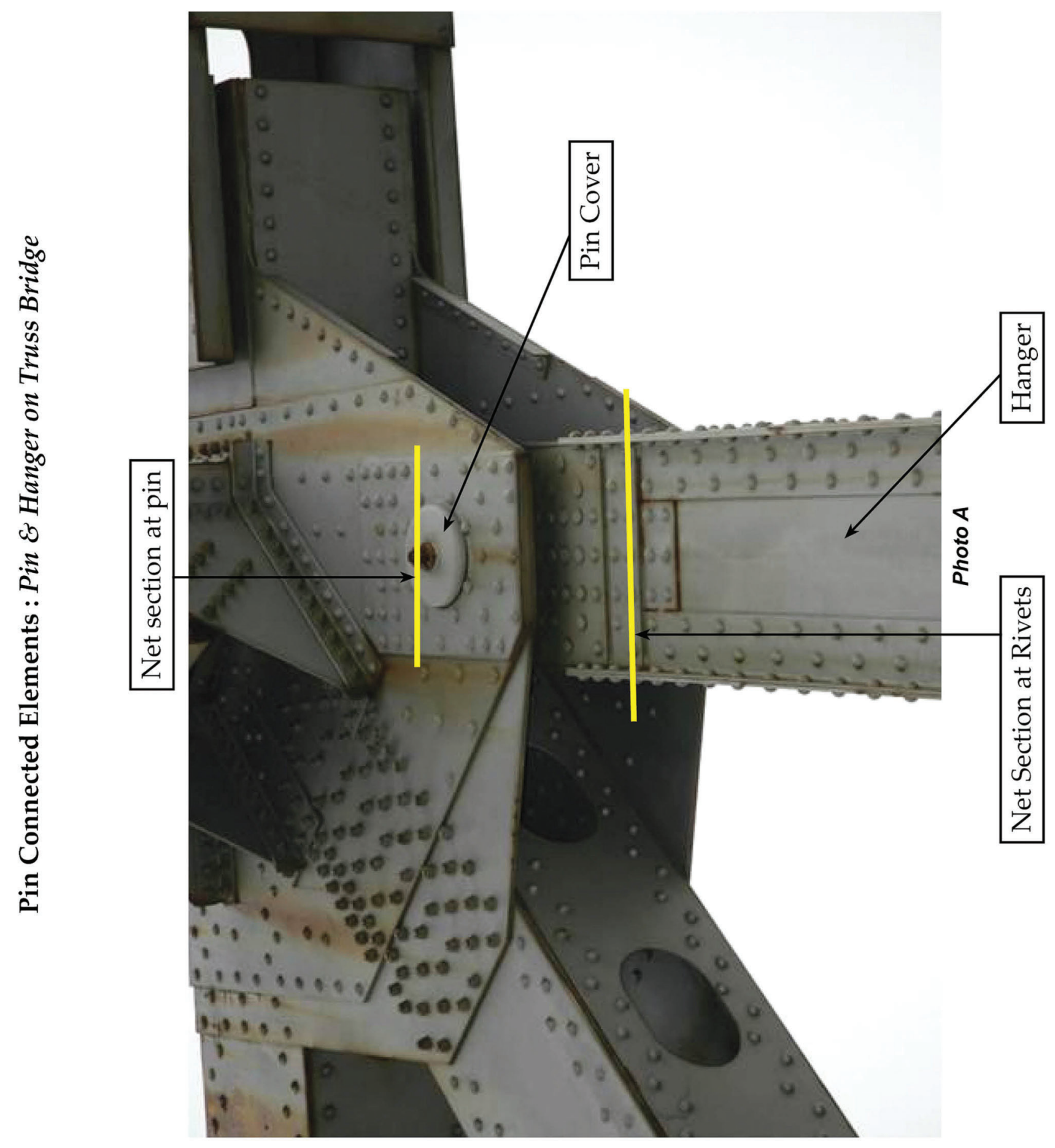




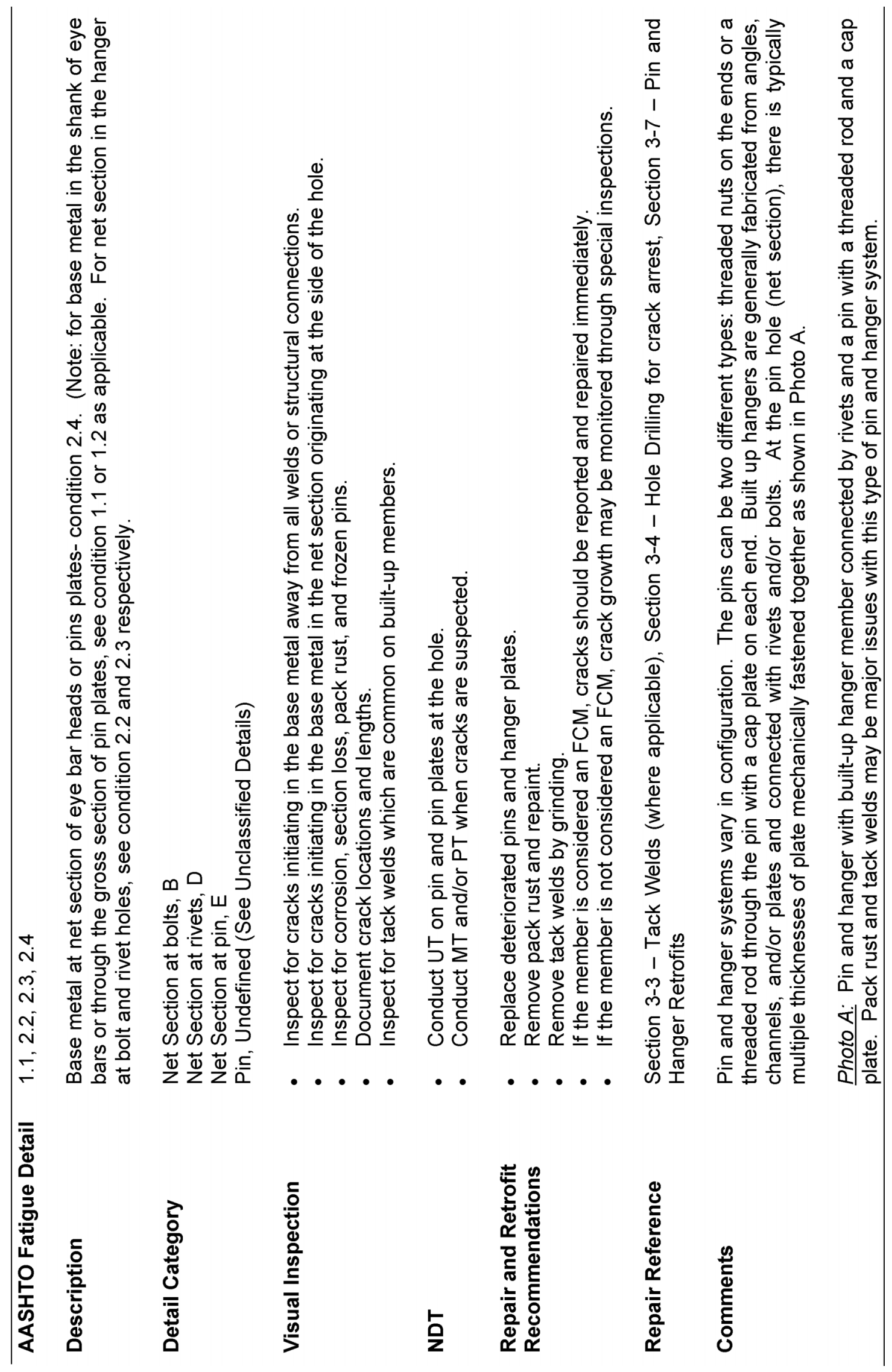




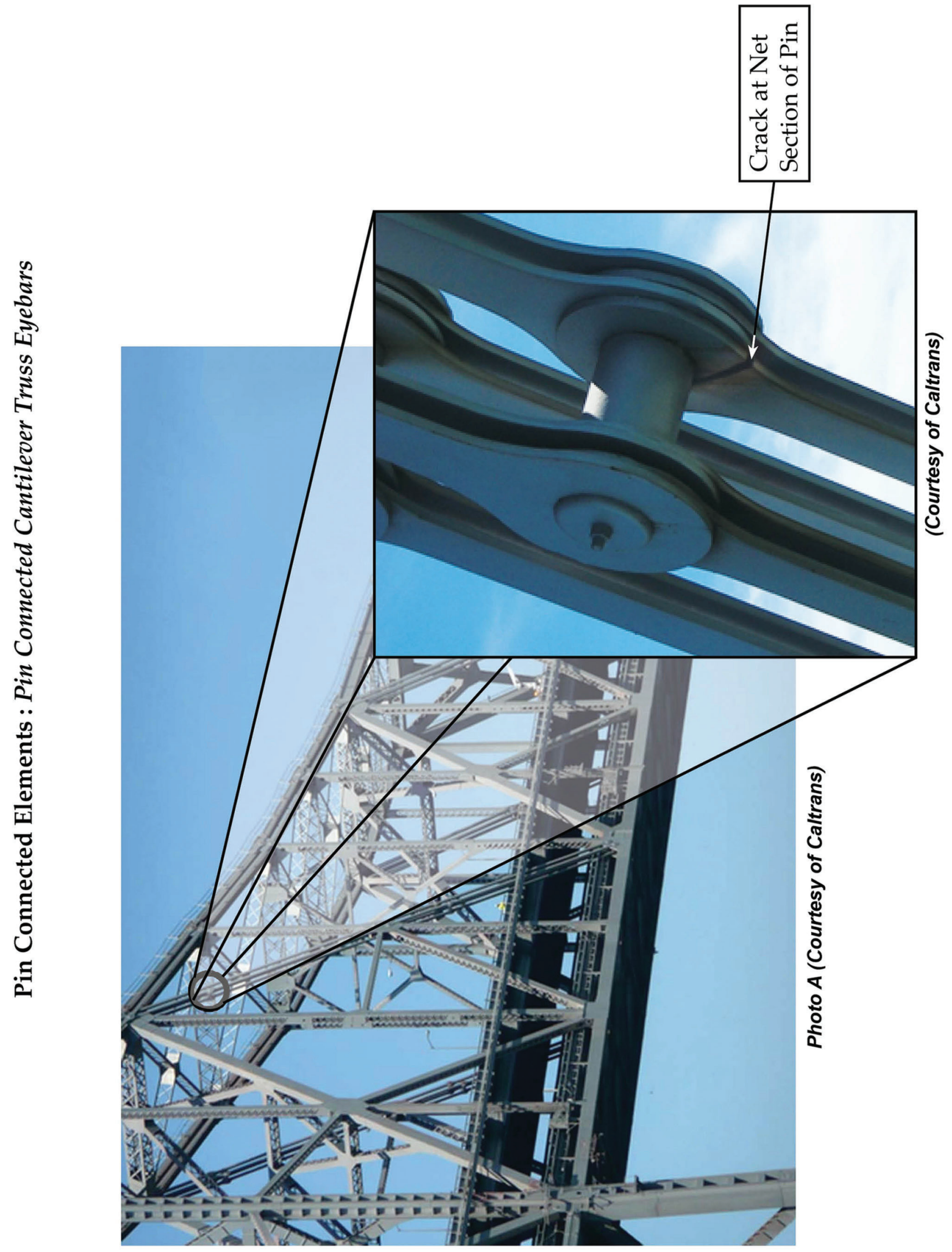




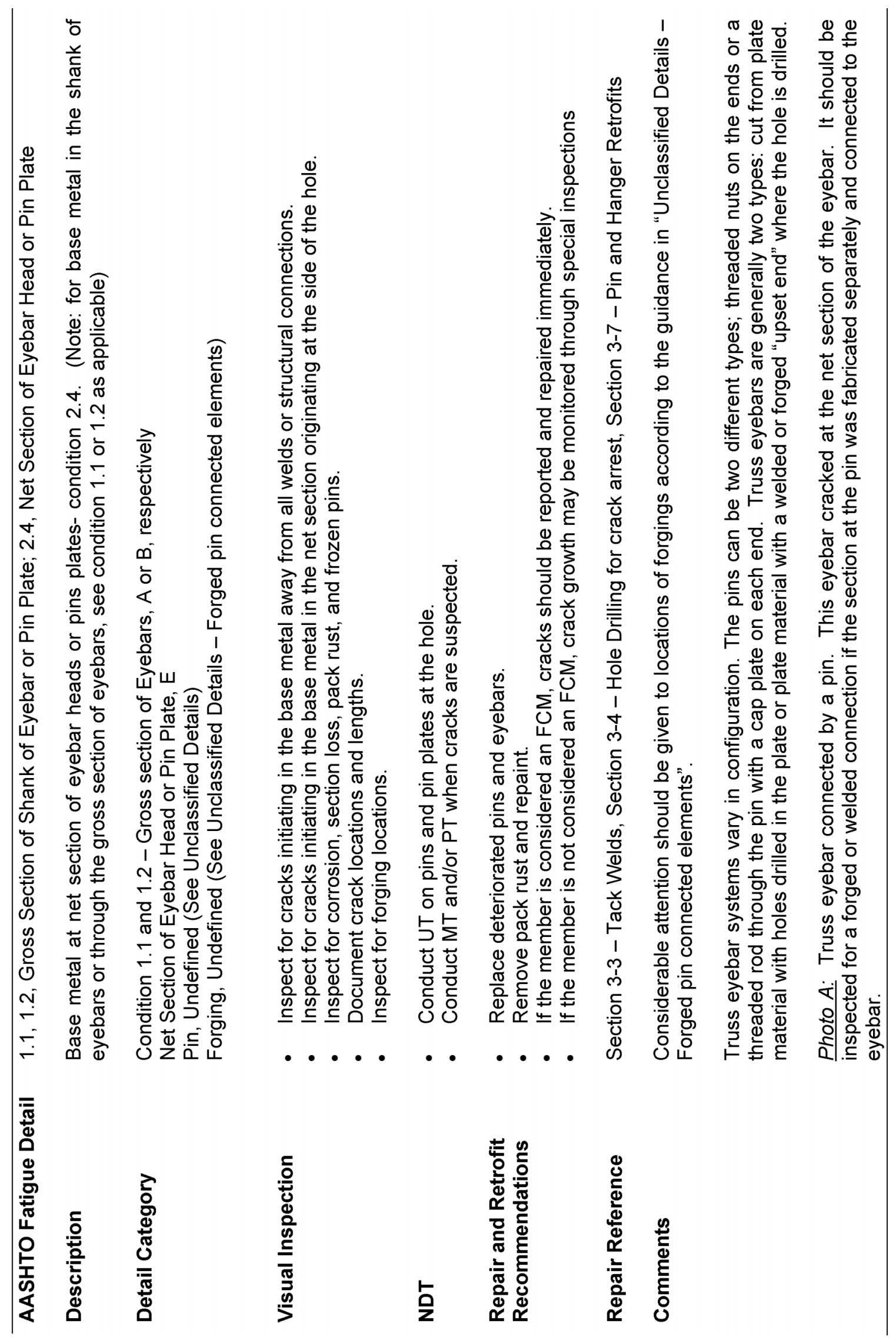




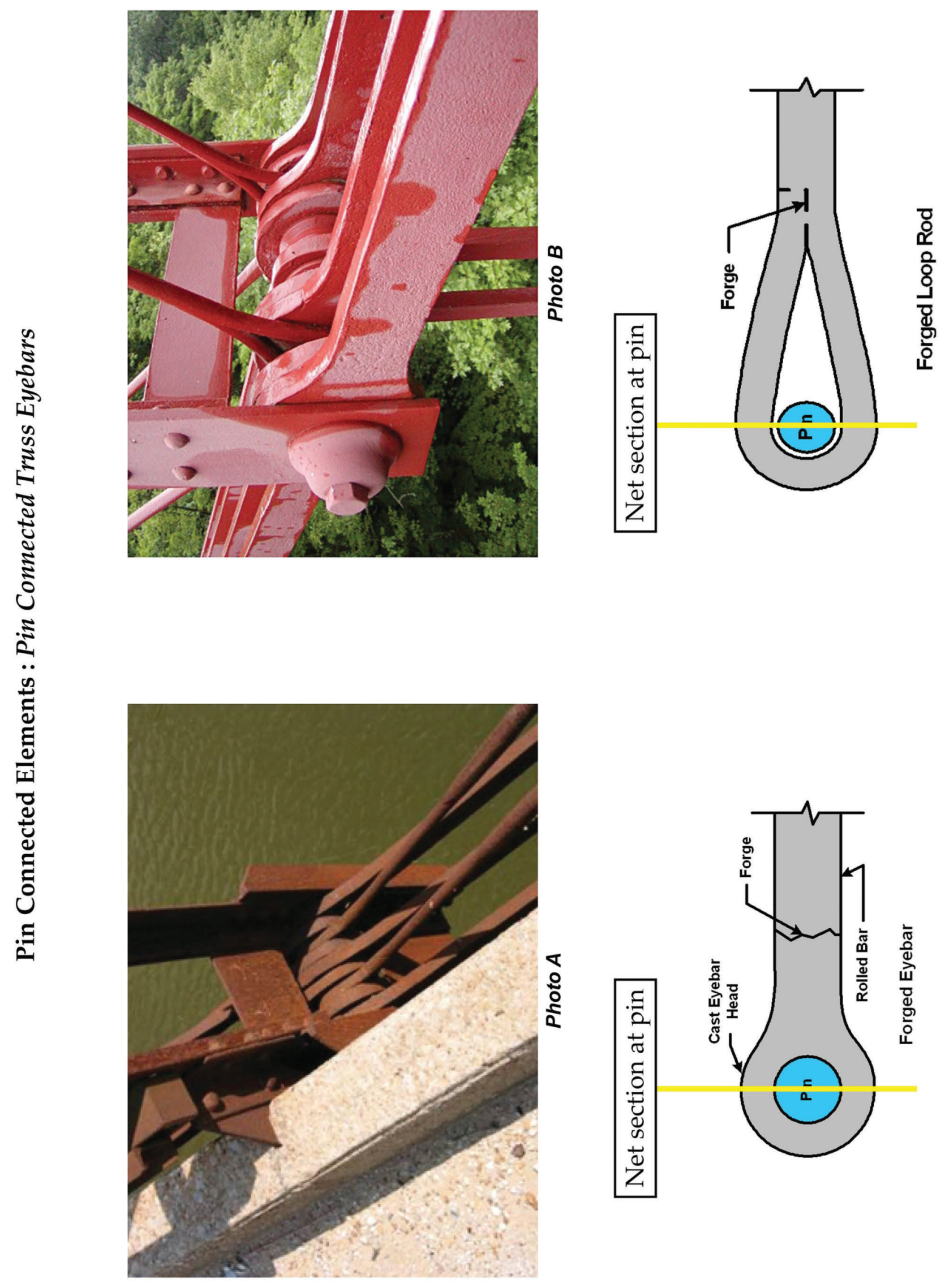




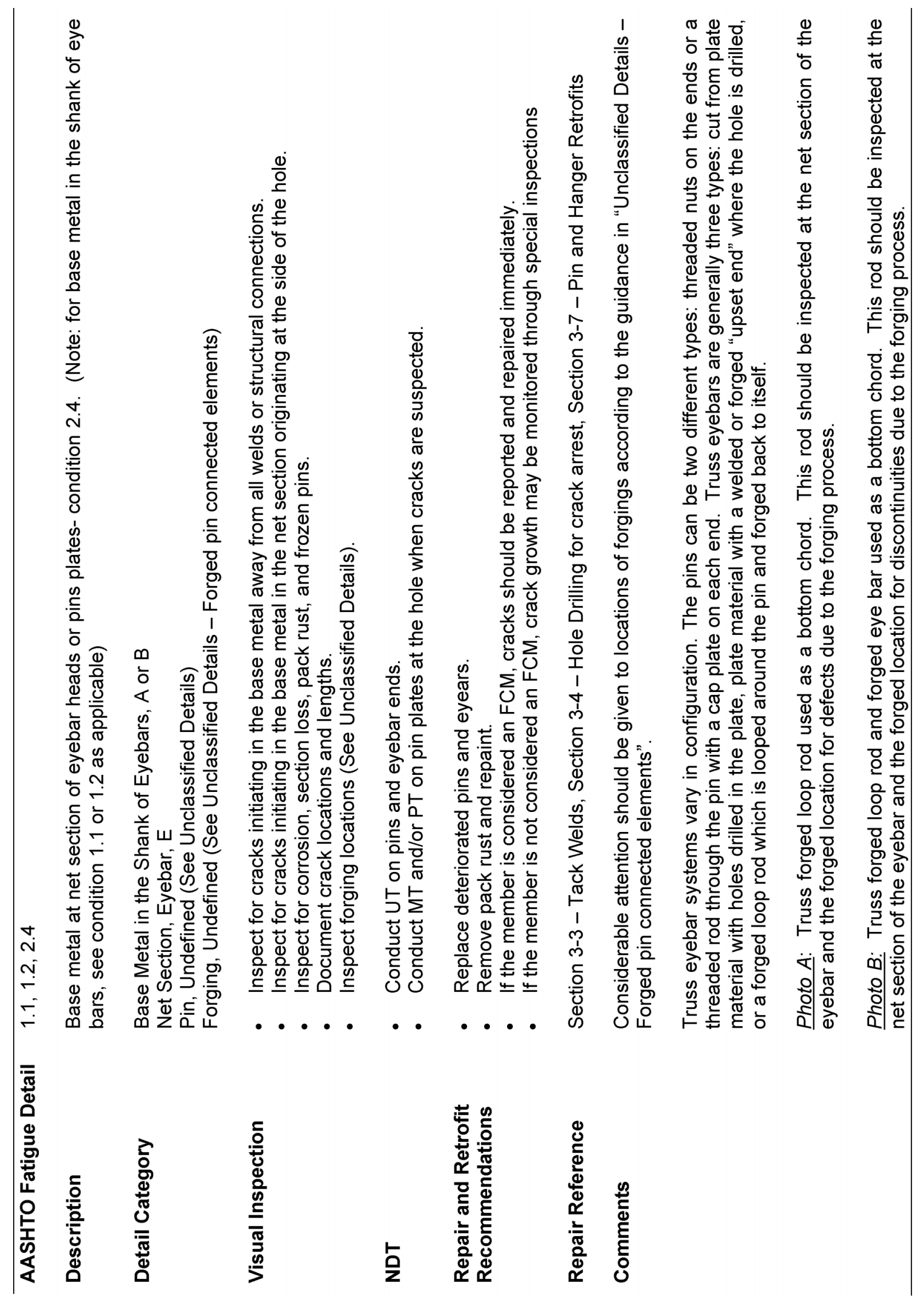


סै

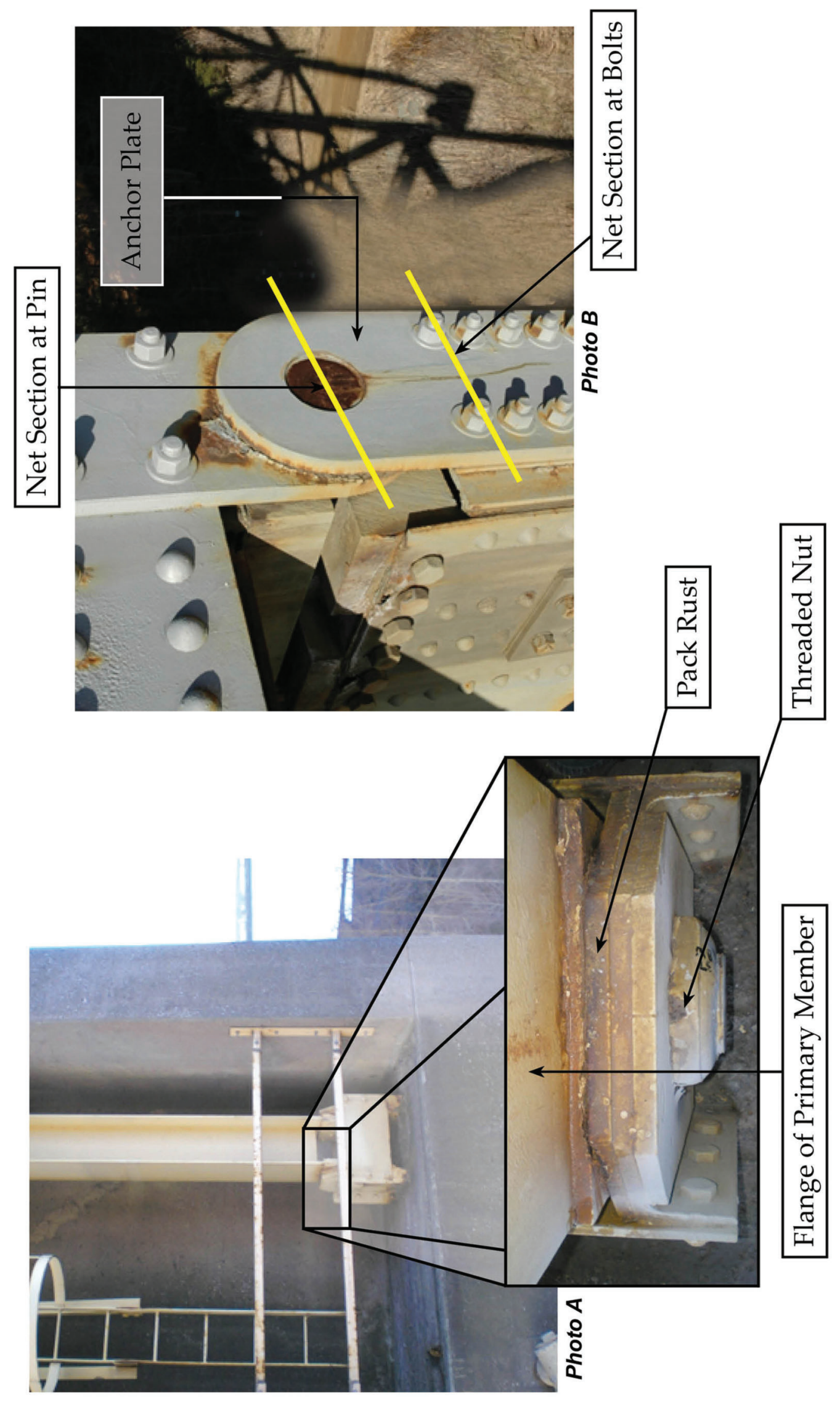




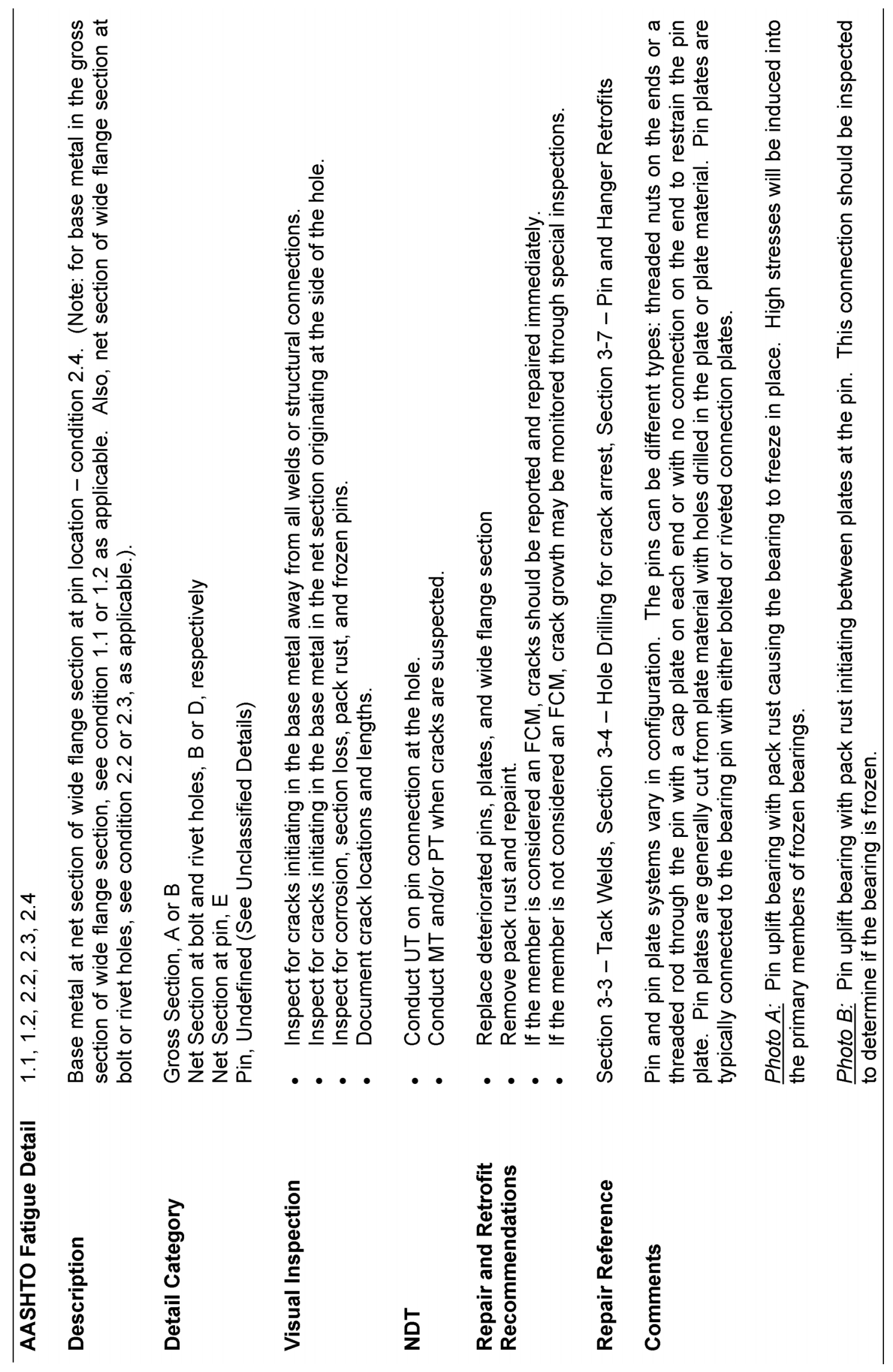




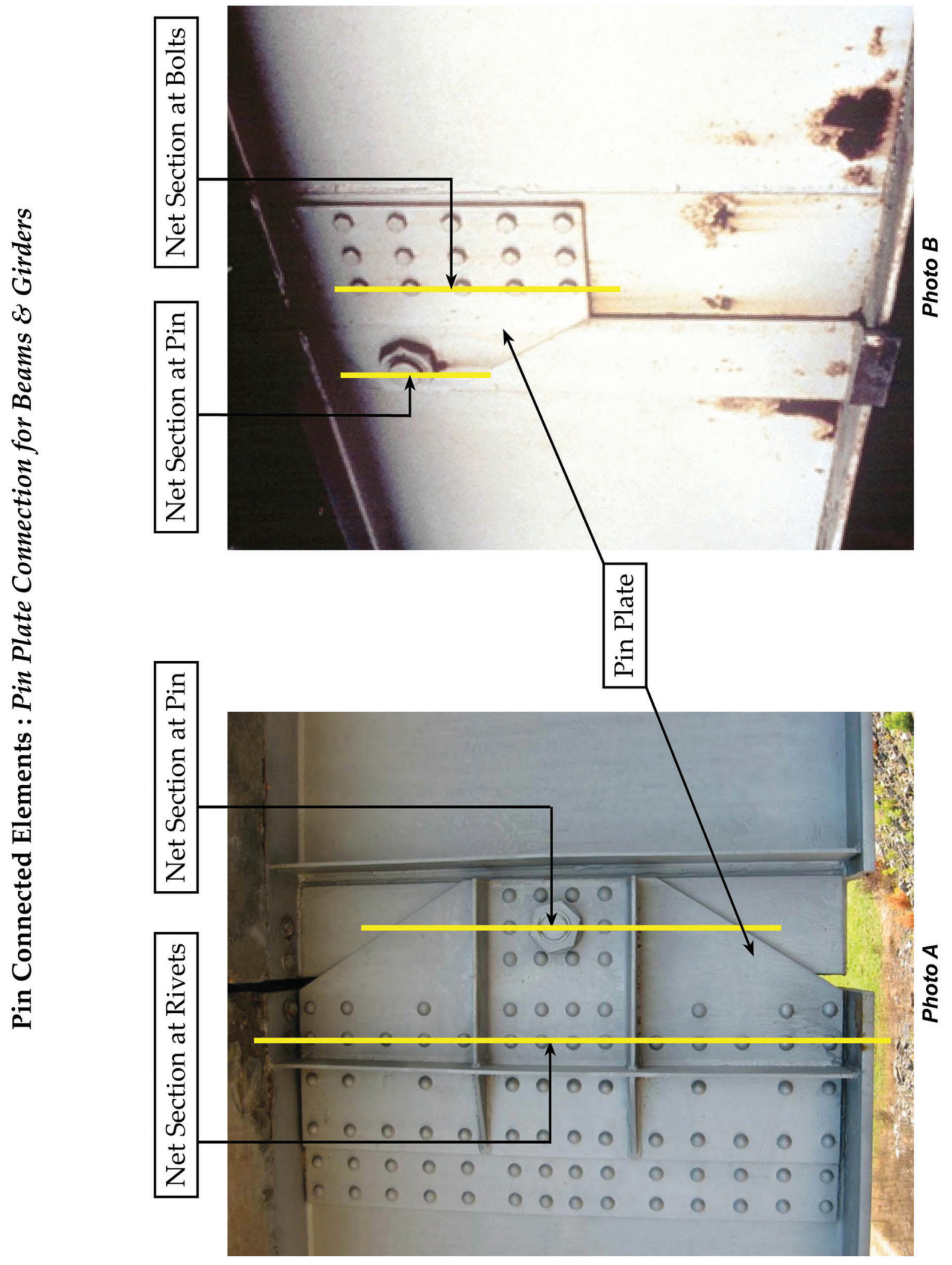




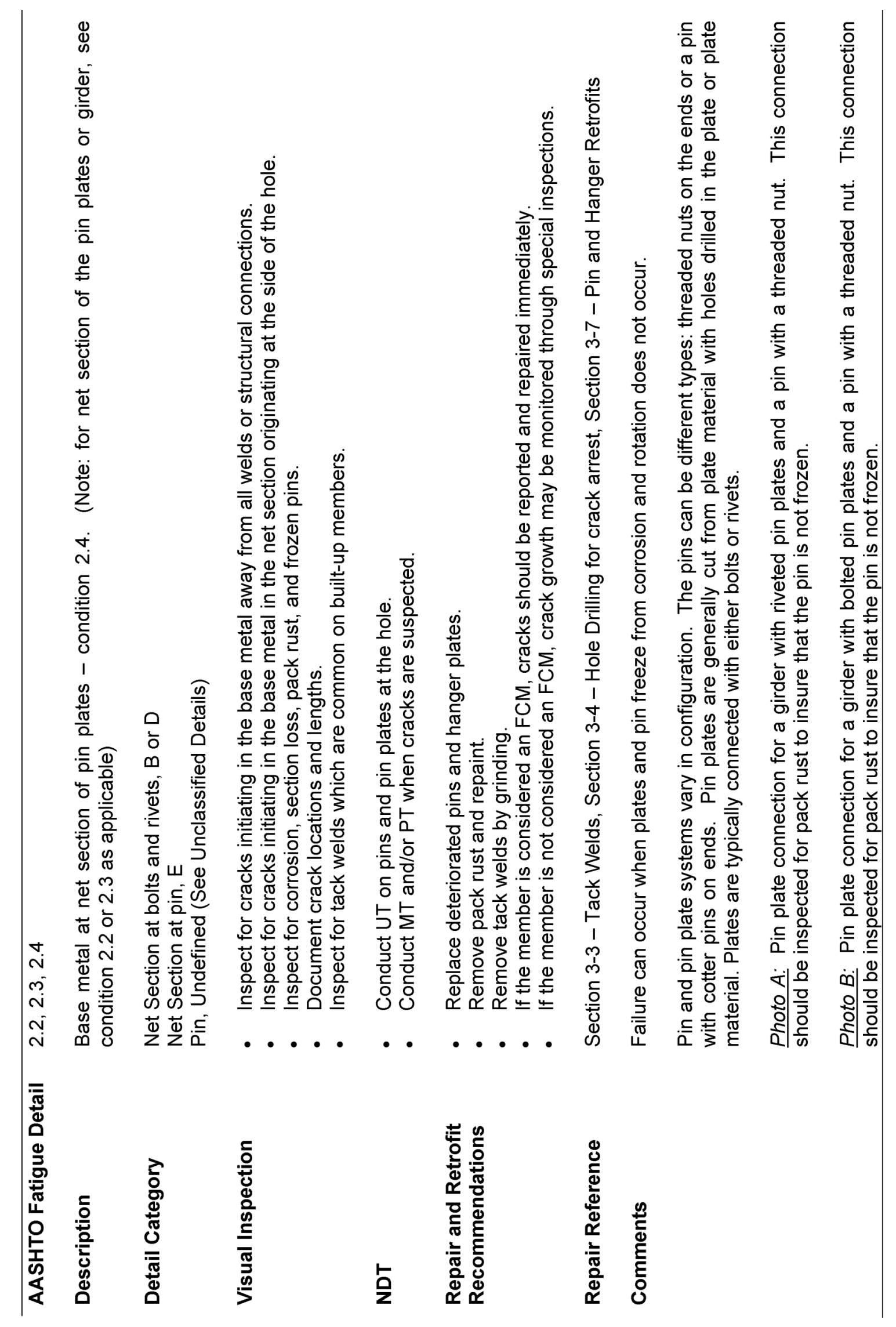




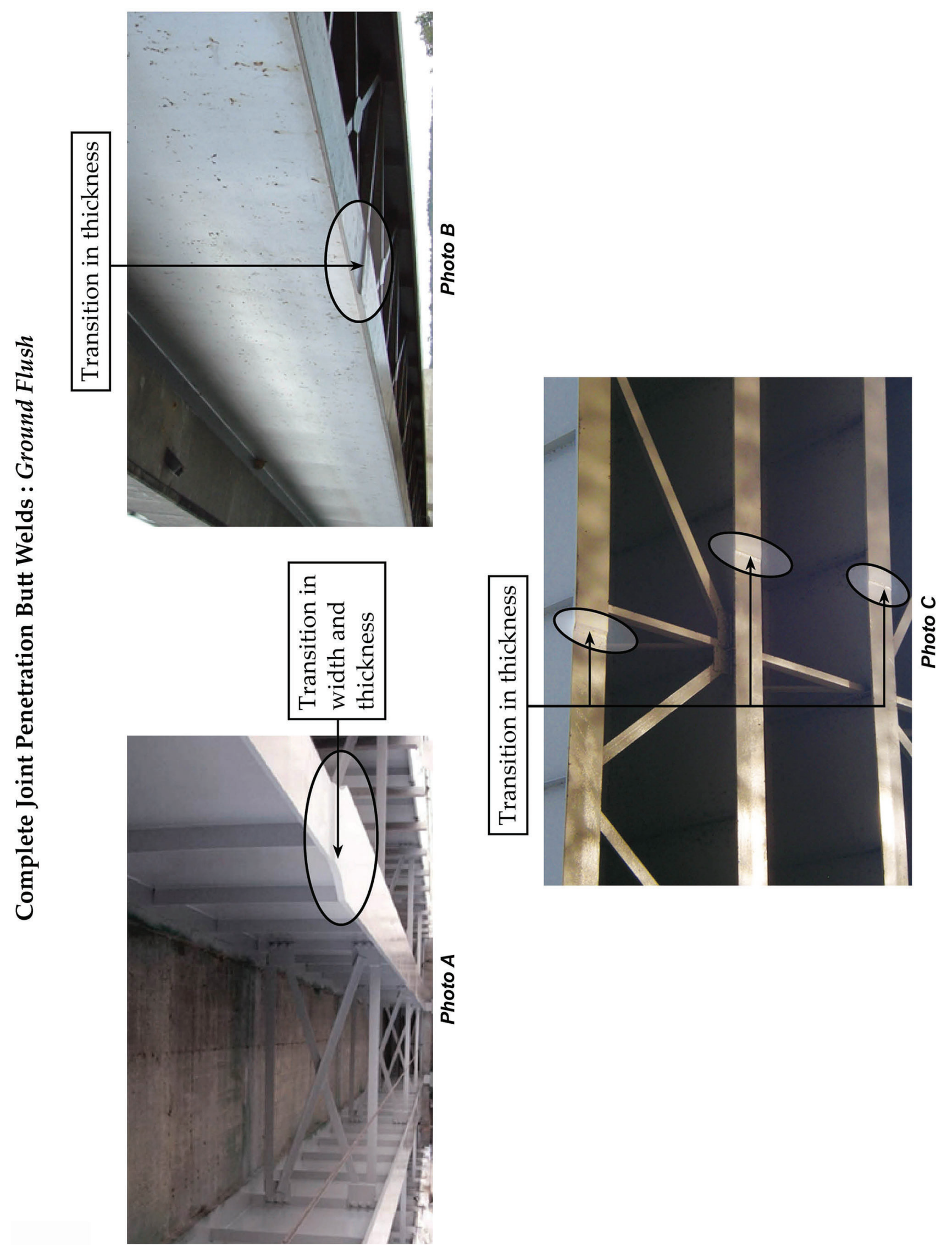




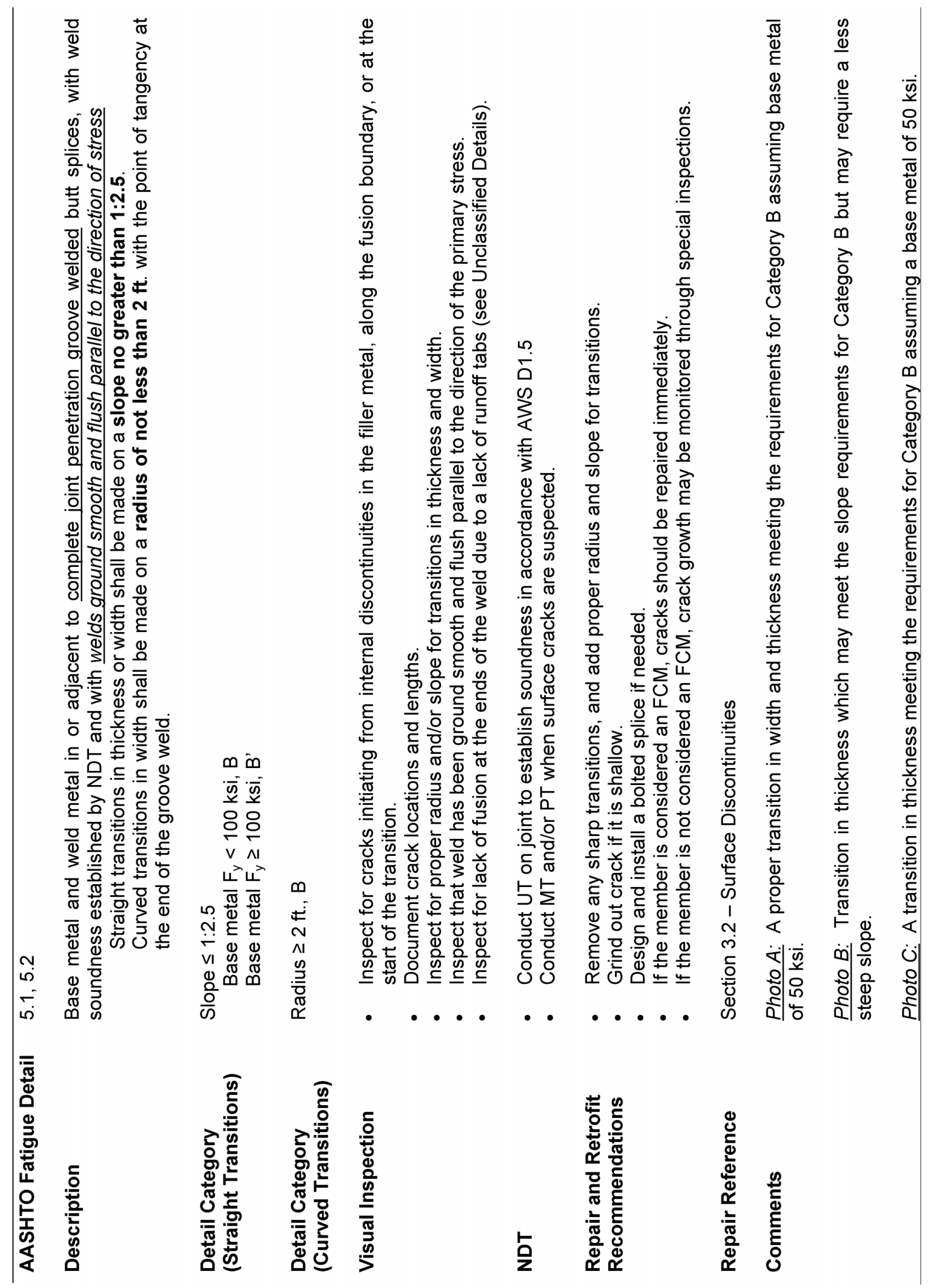




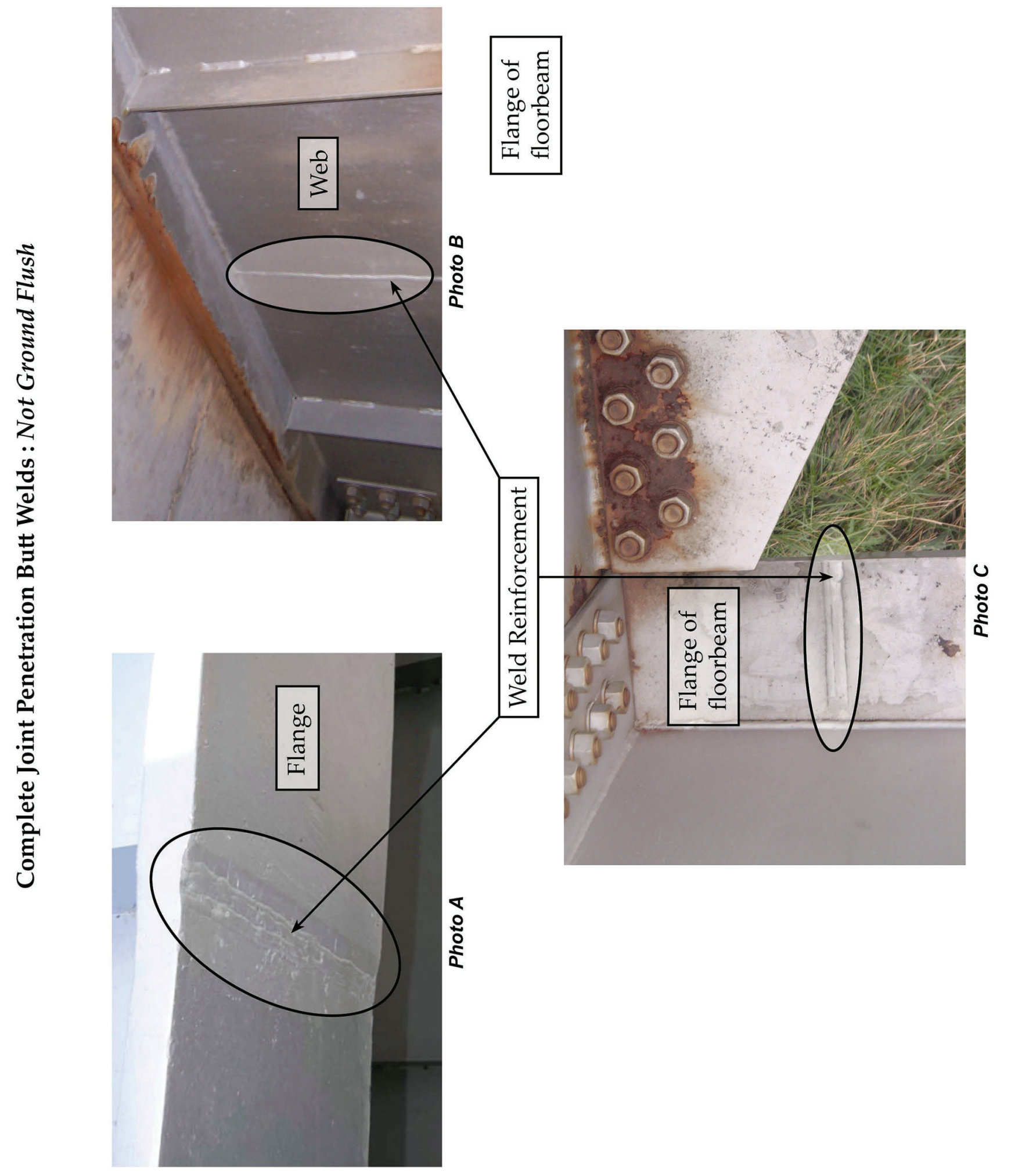




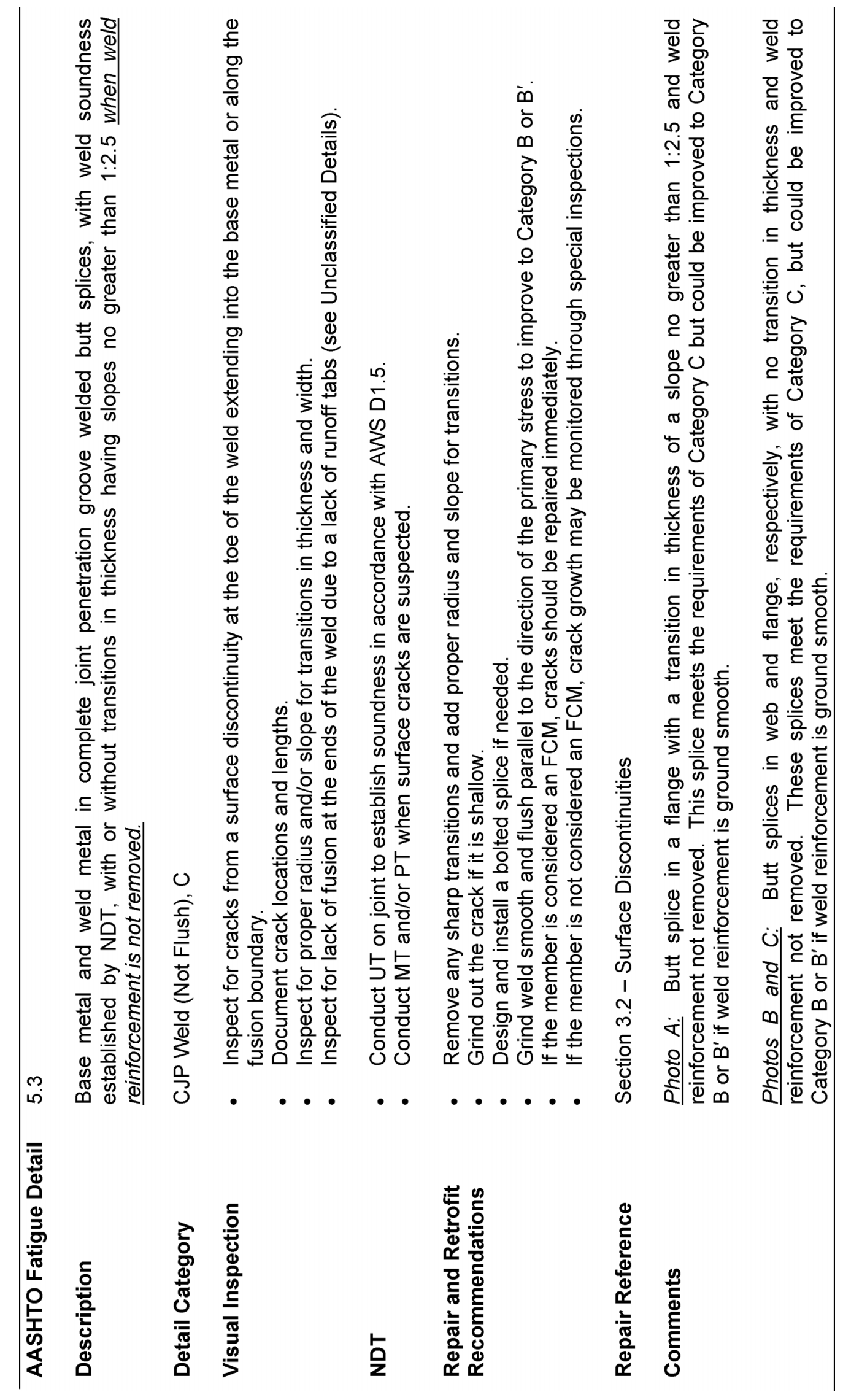




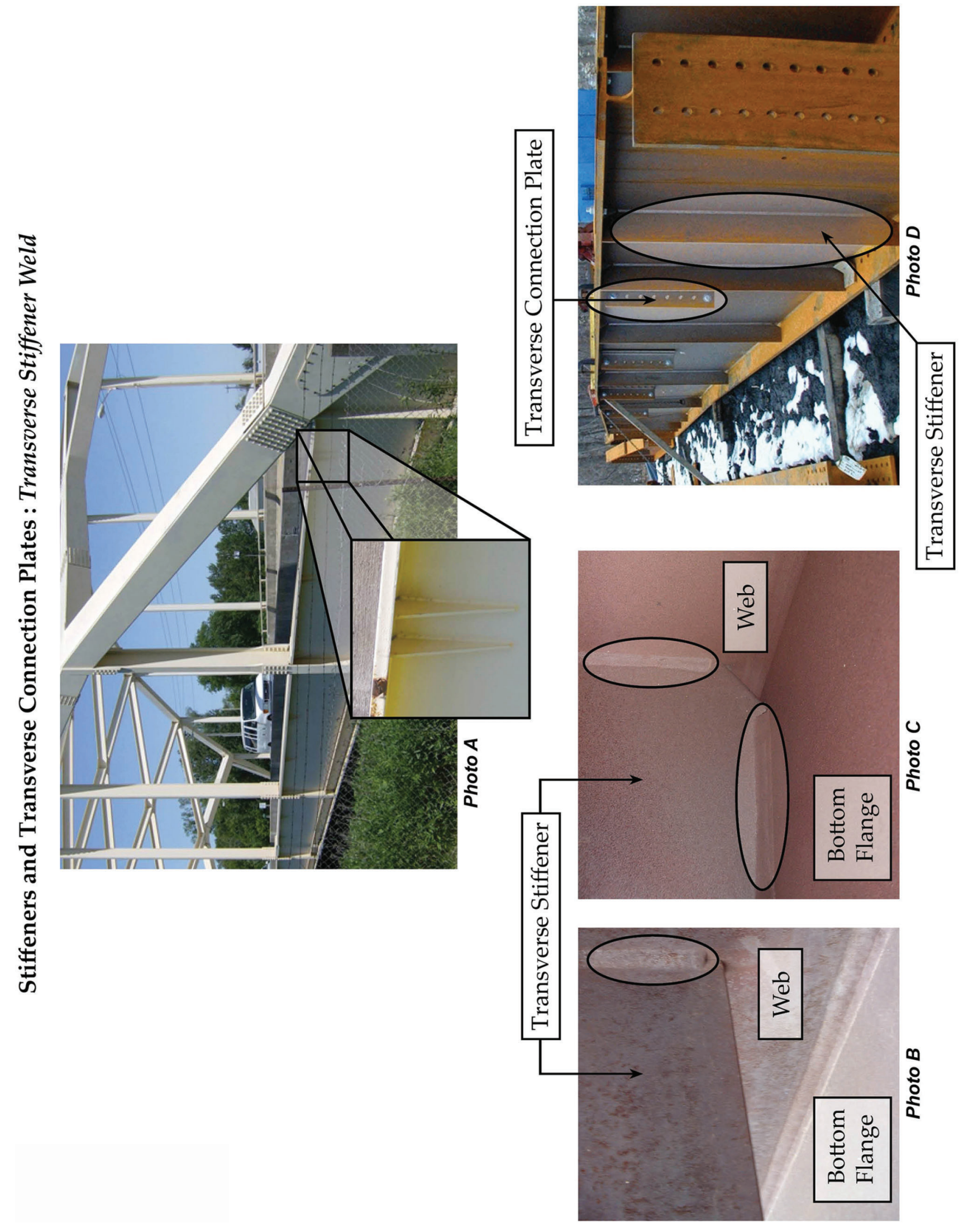




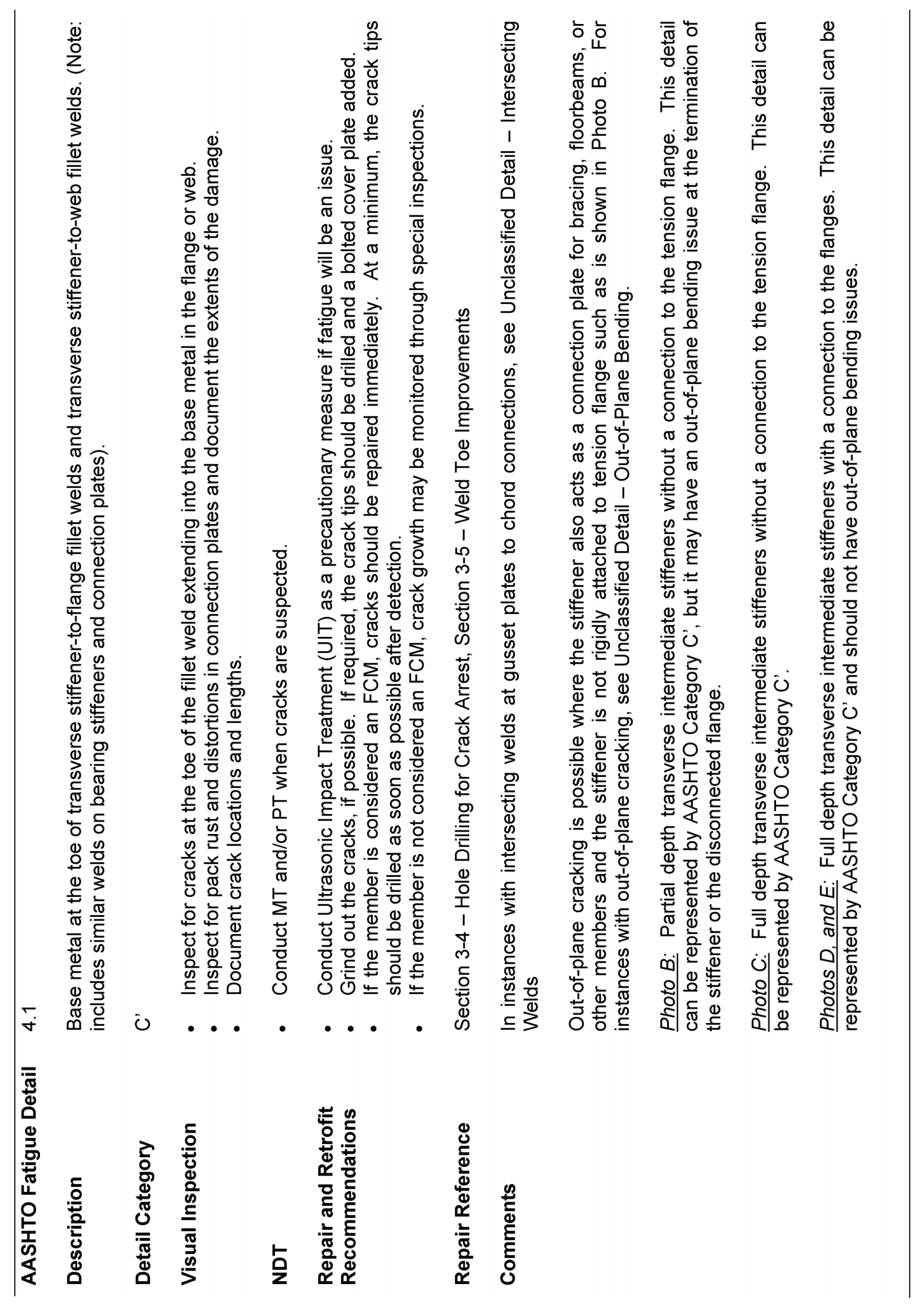




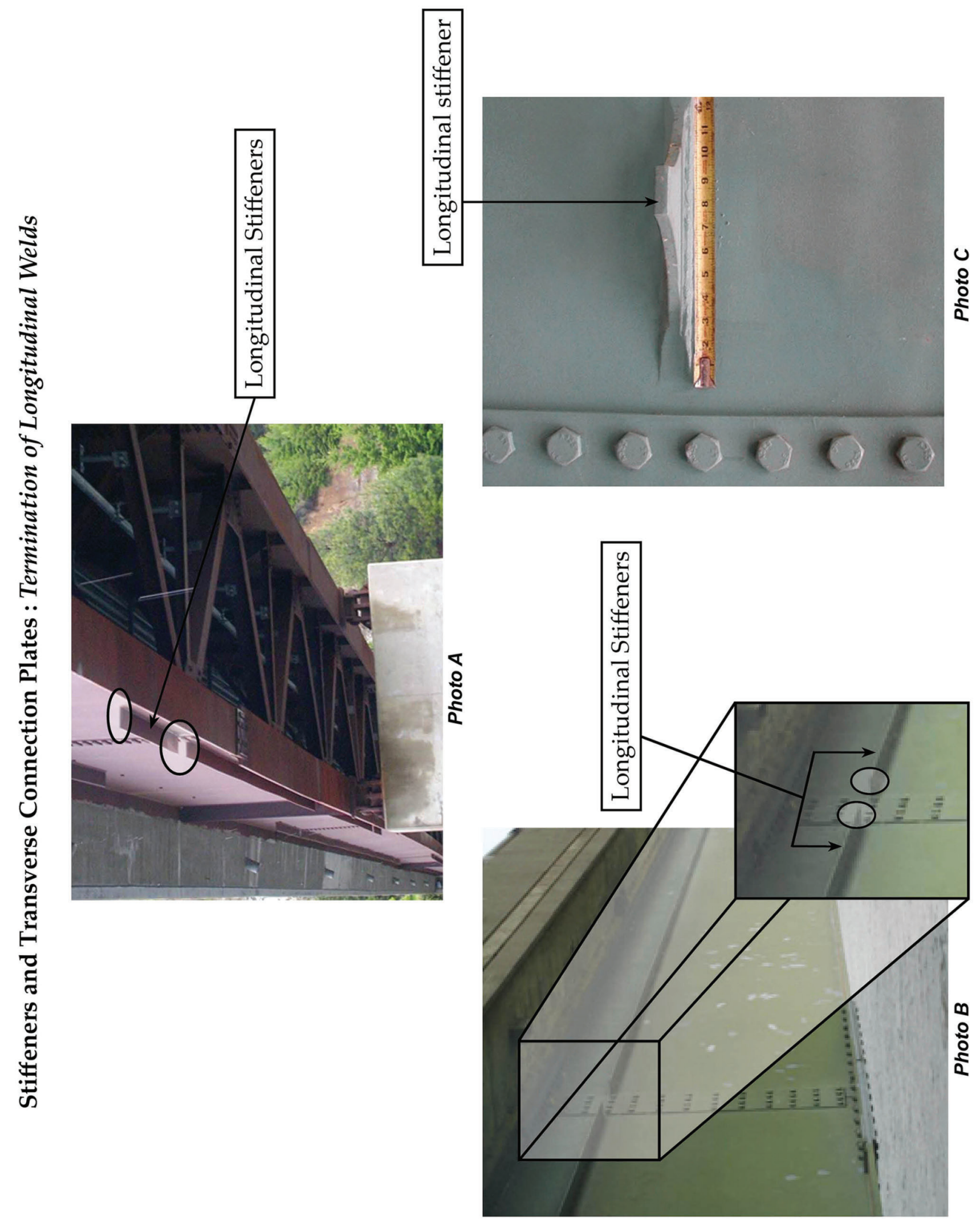




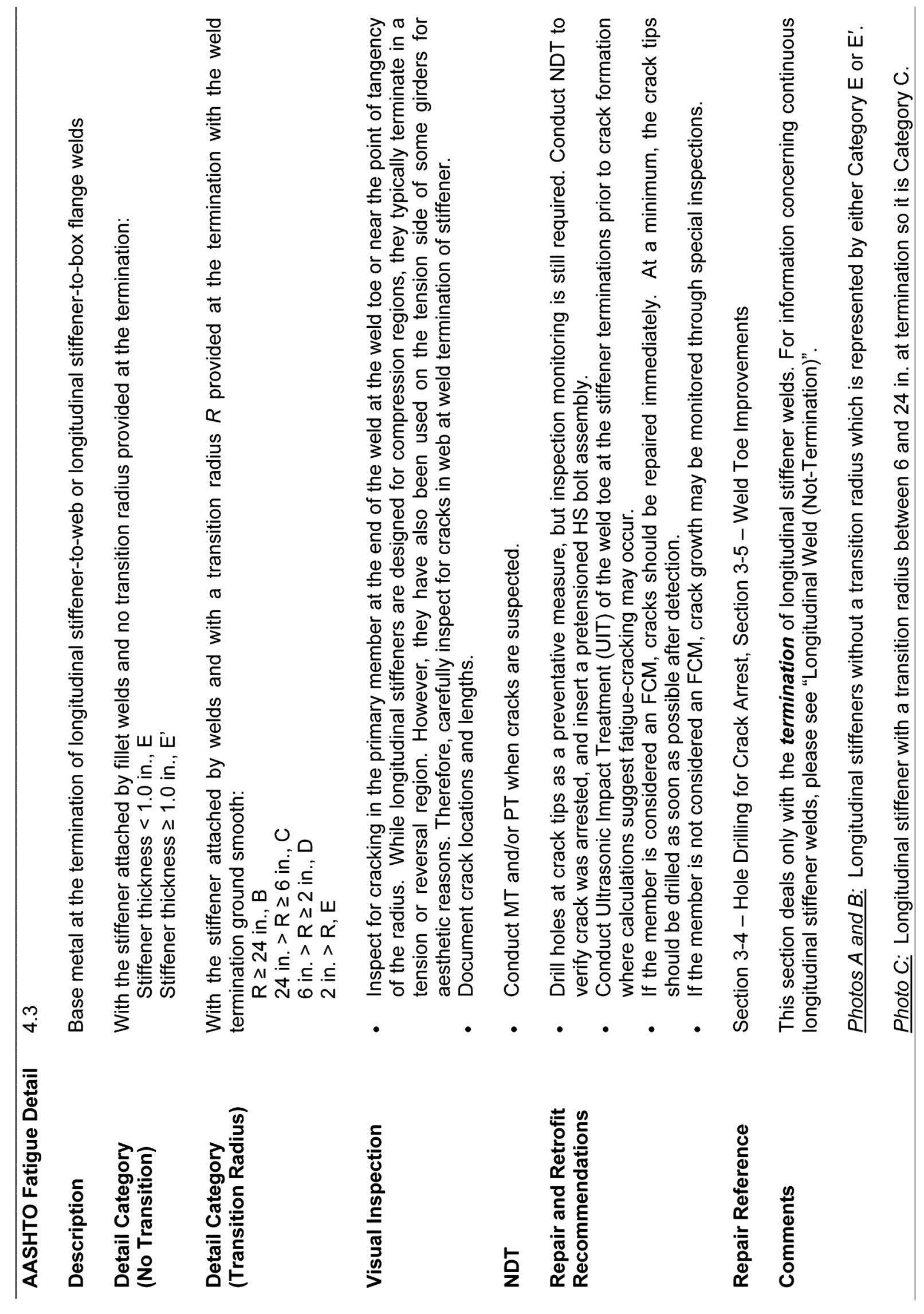



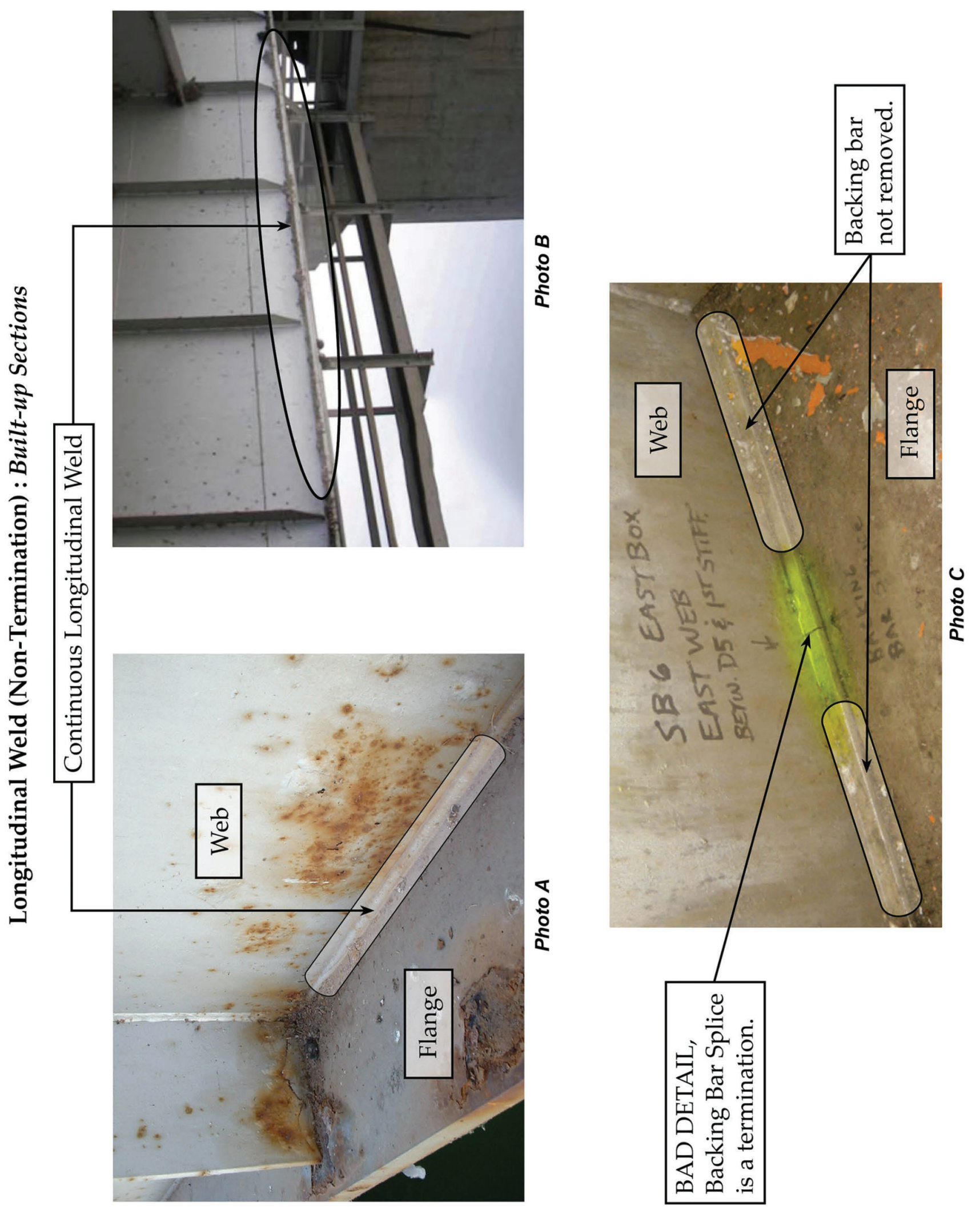


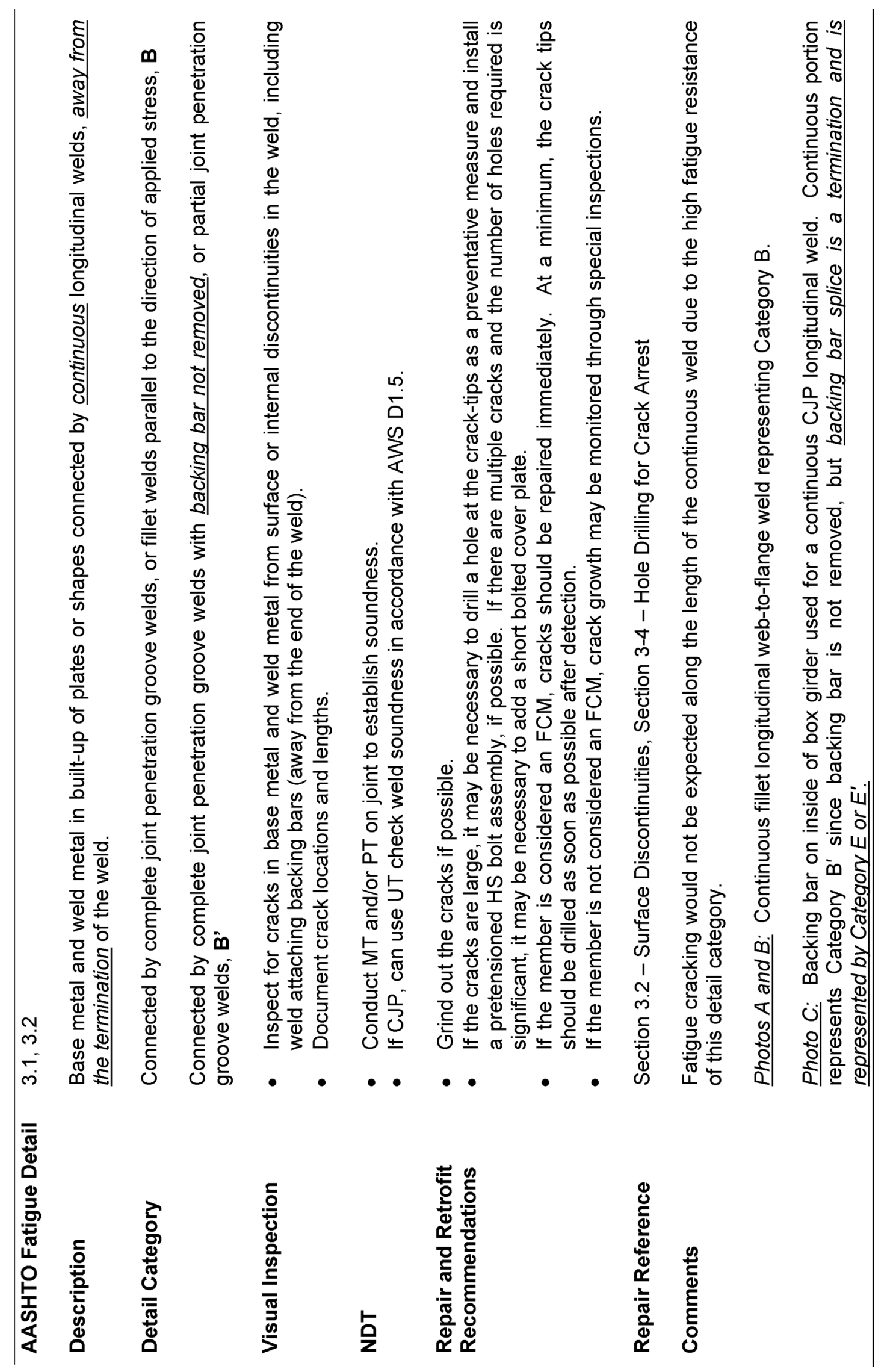



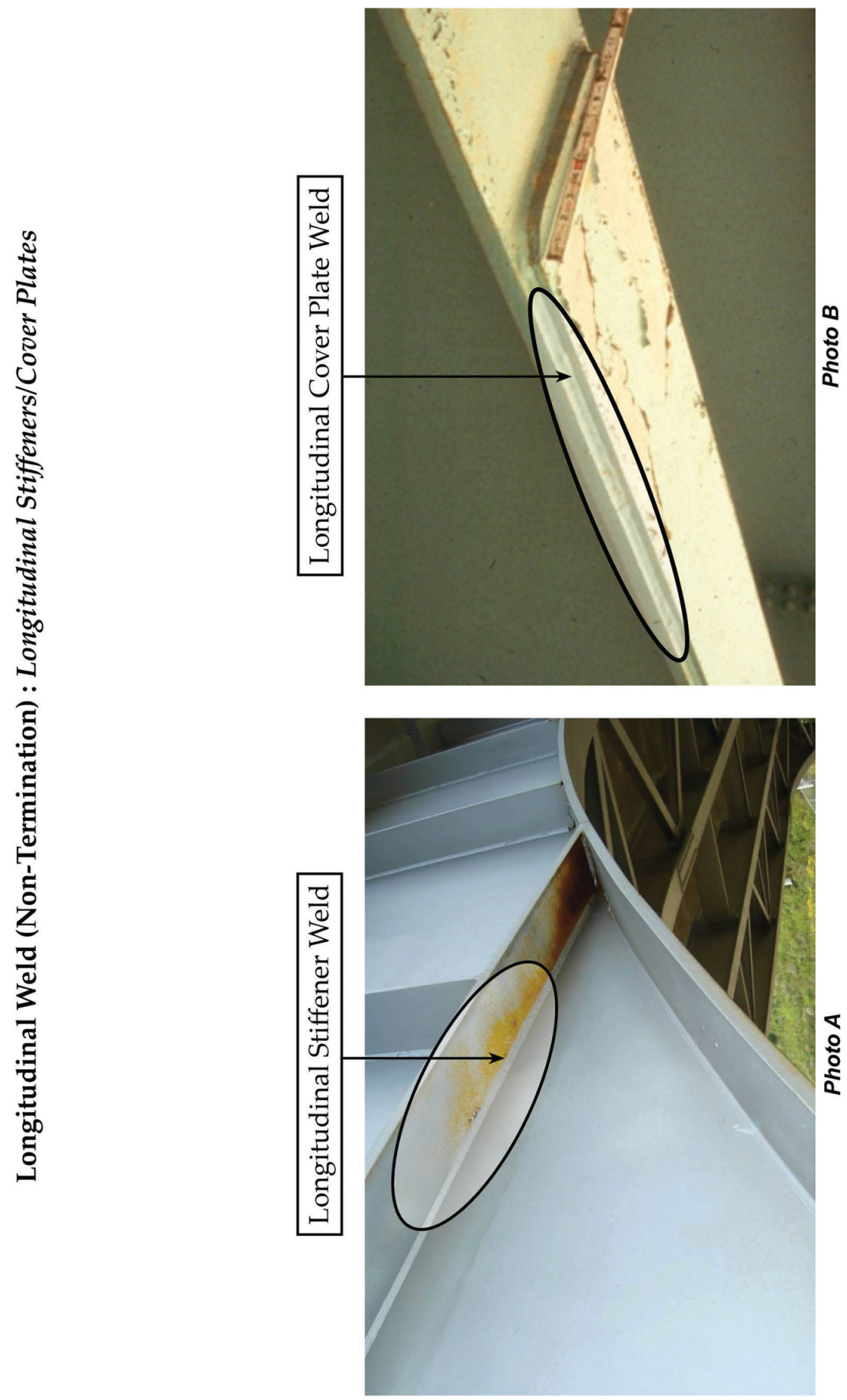


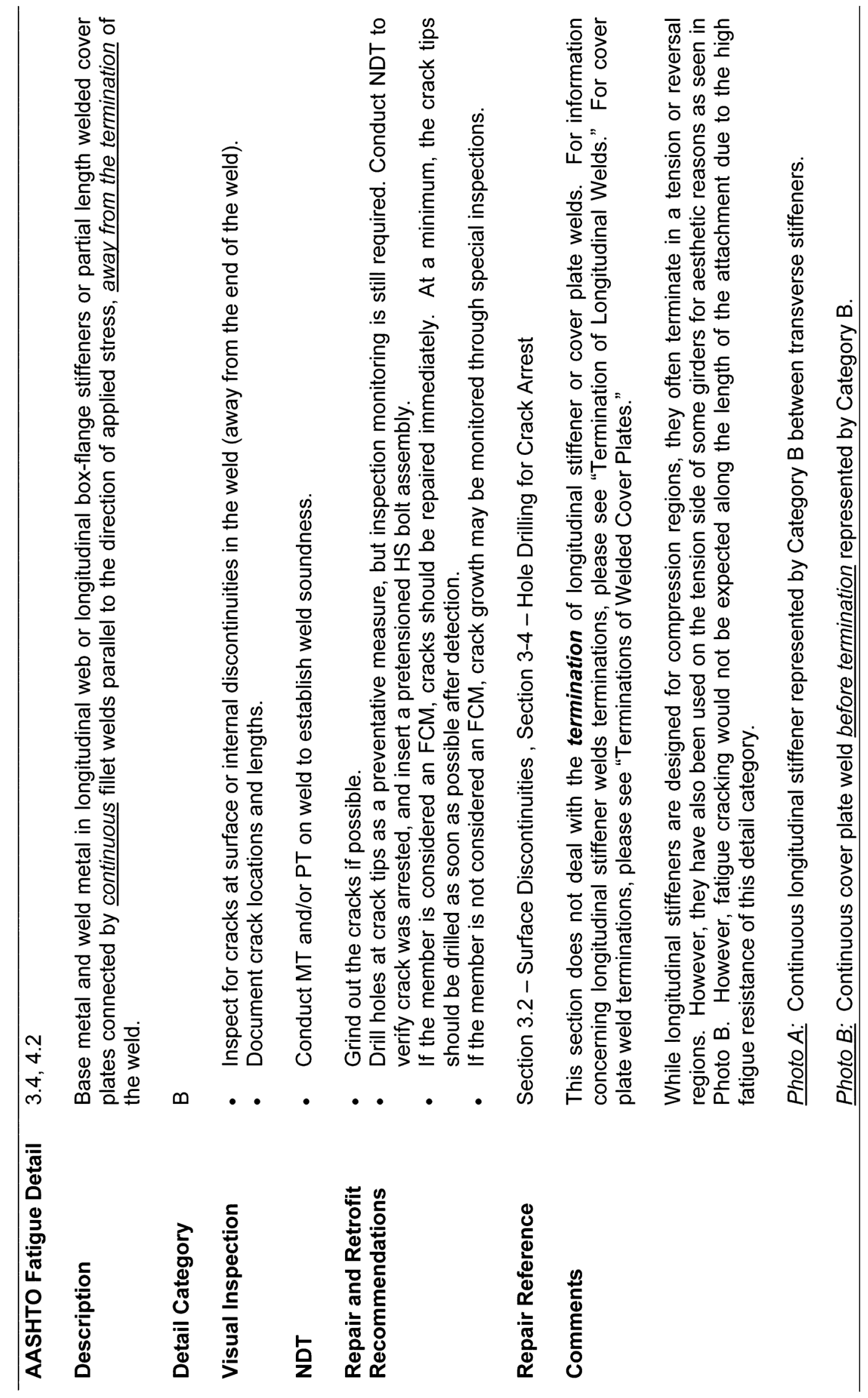



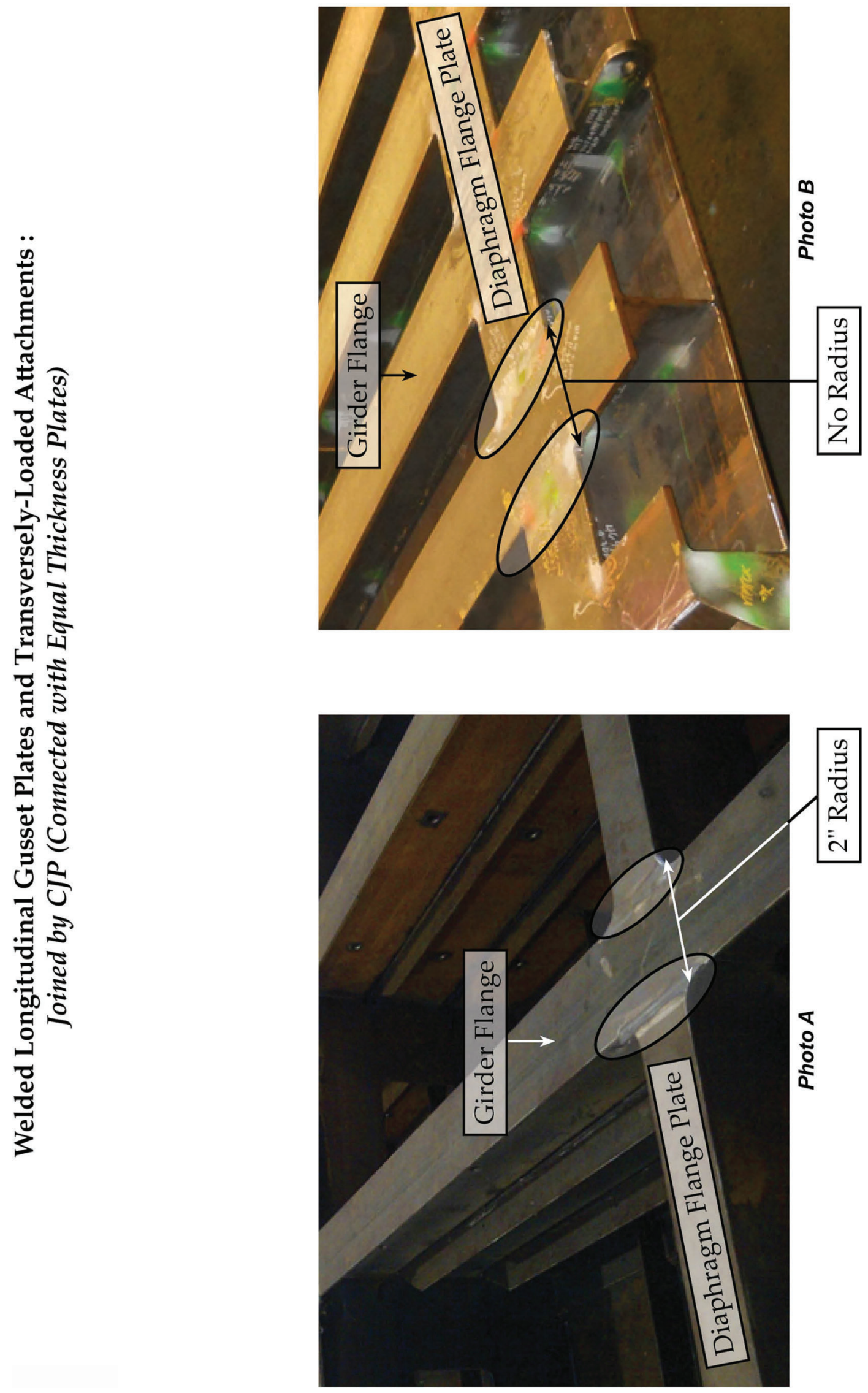


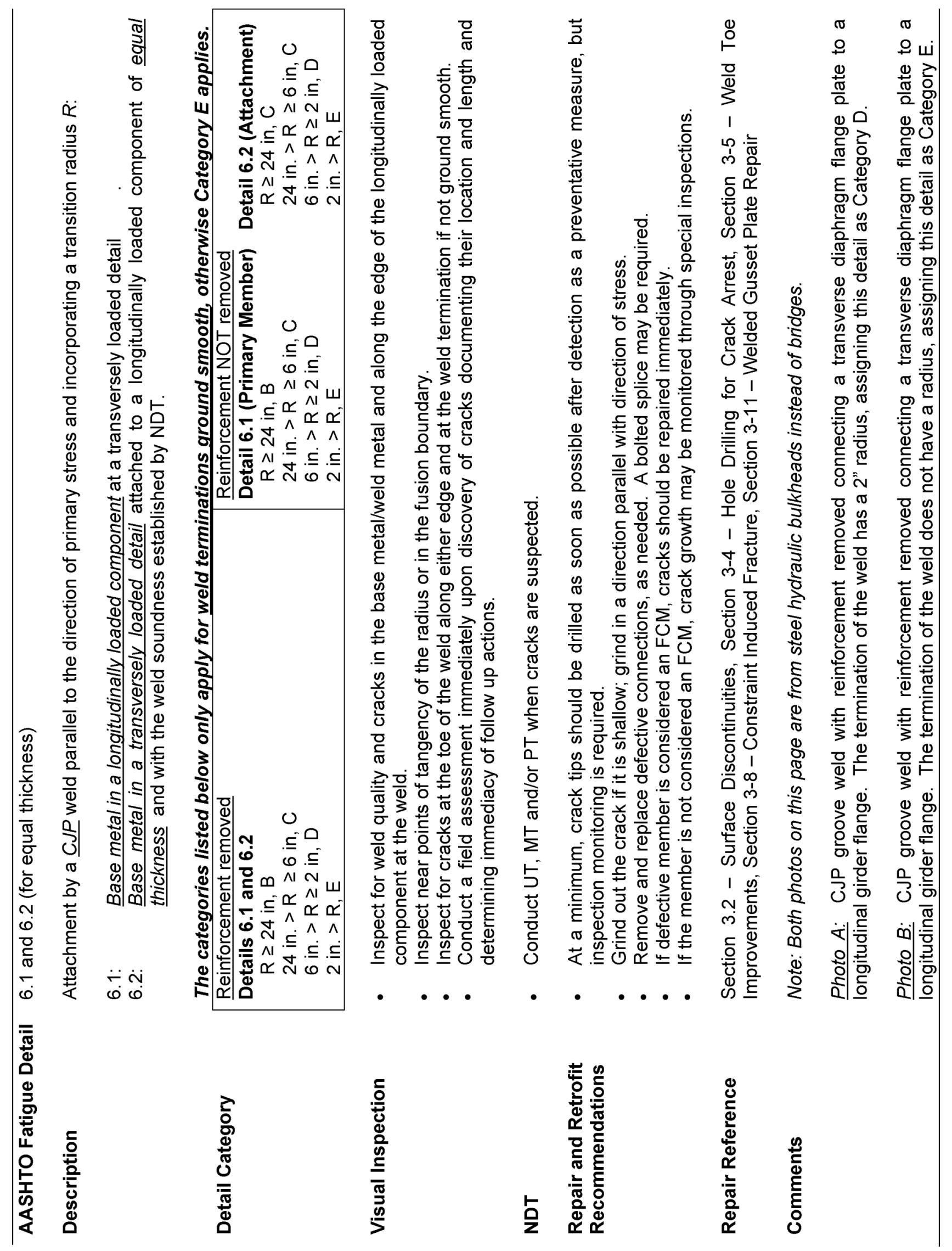



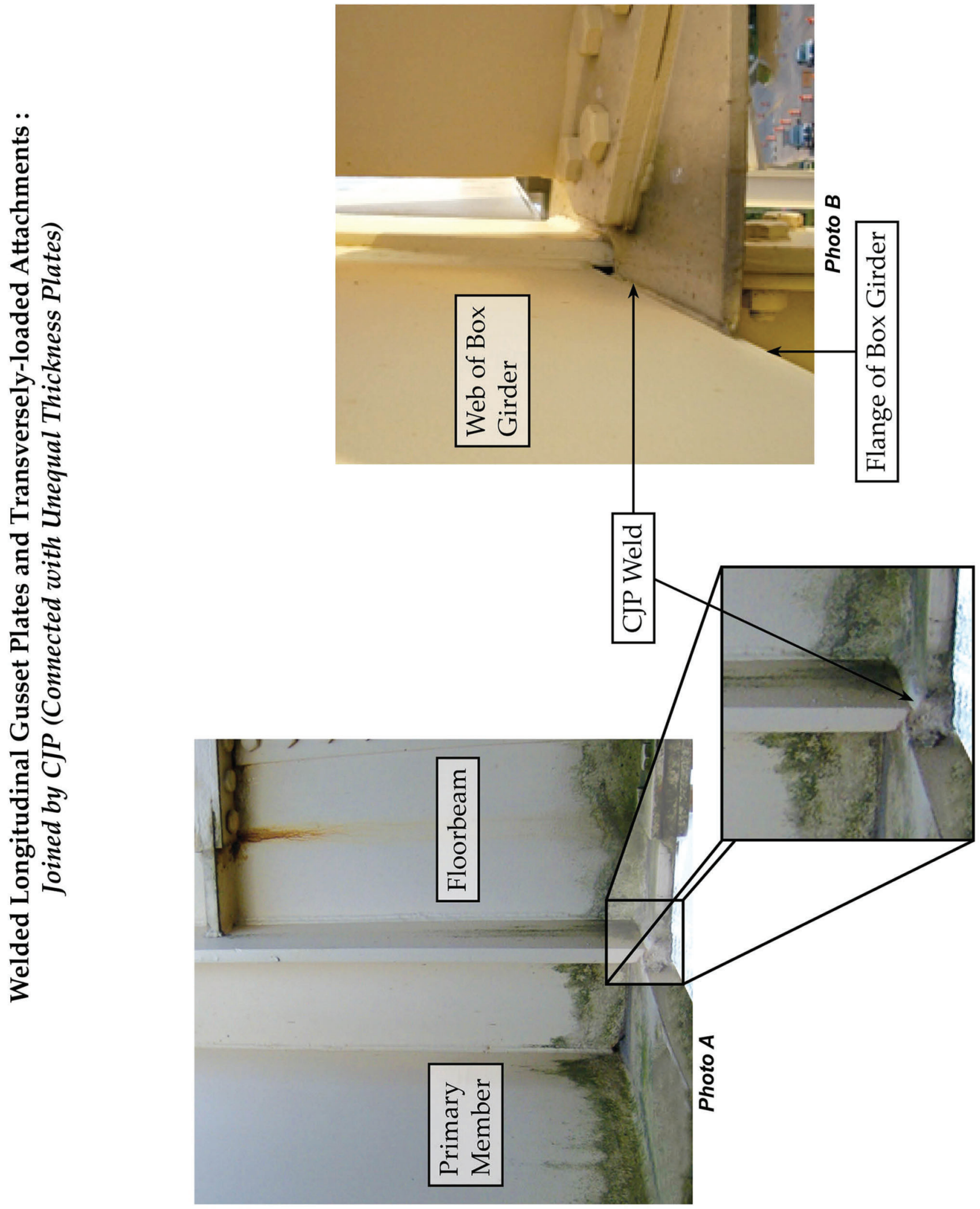


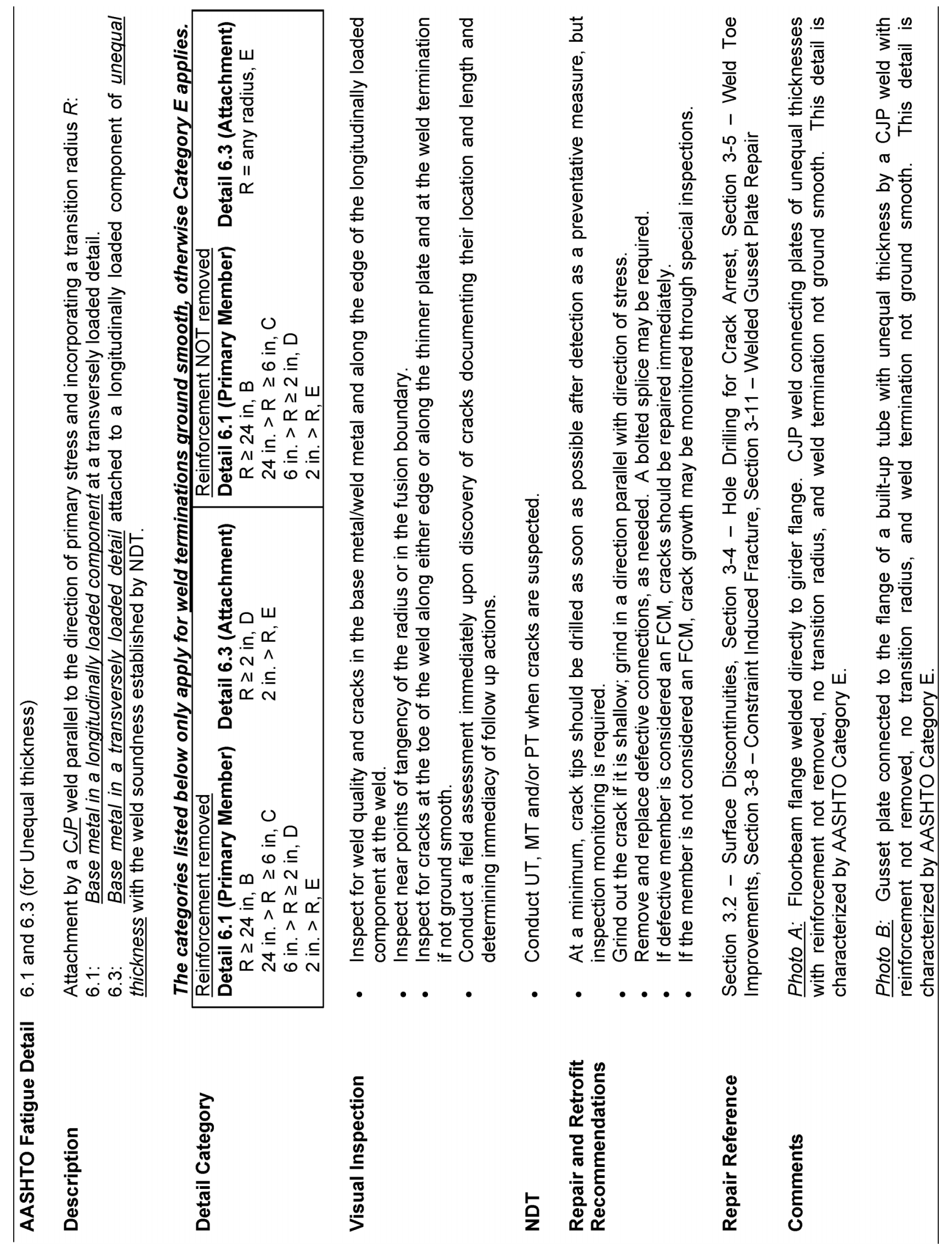




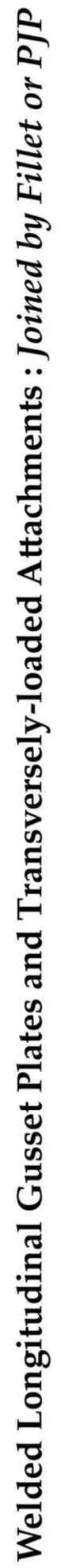

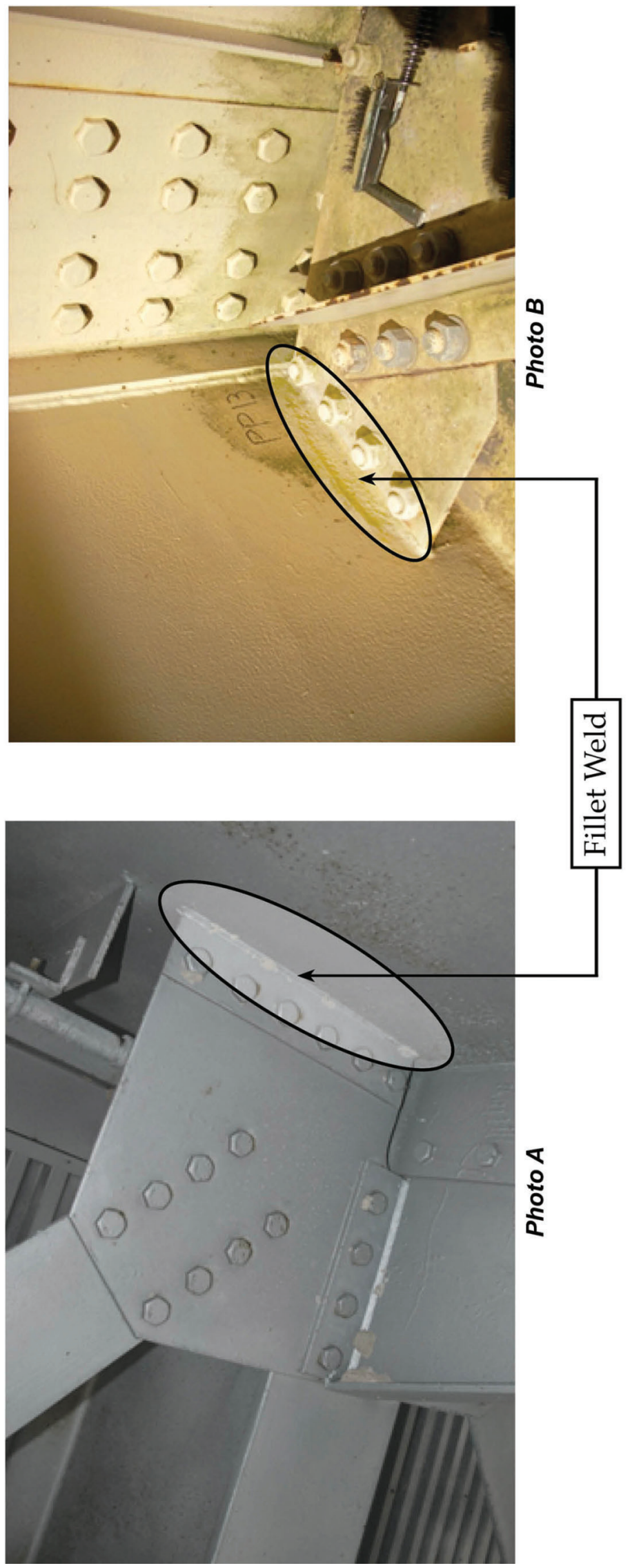




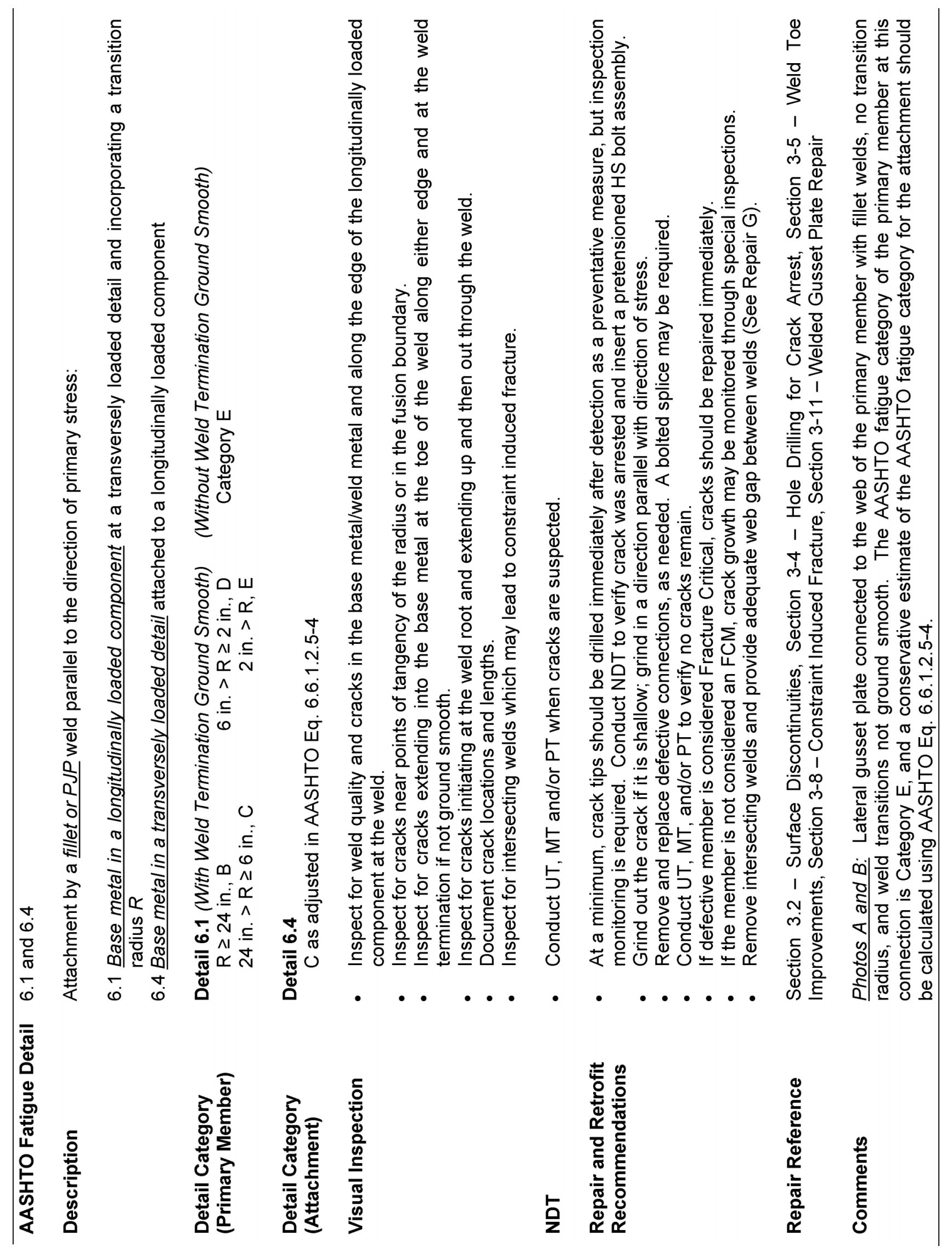




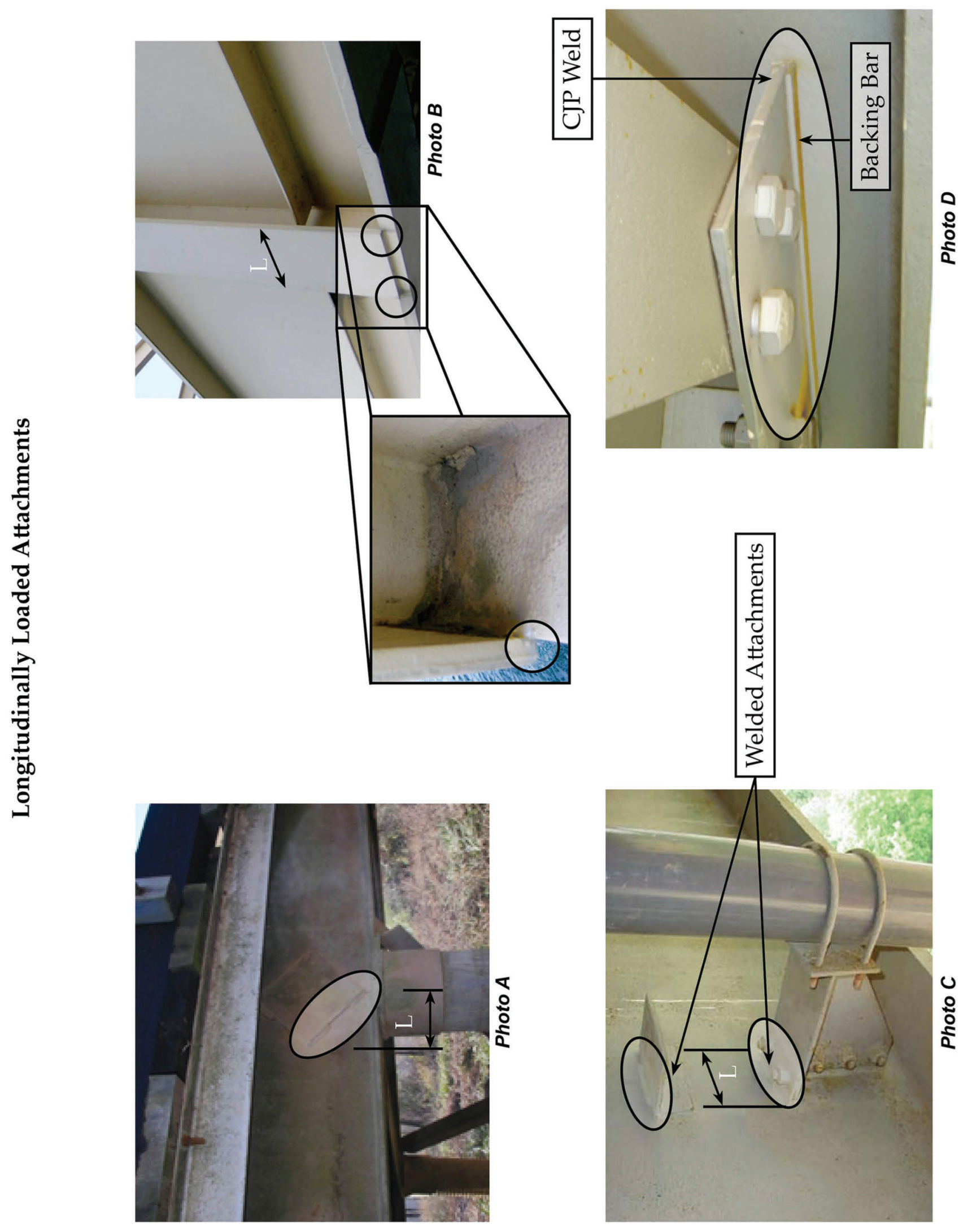




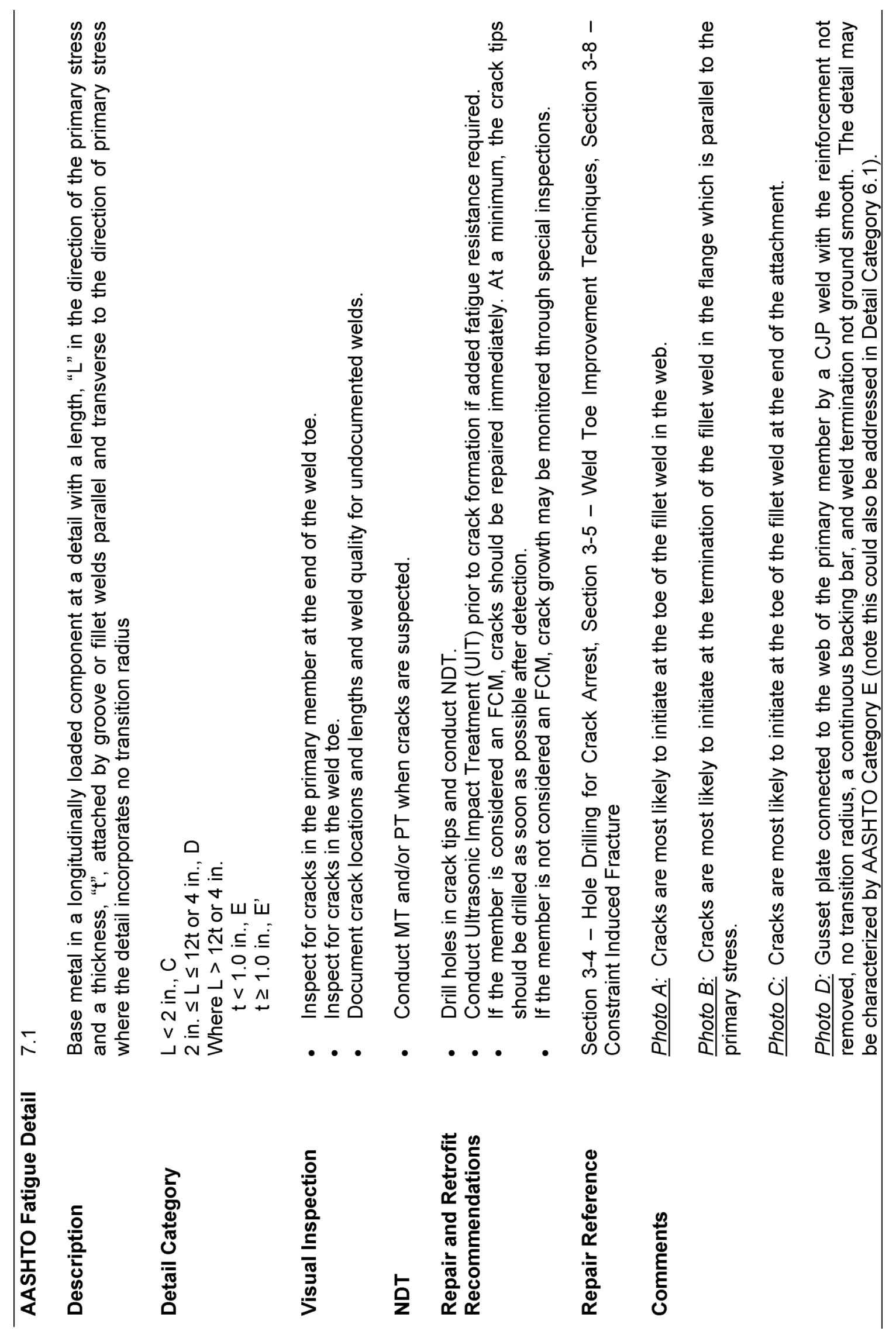


告

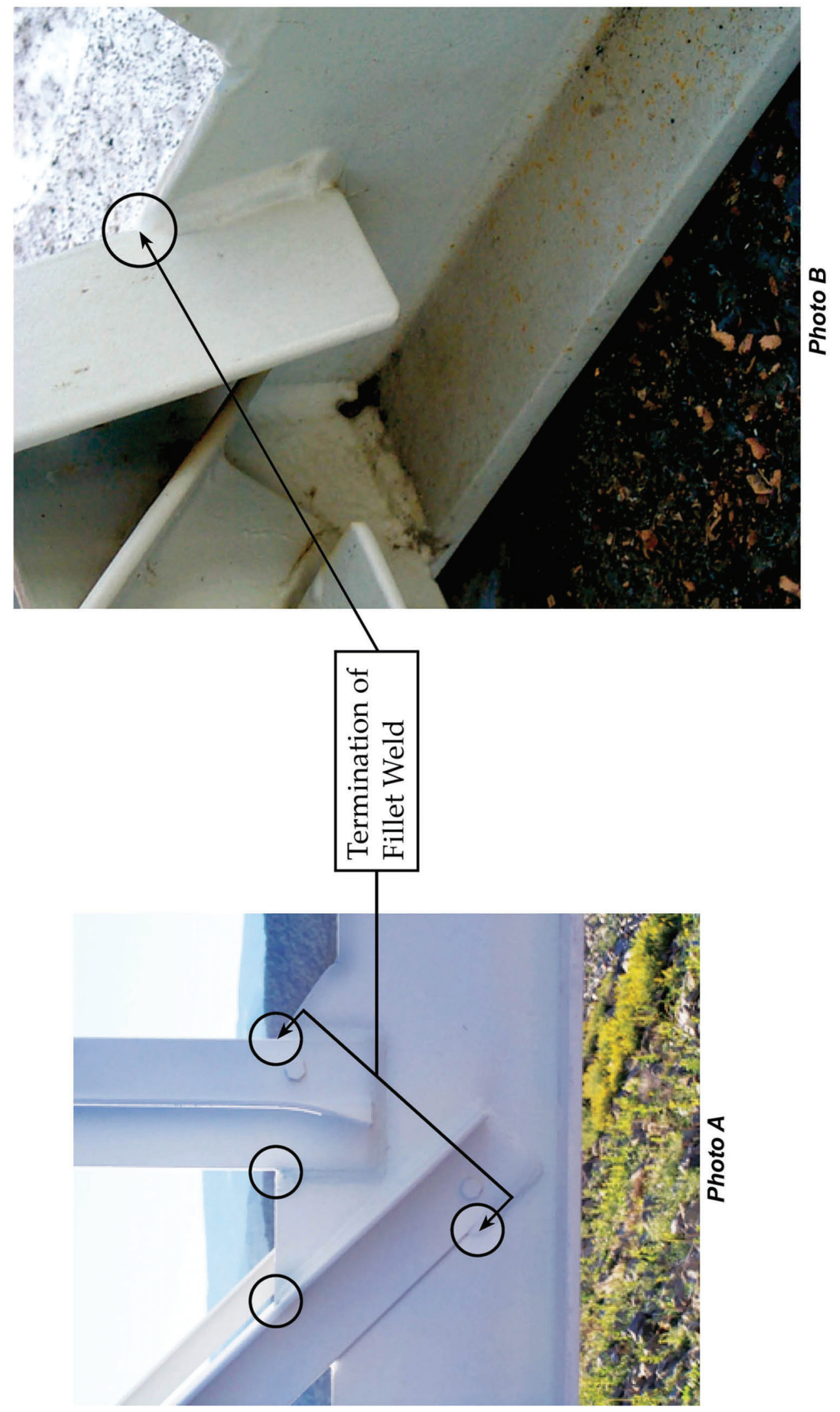




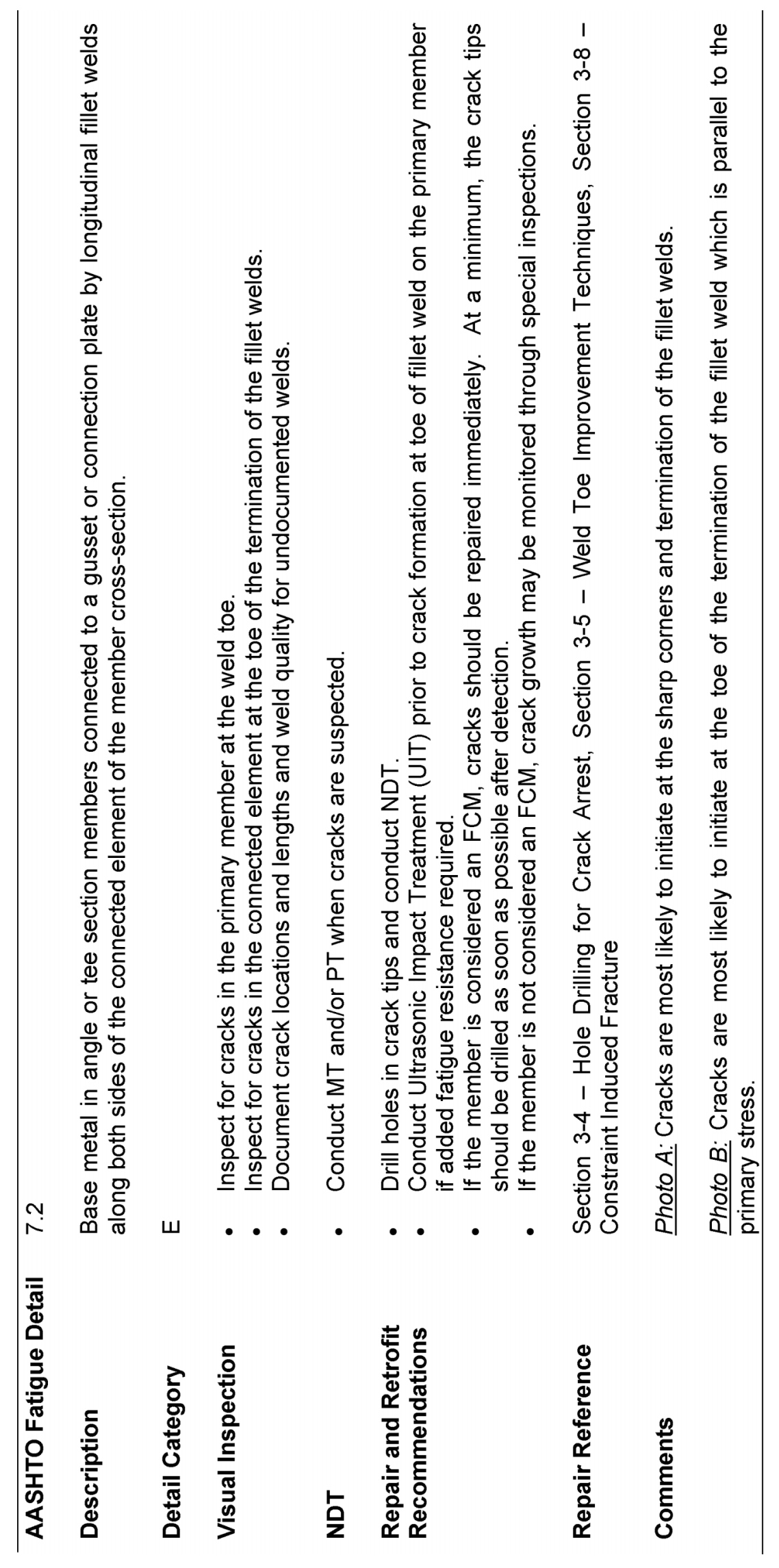


ป
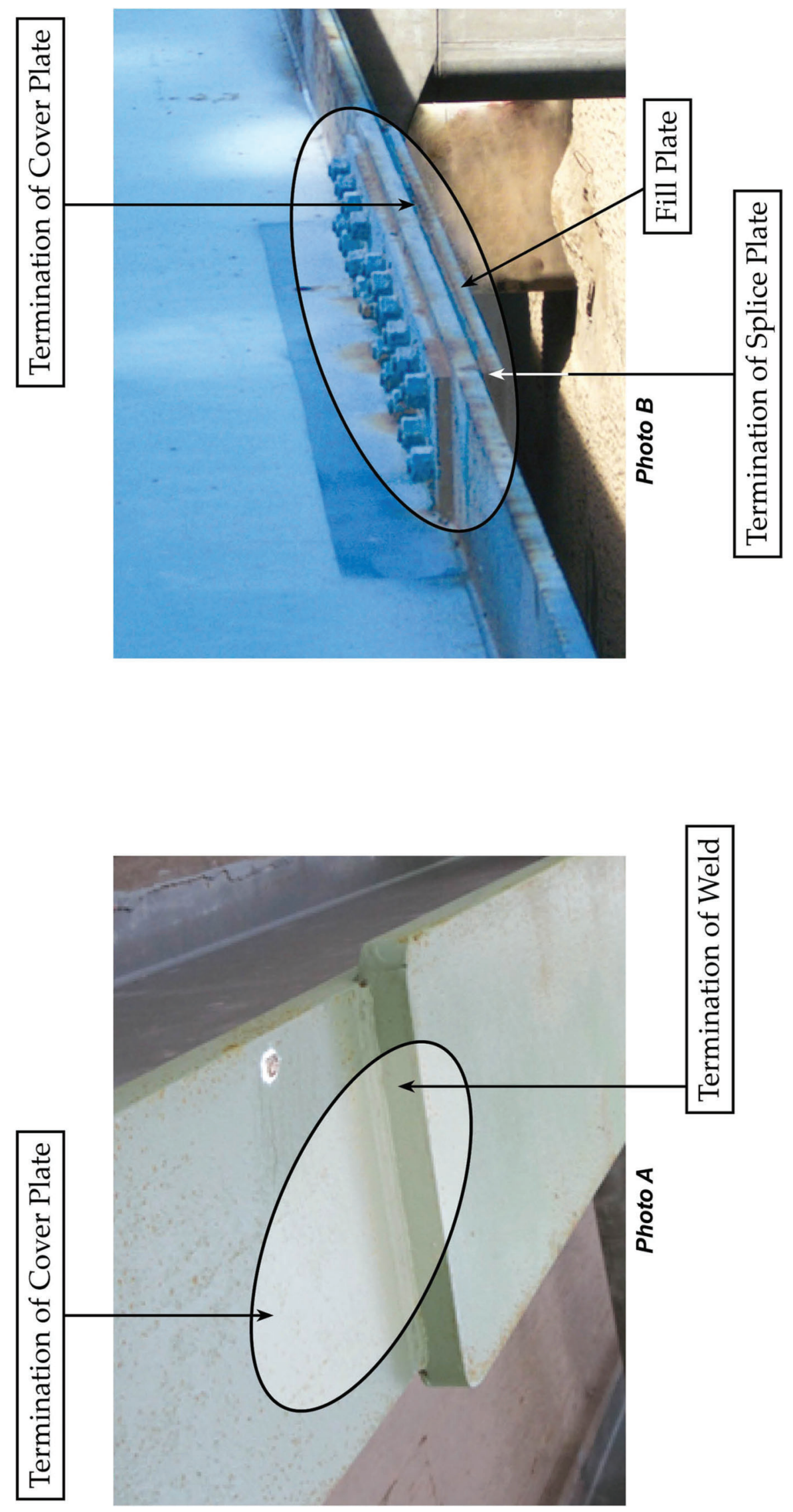


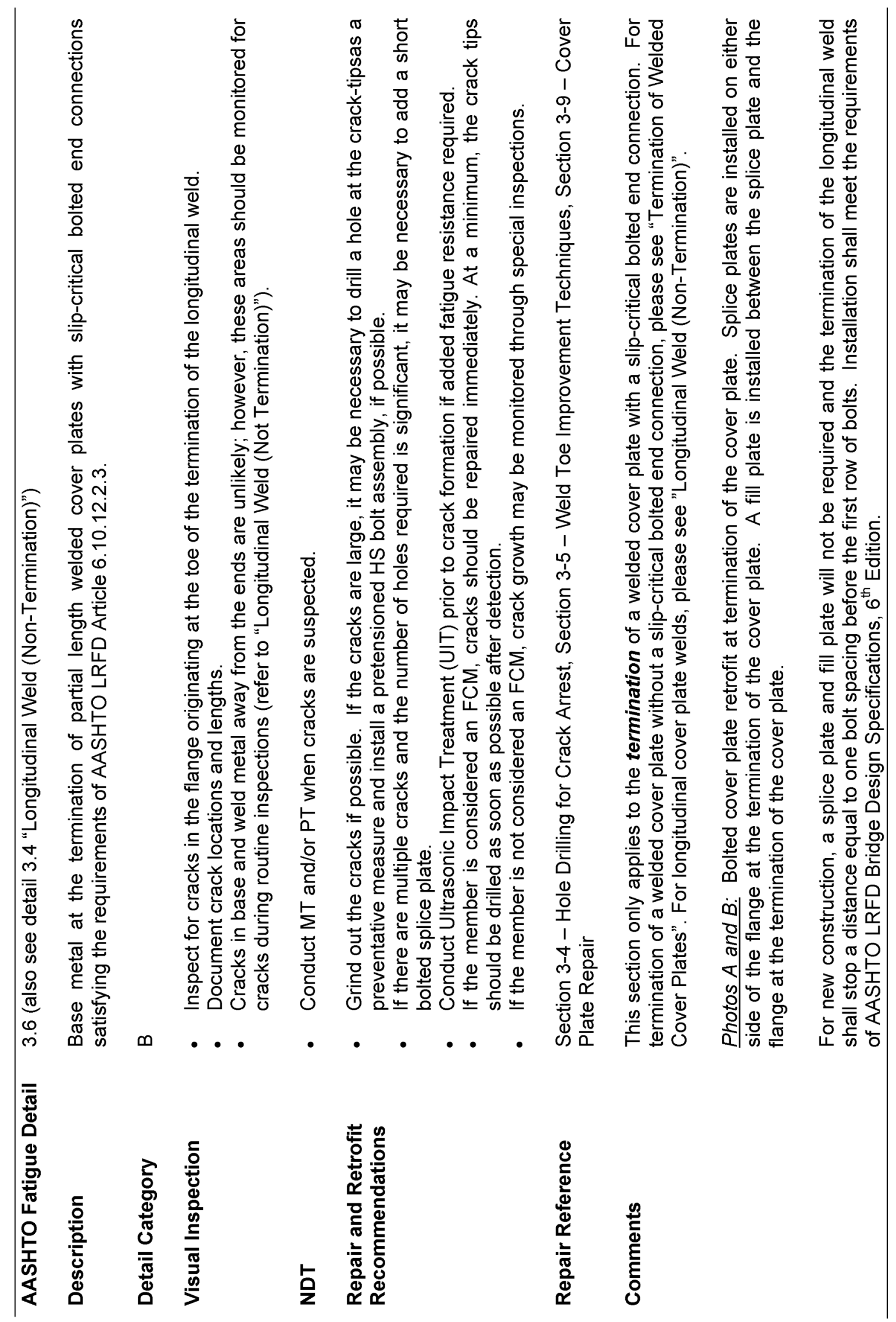




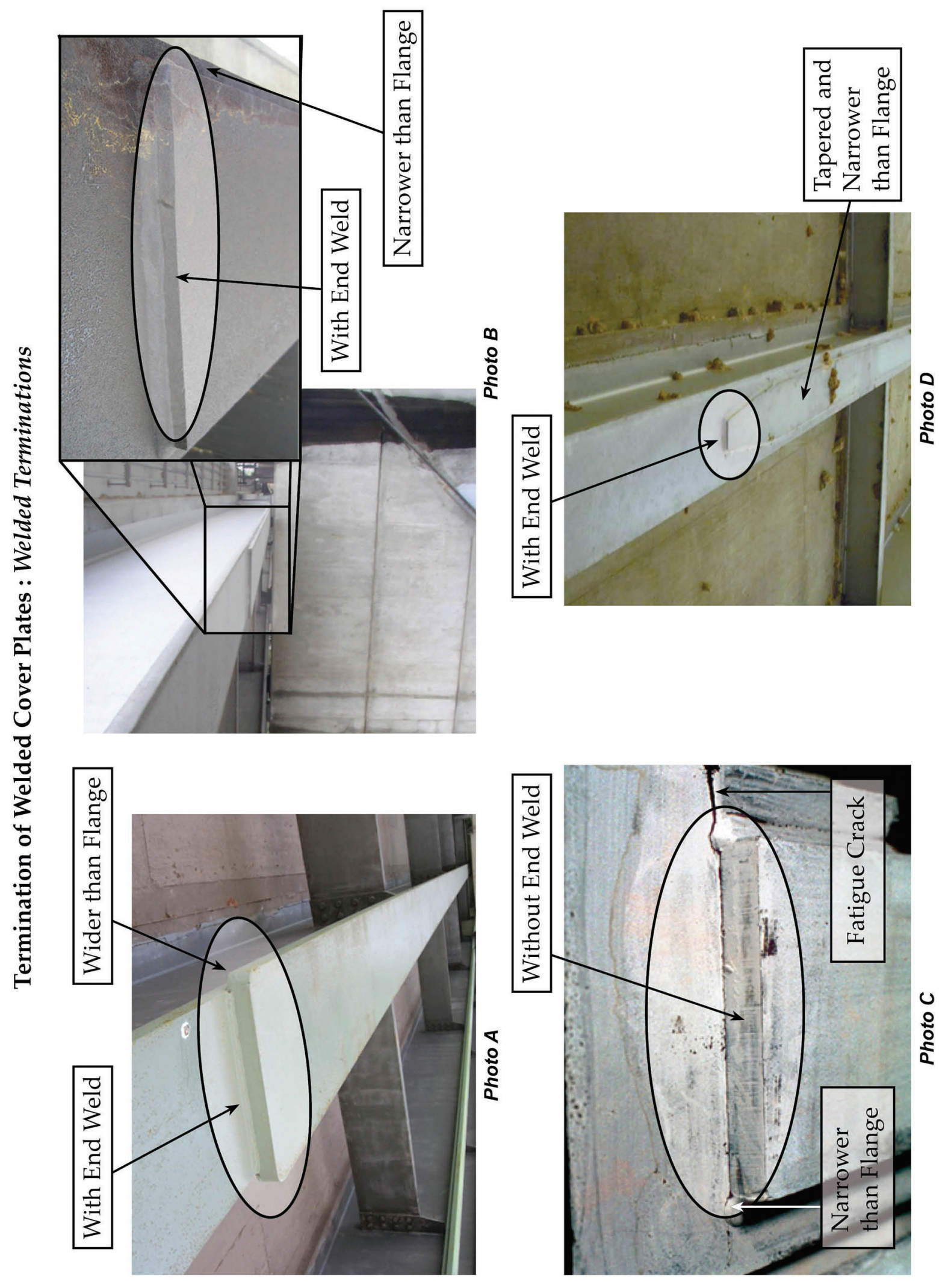




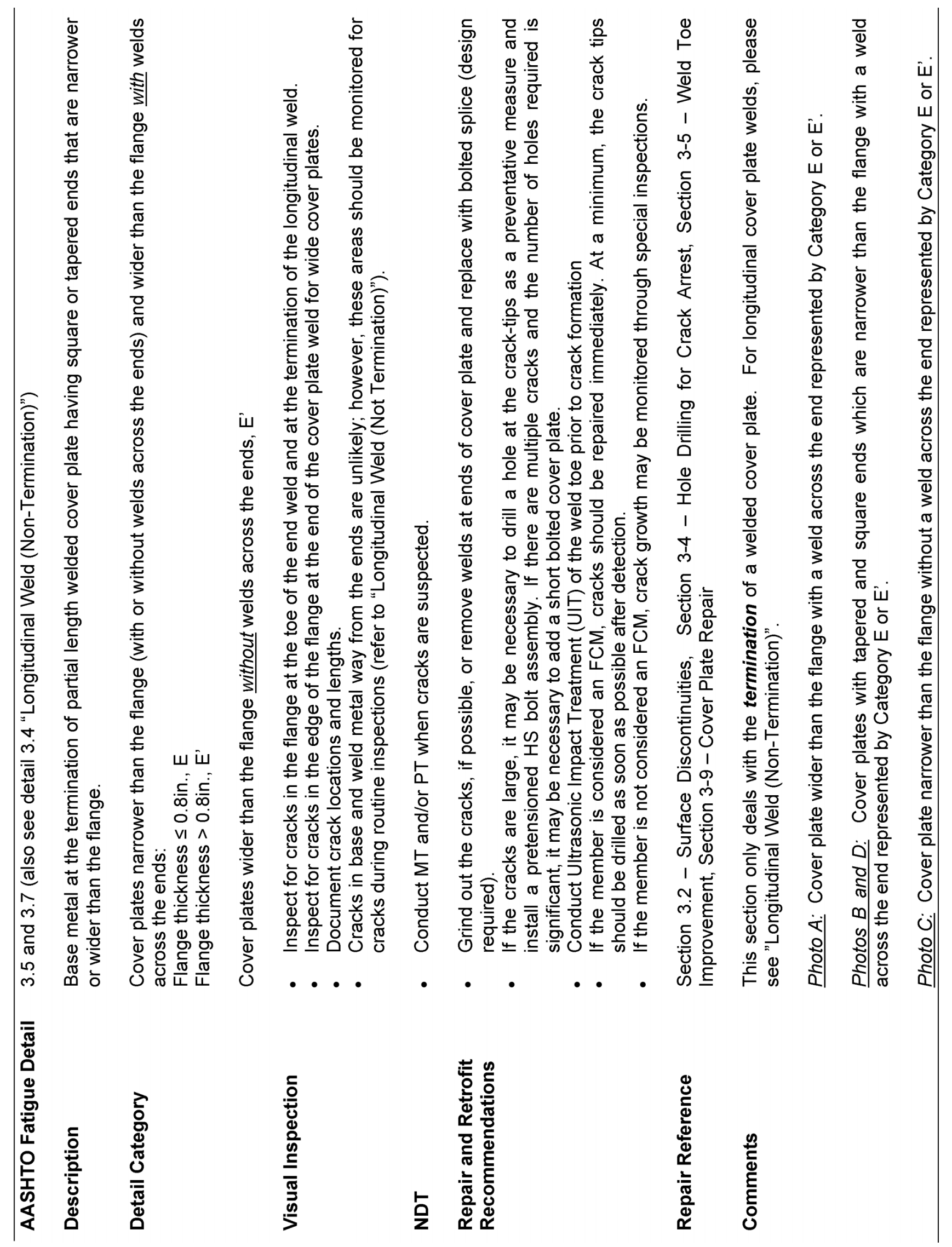


This page intentionally left blank. 


\subsection{Unclassified Details}

This section contains bridge details or conditions that do not have a defined fatigue category and are not listed in AASHTO (2012) LRFD (see bulleted list below). Many of the Unclassified Details are bridge conditions that may have initiated in-service (impact damage, existing cracks, etc.) or are details that were not properly designed and fabricated (tack welds and extraneous welds, undocumented and poor quality welds, notches and rolling flaws, non-compliant repairs, intersecting welds, etc.). In the case of intersecting welds, fracture, not fatigue, is the driving damage mode. Instead of performing fatigue calculations, detailing recommendations are used in design to provide damage resistance from this condition. The bridge details included in this section are as follows:

- Intersecting Welds (Constraint Induced Fracture)

- Tack Welds and Extraneous Welds

- Undocumented and Poor Quality Welds

- Intermittent Welds

- Out-of-plane Bending

- Impact Damage

- Pins

- Forged Pin Connected Elements

- Rolling Flaws and Surface Discontinuities

- Notches and Sharp Corners

- Existing and Repaired Cracks

- Non-compliant Repairs 


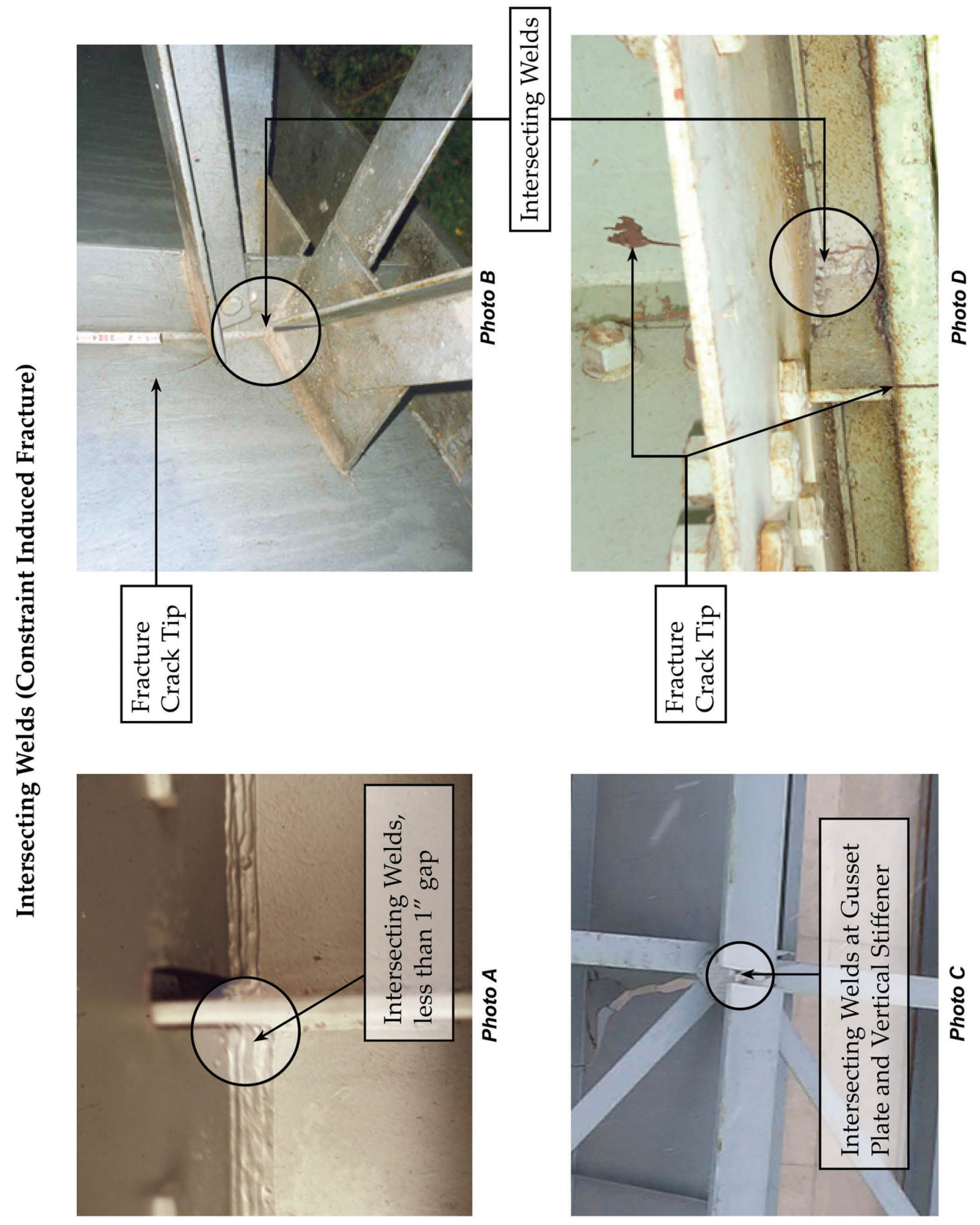




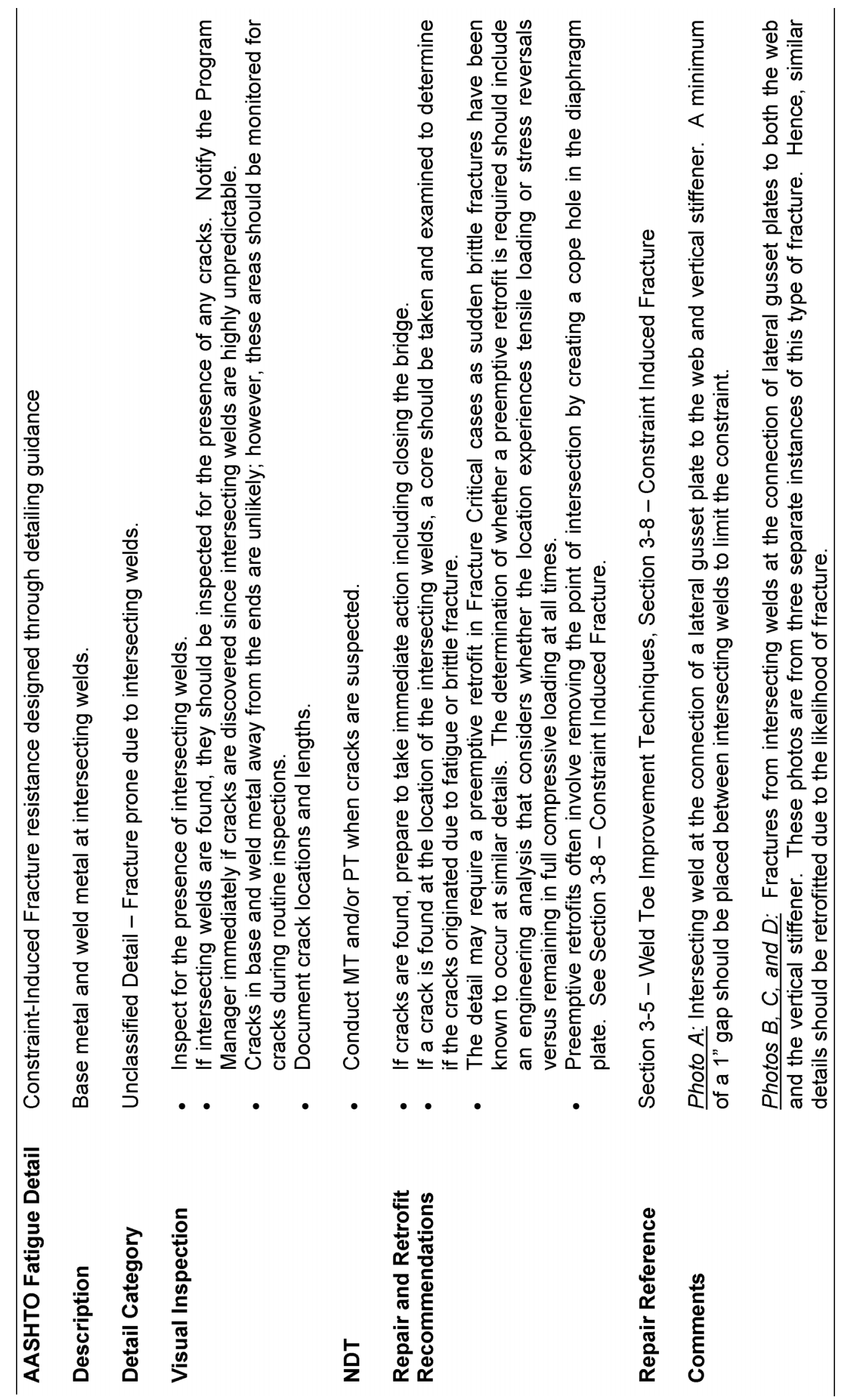




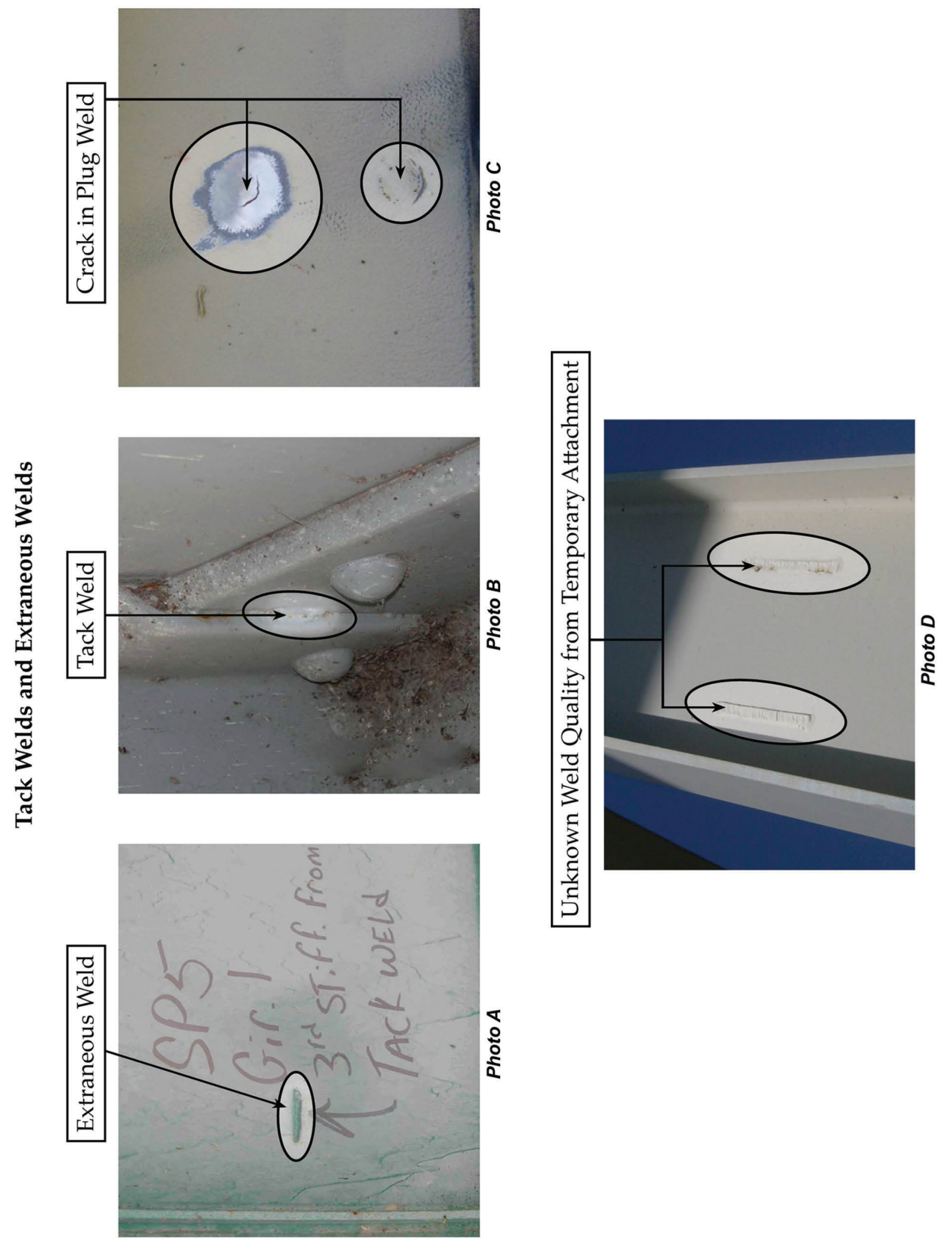




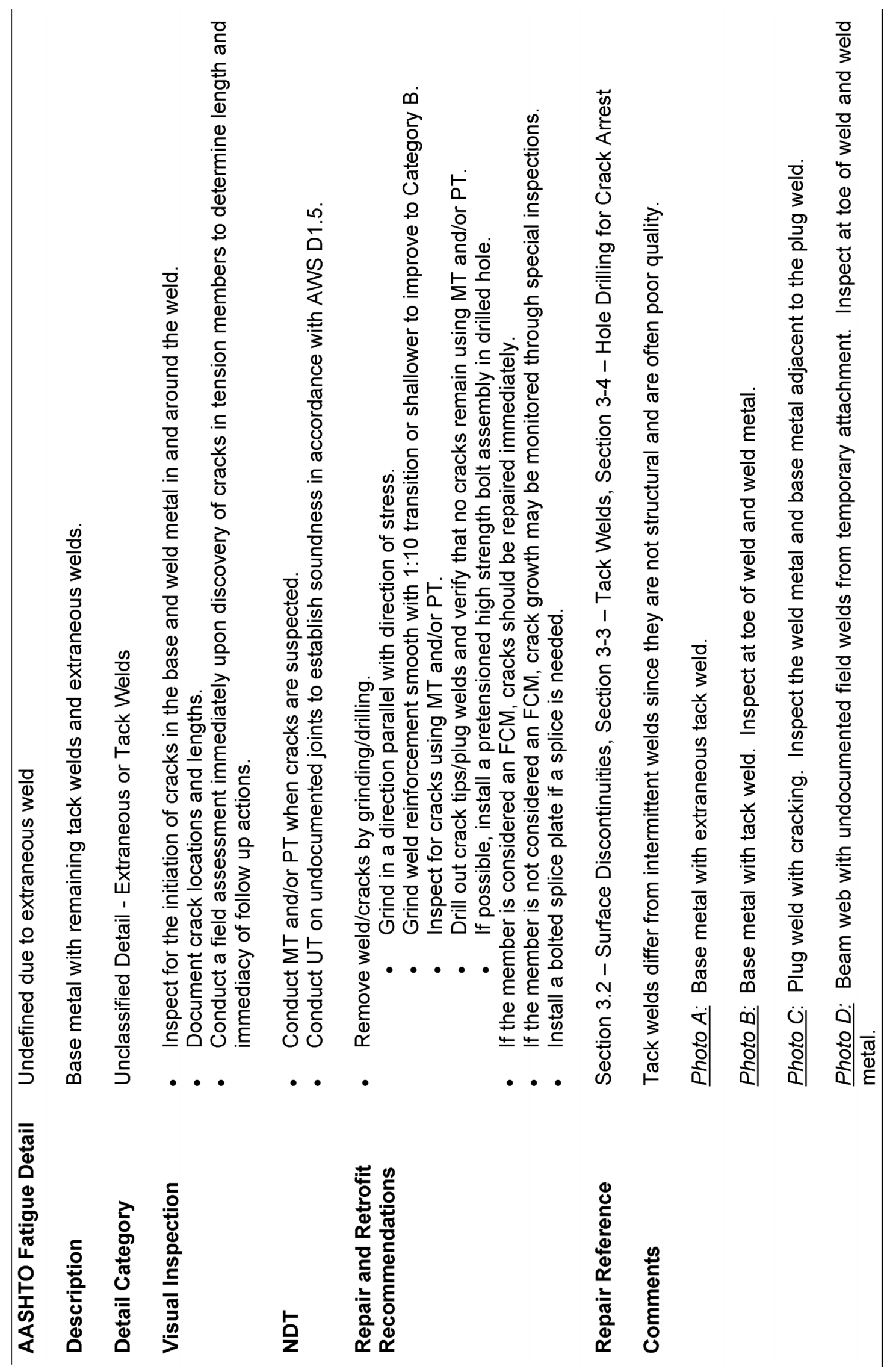




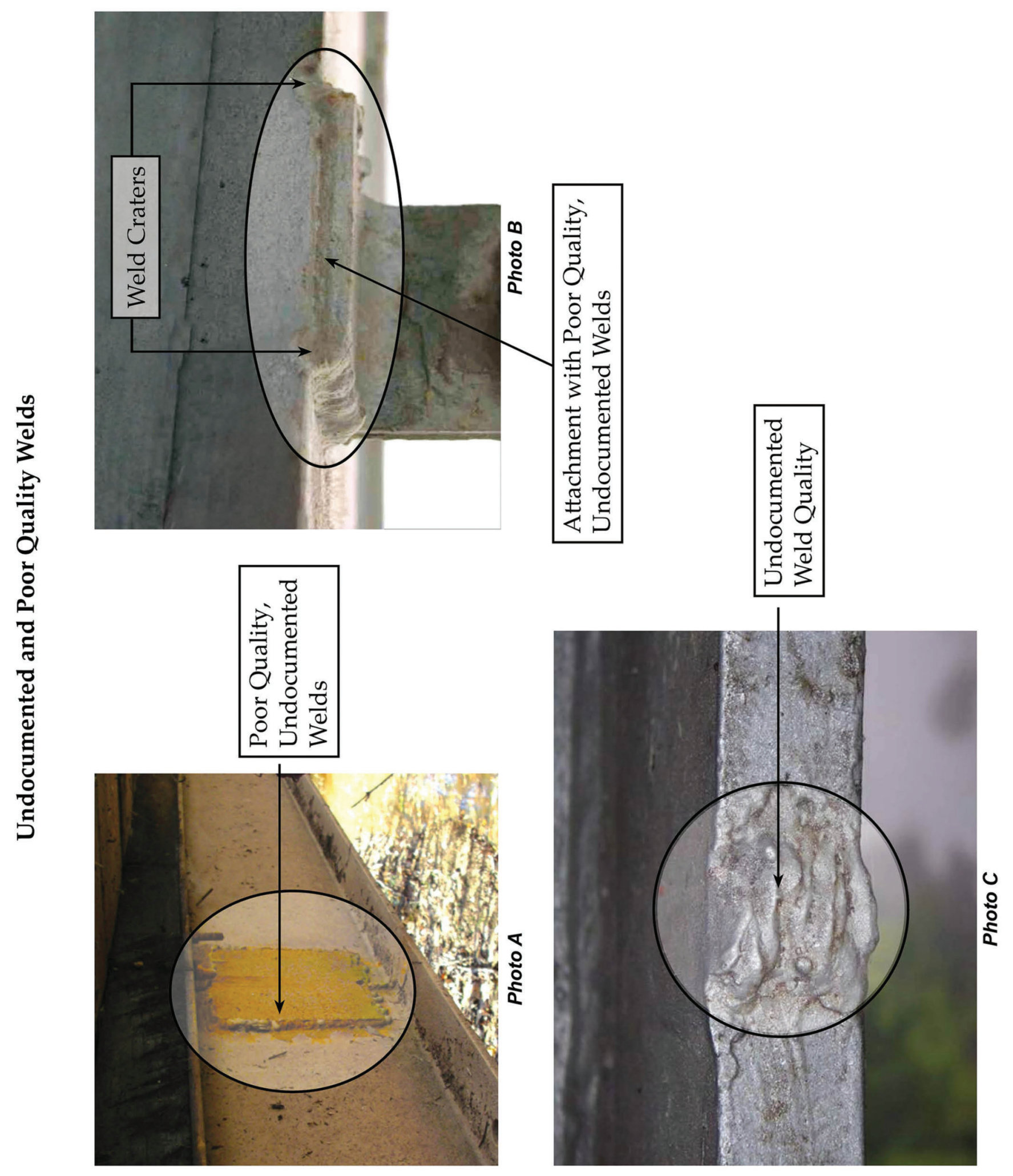




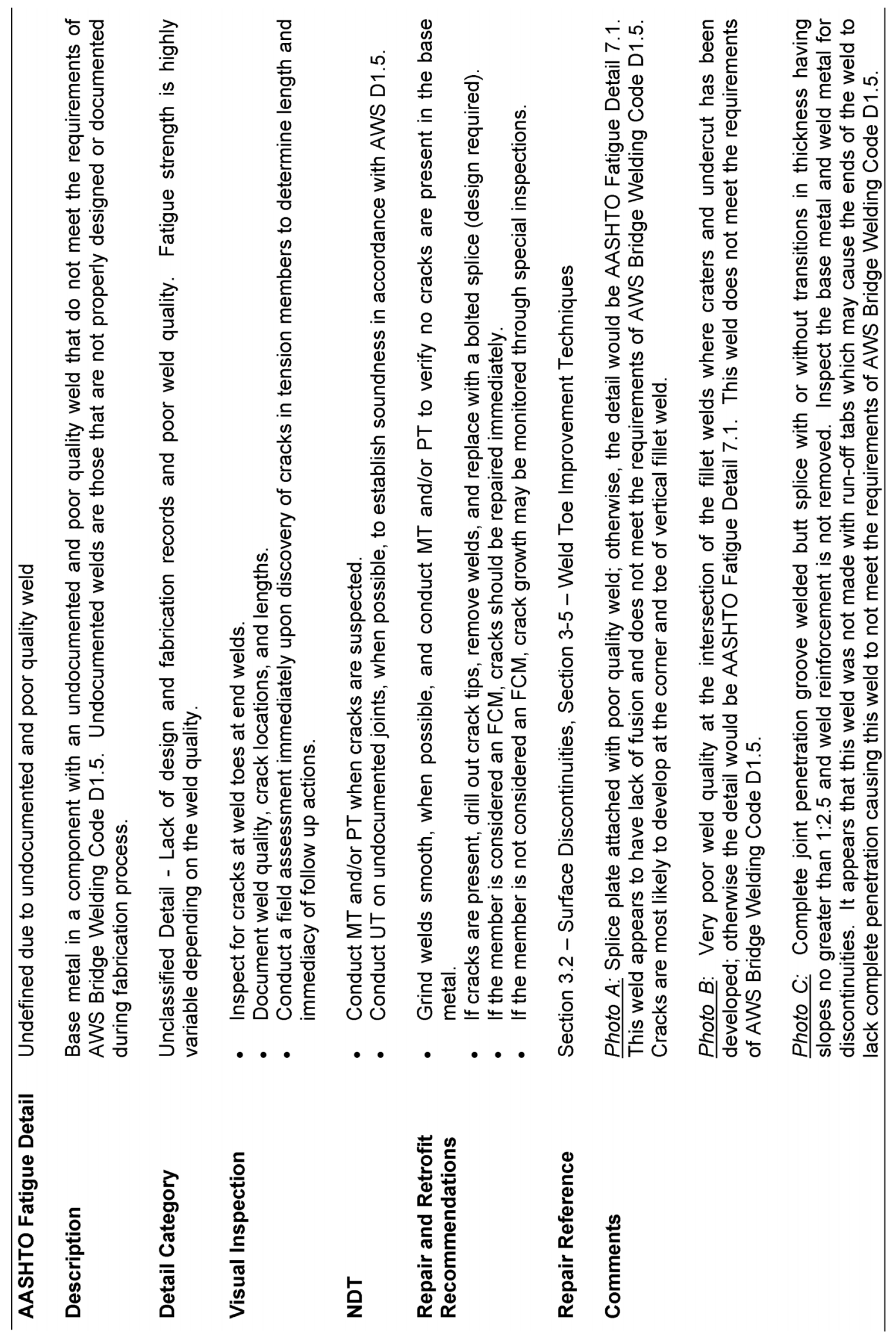




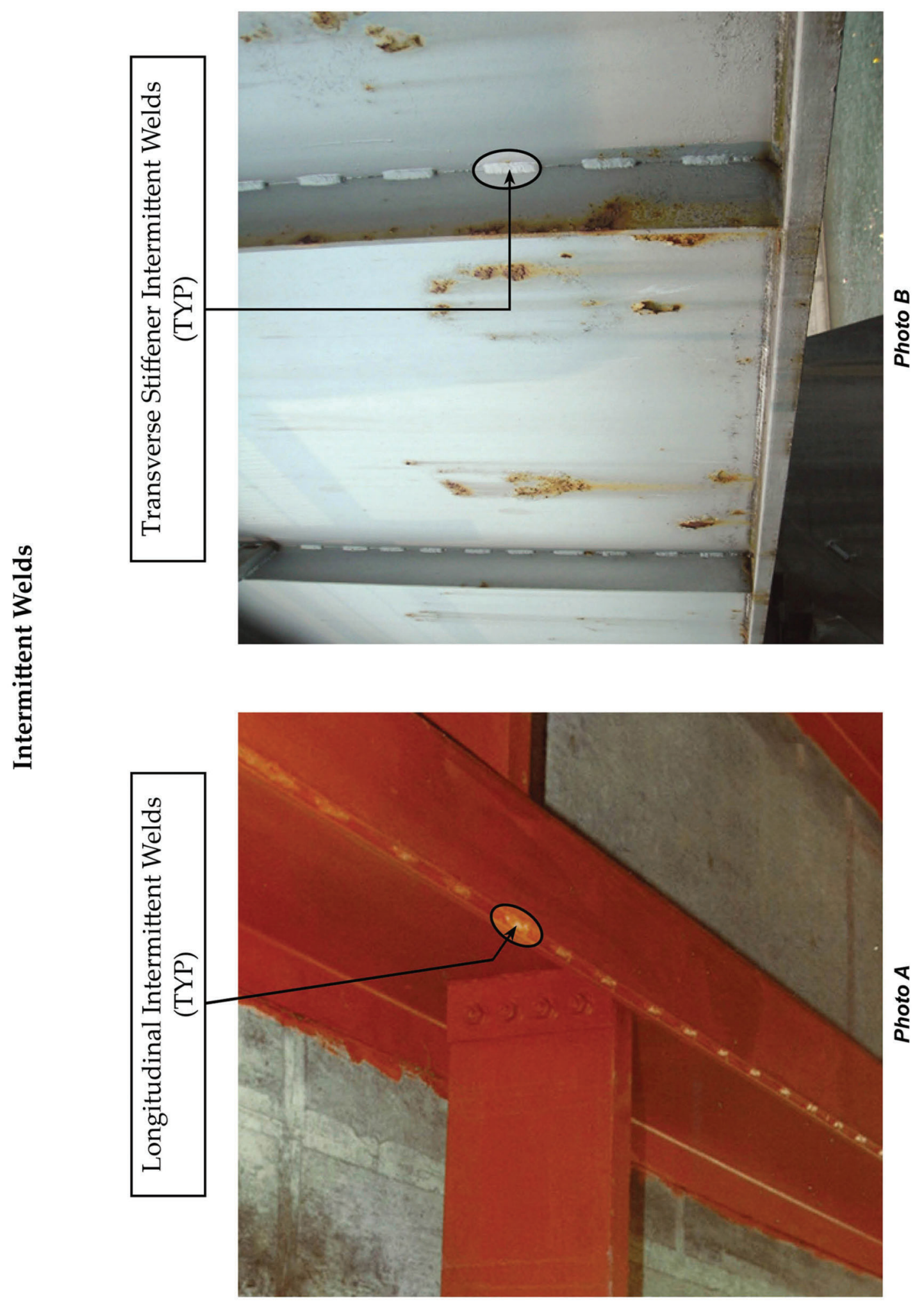




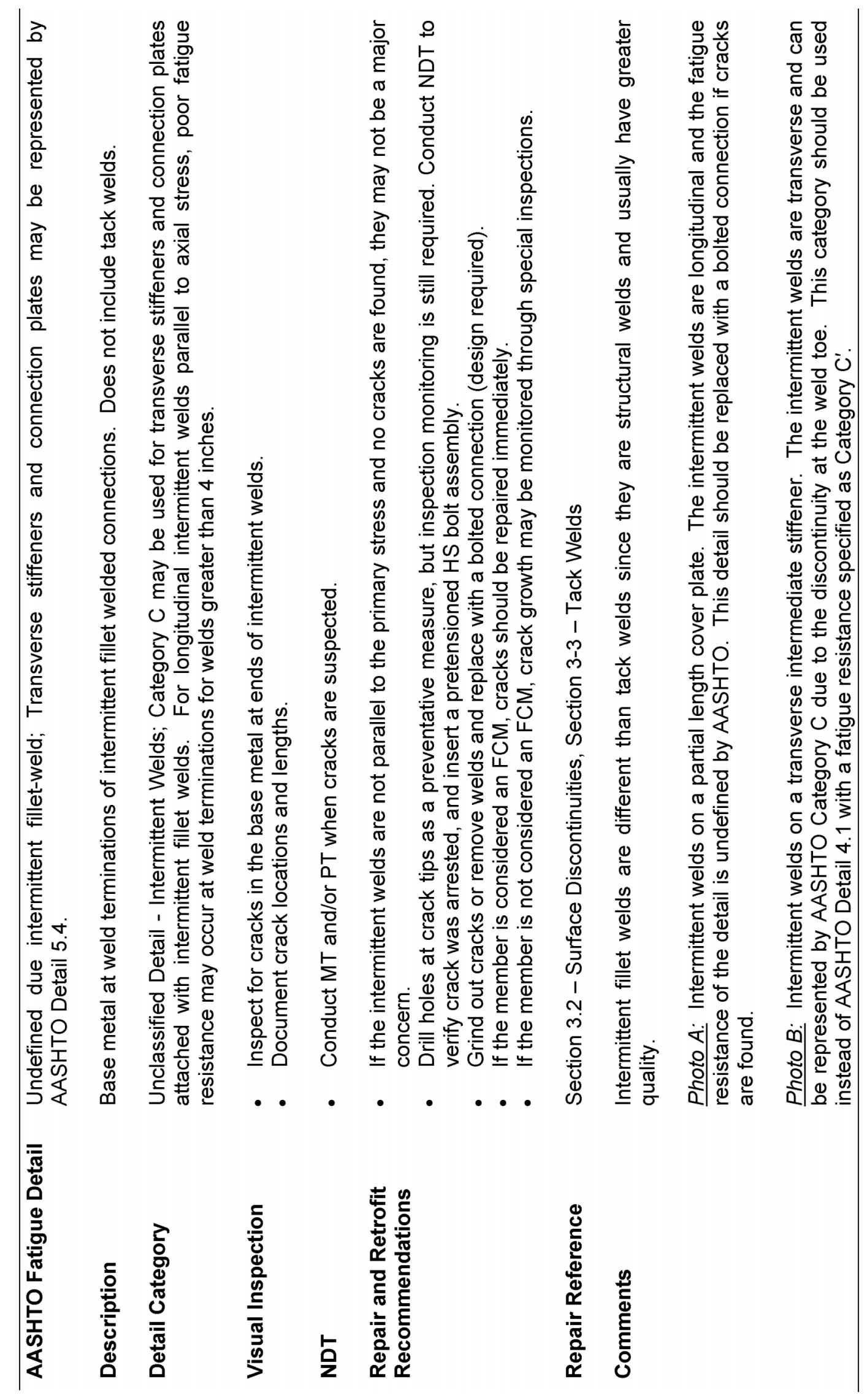



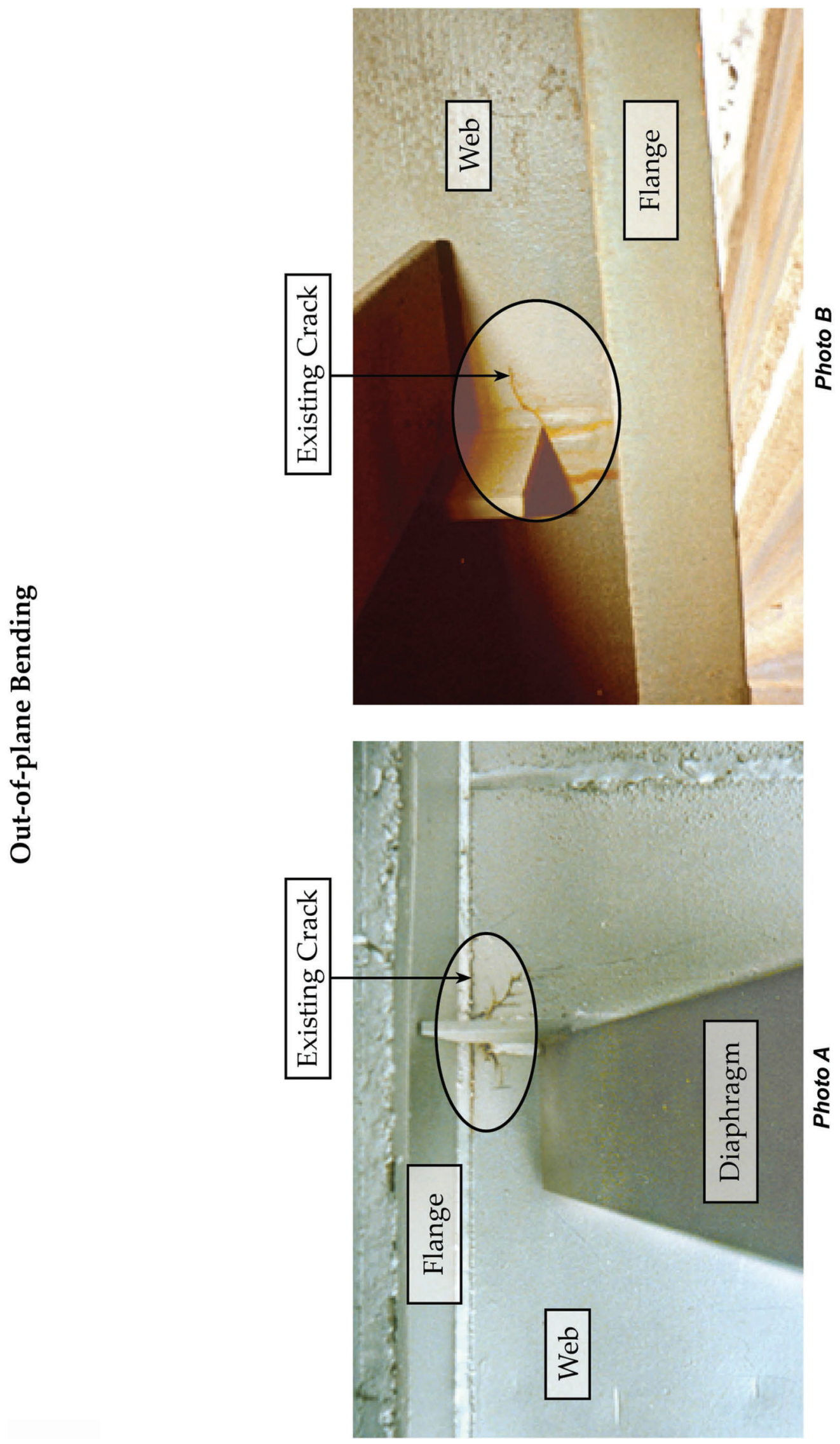


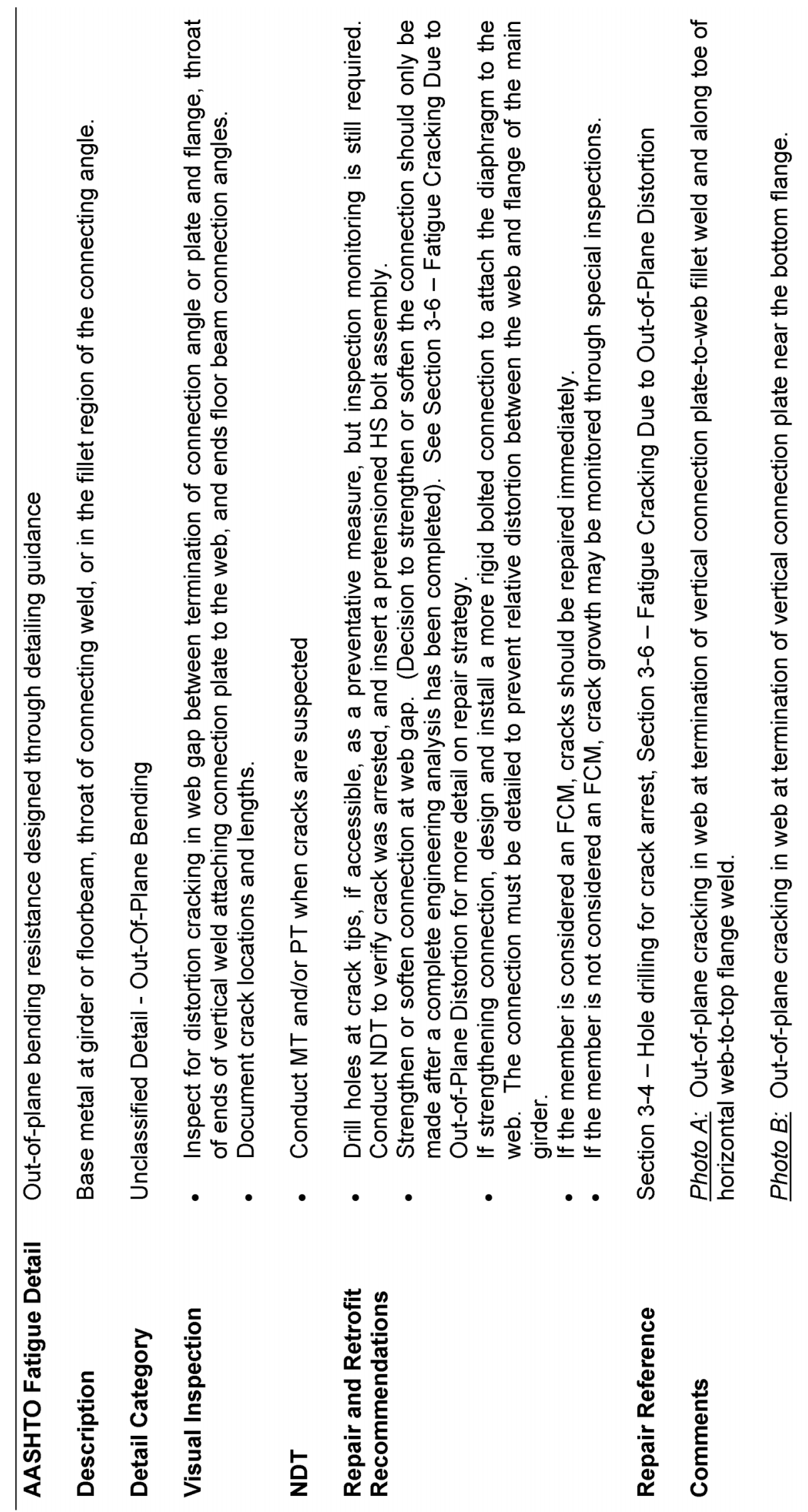




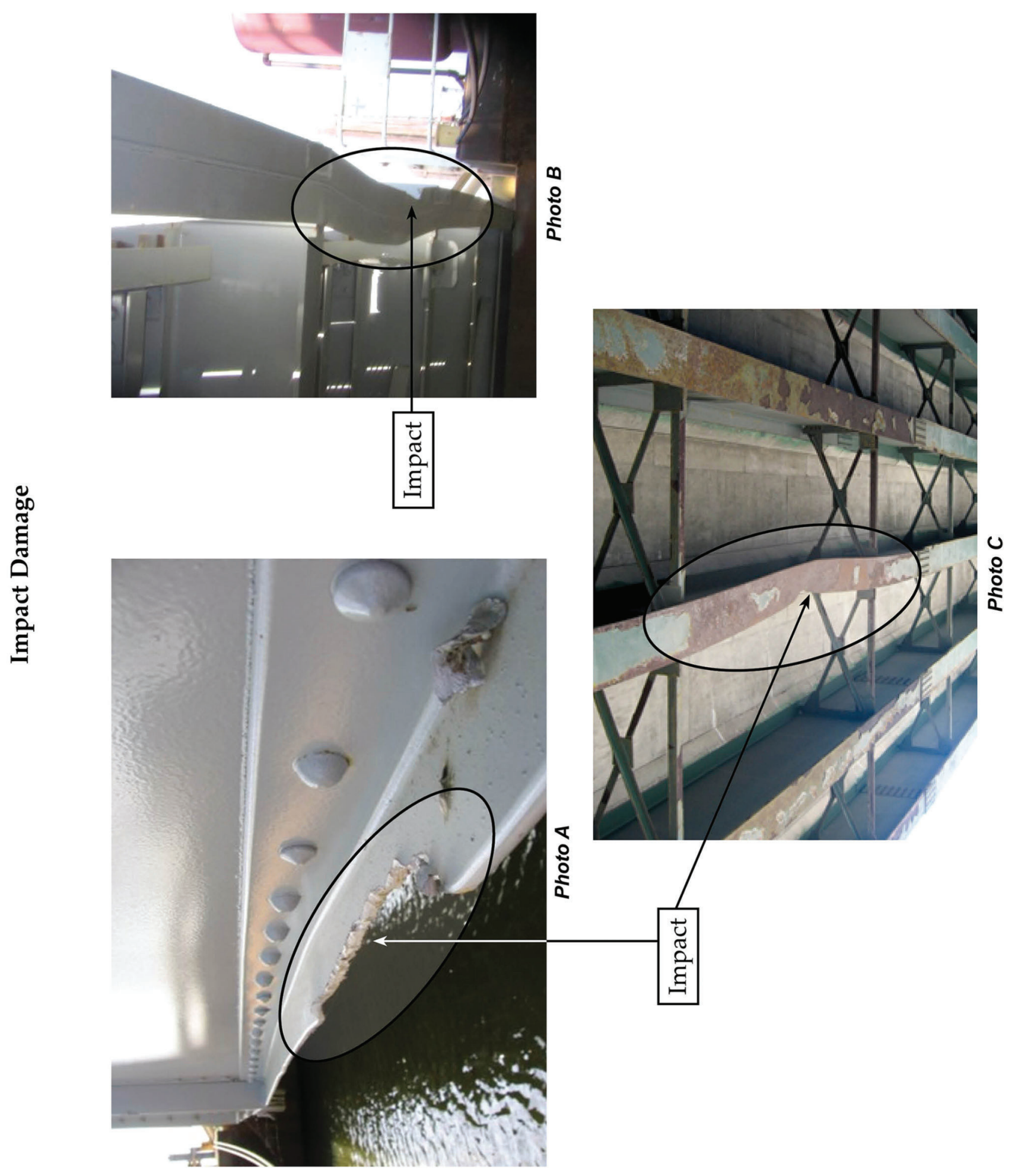




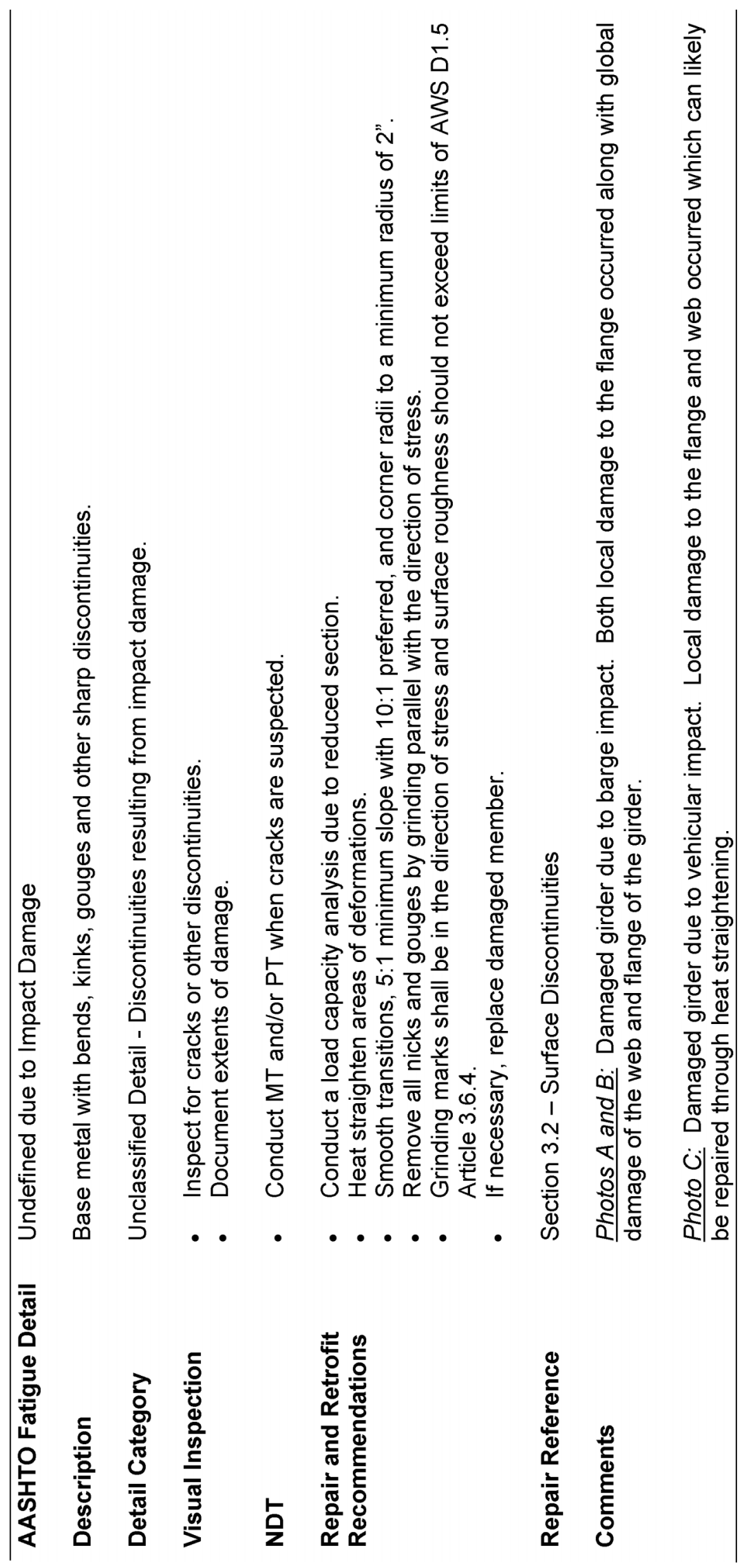




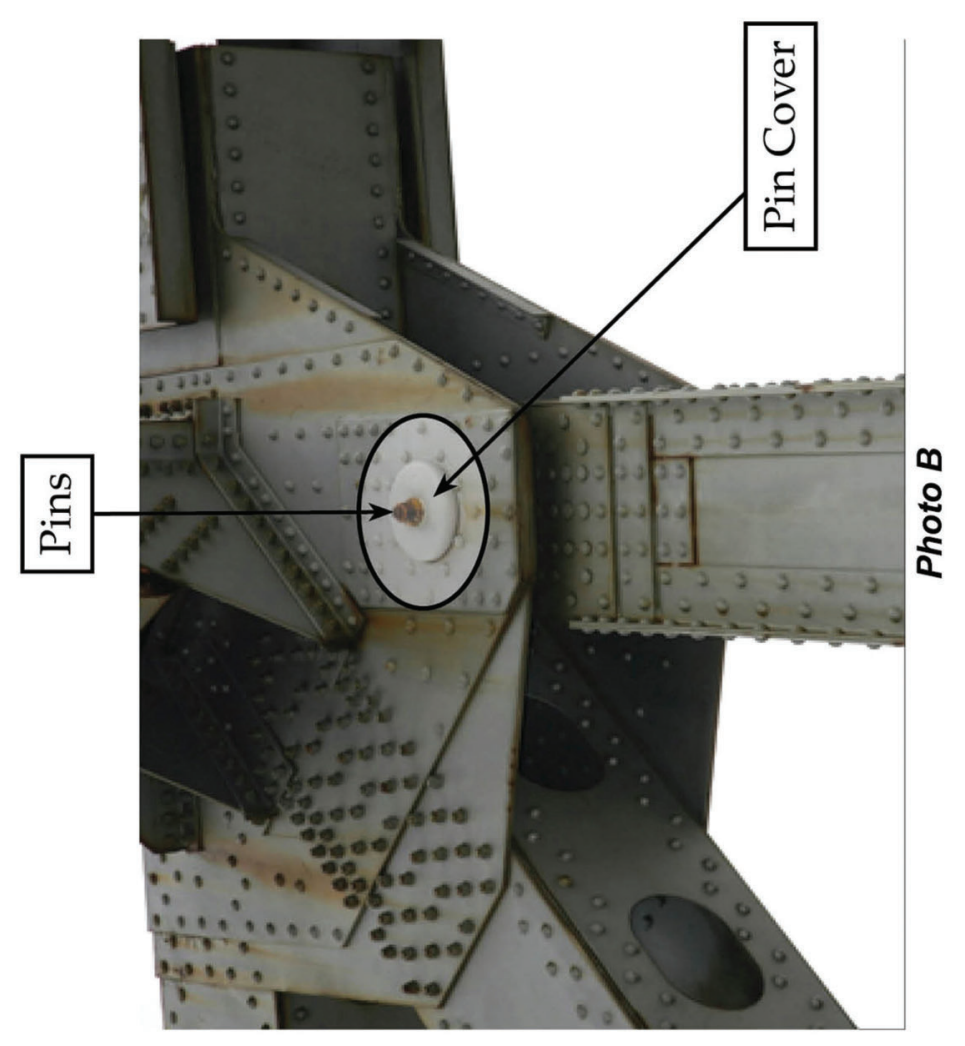

:

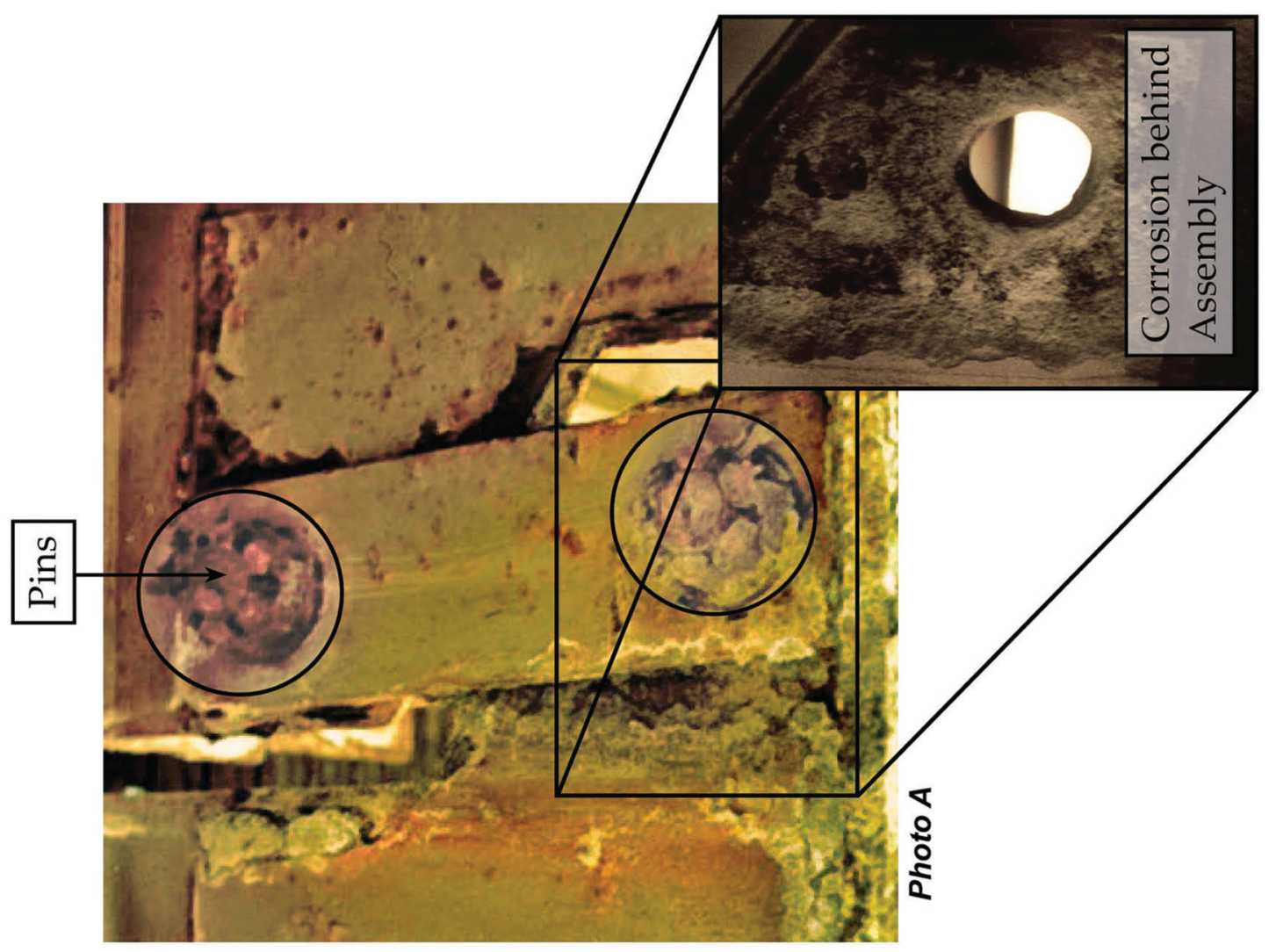




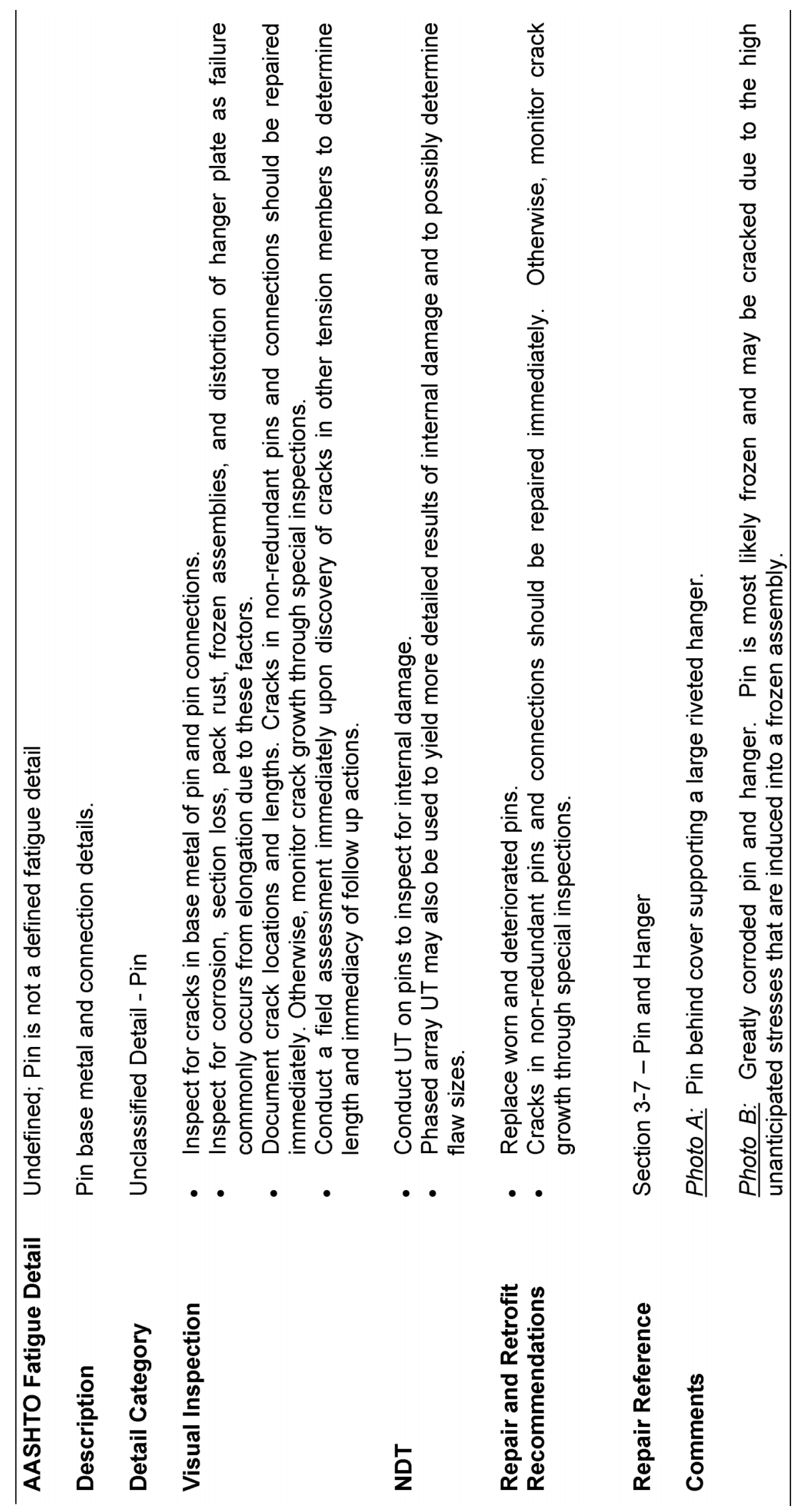



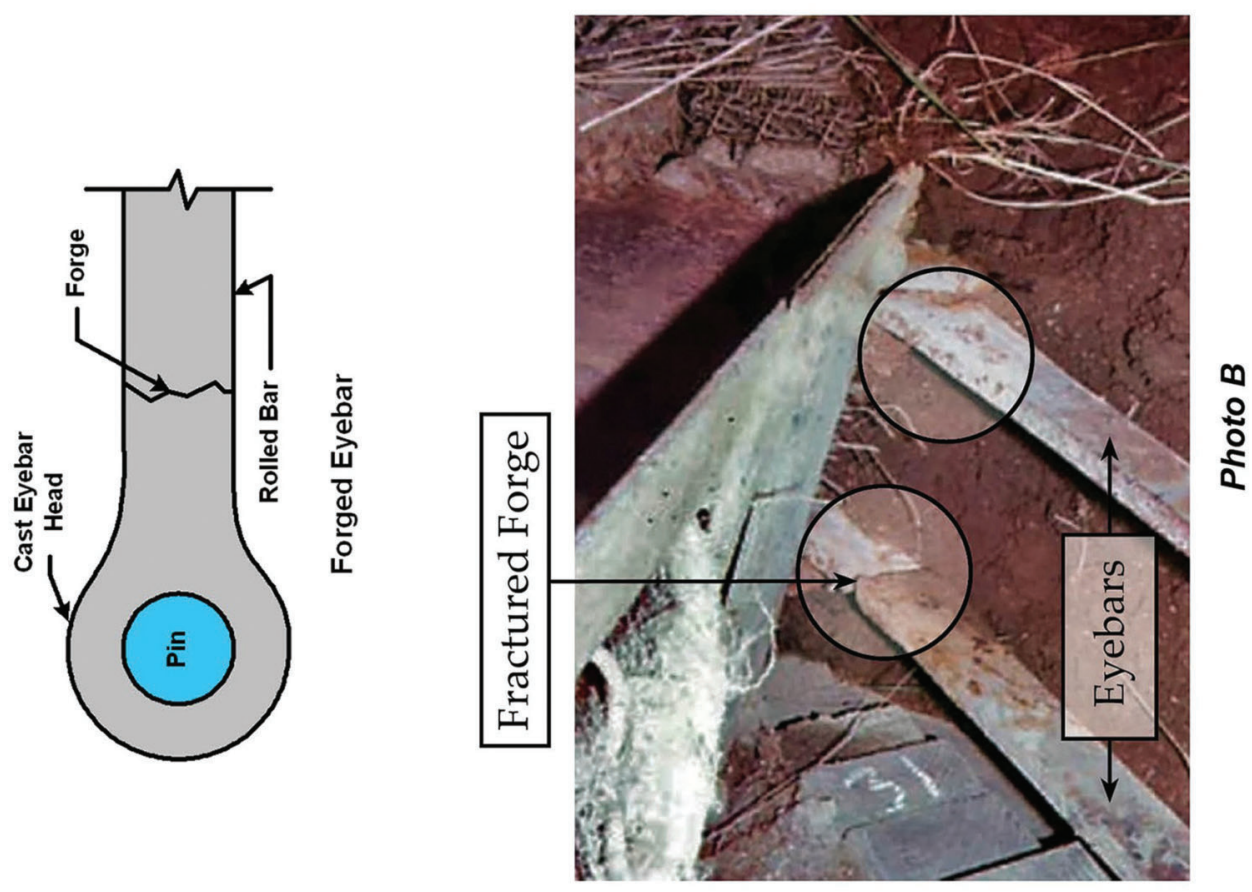

苂
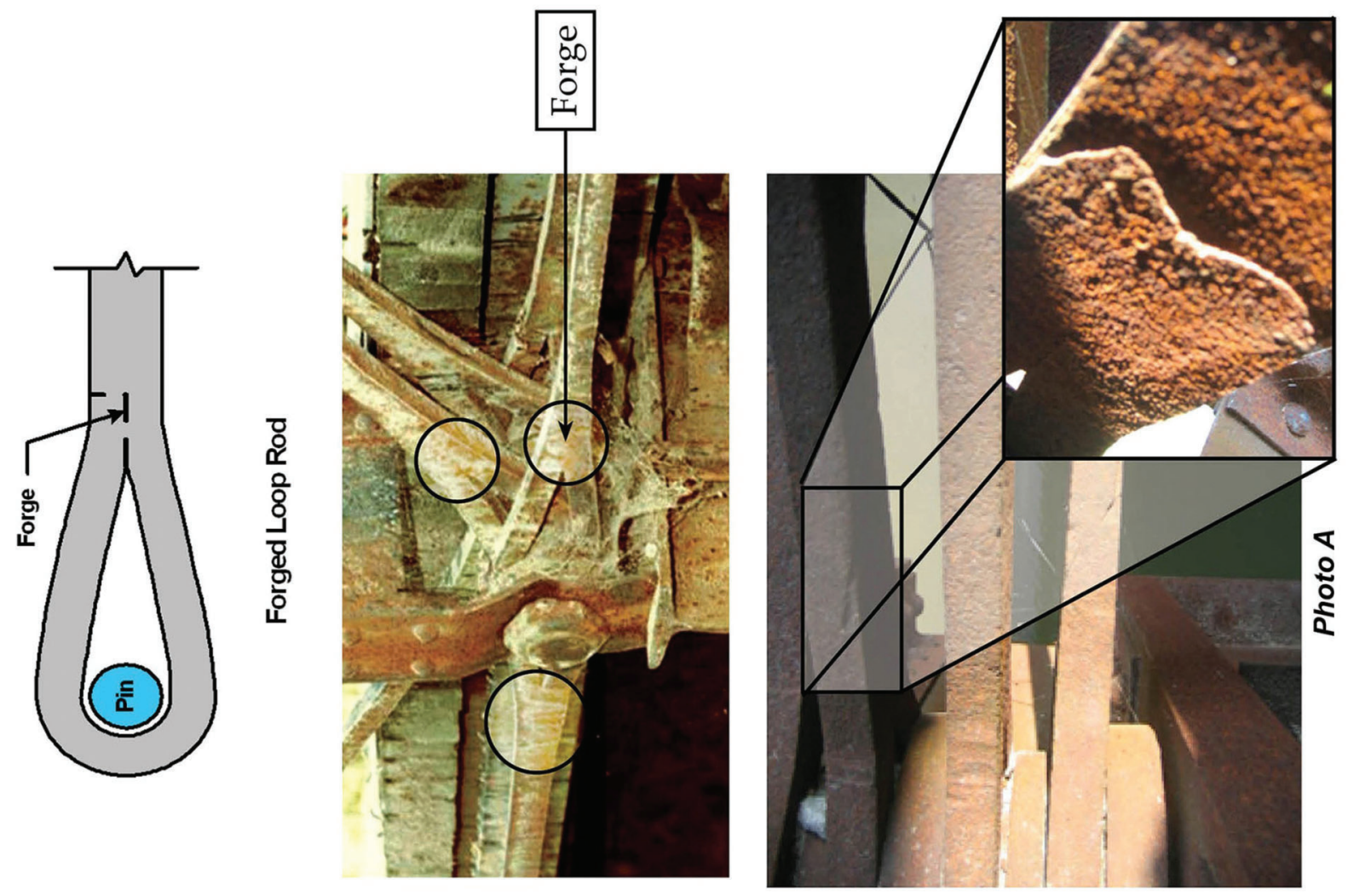


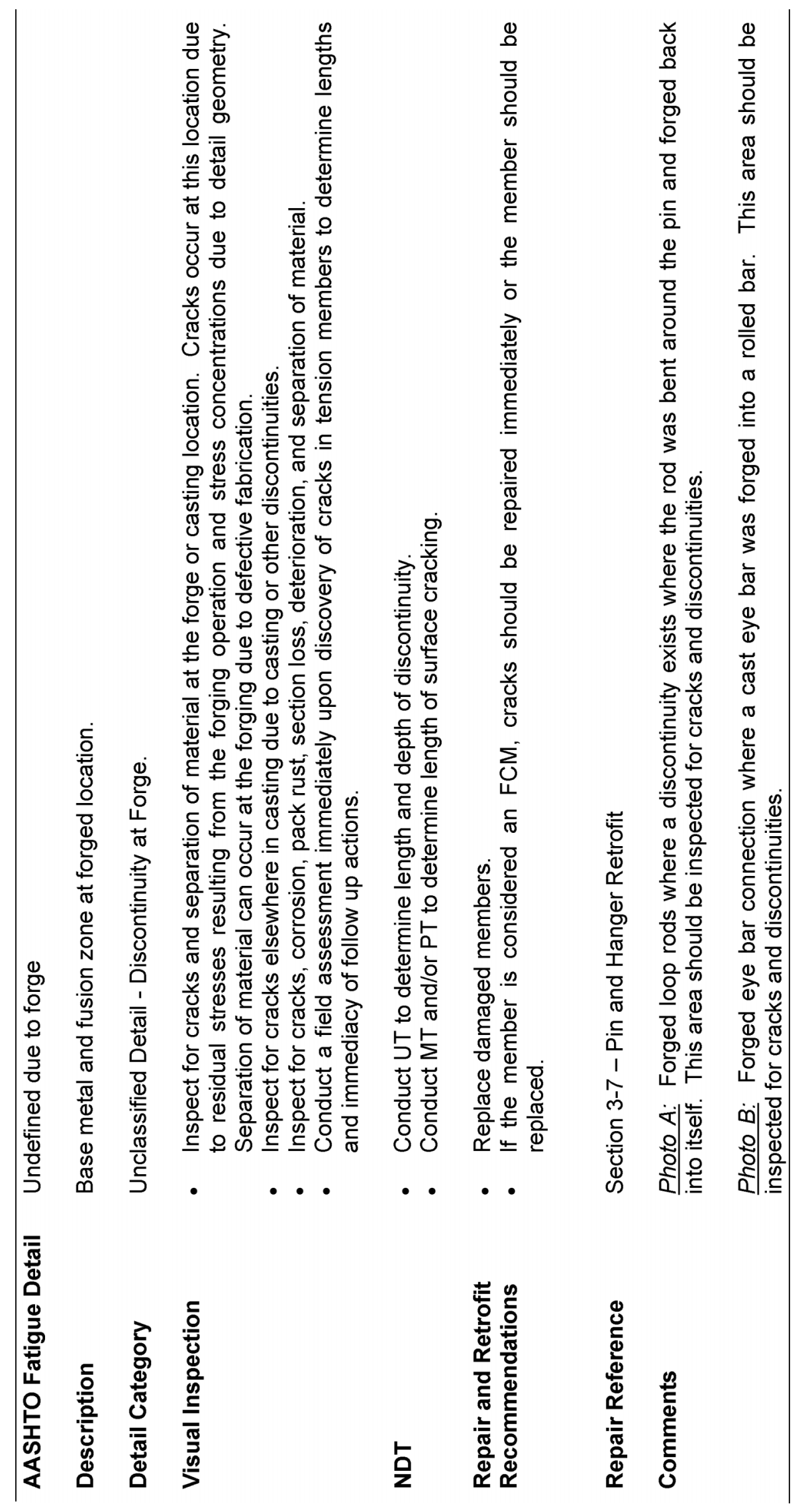



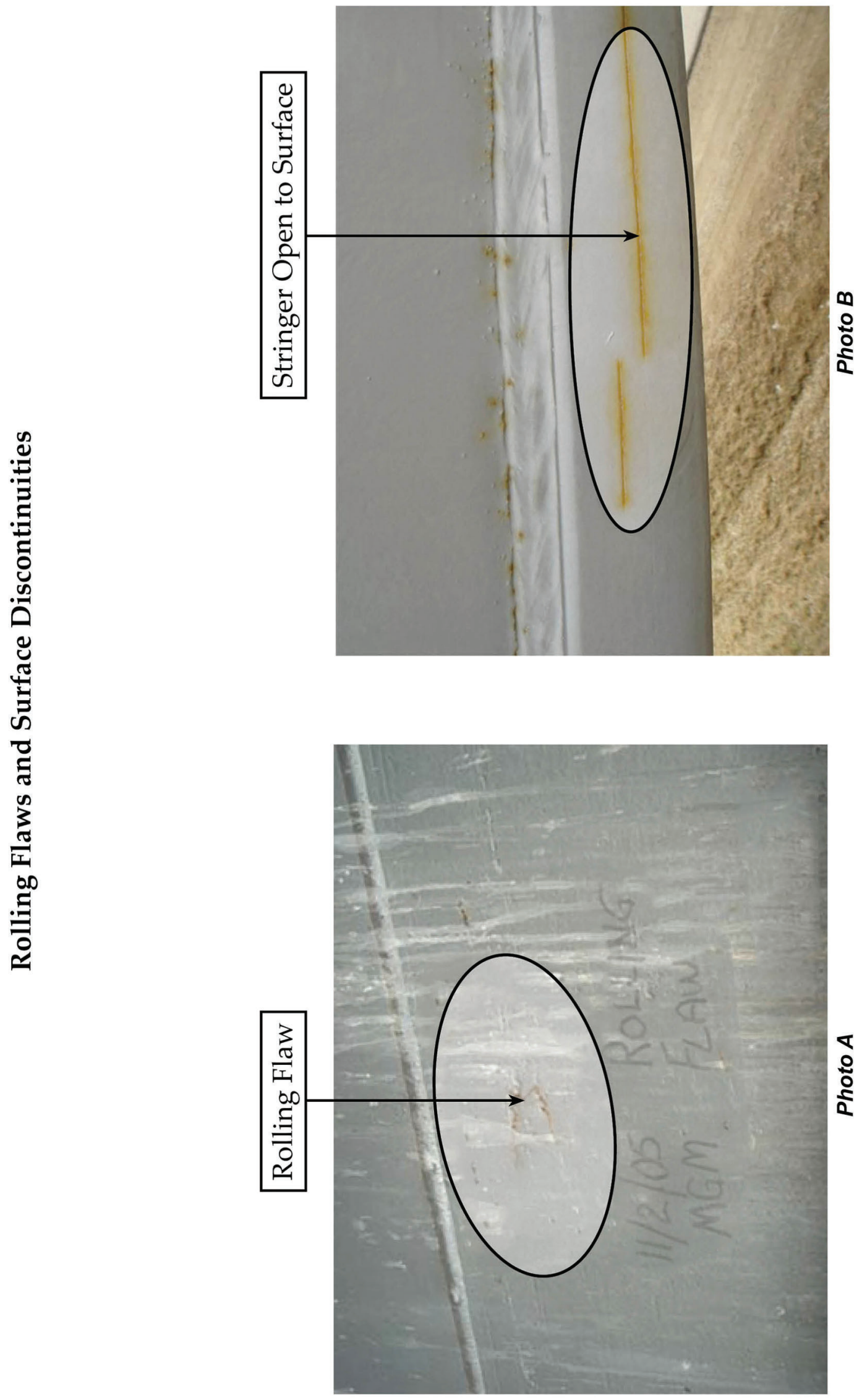


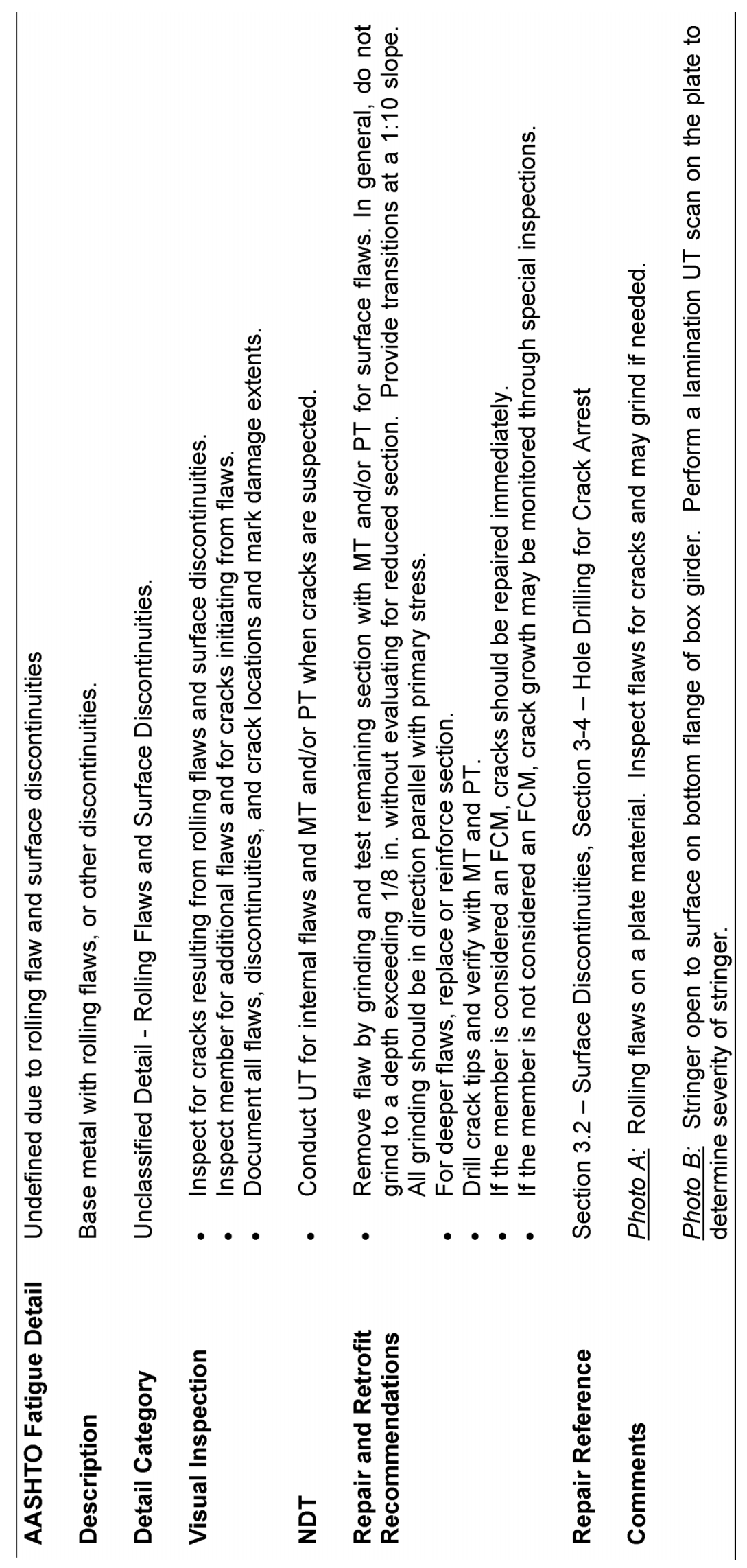




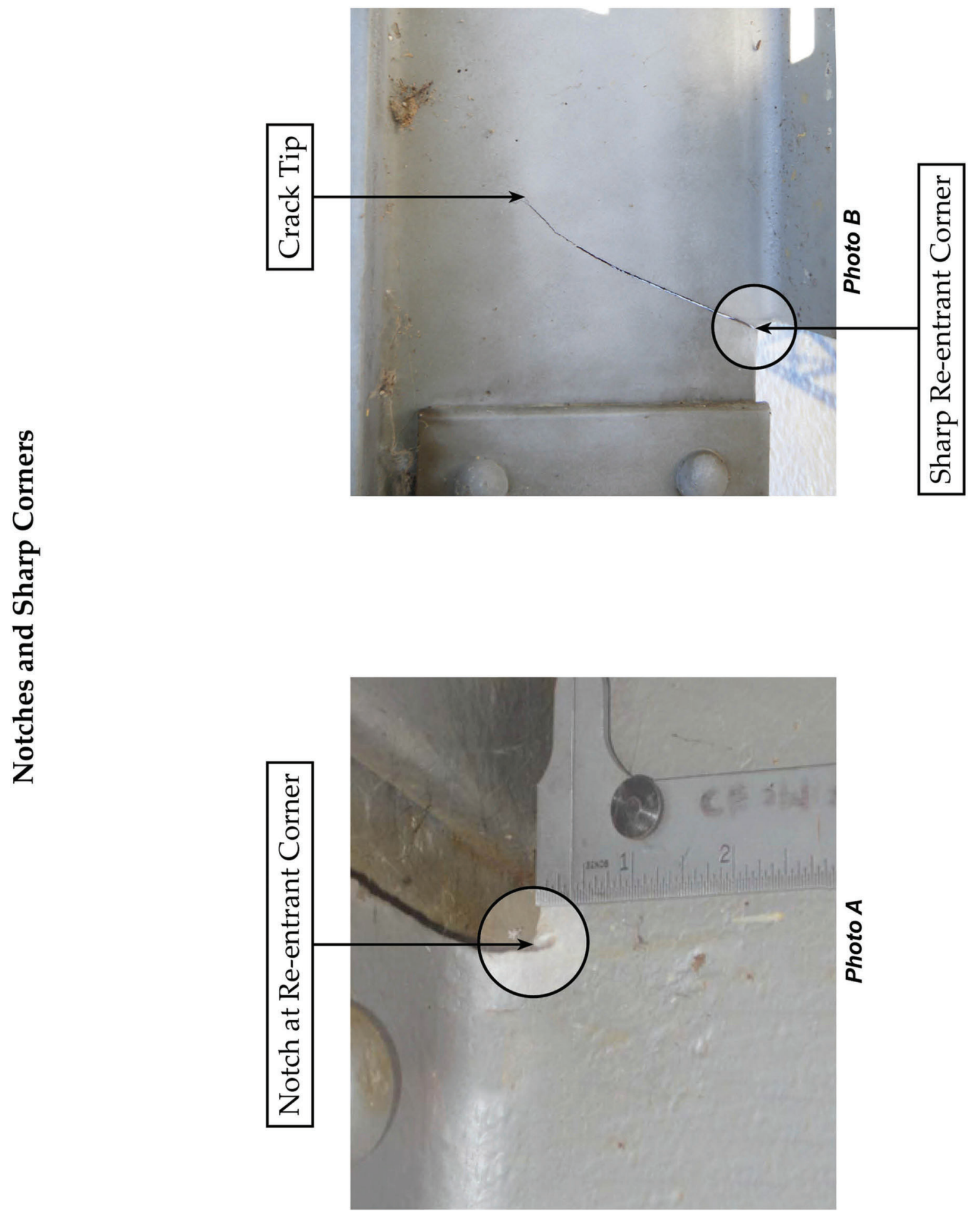




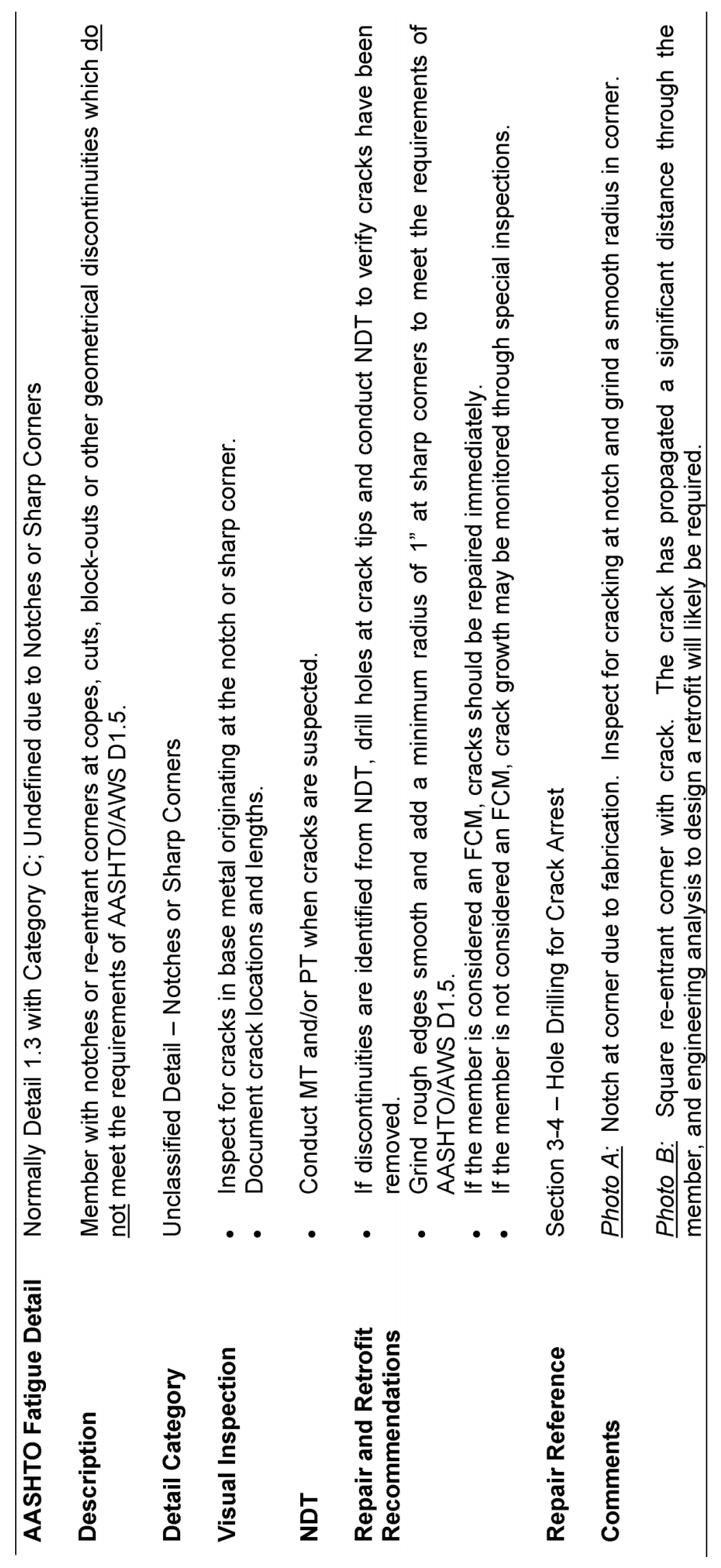



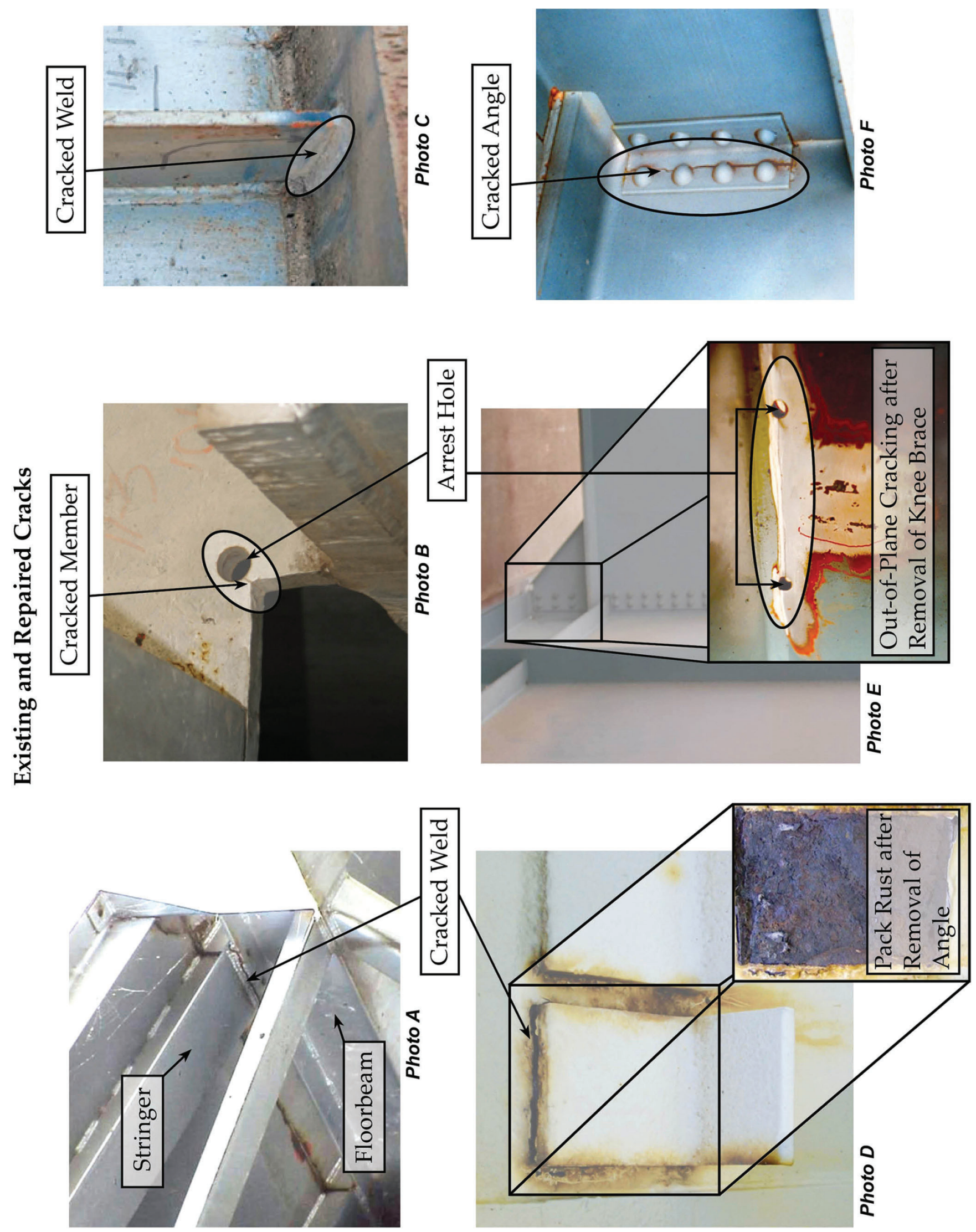


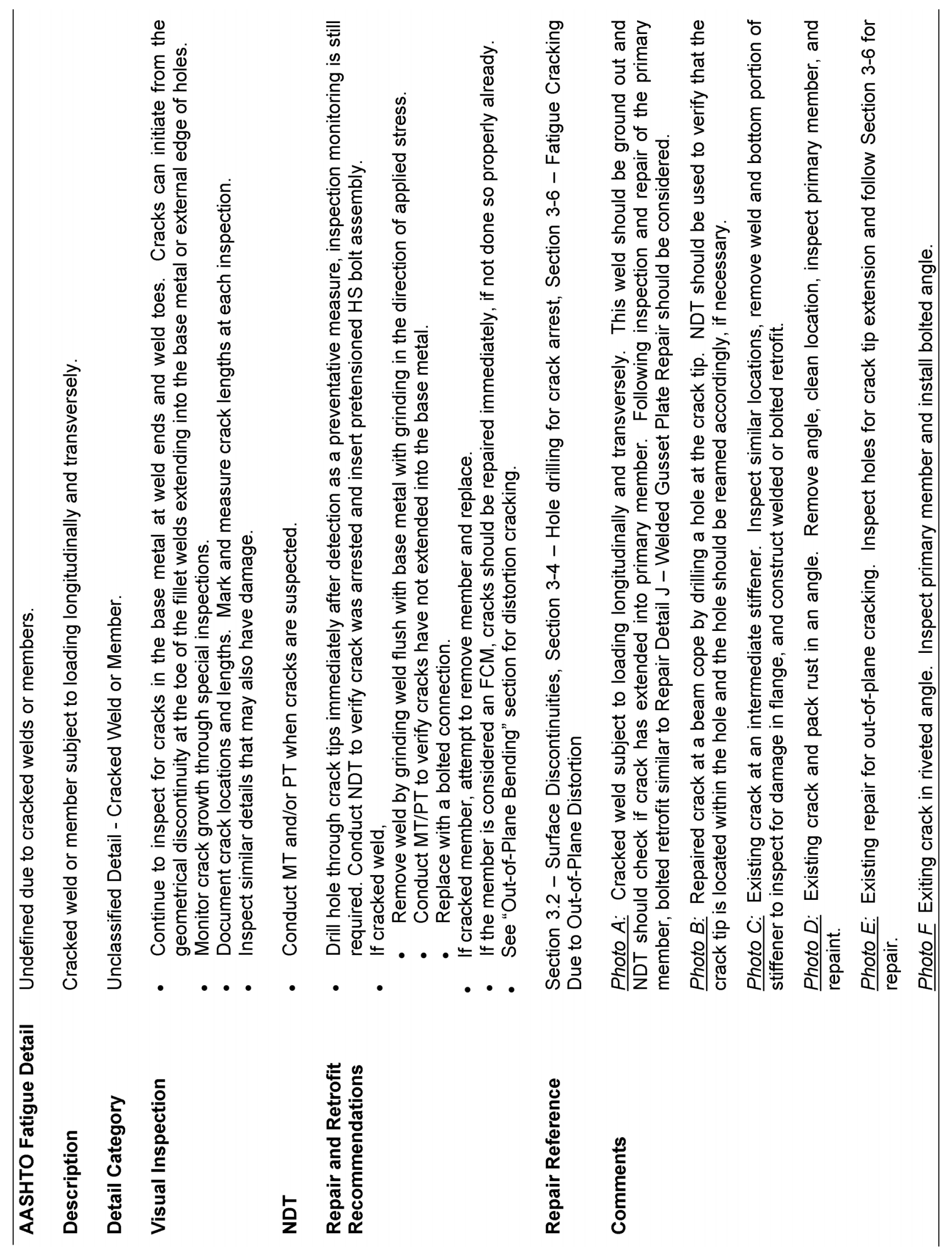




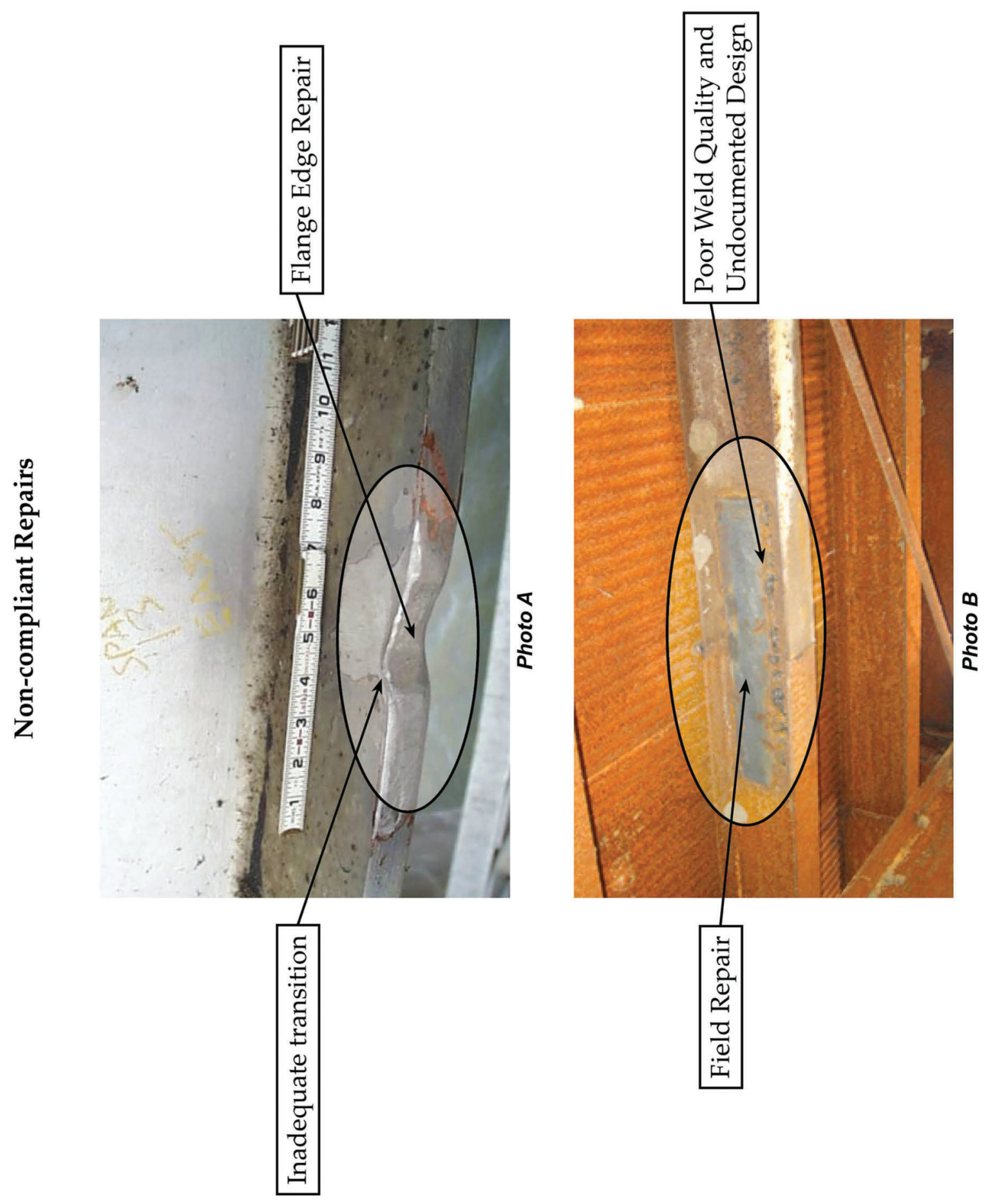




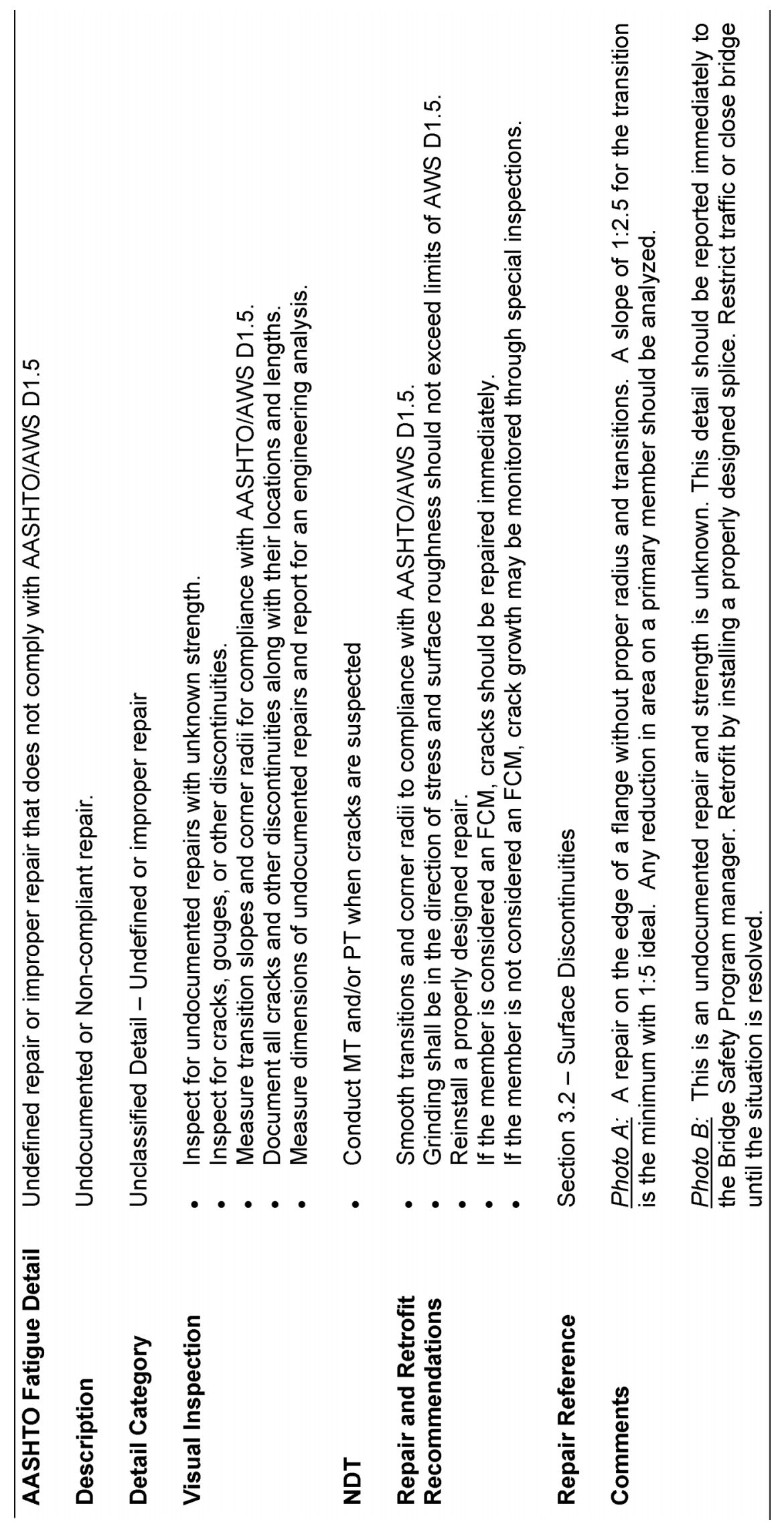




\section{REPAIR AND RETROFIT GUIDANCE}

\subsection{Introduction}

The intent of this document is to provide engineers and inspectors with technical guidance regarding evaluation, repair, and retrofit procedures for nonstandard, noncompliant, or failed details commonly encountered on steel bridge structures. For the purpose of this document, a repair is defined as a maintenance action to correct a localized deficiency and extend the life of an element or component. A retrofit is defined as the replacement of an element or component or modification of a significant portion of an element or component to significantly improve the condition of the element or component.

Each section presents a specific type of discontinuity or detail known to be problematic and discusses procedures available for evaluating the need for repair or retrofit. This is followed by considerations for performing the repair or retrofit. The information presented is based on extensive field experience implementing repair methods as well as the consensus opinion of the latest research into the behavior of the details discussed, especially with respect to fatigue and fracture.

For any weld repairs or welded retrofits on FCMs, the additional requirements of the AASHTO/AWS FCP in Section 12 of D1.5 must be applied. Due to the important consequence of fracture in these members, Section 12 includes additional requirements for weld metal and welding process requirements, increased CVN requirements, fabrication control processes, welder qualifications, and requirements for fabrication inspection.

While this document does not address all possible configurations that could lead to fatigue or fracture damage, it should provide sufficient guidance with respect to some of the general principles of fatigue-resistant design as applied to repairs on in-service structures. Each section of this report ends with a brief set of "Field Directions" that is supplementary to the technical discussion. These could be issued to maintenance personnel to be used as a reference during planning or performance of repair or retrofit work. Please note that the Engineer should review these Field Directions for applicability before issuing to field personnel to insure thoroughness and avoid unnecessary work. Supplemental drawings or field instructions may be necessary in order to fully explain the intent of the repairs for specific circumstances where the required work may go beyond the basic repairs outlined herein.

NotE: Where the term "Engineer" is used in this document with the first " $E$ " capitalized, this is intended to refer to the Engineer of Record responsible for the project.

\subsection{Surface Discontinuities}

\section{A. Introduction}

Surface discontinuities, especially if left unchecked, have the potential to reduce the fatigue or fracture resistance of members in steel structures. A notch or other anomaly related to surface discontinuities creates a stress concentration in the member. In some cases, a seemingly minor surface discontinuity can hide a crack or tear in the member that could grow over time to become a significant issue.

The evaluation techniques and repair procedures presented in this section are intended to generally apply to the following common surface discontinuities in steel structures:

1. Notches

2. Gouges

3. Shallow cracks $\left(3 / 16^{\prime \prime}\right.$ deep or less can generally be considered a "surface" discontinuity)

4. Other (e.g., tack welds-see Section 3.3 for additional discussion of tack welds)

Common causes for such discontinuities after initial fabrication may include impacts to the structure, gouges from lifting chains, flame cutting, flaws from careless welding such as weld spatter, arc strikes, and damage imposed by maintenance operations.

\section{B. Evaluation Techniques}

The primary methodology for identification and evaluation of surface discontinuities is visual inspection. After locating discontinuities that may be of concern to the fatigue resistance of the structure, various nondestructive testing (NDT) techniques can be used to determine the extent of the discontinuities for the purpose of devising a repair. As with all nonstandard, noncompliant, and/or failed details discussed in this document, an understanding of the available evaluation techniques is essential to selecting the appropriate level of NDT to obtain the information needed to design effective repair strategies.

The first step in the evaluation of surface discontinuities is to clearly identify the limits of the discontinuity. For nicks and gouges, this is rather straightforward, and a visual survey is usually adequate. However, the limits of a fatigue crack should be established using dye penetrant testing (PT) or magnetic particle testing (MT) and the ends of the crack should be marked. This is a critical first step which is often overlooked. It is extremely important that the entire crack be removed; despite the fact that crack ends appear to be visually evident, in many cases the actual ends of small cracks cannot be located simply by using visual techniques. Hence, the use of PT or MT is recommended. Ultrasonic testing (UT) may be used to establish the depth of the crack, but should not be the only method used for determining the crack length. If the crack is shallow, MT and PT will likely yield more accurate estimates of the location of the crack tips than UT.

Extensive analysis to determine the need for repair of surface discontinuities can be excessive when compared to the typically straightforward effort required to perform repairs, especially when considering the 3/16" maximum depth criteria used for classification of flaws 
as "surface" discontinuities. In other words, it is often easier to remove a surface discontinuity rather than conduct the level of analysis needed to fully determine the ramifications of leaving the discontinuity in place. Therefore, repair of surface discontinuities is generally recommended for all locations where they are visually apparent and access is not exceptionally difficult. Exceptions may exist where the surface discontinuity is on a member that is not fracture-critical or if it is more cost-effective for the discontinuity to be monitored by NDT to ensure cracking of the member has not developed. An engineering analysis may be justified over a repair if multiple repairs of a similar type are required at details throughout the structure. In most cases the repair consists of simply grinding the discontinuity, as discussed in more detail in the next section.

\section{Repair Considerations for Grinding}

Although grinding can be very effective and easy to perform as a way to eliminate the potential risks associated with surface discontinuities, this repair technique should not be used indiscriminately.

One important consideration is that in order for the retrofit of a surface discontinuity to be effective, the discontinuity must be completely removed. Generally, "shallow" cracks can be removed by grinding a relatively small amount, say between $1 / 8$ and $1 / 4$ inch. Though removing a crack is always better than permitting it remain, in some cases it may be appropriate to perform some type of engineering analysis to confirm that deeper grinding may be permitted. If the "surface" crack being repaired has actually initiated from an internal discontinuity in the member, the crack likely extends deeper than can generally be removed simply by grinding. If the crack cannot be removed by grinding, another repair strategy such as a bolted splice repair detail (engineering analysis would be required) in combination with coring should be considered as removal via grinding may require excessive material to be removed or simply ineffective.

Another important consideration to note is that grinding a crack will often 'smear' metal over the crack, thus giving a false sense that the crack has been removed, although it may remain. To ensure that the crack has been completely removed, NDT methods such as MT or UT as discussed in Section 3-2.b: Evaluation Techniques should be used. PT, though appropriate for initially locating crack ends, may not necessarily work for confirming the location of the crack while repairs are in progress, since the smearing of the metal due to the grinding process can prevent the dye from entering the crack.

In order to ensure the highest quality repair, it is recommended that a multi-step grinding process be utilized progressing from coarse to fine grinding. With little added cost or effort, the quality of the repair can be significantly improved in this manner, even by performing only 2 or 3 increasingly finer levels of abrasive grinding. Beyond improving the chances for a successful repair, high-quality grinding may also make future inspection efforts easier, as it is considerably less difficult to locate a future discontinuity in a very smooth surface.

Once the limits of the discontinuity have been defined via the evaluation methods described in this section, a common die grinder equipped with a stone wheel may be used to perform the rough grinding. Figure 3.1 shows a typical electric die grinder, although air driven pneumatic die or 'pencil' grinders can also be used if available. There are various shaped stone wheels for use in die grinders, some of which are better suited than others for certain access requirements. Grinding for repair of surface discontinuities should be done parallel to the primary direction of the cyclic stress ranges in the member. Care must also be used to ensure that excessive material is not removed during the rough grinding phase. For this reason, carbide burr grinders or burr bits on angle grinders are not recommended, as it may be difficult to control the depth of grinding. If carbide burr bits are used, experienced operators are essential and the depth of grinding should be verified on a similar sample. Additional fine grinding should be performed to meet the surface roughness requirements. Typically, die grinders are used since it allows for the depth of grinding to be controlled. Finished grinding should be performed to $125 \mu \mathrm{m}$ surface finish.

After the rough grinding has been completed, it is recommended that the stone wheel be removed and a sandpaper-type abrasive grinder be used for subsequent stages of material removal. These steps are perhaps best accomplished using a 'flapper' wheel instead of disk grinders. There are many varieties of the "flapper-type" wheels some of which are shown in Figure 3.2.

Grits of 60/80 sandpaper on flapper-type wheels followed by 100/120 and finer, are recommended for steel to attain a shiny, smooth finish, ensuring that all grinding is parallel to the primary cyclic stress range. Once this stage of grinding is complete, the area should be reexamined using MT to ensure the discontinuity has been completely removed. As general guidance, it is recommended that a 101 ratio be used when establishing the limits of the repair with an absolute minimum of 51 where there is inadequate room for the 101 ratio. Hence, ideally the repair of a $3 / 16^{\prime \prime}$ deep discontinuity should be feathered out about $2^{\prime \prime}$ on each side of the
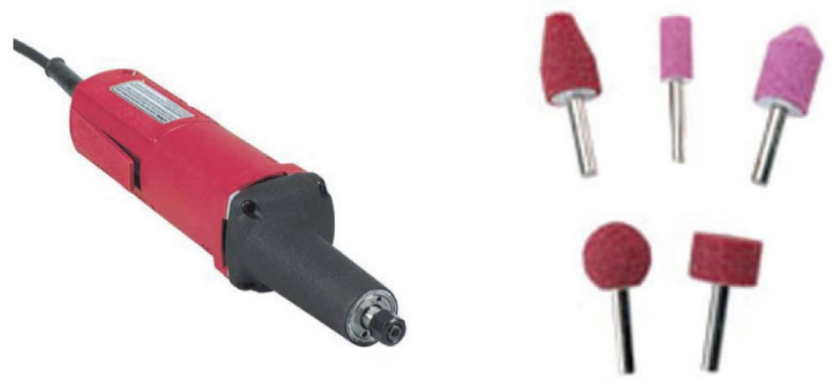

Figure 3.1 Typical die grinder and stone wheels. 


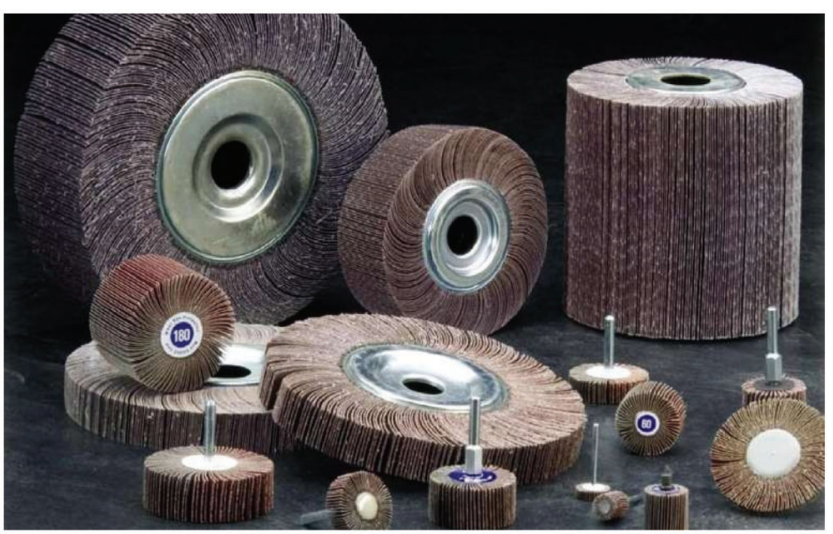

Figure 3.2 Typical flapper-type paper grit sanding/polishing wheels.

discontinuity in order to have a 10:1 ratio. This is required to minimize any stress concentration effects around the repair. All exposed surfaces after completion of grinding should be properly coated with an organic zinc-rich field paint following the repair to protect against corrosion. For uncoated weathering steel bridges, no protective coating is required.

Repair of typical surface discontinuities should not include welding. The use of weld metal to fill in gouges or weld access holes is one example of a widespread "repair" technique used on many structures that can do more harm than good. Adding weld metal in this manner should be performed with extreme caution as it may result in new cracking due to differences in material properties between the new weld metal and the existing member. Insufficient preheat, restraint, and high residual stresses have also been identified as causes which have contributed to cracking at weld repairs. For this reason, grinding is recommended as the preferred repair method for gouges of moderate depth.

A brief set of "Field Directions" for the repair of surface discontinuities, incorporating the considerations outlined herein, is presented in Section 3-2.d: Field Directions for Repair of Surface Discontinuities on the following page.

\section{Field Directions for Repair of Surface Discontinuities}

1. Identify the discontinuity(s) using visual inspection.

2. Mark the limits of the discontinuity (for nicks, gouges, and tack welds) using these methods:

a. Dye penetrant testing (PT) or magnetic particle testing (MT) for cracks.

b. Ultrasonic testing (UT) may be useful to determine depth of discontinuity.

c. Establish limits of repair as approximately 10 times depth of discontinuity.

3. Perform rough grinding with a die grinder; carbide burr grinders are not recommended. a. Always grind parallel to the primary direction of cyclic stresses in the member (consult the Engineer for required direction of grinding).

b. Select appropriate stone wheel for grinder based on access.

c. Take care not to remove excessive amounts of material (see Step 2).

4. Verify the discontinuity is removed using MT or UT.

a. STOP and report damage if discontinuity is still present after removing $3 / 16^{\prime \prime}$ of material.

b. Proceed to fine grinding (Step 5) if discontinuity has been removed.

5. Perform fine grinding with flapper-type sandpaper grinding wheel.

a. Always grind parallel to the primary direction of cyclic stresses in the member.

b. Start with $60 / 80$ grit, then $100 / 120$ grit.

c. Re-examine with MT after grinding.

6. Coat all exposed surfaces with organic zinc-rich paint to protect against corrosion in accordance with written paint application procedures that include surface profile preparation. For uncoated weathering steel bridges, no protective coating is required.

\subsection{Tack Welds}

\section{A. Introduction}

Tack welds are generally defined as very short welds used to temporarily secure pieces in place during fabrication. Ideally, these welds would be placed using the same procedures as the permanent welds, when tack welds are to become part of a final weld. However, the importance of tack welding or rather the potential negative ramifications of tack welds have not always been appreciated in past fabrication practices. Poor quality tack welds incorporated into final weld profiles, or tack welds not covered by final welds, may create situations where repairs are necessary to prevent fatigue damage or mitigate the potential for fracture. Tack welds have also been used to temporarily hold mechanically fastened splice and fill plates together during fabrication and erection. If not removed, they can alter the fatigue category of splices.

The distinction between true tack welds and intermittent welds is pertinent due to the potential demands on a given weld and the expected quality of weld. Unlike tack welds which are used to temporarily hold components together during fabrication, intermittent welds are evenly spaced structural welds used to permanently attach components. Intermittent welds were likely sized during design and inspected during fabrication thus providing a higher quality weld than tack welds, although one must understand that this is not necessarily true for older structures. 


\section{B. Evaluation Techniques}

The need for repairs at tack welds should ideally be established based on an engineering review of available documentation and field conditions, taking into account such items as the following:

- Grade and type of steel - that is, expected toughness, carbon content

- Toughness values for steel grades made prior to 2000 may not be available.

- Information on carbon limits may also not be available.

- Type of member (fracture critical vs. non-fracture critical, tension vs. compression)

- Tack welds on fracture critical members (FCM) should be given priority.

- Tension members should be given priority over compression members.

- Orientation and position of the tack weld

- Generally, tack welds oriented perpendicular to the direction of primary stress range in the main member will be more susceptible to failure.

- Type of weld-tack weld vs. intermittent weld (see discussion, this section)

Although tack welds on steel members are certainly not desirable, in many cases it is acceptable to permit them to remain. Tack welds of good quality and with no cracks may be evaluated for fatigue based upon the requirements of a Category $\mathrm{C}$ detail. This recommendation is based upon the laboratory testing of fatigue resistance of tack welds presented in NCHRP Report 721 (Bowman et al., 2012). Otherwise, the following factors should be considered when establishing if tack welds should be removed:

1. Are the welds actually tack welds or are they intermittent structural welds?

2. Where on the member are the tack welds located with respect to other details?

3. What type of member contains the tack weld? Is it on a fracture critical tension member or on the web of a girder on a multi-girder bridge?

As stated previously, intermittent welds must be distinguished from tack welds. Intermittent welds that are oriented transverse to the primary stress range would not be expected to be of great concern since the stress concentration at the weld toe is similar to the condition at a continuous fillet weld. Figure 3.3 illustrates intermittent welds used to attach a transverse stiffener to the web of a plate girder. Assuming the welds are of reasonable quality (e.g., do not contain crater cracks, undercut, overlap, or porosity), they can be considered an AASHTO Category $\mathrm{C}^{\prime}$ details for the purpose of fatigue life analysis. Since the stiffener in Figure 3.3 is considered a short attachment, the same fatigue category applies had a continuous weld been

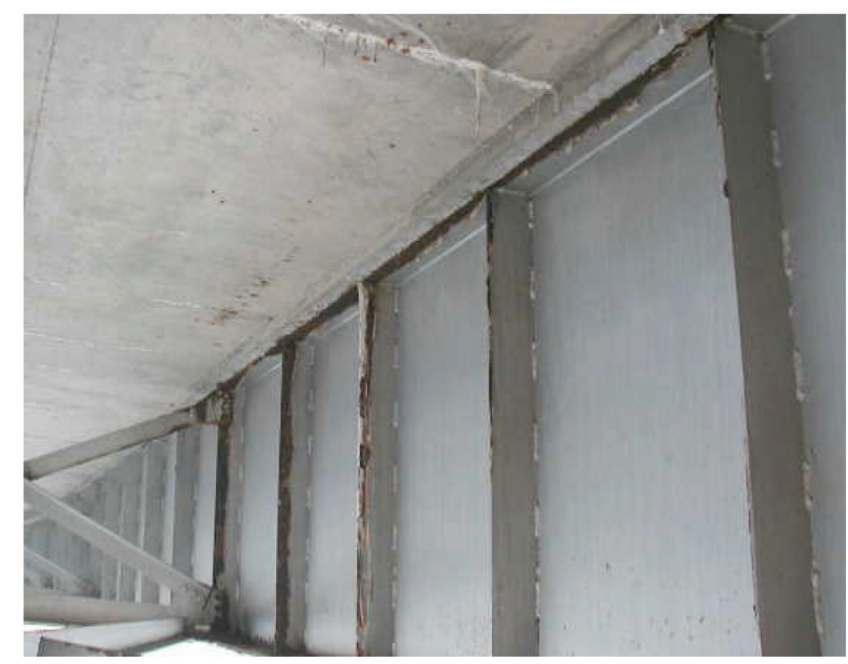

Figure 3.3 Intermittent welds used to attach a transverse stiffener.

used (i.e., Category $\mathrm{C}^{\prime}$ ). Hence, there is no need to remove these intermittent welds for fatigue if the weld quality is acceptable.

Whether or not the intermittent welds were specified and accounted for in the original design of the structure, poor weld quality as characterized by undercut, overlap, and other discontinuities may be present. These discontinuities can lead to poor fatigue/fracture resistance. In evaluating the quality of intermittent welds, one would typically expect to see poorer quality at weld starts and stops, although the entire length of the weld should be evaluated.

Intermittent welds oriented in the longitudinal direction, such as those that are used as for a web-to-flange weld, would generally be of greater concern than welds oriented transverse to primary stresses. The AISC Steel Construction Manual (AISC, 2012) classifies longitudinal intermittent welds as a Category E detail. The intermittent welds in this case are effectively treated like a series of longitudinally loaded welded attachments. Although test data suggest a higher category applies, Category E is specified in the AISC Specifications to discourage the use of intermittent welds in the longitudinal direction. The significant number of weld starts/stops increases the potential for typical discontinuities at the weld termination. One of the most critical situations would be the case of a cover plate welded to a flange. Similar to the case of a continuous weld, the intermittent weld(s) near the end of the cover plate would have reduced fatigue resistance due to shear lag effects making this a critical location for possible toe cracking. Removing the last few welds could be an effective retrofit, but only if a bolted splice is installed at the end of the cover plate to transfer the force between the cover plate and flange ahead of the welds. The welds can be removed by grinding using the processes described previously in Section 3-2.d: Field Directions for Repair of Surface Discontinuities of this document. Grinding should be performed parallel to 


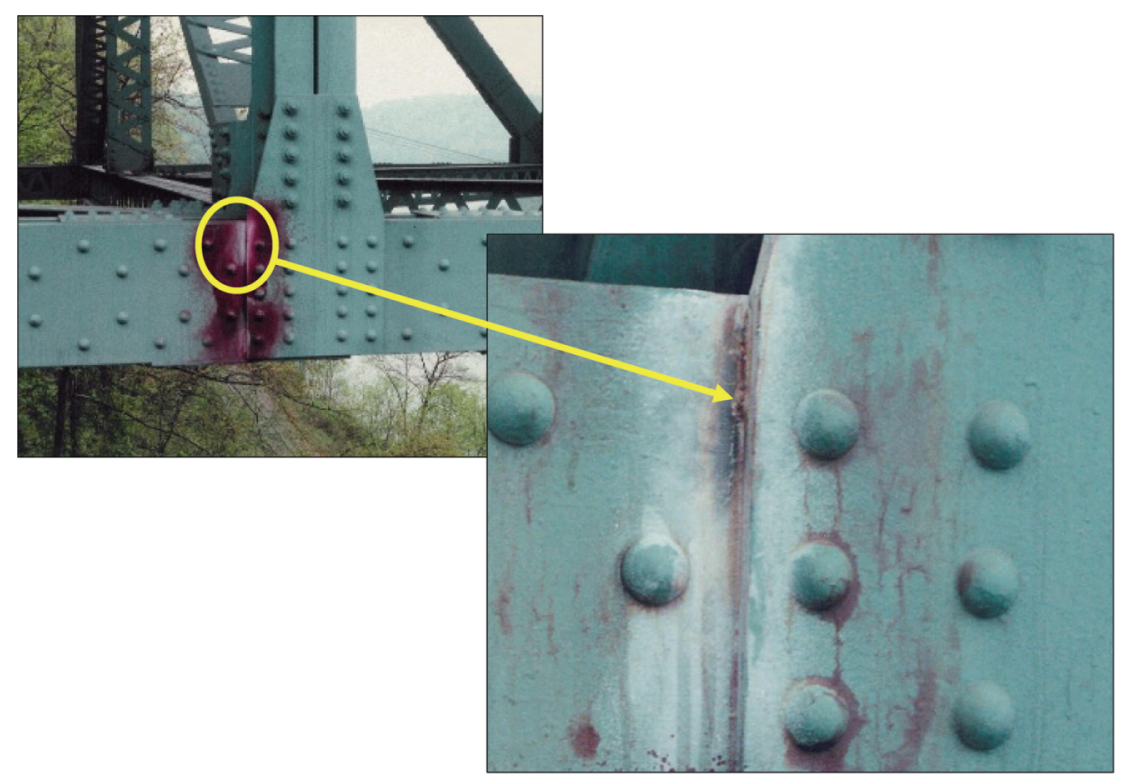

Figure 3.4 Tack weld with $100 \%$ throat crack.

the stress range, and the surface should be finished free of grooves.

True tack welds (i.e., those that were only added to hold components together prior to riveting, bolting, or in some cases, welding) are of the greatest concern to most owners. These welds are generally the lowest quality since in many cases it is apparent that they were not placed with any measurable care and were not sized to carry any specific load. Fortunately, in most cases when cracks occur, the throat of the weld partially or completely cracks and the only possible action to be taken (as time and resources permit) would be to grind the remaining portion off of the base metal.

Examples of complete and partial throat cracks are shown in Figure 3.4 and Figure 3.5, respectively. In cases where the weld is only partially cracked, there is a very slight potential for the crack to grow and eventually turn into the base metal. Hence, it would again be prudent to sever the weld and remove it via grinding from the base metal. Again, the procedures for grinding described in Section 3-2.d: Field Directions for Repair of Surface Discontinuities should be followed.
There generally is no need to remove a tack weld that has completely cracked through the throat. An exception may occur where it is necessary to perform NDT on the base material underneath the cracked weld.

There are documented cases where a fatigue crack initiated at the toe of a tack weld. A classic example is shown in Figure 3.6 where a fatigue crack occurred at the weld toe of a tack weld at the strap plate at a cantilevered floor beam. Although the structure was field riveted, tack welds were used to secure plates together prior to the field riveting. Due to high stress ranges in the strap plate, a fatigue crack developed. Interestingly, it is likely a crack would have developed at any weld toe at this location due to the high stress ranges imposed.

In cases where toe cracking has not occurred, removing the weld by grinding is generally an acceptable retrofit option. If shallow toe cracks have developed, say, less than 3/16", grinding may still be effective, so long as the entire crack is removed. If cracking is more severe, then a more involved retrofit is likely required. In any case, weld toe cracks that have

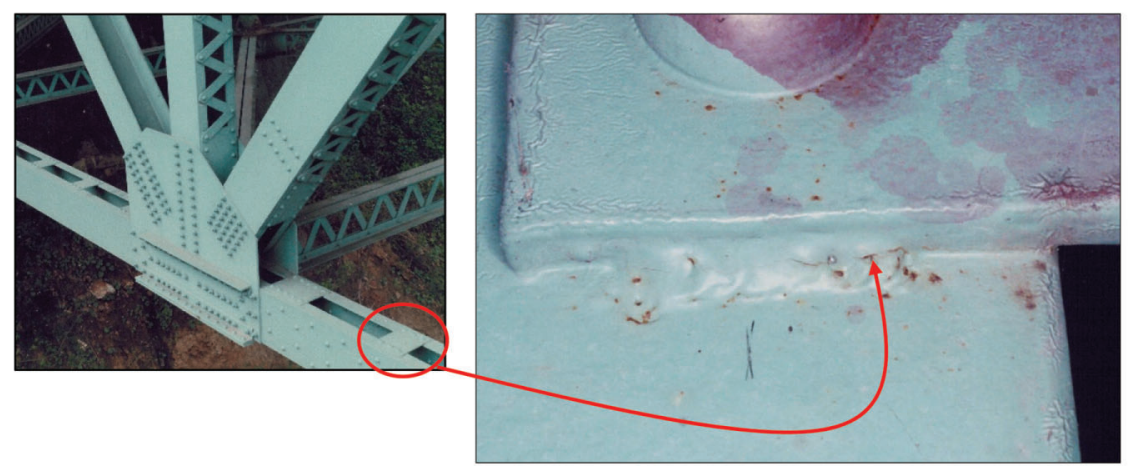

Figure 3.5 Tack weld with partial throat crack. 


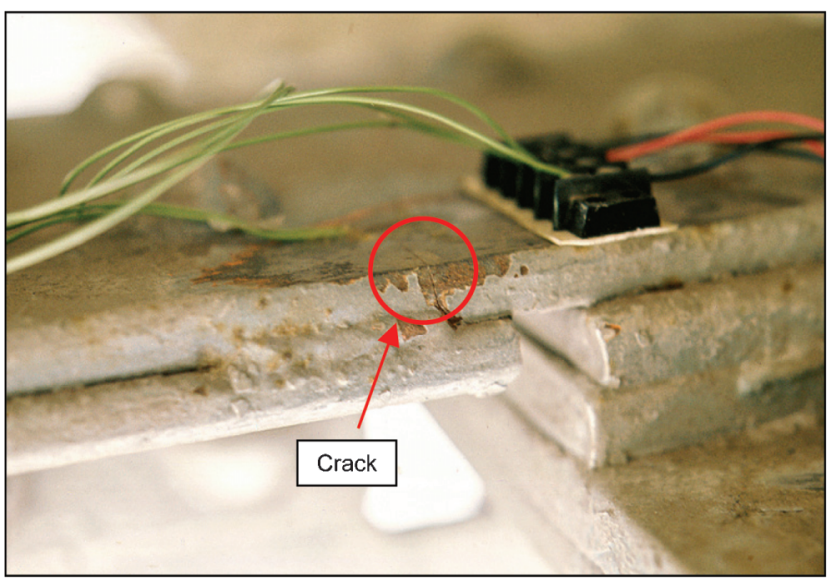

Figure 3.6 Toe crack at tack weld.

extended beyond the tack weld and entered the base metal should be reported to the Engineer prior to initiating any retrofit. In such cases where cracks have already developed from tack welds, NDT can be used to mark the extent of the cracks, as outlined in Section 3-2.b: Evaluation Techniques of this document.

There are also many examples where pack rust has resulted in fracture of tack welds through the throat. Figure 3.7 shows one example of this phenomenon. In such cases, the cracking is entirely due to the forces generated by the pack rust and not cyclic stresses. Hence, there would not appear to be a need to remove the welds from the base metal. The welds could be evaluated as the equivalent AASHTO LRFD Specifications category, depending on their length in the longitudinal direction of the member.

\section{Repair Considerations}

In most cases, tack welds can be effectively removed by grinding. All grinding should be performed in a fashion that is consistent with the procedures described in Section 3-2.d: Field Directions for Repair of Surface Discontinuities. Grinding should be maintained parallel to the stress range, and the surface should be finished without grooves.

"Field Directions" for the repair of tack welds are presented in Section 3.3.d and are based on the nature and extent (or lack) of cracking at the tack welds.

Thousands of structures in service contain thousands of tack welds that are performing very well, with no evidence of fatigue cracking. Such historical performance must be taken into account when attempting to determine if there is actually a need to remove tack welds. Although removal of an individual tack weld is not very difficult, when a structure contains thousands of such welds, the simple scale of the effort can become prohibitive. Thus, in most cases, it is suggested that a thorough evaluation of the need for removal be made. This may include factors already discussed such as loading in the member (i.e., stress range and tension/ compression), type of steel, type of member (is it a FCM?). It is strongly recommended that before tack welds are removed, all these criteria be considered. The most difficult factor to quantify is the in-service stress range. Field instrumentation is recommended as a means to obtain reliable data. It has been shown consistently that calculated stress ranges are greater than those measured under actual field conditions. Thus, when an accurate fatigue analysis is needed, field instrumentation is the most appropriate and often the

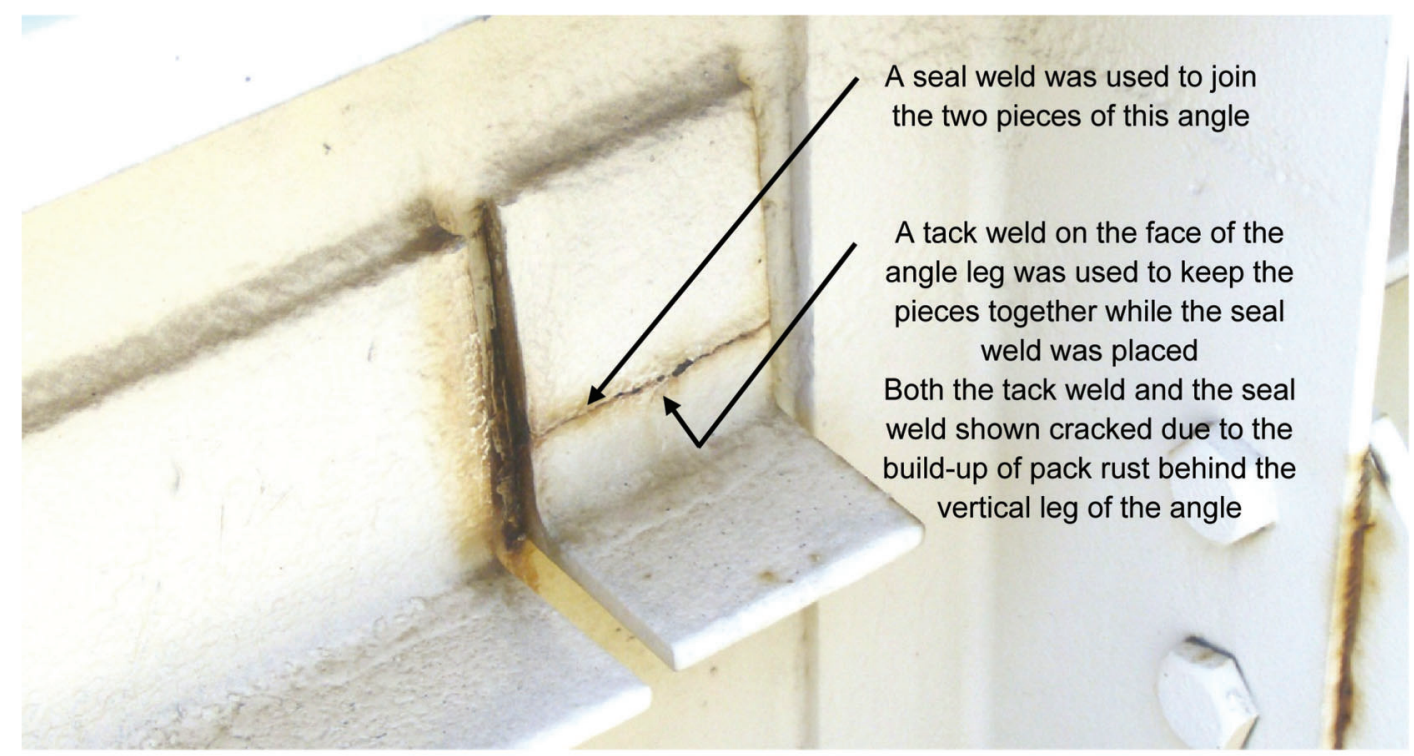

Figure 3.7 Tack weld cracking from pack rust. 
more economical approach used to develop a retrofit strategy.

\section{Field Directions for Repair of Tack Welds}

1. Confirm via documented review by the Engineer, that welds in question are actually tack welds (not intermittent structural welds) and actually require repair.

a. Consider the type of loading in the member.

b. Consider the type of steel used for the member.

c. Consider the redundancy of the member.

d. Consider whether the tack welds have performed well in the structure (i.e., are any cracked?).

e. If it is determined that the tack welds require repair, proceed to Step 2.

2. Determine if throat of tack weld has completely cracked, partially cracked, or remains intact.

a. SPECIAL CASE: If cracking has turned into the base metal, report the conditions to the Engineer for review; do not proceed until a repair has been designed.

b. SPECIAL CASE: If corrosion pack-out has resulted in fracture of tack welds through the throat, there may not be a need to remove the welds from the base metal. Submit any possible instances of this condition to the Engineer for confirmation.

c. If neither of the above two special cases applies, proceed to Step 3.

3. Remove tack welds as appropriate, per the following general guidelines:

a. Where the weld is completely cracked but the crack has not yet turned into the base metal, grind the remaining portions of the tack weld off of the base metal. See Section 3-2.d: Field Directions for Repair of Surface. Discontinuities of for detailed grinding instructions. (Note that the flapper wheel will not work in this application, instead a square-cornered stone wheel may be used to remove the tack weld with the flapper wheel used to finish the surface).

b. In cases where the weld is only partially cracked or toe cracking has not yet occurred, remove the weld from the base metal via grinding.

\subsection{Hole-Drilling for Crack Arrest}

\section{A. Introduction}

The use of drilled holes to arrest or even prevent fatigue cracking has been an economical and effective retrofit strategy that has been around for years. The hole essentially isolates a detail (see Figure 3.8) or can be used to intercept potential cracks before they can propagate further. The basic concept behind holedrilling is to remove the crack tip and thus blunt the sharp condition otherwise present. Theoretically, the stress concentration at a sharp crack tip is infinite. Introducing a radius at the crack tip greatly reduces the

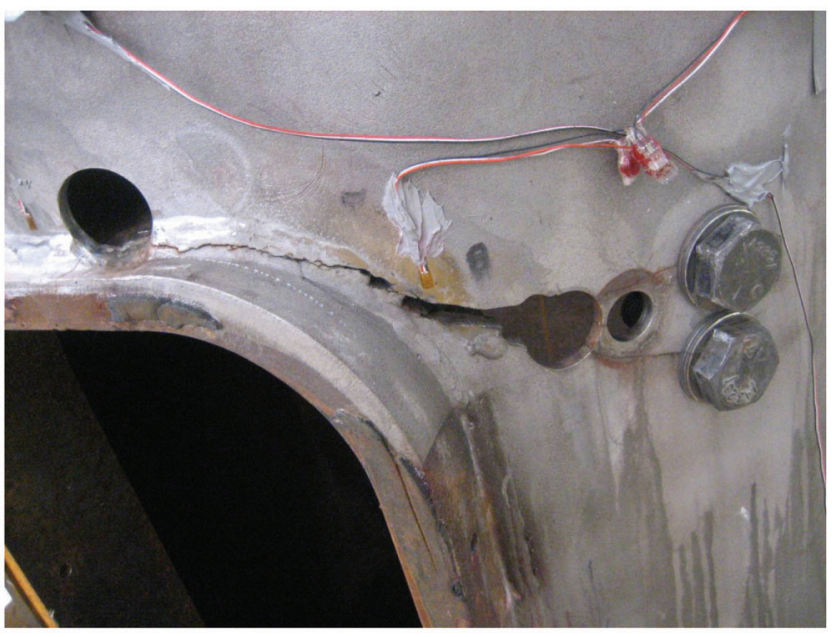

Figure 3.8 Crack arrest holes installed in a high-mast lighting tower.

stress concentration and retards the potential for fatigue crack growth. Hence any technique that blunts the crack tip would improve the stress condition driving the crack.

In this figure, high strength bolts have been installed in two of the holes. An open hole, without edge improvement, is conservatively considered a Category D detail in AASHTO. Installation of a fully pretensioned high strength bolt improves the hole to Category B. The inside of the 2 inch diameter hole was polished with a flapper wheel to improve the fatigue resistance since a bolt could not be installed due to clearance issues. Holedrilling has been shown to be effective for both in-plane (i.e., cracks due to primary stresses) and out-of-plane (i.e., cracks due to secondary stresses) fatigue cracks. Although often thought of as a temporary retrofit, in many cases, hole-drilling serves as an effective long-term retrofit strategy. This is particularly true where cracking due to out-of-plane distortion has been observed. However, in cases where the out-of-plane distortions are high, fatigue cracks often re-initiate either at the hole or some other location near the detail. The use of high strength bolts may also be less effective when the cause is out-of-plane distortion.

\section{B. Evaluation Techniques}

Evaluation techniques to be considered in preparation for an attempt at crack repair/mitigation by holedrilling should focus on accurately locating the extent of the crack. For hole-drilling repairs to be effective, the holes should be placed so as to blunt the tip of the crack and thus remove the high-stress concentration associated with the sharp tip. NDT techniques should be incorporated prior to repairs in order to ensure that the hole removes the entire crack tip. Any portion of the crack tip not removed by the hole will enable further crack propagation. To this end, dye penetrant and magnetic particle testing can be used to locate the crack tip in much the same manner as described in Section 3-2.d: Field 
Directions for Repair of Surface Discontinuities of this report. It is difficult to accurately locate crack tips with simple visual techniques, and it is common for cracks to tunnel and be longer internally compared to the surface. It is usually prudent to place the arrest hole ahead of where the crack tip is identified. As a rule-of-thumb, placing the edge of the hole at the identified crack tip and drilling ahead of the crack provides high insurance that the crack tip has been removed. While it may seem that this is increasing damage in the structure, a longer crack with radius tips is usually preferable to missing the crack tip. This will serve to ensure that the crack will grow into the hole and be captured if it is not encompassed by the hole.

\section{Repair Considerations}

A review of the literature reveals that many different sizes of holes have been used to arrest cracks in the field with varying levels of success. To be successful in arresting the crack, the absolute minimum hole diameter to consider is 1 inch. Larger holes further reduce stress concentrations around the hole edge and provide more resistance to new crack initiation from the hole edge. Therefore, based on experience, a hole diameter of $2 \mathrm{in.}$ to $4 \mathrm{in}$. is recommended, as it has been shown to be more consistently effective. The larger hole diameters also allow internal access to grind and smooth the hole edge. When a more refined estimate of the required hole size is necessary, relationships have been developed to define the size of the hole needed to arrest the crack (Fisher, Barthelemy, Mertz, \& Edinger, 1980; Dexter, Fitzpatrick, \& St. Peter, 2003). Obviously, appropriate checks on the net section capacity of the member should be made prior to drilling any holes.

In the field, holes are typically installed by drilling. Drilling can be followed by reaming to improve the edge condition of the hole. Assuming new drill bits and/ or reamers are used, the fatigue resistance is generally higher than Category D and it is appropriate to use Category $\mathrm{C}$ for fatigue life analysis. For this reason, only new drill bits or drilled and reamed holes should be used. Additionally, the inside surface of the hole should be ground smooth after drilling or reaming, preferably with a flapper wheel. Sharp edges should be chamfered or deburred. In cases where the hole is being used as an out-of-plane distortion retrofit, a bolt should not be placed in the hole as it will have a tendency to stiffen the plate, which will reduce the effectiveness of the retrofit.

A hole by itself can conservatively be considered a Category D detail, which may be acceptable depending on the expected stress ranges and number of cycles at the hole location. By properly tensioning a highstrength bolt in the hole it can be improved to a Category B detail, an example of which is shown in Figure 3.8 on the previous page. The need for a highstrength bolt in holes drilled for crack arrest repairs should be determined by the Engineer's review of the project-specific conditions.
A brief set of "Field Directions" for the repair of surface discontinuities, incorporating the considerations outlined herein, is presented in Section 3-6.b.

\section{Field Directions for Repair of Cracks Using Hole-Drilling}

1. Locate the crack tips via Dye Penetrant Testing (PT) or Magnetic Particle Testing (MT). Refer to discussion in Section 3-2.b: Evaluation Techniques and field directions in Section 3-2.d: Field Directions for Repair of Surface Discontinuities for additional details.

2. Using a magnetic based drill with a carbide-tipped broach drill bit as shown in Figure 3.9, drill a hole in the steel material 2 to 4 inches in diameter that extends beyond the crack tip. The hole size and location shall be determined by the Engineer. The inside surface of the hole should be ground smooth, preferably with a flapper wheel and the edges should be deburred.

3. If directed by the Engineer, properly tension a highstrength bolt in the hole. Refer to the Research Council on Structural Connections (RCSC) Specification for Structural Joints Using ASTM A325 or A490 Bolts (RCSC, 2009) for detailed procedures regarding bolt tensioning. Typically, turn-of-the-nut tensioning procedures are used, but since these bolts are not part of a structural connection, bolt calibration including rotational capacity testing and pre-installation verification will not be necessary. The latest edition of the Structural Bolting Handbook published by the Steel Structures Technology Center is a useful field reference as well.

\subsection{Weld Toe Improvement Techniques}

\section{A. Introduction}

The intersection of weld metal and base metal in a typical fillet weld is commonly referred to as the weld toe. High tensile residual stresses at or near the yield strength are an inherent condition at weld toes due to the differential shrinkage which occurs as the weld cools. When cracks occur, they commonly originate at the weld toe in the heat affected zone or base metal, and

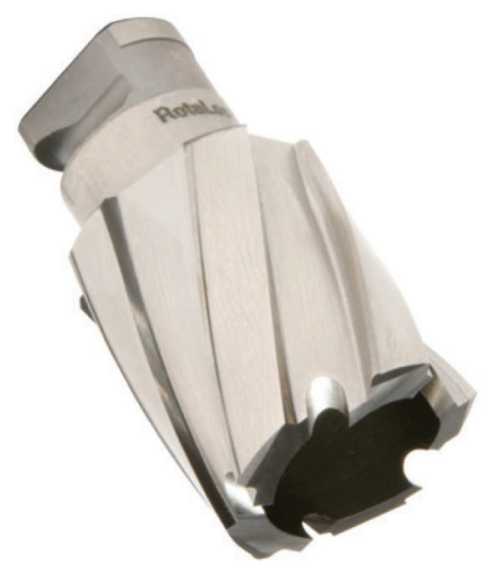

Figure 3.9 Typical broach drill bit. 
initiation is highly influenced by these residual tensile stresses. Weld toe fatigue cracks are further encouraged by any number of common weld discontinuities such as undercut and cold laps, or by sharp crack-like imperfections, just a few tenths of a millimeter deep, which are an inherent feature of most arc welds.

In some industries, the weld toe profile is machined as part of the fabrication process after the weld is placed, in order to relieve residual stress and reduce the geometric stress concentration at the detail. In large-scale civil engineering applications, such as bridge girders, such techniques are generally cost-prohibitive. On a more local application, such as at a particular weld toe in a region that the designer knows will be subject to relatively high stress ranges, simple surface grinding of the welds after placement can result in increased fatigue resistance by improving the weld geometry. More advanced methods of weld toe improvement have also been developed, such as peening and ultrasonic impact treatment (UIT). GTAW toe dressing has also been used effectively but it requires a high level of quality control. (Gregory, Slater, \& Woodley, 1989; Fisher, Hausammann, Sullivan, \& Pense, 1979) Stress relieving, a process where the weldment is heated and held at high temperature for some duration, can be useful to reduce residual stresses in some cases. In summary, one or more of the methods below are typically used to improve fatigue resistance at weld toes:

- For repair welding, the weld procedure should be optimized to provide a good bead profile and minimize the potential for weld defects through preheat and controlled cooling. Automatic and semi-automatic welding processes have been shown to produce more consistent weld quality and higher fatigue resistance.

- Mechanical improvement of the weld toe profile to reduce the geometric stress concentration and remove small surface discontinuities. This is usually performed by surface grinding, but peening can also have some benefit.

- Residual stress reduction at the weld toe to reduce the driving force for crack initiation. This can be accomplished by mechanical peening methods, UIT, or stress relief heating.

It has long been known that any of the above-listed post-weld improvement techniques, when properly executed, can effectively raise the fatigue resistance of a given detail. Grinding produces a smooth transition between the weld and the base metal, thereby reducing stress concentrations. According to the International Institute of Welding, grinding can result in increases in the fatigue resistance as high as $30 \%$ (Hobbacher, 2007). This is the high end of the range of possible improvement. To be conservative, an estimated improvement of only $10 \%$ to $15 \%$ should be anticipated, especially for weld toe improvement techniques executed in the field as opposed to a shop environment. The use of UIT or other peening methods for increasing fatigue resistance can produce even more dramatic results, although the effectiveness may vary widely from one application to the next.

\section{B. Evaluation Techniques}

A proactive approach to the evaluation of existing structures for possible locations where weld toe improvement techniques could be beneficial would involve identifying those details that are most susceptible to fatigue cracking, such as transverse stiffeners and connection plates, cover plates, gusset plates, and other welded attachments believed to exhibit to lower serviceability limit states. Details with AASHTO LRFD Specifications Fatigue Categories C, D, E or E' are good candidates for weld toe improvement techniques.

In the past, consideration of weld toe improvement techniques was mostly a reactive measure after one or more cracks had already developed. Increased awareness of the underlying causes of weld toe cracking has led to a more proactive approach to implementing weld toe improvement measures at details now known to be susceptible to poor fatigue performance. However, the decision to implement any retrofit strategy should be based on engineering data. For example, it is well documented that fatigue life predictions that rely upon simple calculations are very conservative and it is not uncommon to obtain negative fatigue lives, although no cracks have been observed. In such cases, rather than performing costly retrofits, it may be more cost effective to accurately estimate in-service stress ranges using field instrumentation. As always, the cost of the instrumentation vs. implementation of the retrofit needs to be compared. Even if proactive measures are not initially taken, the extent of any existing cracking observed should be documented, and some engineering judgment should be made as to the likelihood of additional cracking appearing at similar details. Perhaps the most important step in the repair process is this evaluation stage to define the scope of weld toe improvement work. Again, the AASHTO Fatigue Categories are a useful means of comparing different details for their relative susceptibility to fatigue-induced crack initiation.

Once the limits of weld toe improvement work have been delineated, selection of the appropriate weld toe improvement technique should include considerations of the cost of performing various procedures. As previously noted, available weld toe improvement techniques include grinding, mechanical peening, and UIT. Mechanical peening efforts in particular are problematic for field repairs as they can be time-consuming and difficult to perform in areas with limited or difficult access for the equipment required. Common peening processes also require a steady, experienced hand to perform properly, as the laborer will likely be working against significant vibrations from the equipment and loud noise and their effectiveness is highly user dependent.

Grinding is a commonly selected repair method, as it does not require a high level of special equipment or training to execute, and the equipment is readily available. It is important to note that in some instances, internal discontinuities will be revealed once grinding begins. Since there is a chance that these discontinuities 
may subsequently propagate in fatigue, all embedded imperfections revealed by grinding to improve the weld toe must be repaired following the appropriate methods as outlined in this document or other resources. Often, internal discontinuities can simply be ground out, but in some cases, more substantial repairs may be necessary such as removal of the detail or installation of a mechanical splice.

For a more controlled repair process, UIT offers some advantages over other available methods. Operating at a higher frequency (typically about $27 \mathrm{kHz}$ ), noise and vibration are greatly reduced in comparison to mechanical peening tools. UIT tools vary by manufacturer but are typically handheld devices. Training requirements for UIT tools are minimal. Another attractive feature is that UIT tool heads and tips can be switched out as needed, depending on project conditions. Tool and attachment selection should be coordinated with the equipment manufacturer in order to optimize performance. UIT generally produces a more uniform finished profile than grinding.

Costs are typically lower for UIT compared to conventional retrofits, such as adding a bolted cover plate extension at the end of the welded cover plate. The length of weld that should be treated with UIT will vary from case to case; extensive research has been done on effectiveness of UIT that may help to guide the Engineer. UIT has been shown to be an effective technique for improving the fatigue strength of a wide variety of details, such as improving the fatigue performance of Category $\mathrm{E}^{\prime}$ cover plate weld details to a fatigue strength performance closer to Category $\mathrm{C}$. Category $\mathrm{C}$ transverse stiffener details have also been improved via this technique to perform at the level of Category B or better for fatigue resistance (Fisher et al., 2001).

Most of the research on the effectiveness of weld toe improvement techniques has focused on welds adjacent to base metal with a tensile stress range. The value of these techniques has not been evaluated for details where the loading causes shear in partial penetration or fillet welds. Therefore, it must be accepted that any use of weld toe improvement for shear loads should be considered experimental in nature. Further, the effectiveness of UIT for treating out-of-plane distortion cracking at transverse connection plates has not been thoroughly evaluated and may be impractical to limited access within the web gap (i.e., it may not be possible to actually treat the weld toe within the gap where stress ranges are the greatest).

\section{Repair Considerations}

A sample peening detail from actual repair documents is reproduced (with some project-specific notes deleted) in Figure 3.10. As shown in the figure, only the base metal adjacent to the weld toe is affected by the UIT treatment. Care should be taken to ensure that the weld material is in fact peened the full desired length, as peening base metal alone will not have the intended effect. This may be difficult since weld metal is typically stronger than base metal and the tool may favor the lower strength material.

Note that after UIT work is completed, its effectiveness cannot fully be judged by visual inspection alone, although successful peening will leave a characteristic bright metal finish along the weld toe. To establish performance criteria for completed repairs beyond visual inspection, a series of trials should be performed on sample plates with weld sizes representative of actual project conditions. These trials can serve as a means to determine appropriate tool settings, ideally in coordination with the equipment manufacturer. As time and resources permit, fatigue testing can be conducted on sample plates to ascertain a quantitative measure of fatigue performance improvement.

Section 3-5.d "Weld Toe Improvement By Ultrasonic Impact Treatment (UIT)," beginning on the following page, reproduces, with minor format modifications, the sample UIT procedure outlined in the AASHTO LRFD Bridge Construction Specifications, 3rd Edition. Note that equipment manufacturers may have
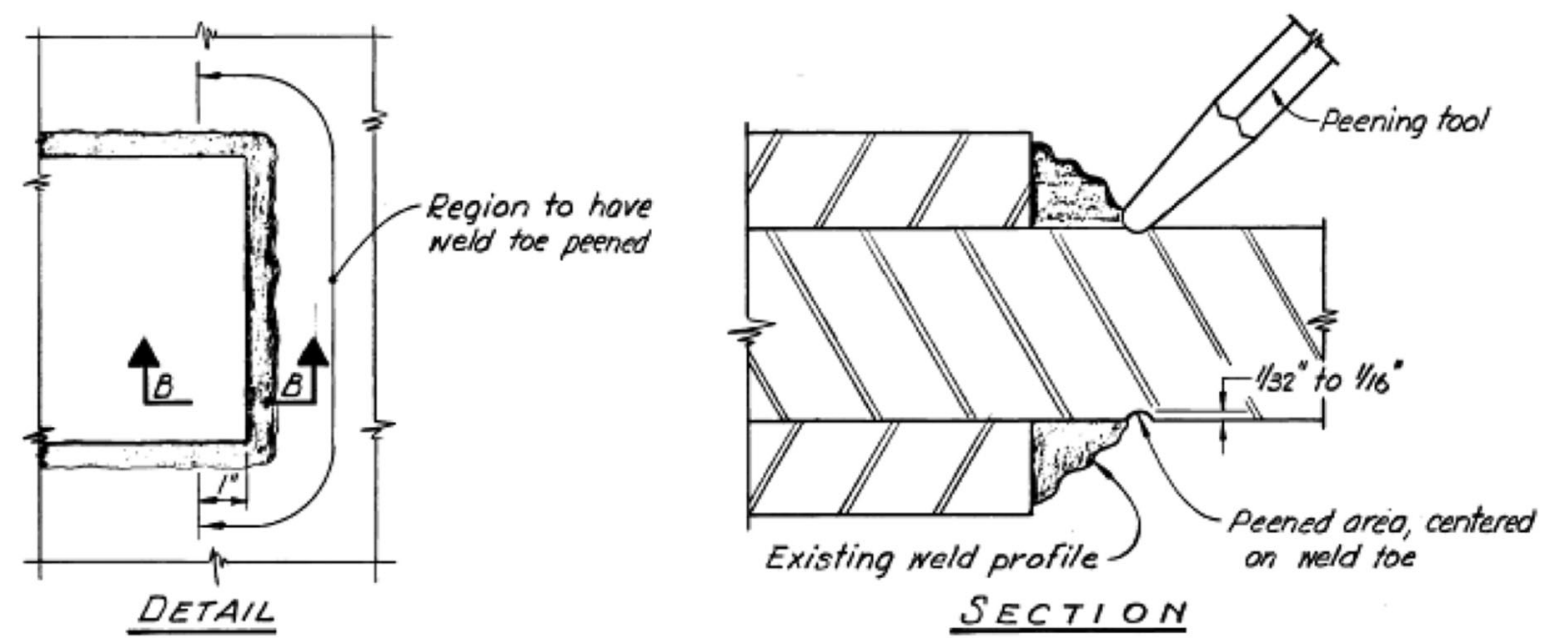

Figure 3.10 Sample peening detail (detail courtesy of Oregon Department of Transportation). 
special requirements that supersede the general requirements. AASHTO recommends removing existing paint and performing magnetic particle testing (MT) prior to UIT work in order to locate any discontinuities in the weld that may require repair beyond UIT. AASHTO also recommends centering the tip of the UIT tool at the weld toe, as shown in Figure 3.10. Further commentary on grinding as a possible alternative to UIT is included as Section 3-5.d "Weld Toe Improvement by Grinding".

\section{Field Directions for Weld Toe Improvements}

As a precursor to weld toe improvement work, remove paint or other finishes by surface grinding or other means approved by the Engineer. The length of weld to undergo the weld toe improvement processes shall be dictated by the Engineer. After removal of paint, perform MT to verify that the welds are not cracked and do not contain discontinuities greater than $1 / 32^{\prime \prime}$ in size. Report any issues identified by MT to the Engineer. If no issues are noted, for weld toe improvement by UIT (recommended where possible), proceed via Section 35.d "Weld Toe Improvement by Ultrasonic Impact Treatment (UIT)" below. For directions on grinding, see Section 3-5.d "Weld Toe Improvement By Grinding."

Weld toe improvement by Ultrasonic Impact Treatment (UIT). The following instructions for UIT have been adapted from the AASHTO LRFD Bridge Construction Specifications, 3rd Edition with:

1. Position the UIT tool tip at the weld toe in a manner that both the weld metal and base metal are equally treated. This will normally be achieved by holding the tool needles in contact with, and centered about, the weld toe and gently rocking the tool back and forth normal to the longitudinal weld axis up to $10^{\circ}$ from the mean position. The inclination of the tool will depend on the condition of the as-welded toe, and in most cases the tool axis should be oriented between $40^{\circ}$ and $80^{\circ}$ with respect to the base metal surface in the plane of the cross section to satisfy this requirement.

2. Sufficient force must be applied to keep the hand-held tool in position and to prevent jumping or unsteady movement when the vibrating needles come in contact with the weld toe. The self-weight of the tool is sufficient for this purpose and it is not necessary for the operator to exert undue force to achieve the required treatment.

3. The treatment shall progress at a travel speed of 1.0 to $5.0 \mathrm{ft} / \mathrm{min}(0.3$ to $1.5 \mathrm{~m} / \mathrm{min})$ in multiple short passes. At least five passes shall be made to ensure completeness of the treatment. In addition, the tool axis must be maintained at $90^{\circ}$ with the direction of travel.

4. The diameter of the indenters influences the resulting appearance of the treated surface. In general, the smaller the diameter, the greater is the likelihood of eliminating the original weld toe. Thus, the treatment at the weld toe shall be carried out using 0.12 in. $(3 \mathrm{~mm})$ diameter pins. Pin holders accommodating four pins at various inclinations are generally used, except at narrow re-entrant corners, where a special pin holder having only one 0.2 in. $(5 \mathrm{~mm})$ diameter pin must be used.
5. The treatment shall result in a uniform groove appearance without a trace of the original weld toe and shall be free from indentation marks produced by individual needle to toe impact. All sharp transitions, undercuts, and re-entrant corners along the weld toe shall be removed. The groove shall have a bright metallic surface and ideally have a notch radius of $0.12 \mathrm{in} .(3 \mathrm{~mm})$ or greater. Dimensional limits have been recommended by the Manufacturer on the width and depth of the groove cross section, which are essentially related to the groove radius. Since it is difficult to make any accurate measurement of the treated toe, a visual determination of the depth of indentation below the plate surface of 0.010 to 0.020 in $(0.25$ to $0.5 \mathrm{~mm})$ is recommended as a guide, but not as a requirement of sufficient treatment.

6. The extent of treatment and general uniformity of appearance must be checked visually with the aid of a $10 \times$ magnifying glass.

7. Clean and paint all exposed steel surfaces after completion of weld toe improvement work.

Note: Once UIT work has been completed, it is not recommended to execute other weld or base metal treatments, such as heat treatment of the treated UIT. Such treatments may relieve the induced compressive residual stresses imposed by the UIT process.

\section{Weld toe improvement by grinding}

- As an alternative to Section 3-5.d "Weld Toe Improvement by Ultrasonic Impact Treatment (UIT)" where access or equipment availability prevents the use of UIT, or where otherwise directed by the Engineer, repair crews may use a grinder to modify the weld toe profile. Weld improvement by grinding is an accepted method of improving fatigue performance of weld toes. The effect on the fatigue resistance of various details is discussed in International Institute of Welding (IIW) document XIII2151-07/XV-1254-07 (Hobbacher, 2007). Grinding only needs to be deep enough to improve the weld toe transition and excessive grinding is not needed. To achieve the desired improvement, no more than $1 / 16^{\prime \prime}$ of material should need to be removed.

- MT should still be conducted before grinding in order to detect flaws that would require repairs and after grinding to ensure that the flaws have been removed. For weld toe improvement by grinding, all equipment settings should be verified on test strips prior to execution in the field in order to determine an appropriate combination of grinding wheels, speeds, orientation, etc. Depth of grinding should be limited to 1/32" or 1/16". See Section 3-2.d: Field Directions for Repair of Surface Discontinuities for additional considerations with respect to grinding.

\subsection{Fatigue Cracking Due to Out-of-Plane Distortion}

\section{A. Introduction}

Out-of-plane distortions across a small web gap are by far the most common known cause of cracking in existing bridge structures. In fact, it is estimated that $90 \%$ of all fatigue cracks observed in steel bridges in the United States are the result of out-of-plane distortion 


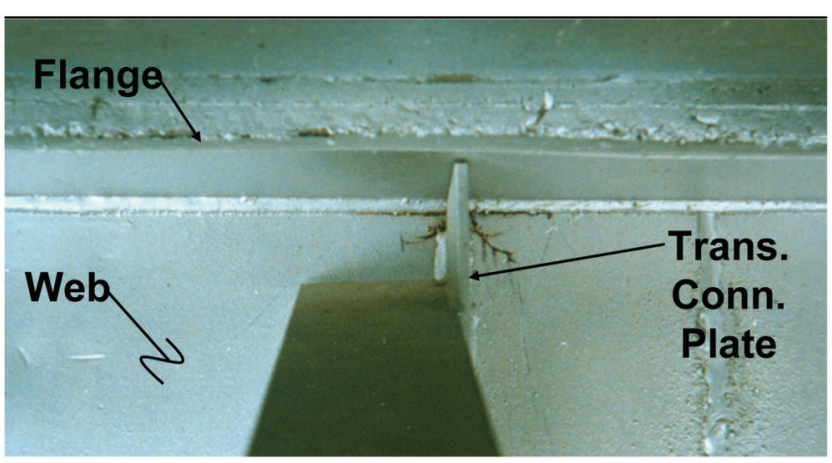

Figure 3.11 Web gap cracking at a diaphragm connection plate.

or other secondary effects (Connor \& Fisher, 2006). Welded details on girder webs have proven themselves to be problematic in a number of configurations (see Figure 3.11 for one typical example). Predominant detailing philosophy prior to the early to mid-1980s included a strong desire to avoid welding transverse stiffeners and connection plates to the tension flange of bridge girders. As a result, a positive rigid connection between girder flange elements and web-mounted stiffeners and connection plates were generally not provided.

Cracking from out-of-plane distortions usually initiates in a plane parallel to the primary loading stress range. As a result, such cracks have typically not been particularly detrimental to the performance of the structure, providing they were discovered and retrofitted before turning perpendicular to the applied primary stress range (i.e., turning up or down and entering the flanges). In some structures, cracks from out-of-plane distortion have arrested in low stress areas and thus have served to relieve local restraint conditions. However, in a number of bridges, cracks have formed at gusset plate web gaps, with cracks oriented perpendicular (i.e., vertically) to the applied stresses. In this scenario, the cracks are more susceptible to fatigue crack extension from applied live loads in locations which experience tensile loading.

The AASHTO LRFD Specifications (AASHTO, 2012) do not explicitly classify details susceptible to out-of-plane distortion. Rather, prescriptive rules are provided for designers as a way to prevent configurations that are known to initiate such cracking. For example, the left side of Figure 3.12 shows some of the detailing recommendations that may apply for a transverse connection plate. The right side of Figure 3.12 illustrates recommended detailing at the intersection of a gusset plate, transverse stiffener or transverse connection plate, and web in a plate girder. Transverse and longitudinal connection plates are now required by the AASHTO LRFD Design Specifications to be rigidly attached to all components of a plate girder (i.e., attached to the web and flange, or web and transverse stiffener) to prevent relative movement between elements.

While web gap cracking represents a localized fatigue problem, global incompatibilities between elements, such as the deck system and the supporting elements, have also been known to lead to fatigue problems
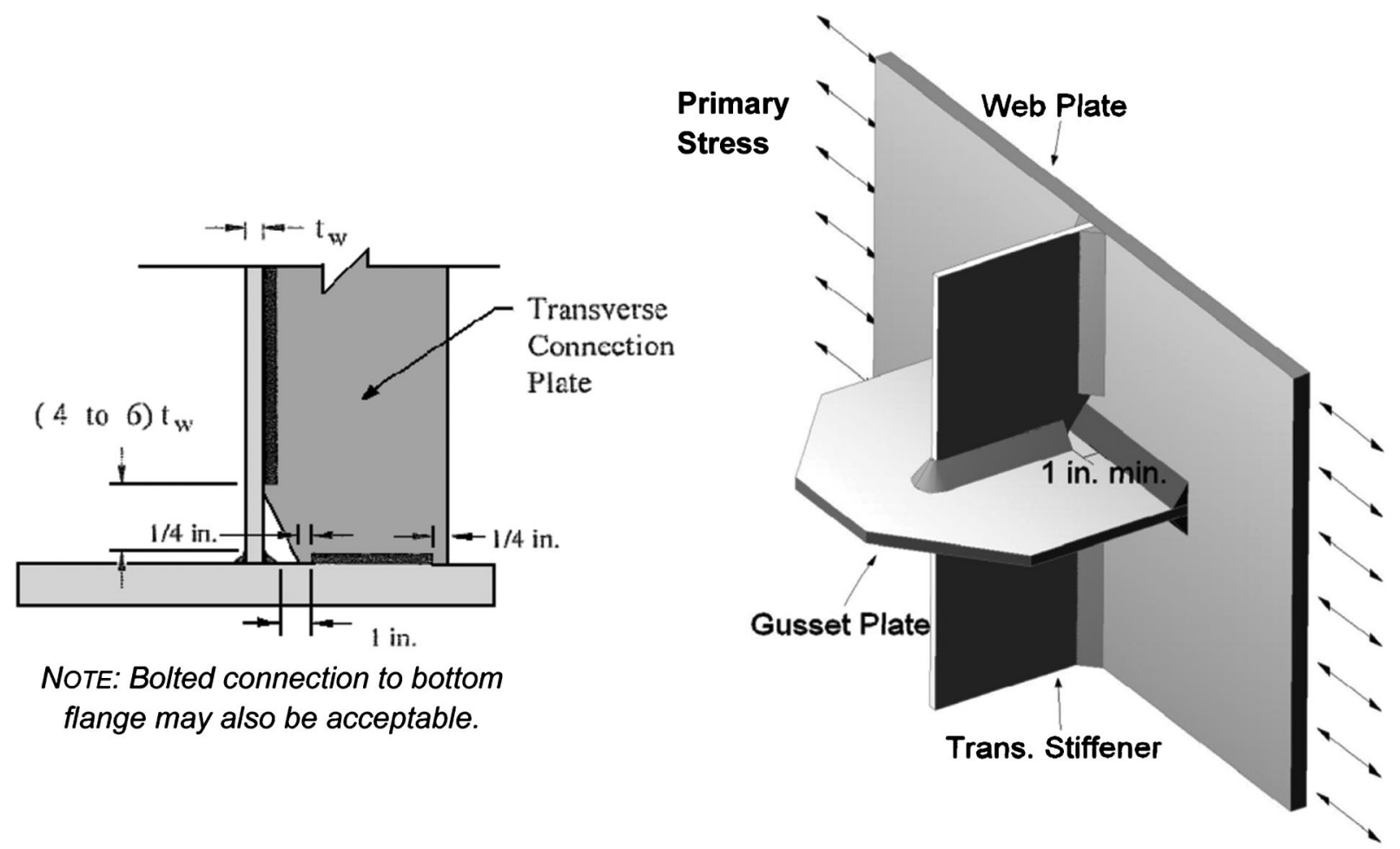

Figure 3.12 Detailing considerations to prevent web gap cracking (left) at transverse connection plate; (right) at gusset plate. 
(Barth \& Bowman, 2001; Connor, Hodgson, Mahmoud, \& Bowman, 2005; Mahmoud et al., 2005; Fisher, 1984). Although the modern bridge design specifications attempt to address these problems through improved detailing, there are many older bridges still in service today that in theory are susceptible to such cracking.

\section{B. Evaluation Techniques}

As stated, the AASHTO LRFD Specifications do not explicitly "classify" details susceptible to out-ofplane distortion. However previous testing has been conducted where the experimental data reasonably support classification of a wide range of common details as Category C (Fisher et al., 1980; Fisher, Jim, Wagner, \& Yen, 1990; Mueller \& Yen, 1968). This classification is intuitive to a degree when considering the type of cracking, particularly in the context of web gap cracking, as discussed below.

In addition to local out-of-plane bending stresses, the web plate at typical transverse connection plates is subjected to longitudinal "nominal" in-plane stresses generated by the longitudinal bending of the girder (i.e., $\mathrm{Mc} / \mathrm{I})$. Under the stress state represented by such "nominal" bending stress, AASHTO Category C reasonably reflects the stress concentration of a weld toe at a short attachment (i.e., the transverse connection plate). However under certain conditions, the effects of the global stresses (i.e., the nominal in-plane bending of the girder) are much smaller than the local out-of-plane bending stresses (Connor \& Fisher, 2001; Connor et al., 2005; Fisher et al., 1990; Koob, Frey, \& Hanson, 1985). The cracking commonly observed at web gaps has thus proven to be the result of local outof-plane bending stress in the web.

Since the primary parameter influencing cracking is the local stress at the weld toe, similar to other short attachments, it is reasonable to classify the transverse fillet weld detail as Category C. However, it is critical to note that for this statement to be true, an accurate measurement or calculation of the stress range at the weld toe which is consistent with the experimental data is required. Thus it would be inconsistent to evaluate the detail as Category $\mathrm{C}$ and compare it to nominal stress ranges due to the addition of the out-of-plane stress component. It is also noted that some have arbitrarily assigned these details as Category E or $\mathrm{E}^{\prime}$ in order to "be conservative." This practice is fundamentally incorrect for several reasons. First, the fatigue resistance and cause of the cracking cannot be addressed simply by using a lower category and nominal in-plane stresses. Second, and possibly more importantly, such an approach would likely arrive at a nonconservative evaluation of the detail. It has often been shown with field measurements that the nominal inplane stresses are low even when assuming the leastresistive detail categories (e.g., E or $\mathrm{E}^{\prime}$ ) yet out-of-plane cracking is readily observed. Hence, this results in confusion for inspectors and designers alike.

\section{Repair Considerations}

Repair strategies for out-of-plane distortion cracks traditionally are based on two alternative approaches: (1) stiffening techniques and (2) softening techniques. Both have been used successfully in various cases. However, there are also examples where the technique selected (i.e., stiffening or softening) did not perform as intended and fatigue cracking continued. Each will be discussed separately. Hole-drilling can also be effective as a short-term repair technique (or long-term repair where out-of-plane distortion is relatively minor) and will be discussed first. Finally, removal of the secondary members which are transferring the out-of-plane forces into the primary members may also be a consideration where it can be shown through engineering analysis that these members are not necessary for the stability of the bridge.

The driving force behind distortion can be considered to be an imposed displacement on the connection. The cause of this displacement can be incompatible deflections between the connected members, such as differential deflection of two adjacent girders under live load. The causes can also be differential thermal expansion between adjacent members. For example, the deck and cross frame between two girders may expand and contract differently due to temperature gradients and the different coefficients of expansion of the materials. In general, the cause of distortion may be a combination of effects that are difficult to quantify. It is therefore difficult to determine a magnitude of the distortion that can be used in engineering calculations to determine stresses. The softening techniques reduce the stiffness of the connection so that the imposed displacement does not cause stress ranges high enough to cause fatigue. The imposed displacement remains, but it no longer causes fatigue damage. The stiffening techniques attempt to resist the displacement. This introduces forces in the connections, and the load path for these forces must be designed to control the resulting stress levels. Success or failure of the retrofit depends on having some understanding of the driving force behind the distortion. Earlier versions of the AASHTO specification required a lower lateral bracing system for bridges with a span length greater than $125 \mathrm{ft}$. These systems may not be needed for the structural stability of the bridge once the deck is in place. Removal of the lower lateral bracing system may be an option to limit or remove the driving mechanism for out-of-plane stresses in primary members of select bridges where modern engineering analysis demonstrates that the lower lateral bracing system is not necessary. Obviously, if the deck were to be replaced, such bracing may be required and a sufficient analysis may be required.

Given that nearly $90 \%$ of all fatigue cracking results from out-of-plane distortion or other unanticipated secondary stresses at fatigue sensitive details (Connor \& Fisher, 2006), neither design specifications nor evaluation specifications currently provide any guidance on 
how to evaluate the in-service potential for fatigue cracking at these details. As a result, the effectiveness of various retrofit procedures is often questionable and illfated. There are many examples where implemented retrofit procedures did not work and fatigue cracking re-initiated or propagated. In cases where there are many details requiring retrofit, such as in long multispan bridges where there may be hundreds of instances of the same detail, implementation of one or two prototype retrofits is a useful means of ensuring that effective retrofits are developed. Field instrumentation and testing is an effective means to determine the behavior of a given retrofit strategy. Detailed solid finite element analysis of the retrofit assembly is another option to make a relative comparison between different retrofit options abilities to resist the out-ofplane distortions. Caution must be taken to ensure that the model represents the correct boundary conditions, stiffness properties, and has a fine mesh that can capture the small distortions in the web gap. There are also other considerations such as the contact between plates and the bolt pretension which causes these models to be quite complex. Stress distribution and other behavior that may not be anticipated can be identified prior to installing the retrofits on a large scale. This type of proactive approach to retrofitting is highly recommended as a means to prevent future problems.

1. Hole-drilling. In some cases, distortion-induced cracks may be retrofitted by drilling holes at the crack tip (see Figure 3.13). This technique will most likely only be effective as a long-term repair for web gap cracking at transverse connection plates adjacent to the top or bottom flange of a plate girder where the amount of relative movement (i.e., out-of-plane movement) is rather small. Both field and laboratory studies have shown hole-drilling repairs to be ineffective when distortion levels are high. 'Small' and 'high' are subjective terms and the actual displacement should

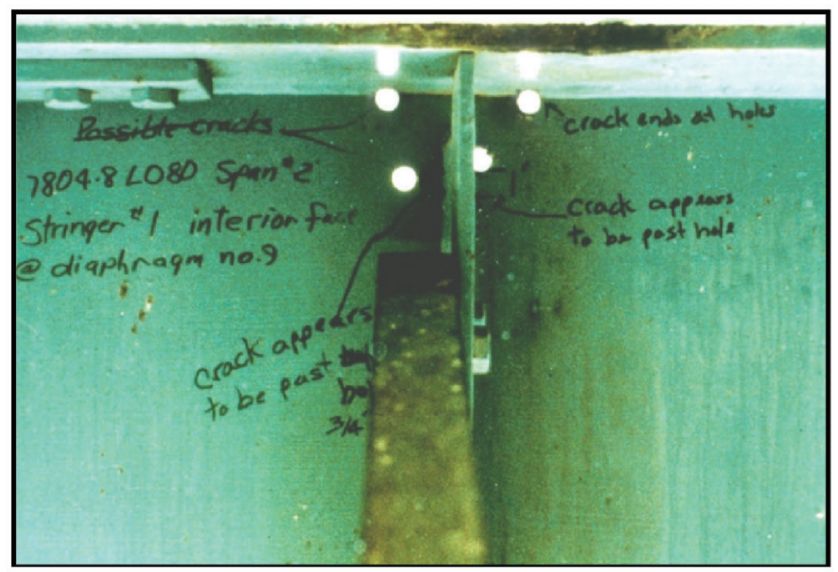

Figure 3.13 Crack arrest holes drilled at a transverse connection plate attached to a diaphragm. be determined in the field using instrumentation or dial gauges. Nevertheless, in cases where the amount of distortion is small, hole-drilling techniques have been shown to be effective.

The size of the hole should be as large as possible, and diameters of 3 to 4 inches are generally the most effective. These larger holes will tend to soften the detail and provide sufficient flexibility such that the movement can be accommodated without further cracking. Also, the larger radius provides for smoother stress flow and the edges of these larger holes can more easily be ground, polished, and inspected. It is noted that small holes are sometimes used (e.g., 1/2" to $1^{\prime \prime}$ ) in cases where one does not wish to place a large hole in the web. While this approach may work in a number of cases, it will likely not be effective in stopping future crack growth and should only be considered as a temporary strategy to blunt the crack tip.

Hole-drilling as an out-of-plane cracking retrofit approach is very attractive in that it is easily implemented using general laborers. In addition, more holes can be drilled during subsequent inspection cycles should it be found that the cracking is continuing. Obviously, if the cracking becomes excessive, other repair strategies should be considered. As a guideline, "excessive" cracking can be defined as fatigue cracking that continues to grow over two subsequent inspection cycles, including cracks that propagate past drilled holes. When cracks do extend past drilled holes, the idea of drilling a new hole to capture the crack tip only has some merit as a shortterm repair.

2. Connection stiffening. Retrofit strategies that are intended to stiffen the connection attempt to replicate the condition that would exist in new bridges where the individual components are rigidly attached. For example, using heavy angles or WT sections to attach a connection plate to a flange are simply attempting to provide the same level of stiffness that would exist had the connection been welded during fabrication.

The use of WT shapes is commonly preferred over hot-rolled steel angles as a means of connection stiffening as the section properties of available WT shapes can provide for a stiffer connection. Connection stiffening using an angle is shown in Figure 3.14. WT sections such as WT13.5 $\times 89$ and WT12 $\times 55$ have been used at similar locations, as shown in Figure 3.15, on other bridge structures with much success (Connor \& Fisher, 2001). Although these WT sections may seem heavy, it is important to understand that this retrofit is sized for stiffness rather than strength. The primary objective of a bolted retrofit with WT or angle connectors is to ensure that there is no (or as little as possible) relative displacement between the web, flange, and transverse connection plate. Based on field measurements, the magnitude of out-of-plane distortion that can produce web cracks is on the order of 0.003 to 0.005 inches (Connor \& Fisher, 2001; Connor et al., 2005). Thus, to prevent such small displacements, a very stiff connection is required. 


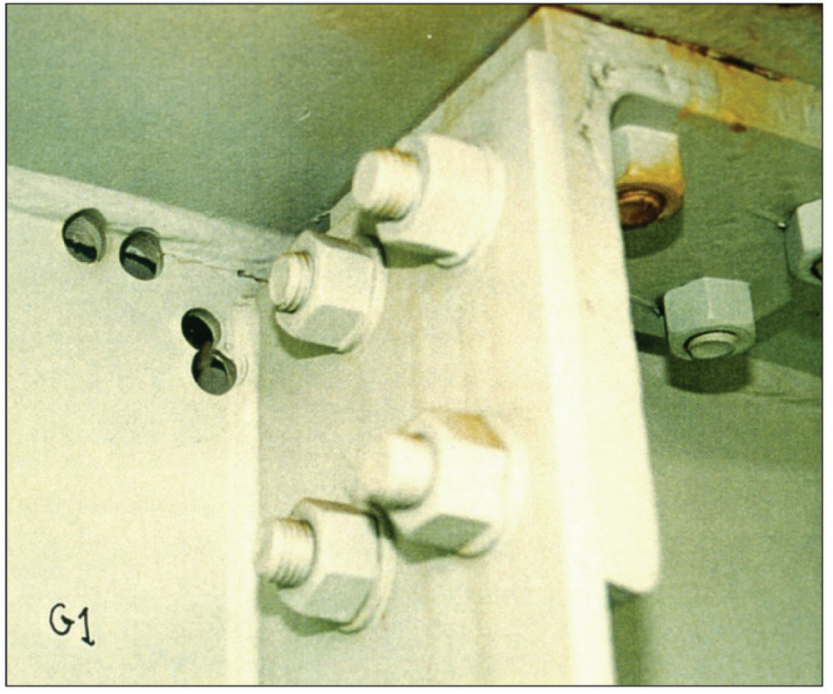

Figure 3.14 Stiffening angle bolted to transverse connection plate and top flange.

As shown in the photograph in Figure 3.14, if angles are used, four bolts must be placed in the connection plate and flange to ensure adequate stiffness is provided and that out-of-plane movements are reduced to an acceptable level. There are documented cases where connections that were too flexible were installed and cracking continued (Connor \& Fisher, 2006). NCHRP Report 721 (Bowman et al., 2012) found that retrofits utilizing back-to-back double angles performed better than single angles. Single angle retrofits require the angle to be exceptionally thick or else the angles themselves may begin to crack due to unsymmetrical bending.

3. Softening. Increasing the web gap region effectively increases the flexibility of the connection. When properly executed, this can create sufficient flexibility

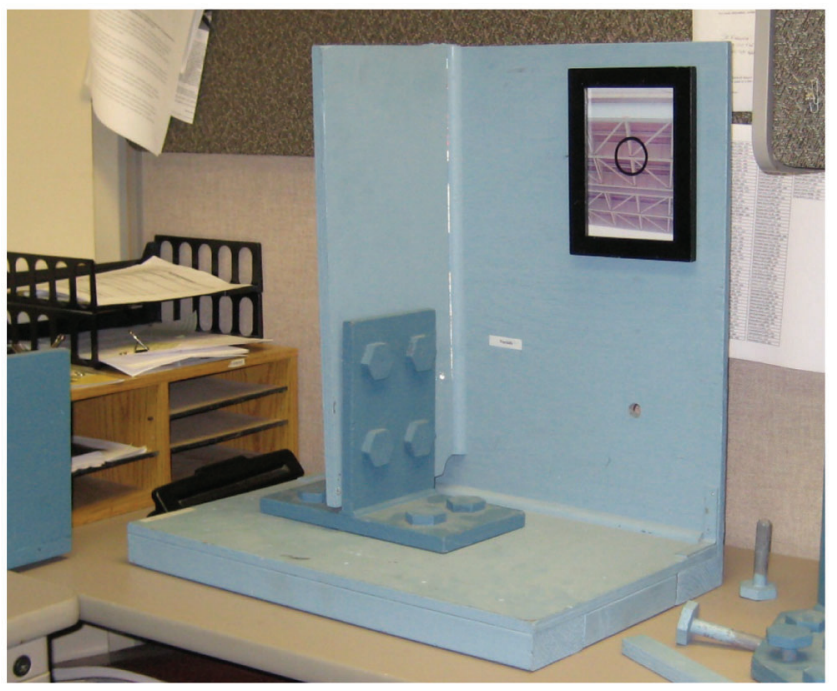

Figure 3.15 Mock-up of WT connection plate retrofit concept. at the area of concern such that web cracking will not be induced. However, this retrofit technique has proven effective only if the distortion does not increase as a result of reduced detail stiffness. The quality of workmanship for the repair also heavily influences the potential for retrofit to be successful. Experience with past projects indicates that the length of the exposed web must be substantial, on the order of eight to twelve inches (Koob et al., 1985). A good example of this type of retrofit is shown in Figure 3.16. It is noted that sufficient clearance between other members, such as floor beams or diaphragm connectors, must be available to implement this retrofit strategy.

An oxy-acetylene or plasma torch can be used to cut out a portion of the transverse connection plate as shown in Figure 3.16. With any cutting, the edges where material was removed should be ground smooth and subjected to magnetic particle testing in order to eliminate surface discontinuities such as nicks or gouges from the cutting process. If such discontinuities are left in place, especially at the web of the member, fatigue cracking is likely to reinitiate. This was the case after a retrofit at the Lexington Avenue Bridge in Minnesota, where the contractor elected to leave a small portion of the connection plate attached to the web (see Figure 3.17). Cracks were observed to reinitiate at the termination of the connection plate. To arrest this cracking and to prevent further cracking, a hole was placed at the remaining end of the connection plate as shown in Figure 3.17.

4. Large hole retrofit. As an alternative to removing portions of transverse connection plates, large holes ( $3^{\prime \prime}-4^{\prime \prime}$ diameter) can be placed on each side of the plate, as shown in Figure 3.18 on the following page. This "large hole" retrofit is very attractive as it is easy to install, easy to inspect, and can be performed in a limited number of steps. In comparison to the softening technique described in the previous section, large hole retrofitting can often be much more cost effective. While small holes as described in Section 3.6.c.1 can be used to capture small cracks as they appear, larger holes will intercept or remove multiple cracks in the vicinity of the web gap. Because the radius of the holes is very large, the retrofit can accommodate much more movement than the standard $1 / 2$ inch or 1 inch holes discussed earlier and thereby greatly decrease the likelihood of crack re-initiation. An example is shown in Figure 3.19 as implemented on the Poplar Street Complex in East St. Louis and the I-80 bridge over the Missouri River (Koob et al., 1985). Note that the hole should be positioned to remove about $1 / 8^{\prime \prime}$ of the vertical and horizontal welds, in order to remove the weld toes at this location.

5. Welded retrofit. Another repair of out-of-plane distortion cracking is to weld the transverse connection plate to the girder flange. This retrofit is most convenient for details where the transverse connection plate was extended the full depth of the girder. Before 

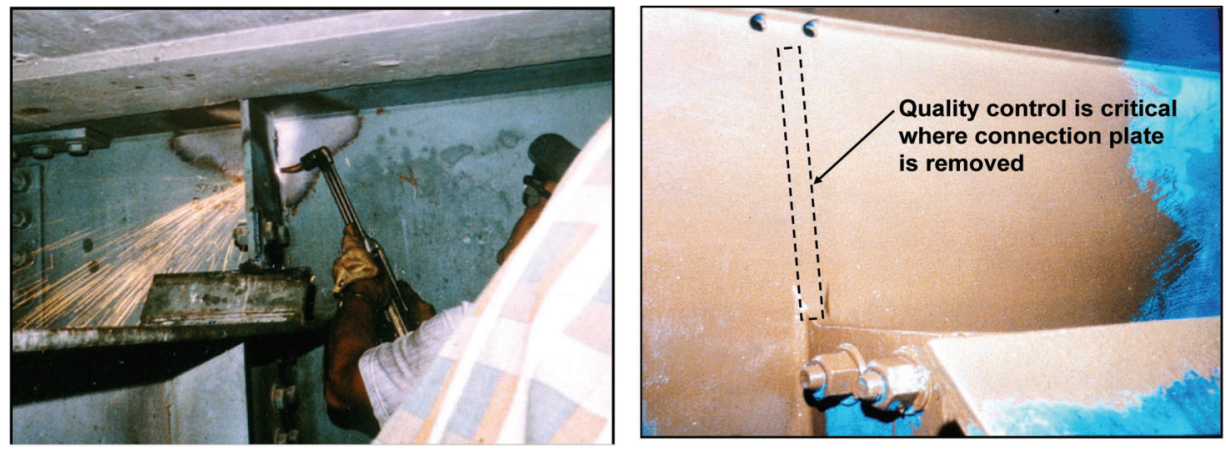

Figure 3.16 Example of web gap softening technique.

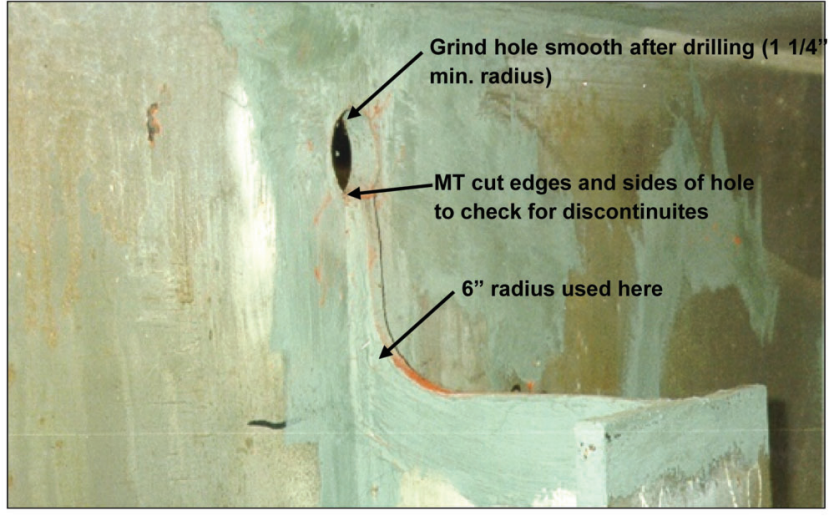

Figure 3.17 Web softening technique (photo courtesy of Minnesota Department of Transportation).

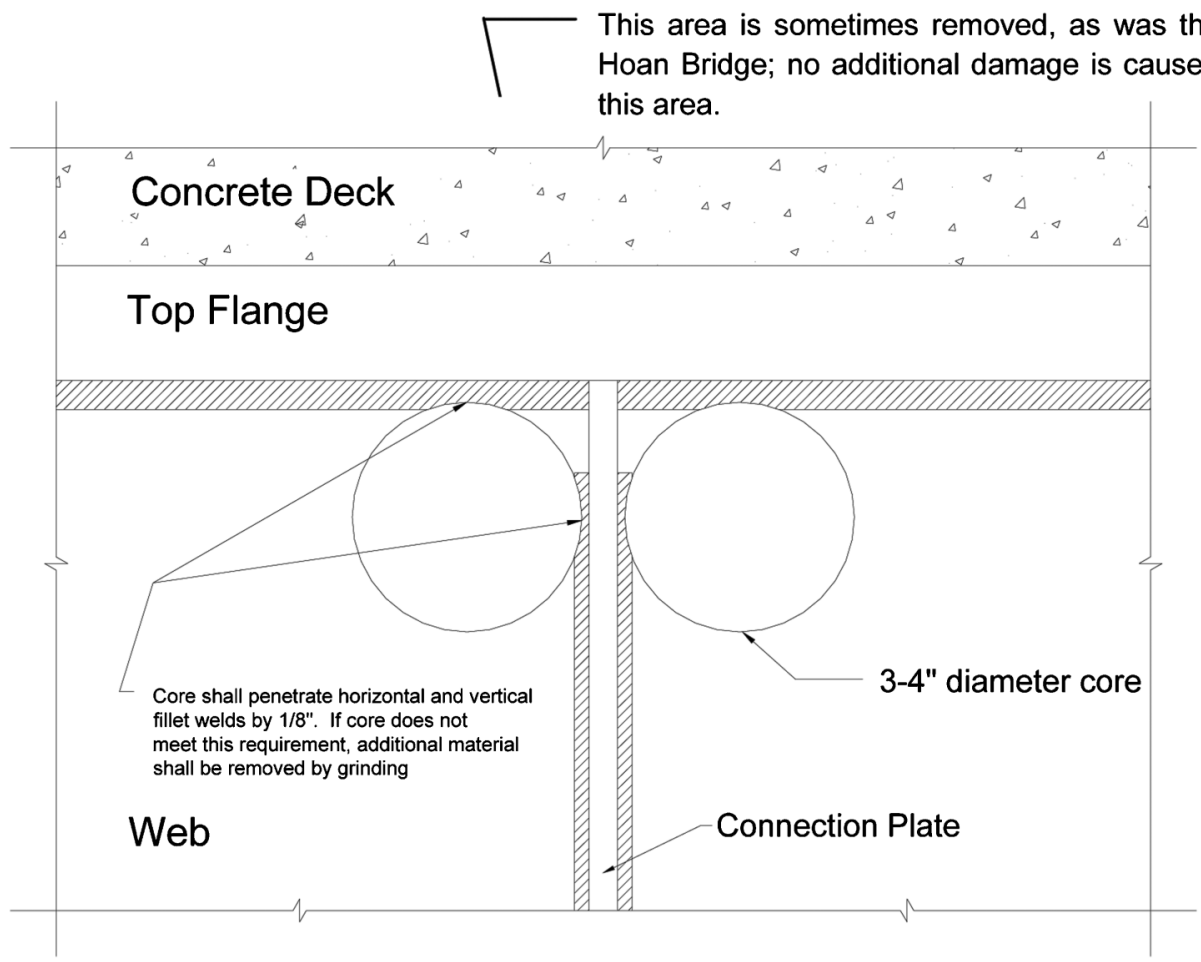

Figure 3.18 Schematic of typical large diameter hole retrofit (drawing by Wiss, Janney, Elstner, and Associates). 


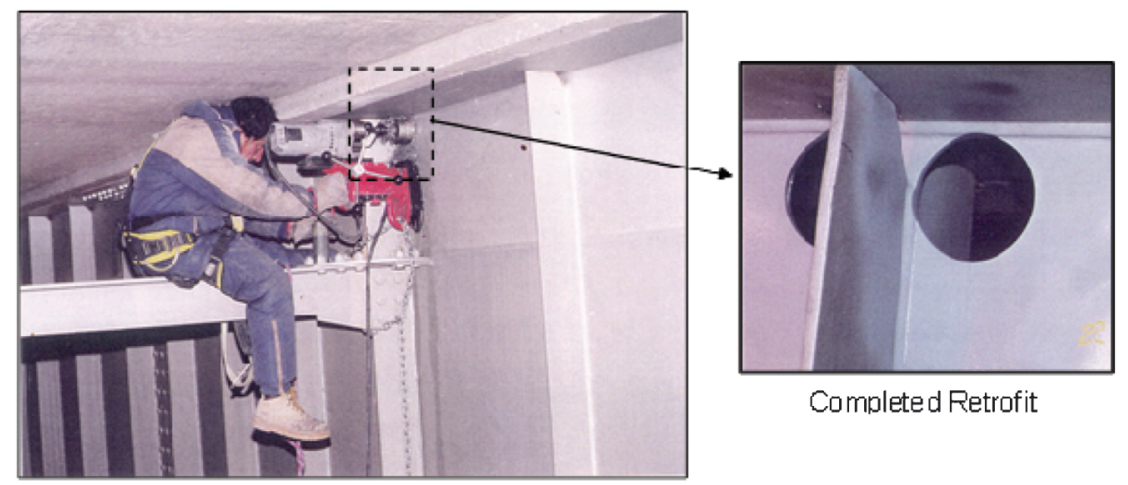

Figure 3.19 Implementation of large hole retrofit (photo courtesy of Iowa Department of Transportation).

initiating any welding, it is important that proper welding and quality control procedures are developed and implemented. The welds should be designed by an Engineer, but fillet welds are likely sufficient. Often, a mock-up of the connection is used to test the welding procedure, constructability, and quality. This mock-up may involve fabricating a sample which represents the portion of the girder at the connection with equivalently sized plates and material grades. Consideration should be made for the skills and qualifications of the personnel performing the welding. Sound overhead welds are much more difficult to perform than welds in the flat position. It may be necessary to qualify individual welders on the mock-up fabrications when overhead welds or vertical welds are required.

6. Removal of secondary members. Secondary members are typically left in service although, in certain instances, they may not be necessary for structural stability once the bridge deck has been constructed. Since the secondary members carry the out-of-plane forces into the girder, removal of these members is an option to reduce or even eliminate outof-plane cracking at poor details. This option requires that an engineering analysis is performed to ensure stability of the bridge without the bracing provided by these members. Other considerations are whether these members will be required if the conditions change in the future such as redecking and what the cost of temporary shoring or installation of temporary struts during these activities could entail. If removal of the secondary members is pursued, it may be most cost effective in locations where the secondary members can be effectively removed by loosening the bolts so that they do not carry stress while leaving the members in place. This may also require the bolt holes to be widened or slotted. This could allow for the members to be implemented again if needed during redecking. If the member must be completely removed from the bridge and the connection plates will be left in place, it would be helpful to check during the engineering analysis that there are no anticipated fatigue issues at the connection plate details due to the in-plane stresses which will continue to pass through the detail. A common example of this is Category $\mathrm{E}^{\prime}$ lateral gusset plates that would cause a stress concentration in the primary member even if the secondary members have been removed.

\section{Field Directions for Repair of Fatigue Cracking}

Obtain guidance from the Engineer as to the appropriate repair approach at each location. For a given structure, more than one approach may be required. Project-specific details will likely be required for some or all of the conditions to be addressed.

Proceed with repair options specified including, but not necessarily limited to, the following:

1. Repair of fatigue cracking by hole-drilling. Holedrilling at cracks: Follow instructions of Section 3-6.b for hole-drilling. Place center of holes at tips of distortioninduced cracks; for this application, hole diameters of 3 to 4 inches are generally the most effective. Smaller holes $\left(1 / 2^{\prime \prime}\right.$ to $1^{\prime \prime}$ diameter) may be dictated by the Engineer based on the Owner's preferences.

2. Repair of fatigue cracking by connection stiffening. Connection Stiffening: Attach angle, WT, or other shape as specified by the Engineer to stiffen the detail. Bolted connections are generally preferred. New bolt holes in existing material should be drilled following the general guidelines of Section 3-6.b. For top flanges embedded in concrete, it may be possible to drill and tap threaded holes in the flange after confirming that the hardness of the girder steel is suitable for drilling and tapping and ensuring that full pretension of the bolt can be attained.

\section{Repair of fatigue cracking by connection softening.} Connection Softening: remove portions of connecting elements as directed by the Engineer. Grind remaining pieces smooth of any nicks or gouges using procedures in Section 3-2.d: Field Directions for Repair of Surface Discontinuities. Hole-drilling per Section 3-6.b may also be required if cracks are discovered.

4. Repair of fatigue cracking by large hole retrofit. Large Hole Retrofit: Where directed by the Engineer, 
large holes ( 3 to 4 inch in diameter) are typically placed on each side of the transverse connection plate. Note that the hole should be positioned to remove about $1 / 8^{\prime \prime}$ of the vertical and horizontal welds. General guidelines for hole-drilling shall be as stipulated in Section 3-6.b.

5. Repair of fatigue cracking by welding. Welded Retrofit: Weld procedures and quality control requirements should be developed. A mock-up of the connection may be advised to ensure constructability and quality of the weld. Remove paint from the connecting elements and prepare the area for welding. Check for cracking and remove any crack tips through hole-drilling as specified in Section 3-6.b. Weld the transverse connection plate the full width of the stiffener to the flange. Ensure that there is an adequate cope so that there are not any intersecting welds. Inspect the completed weld for quality.

6. Repair of fatigue cracking by removal of secondary members. Removal of Secondary Members: Perform an engineering analysis to determine if the bridge will remain stable if the secondary members are removed from the bridge and will not be available to brace the primary members or carry secondary loads. Consider future redecking actions and the costs associated with temporary bracing that may be required. Loosening of the connection to the secondary members may be considered as an option to remove the out-of-plane stress from the detail rather than fully removing the members from the bridge. It is recommended a fatigue analysis be performed during the engineering analysis to check for future fatigue damage on any details with low fatigue resistance that will remain in service.

\subsection{Pin and Hanger Retrofits}

\section{A. Introduction}

Pin and hanger assemblies are a common feature of pre-1970s multi-span bridges. A typical configuration is shown in Figure 3.20 (note the slotted hole on one side of the "wind lock" plate connecting the two girders at

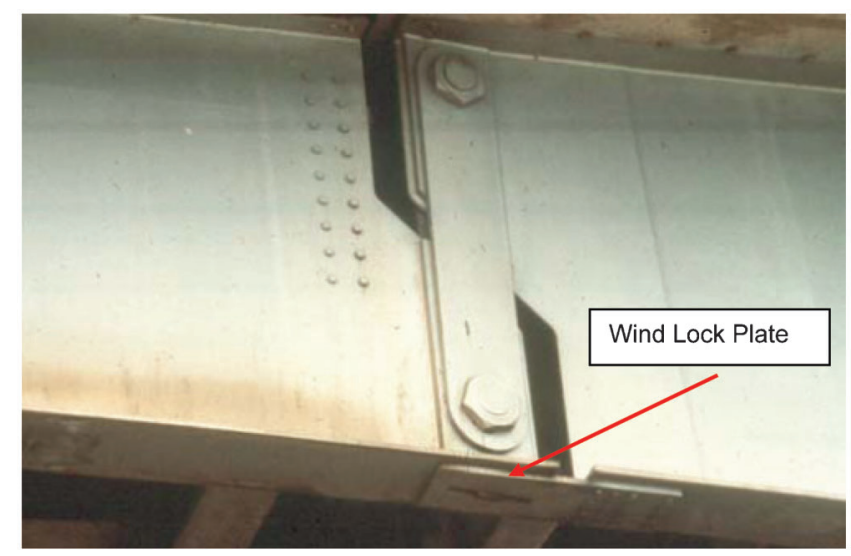

Figure 3.20 Photo of typical pin and hanger assembly. the bottom flange). Pin and hanger assemblies had two perceived benefits: they act as hinges (useful to the Engineer as a way of simplifying the analysis of multispan bridges) and permit expansion between girder spans at a point away from substructure supports. The former of these is no longer as important with the advent of modern bridge design software packages. The latter characteristic allowed bridge deck expansion joints to be located away from piers and bearing assemblies. Unfortunately, pin and hanger assemblies are in many ways less resilient than piers and bearing assemblies to the deterioration mechanisms initiated by water and road salts that tend to be associated with leaking bridge deck expansion joint systems.

The pins in these assemblies do not fit a specific AASHTO Fatigue Category per se, although the hanger portion of the assembly is classified as belonging to Fatigue Category E. Furthermore, the hanger component of pin and hanger connections on two- or three-girder systems is listed as an example of FCM in the AASHTO Manual for Bridge Evaluation. And while the pins themselves are not considered Fracture Critical, they are Failure Critical since the failure of the pin could result in partial or complete collapse of the bridge. Even in multi-girder bridges, progressive collapse of a series of these assemblies can be initiated by failure of just one of them.

Failure mechanisms (which for Fracture Critical cases could cause failure of an entire bridge span) include fracture of the hanger, fracture or shear in the pin, and movement of the hanger off the pin. Pins and hangers properly designed for anticipated shear and tension loads, respectively, can nevertheless fail over time due to the slow accumulation of pack rust or other deterioration causing the hinge to become fixed. In fact, the primary reason for repair of pin and hanger assemblies is usually corrosion.

The parts of a typical pin and hanger assembly are shown in Figure 3.21 (Note that this drawing represents only one of many possible configurations). Fatigue considerations and typical deterioration mechanisms for pin and hanger assemblies vary with the type of components included, as discussed in the following paragraphs.

Hangers are generally made of flat plate material. Fatigue could be expected to initiate at surface irregularities in the plate material. Hangers can also be constructed of eyebar plates, or built-up members (bolted, riveted, or welded assemblies). Each type of built-up hanger has its own fatigue-prone characteristics, i.e., forging locations at eyebars, punched holes in bolted or riveted connections, or weld discontinuities and residual stresses at welded components.

The pins were typically designed only for shear, with little or no accounting for the possibility of friction at the pin bearing. Pins were also commonly designed based on the full thickness bearing of the hanger. In reality, the potential exists for pins to experience fairly high torsion and bending forces if the connection locks up and the pin loses the ability to turn freely. Any such 


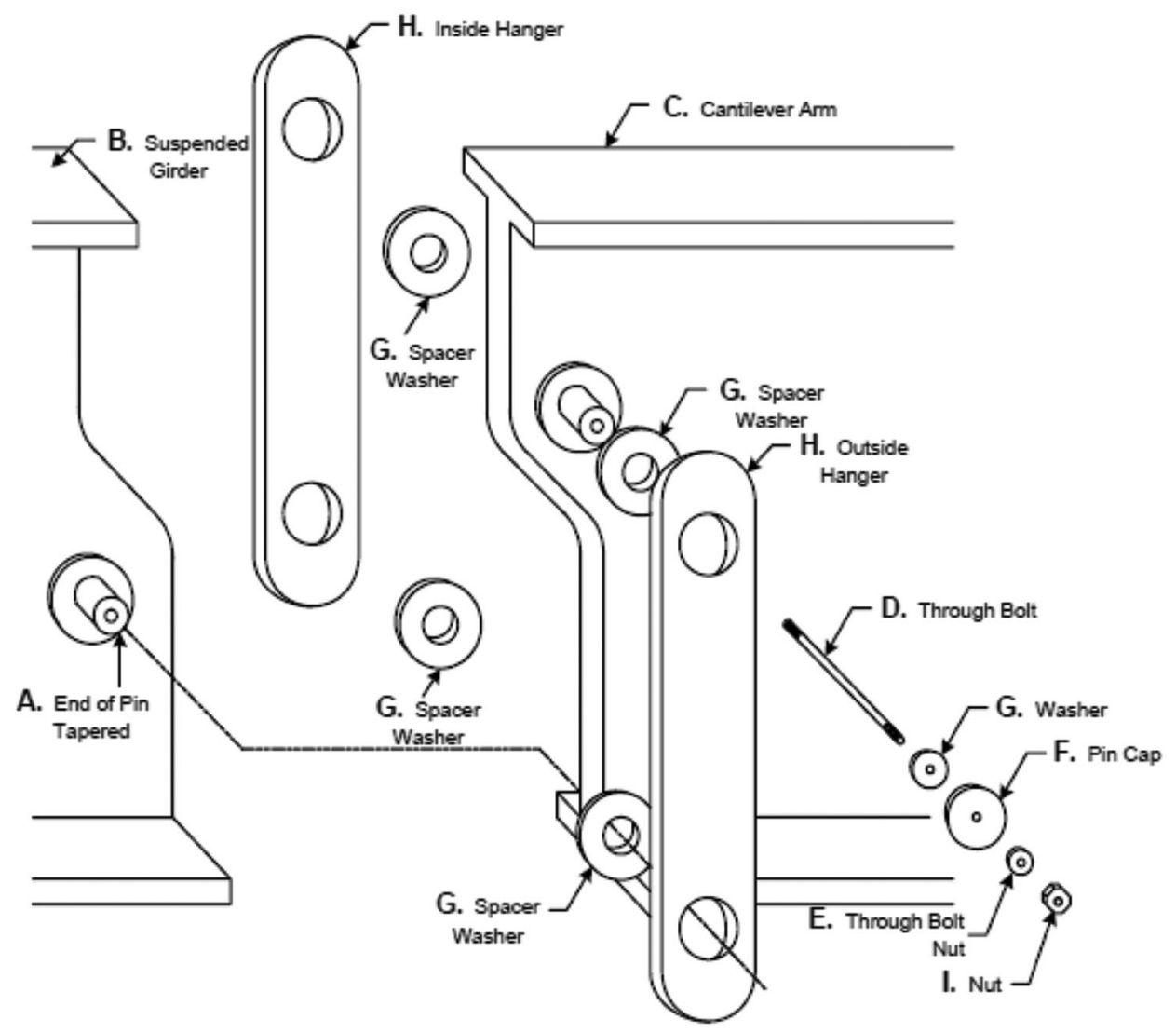

Figure 3.21 Exploded view of typical pin and hanger assembly.

torsion stress would be additive to the shear stress, with the possibility to create an overload condition. Pins can also be subjected to excessive bearing stress at any areas where the bearing surface of the hanger is reduced by corrosion or wear. Reduction of the bearing surface can also occur if the link shifts partially over the pin shoulder due, for example, to pack rust. A final consideration for pin and hanger assemblies is the possibility of fretting fatigue. Cracks can eventually initiate on the surfaces of parts that move relative to one another under high contact forces. This may reduce the fatigue resistance below what might be expected based on calculated stress ranges in the parts.

\section{B. Evaluation Techniques}

During normal inspection procedures, the condition of the pins and hangers should be checked to verify that the hanger is aligned with the adjacent beam webs. Corrosion at the hanger plate may indicate that the deck is draining onto the assembly, which could contribute to accelerating the deterioration of the components. Pack rust may be visually evident between the webs of the girders and back faces of the hanger plates. If possible, another useful step in initial evaluation is to determine if movement, as should be permitted by the detail, is actually taking place. If the assembly has been painted, check to see if there are any cases of unbroken paint film across a surface where relative movement should be taking place; this indicates the joint is locked in place. The rotation of the pins and hangers under numerous cycles of live load and thermal expansion can also lead to fretting corrosion, recognizable by the presence of powdery red or black rust and/or staining where the surfaces rub together.

The hanger bar shown in Figure 3.22 was removed from a pin $\&$ hanger connection on a bridge structure. The visible section loss on the interior of the hanger indicates the bearing surface on the hanger bar had fused to the pin as a result of corrosion, thus preventing rotation between the pin and hanger from taking place.

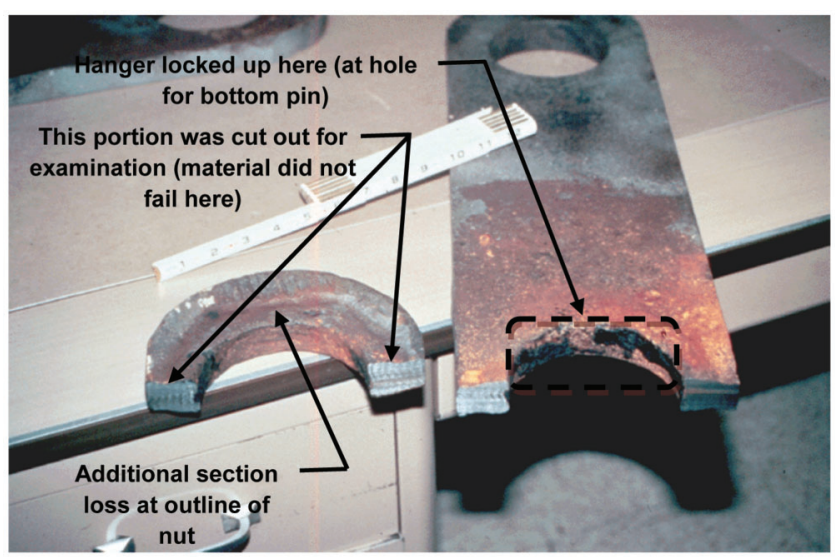

Figure 3.22 Examination of failed hanger bar. 
There is also visible section loss on the exterior surface of the pin outlining the nut, indicating that pack rust between the girder, hanger and nut further restricted movement of the hanger. These conditions are typically related by a combination of moisture and chlorides migrating on to the pin $\&$ hanger connection through an open joint in the roadway deck. As the amount of corrosion increases, the amount of allowable rotation decreases until the pin becomes locked to the hanger and/or the hanger becomes locked to the side of the girder.

Hanger plates should be examined closely for bowing or cracking, which may result from the stress buildup generated from a locked-up connection. The ends beyond the pin centerlines in particular are susceptible to cracking. When eyebars are used for hangers, the juncture between the heads and shanks of eyebars is another area where cracking is common. The AASHTO Manual for Bridge Evaluation (2011) describes additional inspection procedures in some detail.

In a pin and hanger connection, most of the wear will occur at the top of the pin and the top of the hanger on the cantilevered span as well as at the bottom of the pin and the bottom of the hanger on the suspended span. Sometimes wear, loss of section, or lateral movement may be indicated on the expansion joint or surface over the pin and hanger assembly.

The concealed nature of a pin and hanger assembly combined with a number of interface planes between components make it difficult to use anything but ultrasonic testing methods of NDT. Additionally, the large size of the assembly components rule out performing PT, Eddy Current Testing (ET), and MT for anything but surface fractures that are already visible.

UT should be performed on all pins. The hanger bars are thick sections of steel that are only accessible from one side, thus making them ideal candidates for UT testing. Following a thorough visual examination, UT, PT, or MT of hanger plates is generally necessary to detect cracks.

Removal of the retainer nuts or caps should not be attempted unless an alternate means of retaining the hanger on the pin is in place. Hanger links and pins are generally difficult to remove even after the retaining assemblies are taken off. This is not always true, however, and a pin on the verge of failure due to rust packing could fail precipitously if its nuts are loosened. Disassembly of a pin and hanger joint should be undertaken only after proper engineering design is performed and auxiliary support supplied. It is not a routine bridge inspection procedure.

\section{Repair Considerations}

Pin and hanger components can be replaced with stainless steel parts or non-metallic inserts \& washers. Replacement of the pin and hanger assembly in-kind with a structural grade of stainless steel eliminates potential failures due to corrosion-related problems.
Placing a non-metallic insert and washer prevents corrosion between the pin and hanger and allows for normal rotation. Both repairs require disassembly of the pin and hanger system and a great deal of advance planning to provide the necessary temporary support of the bridge girders while work is being performed. Material availability and cost may also preclude the use of this repair method. The remainder of this section will therefore address two more common alternative approaches.

1. Supplemental "catcher" systems. Retrofit schemes have been devised to provide added redundancy for pin and hanger assemblies. These include, but are not limited to rod-and-saddle and under-slung catcher connection details. These methods are added on to the structure such that they only carry load after failure of the pin and hanger assembly. It is important to note that although either of these schemes would improve the redundancy of a given pin and hanger assembly, they do not necessarily add load path redundancy to the entire structure.

This form of retrofit is typically used on pin and hanger systems. In the typical application, an additional group of components are added to "catch" the suspended girder should the existing pin and hanger system fail. Typical installations of this system in two of the more common configurations are shown in Figure 3.23 and Figure 3.24.

The attachment of the saddle system needs to be designed with consideration of both impact loading due to hanger failure and possible restraint to movement of the joint. Typically, either a very small gap is designed between the "catcher" or "saddle" and the girder or a neoprene bearing may be included in the assembly to permit movement. If a gap is designed, it should be kept small in order to limit impact loading but should not be too small as to restrain movement. If the neoprene bearing is utilized, the saddle system may be pre-loaded with no gap in order to limit any impact loading while still allowing for joint movement. Design of the saddle

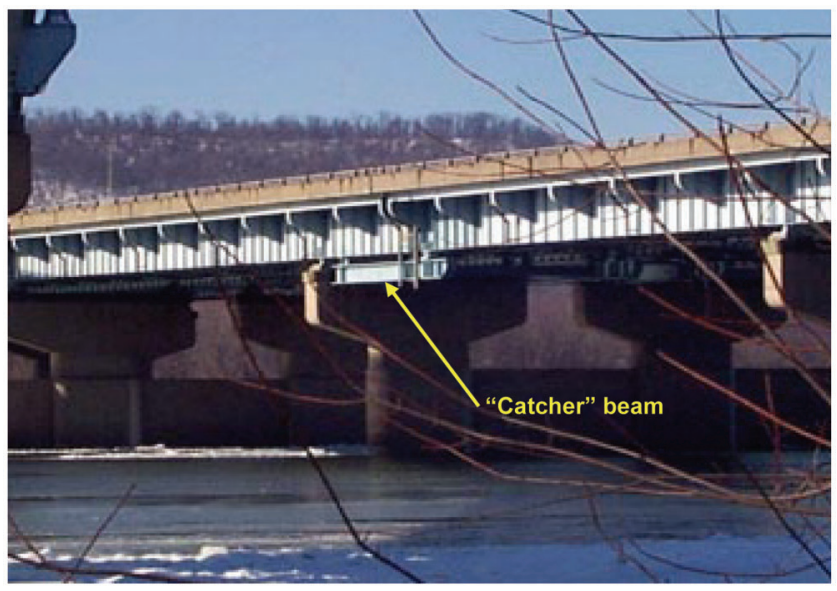

Figure 3.23 Catcher system on a typical pin and hanger bridge (photograph courtesy of Modjeski and Masters, Inc.). 


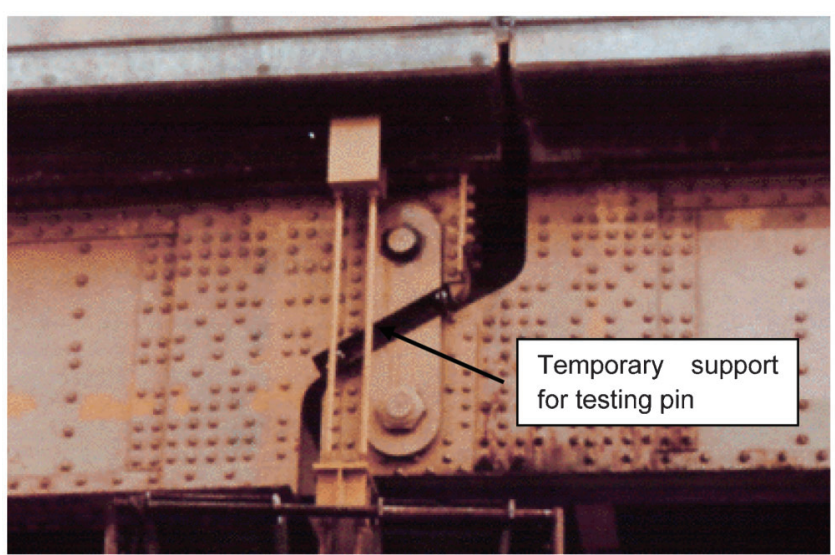

Figure 3.24 Rod-and-saddle system on a typical pin and hanger bridge (photograph courtesy of Modjeski and Masters, Inc.).

system should also consider steels with a very high toughness such as HPS steels or some military grade steels in order to better absorb the energy from the falling span.

2. Removal of the pin and hanger assembly. Another option for dealing with pins and hangers is to actually remove the pin and hanger and replace the detail with a full moment connection. In this approach, the entire pin and hanger assembly is removed and replaced with a new short section of a girder. The new section is attached to existing portions of the girders with full moment splices. The girders are then made continuous for live load and even some portion of dead load. Field instrumentation conducted on the bridge in Figure 3.25 confirmed that after the retrofit, the bridge behaved as a typical continuous multi-span bridge.

Due to the change in the boundary conditions at the connection, the ability of the structure to behave as a continuous multi-span bridge, primarily in the negative moment regions, must be adequately checked. Because

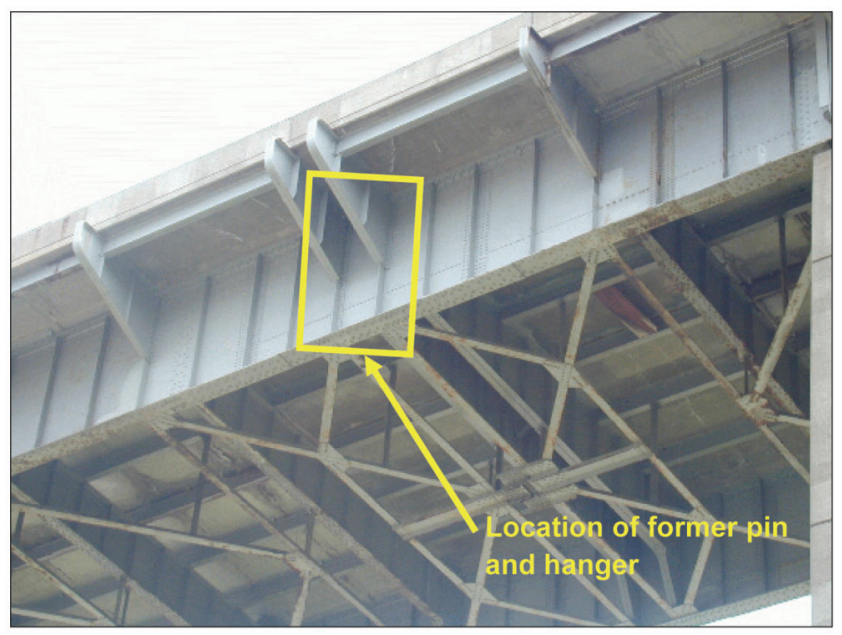

Figure 3.25 Complete girder splice installed to replace a pin and hanger connection in a two-girder bridge. the pin and hanger connection is often designed as a location to permit expansion, adequate expansion must be permitted elsewhere in the bridge when this connection is converted into a full moment connection. This may require converting fixed bearings into expansion bearings and possibly the addition of an expansion joint in the bridge deck.

During construction, either false work or strong backs are required to ensure the bridge is stable. These provisions will need to be developed as part of the construction engineering required by the contractor responsible for performing the repair work; this is beyond what typical repair and maintenance crews can provide. The process can usually be completed with live load traffic on the bridge throughout the repair process. Figure 3.25 illustrates a 2-girder bridge where the pin and hanger were removed and replaced.

\section{Field Directions for Pin and Hanger Retrofits}

Pin and hanger retrofit work should not generally be performed by maintenance personnel unless they have training or experience on the specific issues in pin and hanger construction. Furthermore, a design plan needs to be developed in great detail to guide the remediation effort.

\subsection{Constraint Induced Fracture (CIF)}

\section{A. Introduction}

1. Gusset plate connections. On December 13, 2000, cracks were detected in the steel girders supporting one of the southern approach spans of the Hoan Bridge in Milwaukee, WI. Two of the three girders had full-depth fractures, leaving the span near collapse. The entire roadway, both northbound and southbound, was immediately closed to traffic. On December 28, the most critically-damaged section of the northbound roadway was removed by explosive demolition. The southbound roadway was re-opened to two-way traffic on February 17, 2001, with weight and speed restrictions on bridge traffic after temporary retrofits were implemented.

An in-depth investigation into the failure of the girders revealed that the fractures were all brittle in nature and no evidence of fatigue crack growth was observed (Wright, et al. 2001). Material testing indicated that the quality of the steel was acceptable and not the cause for the fractures. The results of the investigation revealed the fracture(s) initiated at the intersection of the longitudinal gusset plate, transverse connection plate, and web (the gusset plate was not welded to the transverse connection plate). At the point of initiation, the web plate was subjected to high residual stresses, a triaxial state of stress due to constraint, and a considerable stress concentration due to the discontinuity in the gusset plate at the cope.

The failure mode has been termed "ConstraintInduced Fracture" (CIF) and can occur without any 
detectable fatigue crack growth, and, more importantly, without any warning. Hence, details which are susceptible to CIF cannot be examined during routine inspection as a preventative maintenance approach as is typically done with fatigue cracks. If a detail is identified as being susceptible to CIF, the condition must either be retrofit to prevent the possibility of future failures or accepted as a source of potential brittle fracture due to CIF.

2. Longitudinal stiffener splices. Prior to the modern bridge design and fabrication specifications, weld splices in secondary members such as longitudinal stiffeners were not subjected to the same level of quality control as other primary load-carrying members. This was due to the fact that these members were considered "architectural" and were not counted upon as actual load-carrying components. However, welds used to attach longitudinal members to the web enforce full strain compatibility between the two plates. Although not included in design calculations, in reality, the two components function together. As a result, stiffener splices (which often contain flaws) are subjected to essentially the same stress range spectrum as the web. There are numerous examples where cracks have developed in poor quality splices in longitudinal stiffeners which have grown due to fatigue and have ultimately resulted in nearly complete fracture of the girder. These fractures have occurred with little or no advance warning or visual evidence of fatigue cracking. In light of this, it is recommended that these details be given a high priority for retrofit to avoid the chance of a brittle fracture.

\section{B. Evaluation Techniques}

1. Gusset plate connections. The results of a parametric Finite Element Analysis showed that details similar to that of the Hoan Bridge with zero web gap experience a great deal of constraint and are highly vulnerable to fracture. It is extremely important to note that with the Hoan Bridge, as well as with the more recent fracture of the US 422 Bridge over the Schuylkill River in Pottstown, PA (Kaufmann, Connor, \& Fisher, 2004), there was no sign that failure of the details subject to CIF was imminent. Simply stated, such details cannot be inspected to detect discontinuities which could initiate fracture. Hence, it is of utmost importance to identify details that may be susceptible to CIF and implement a retrofit program even when no cracking has been observed.

Analysis of the Hoan Bridge showed that a web gap of $1 / 4^{\prime \prime}$ is sufficient in reducing the constraint and allowing for yielding in the web gap area. It was clear from the analyses that the size of the web gap plays a big role in determining the potential for brittle fracture. It has been concluded from studies that if the web gap size is less than $1 / 4^{\prime \prime}$, the fracture potential of the detail is high and a retrofit procedure needs to be considered (Mahmoud et al., 2005). Figure 3.26 is a photograph of

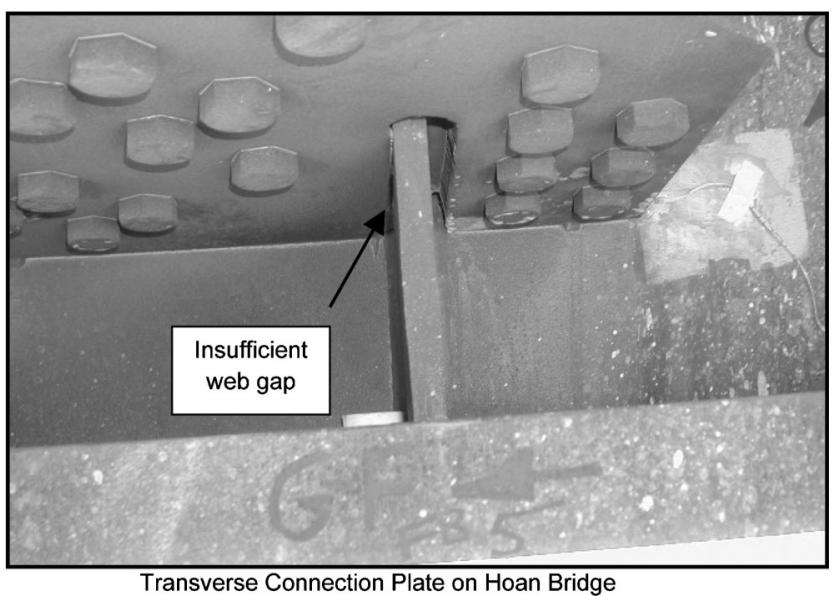

Figure 3.26 View of lateral gusset intersection with transverse connection plate on Hoan Bridge.

a gusset plate detail where the gap between the gusset plate and the transverse connection plate is too small on the left hand side of the connection. Retrofit of this detail was performed by removing the transverse connection plate and lateral bracing system.

Several details common to other bridge types, such as box girders and tied arches, are also susceptible to CIF, depending on how they are detailed. These conditions also need to be evaluated on a case-by-case basis to determine if a retrofit is needed. However, in lieu of further study, the same 1/4-inch gap limitation can be applied as a general rule of thumb.

In addition to evaluating web gaps and details, the cracking history of the bridge should be examined for evidence of large cracks appearing between inspection cycles. Large cracks can somewhat arbitrarily be defined as $12 \mathrm{in}$. or more. Fatigue cracks can be expected to propagate at relatively slow rates, maybe several inches in a given inspection cycle. CIF cracks pop-in suddenly and sometimes arrest when they propagate away from the point of constraint. History has shown that CIF cracks that arrest are often diagnosed as fatigue cracks. Fatigue crack retrofits, such as hole-drilling, are also effective to isolate CIF cracks that have arrested. The problem, however, is that future CIF cracks from similar details may occur under conditions where the cracks will not arrest. Extreme low temperatures or plates with lower toughness may make arrest less likely. In retrospect, the Hoan Bridge showed evidence of CIF before the failure event. Several cracks were discovered during inspection cycles that exceeded 12 in. from gusset plate details prior to the failure event. CIF was an unknown failure mode at that time and the cracks were treated as fatigue cracks. These cracks were actually CIF events that arrested in the web plate. In general, anytime a large crack is found for the first time in any inspection cycle, the situation should be evaluated for the possibility of CIF.

2. Longitudinal stiffener splices. In bridges where there is a question regarding the quality of the welds 


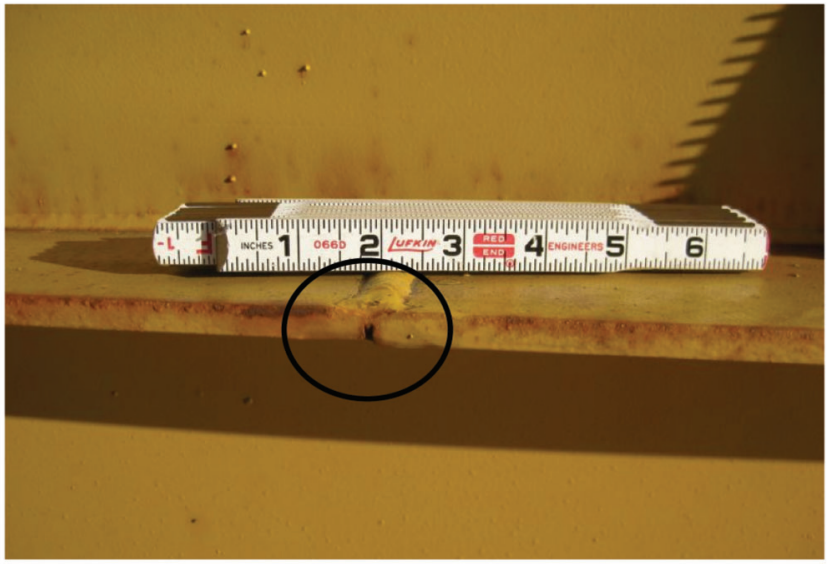

Figure 3.27 Incomplete fusion in weld of transverse splice in longitudinal stiffener.

used to splice longitudinal stiffeners, consideration should be given to detailed inspection. Available methods include visual inspection, MT, and UT. In some cases, the discontinuities can easily be seen with the naked eye, as shown in Figure 3.27.

\section{Repair Considerations}

Since the fracture of both the Hoan Bridge and the US 422 Bridge, there has been considerable interest in identifying effective methods to retrofit similar details known to be susceptible to constraint-induced fracture.

It appears that removing any one of the three conditions required for CIF (residual stresses, a triaxial state of stress due to constraint, and a considerable stress concentration due to the discontinuity in the gusset plate at the cope as shown in Figure 3.26) will decrease the potential for CIF to acceptable levels. However, of the three factors, the only one that can be easily mitigated in the field is triaxial constraint. Constraint can be removed by increasing the gap between elements and exposing more of the web. (Note that opening the gap also reduces the stress concentration if the original geometry is similar to that shown in Figure 3.26). When holes are drilled in the gusset plate, this retrofit strategy also decreases the stress concentration as a smooth taper is usually produced at the end of the longitudinal attachment providing added benefit (see Figure 3.29). This can be achieved in design by providing sufficient web gaps between elements to minimize constraint.

In addition to drilling holes in the gusset plate, there are other retrofit options to prevent CIF at details that have been determined to be vulnerable, such as at longitudinal stiffener splices or at longitudinal stiffener intersections with transverse stiffeners.

Each case that is a candidate for CIF has to be evaluated on an individual basis. Geometric constraints, access limitations, contractor capabilities, and long-term performance are factors that need to be considered when selecting options. Retrofit details and procedures should be individually evaluated by an engineer to determine: (1) if the risk of constraintinduced fracture is eliminated, (2) if the strength of the resulting joint is adequate to carry all applicable loads, and (3) if the retrofit will provide adequate fatigue performance over the intended life of the structure.

For gusset plate details, the recommended method is to drill holes in the gusset plate near the intersecting welds in order to increase the gap and reduce constraint

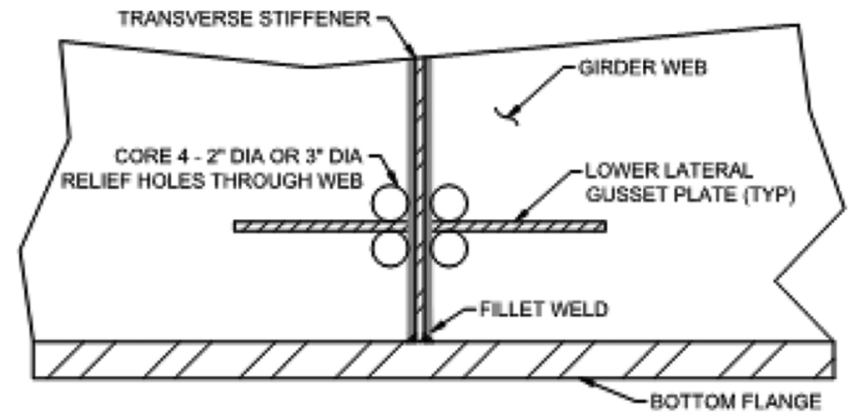

Retrofit Detail Illustrating Crack Arrest Holes in Girder Web

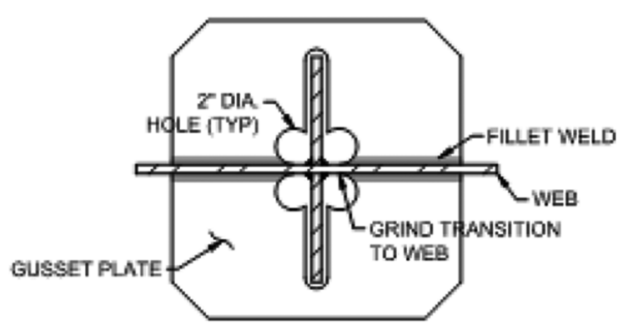

Retrofit Detail Illustrating Holes in Gusset Plate to Relieve Constraint

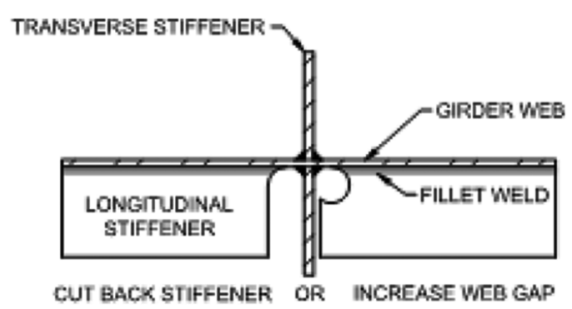

\section{CIF Retrofit at Longitudinal Stiffener Splice Where Stiffener is Cut Back to Relieve Constraint}

Figure 3.28 Typical retrofits for CIF details at gusset plates and longitudinal stiffeners. 


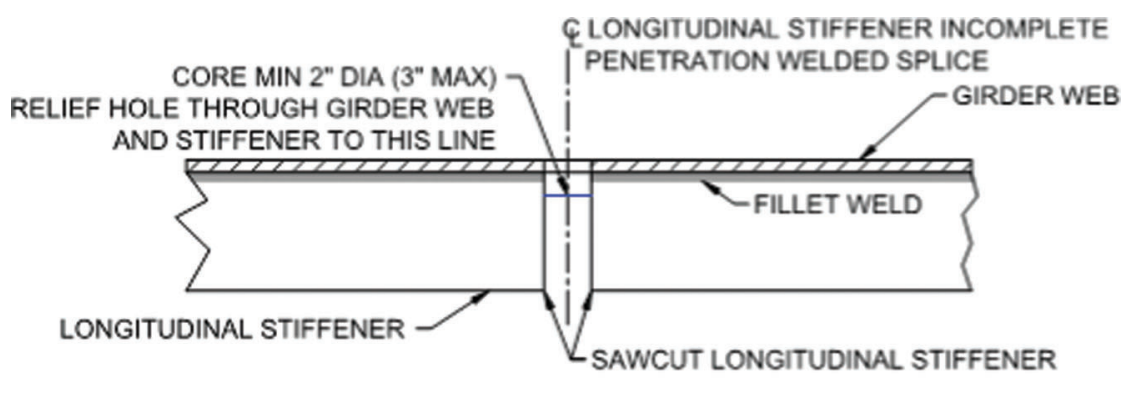

PLAN VIEW

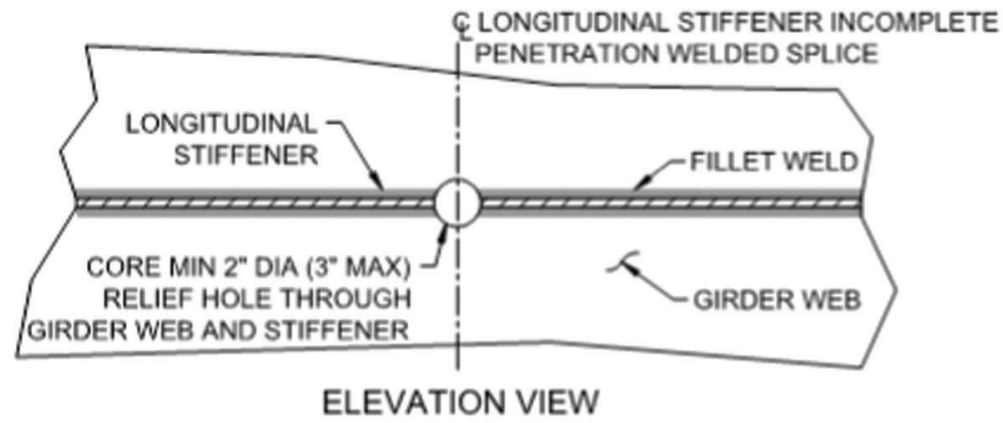

\section{Details for CIF Retrofit at Longitudinal Stiffener Splice Where Entire Splice in Stiffener is Removed}

Figure 3.29 Retrofit for longitudinal stiffeners with poor quality welded splices.

and the tri-axial stress condition. This method will allow for the through thickness deformation of the web through Poisson's affect. Special attention must be given to whether or not the detail will become susceptible to distortion-induced fatigue cracking as a result of the drilled holes. This will depend on the connections of the gusset plate to the other elements. Other difficulties may occur due to the limited room for access at most of the details and alternate strategies have been developed. In addition, quality control must be maintained to ensure that the web plate is not "nicked" or "gouged." After the holes are in place, the web gap area must be ground smooth using appropriate die grinding equipment and flapper wheels to provide a smooth surface finish. If the gusset plate or longitudinal stiffener is fillet welded to the web, smooth tapering of fillet welds can result in hair-thin cross sections of weld metal that can be vulnerable to fatigue cracking. Care should be taken to blunt the thin termination of the fillet weld to reduce the potential for fatigue cracking. Typically, a cold chisel and hammer is used to perform this task. Poor quality work can result in fatigue cracking at the retrofit or other problems.

Typical sketches of effective retrofits for CIF details at gusset plates and longitudinal stiffeners are shown in Figure 3.28. In these examples, the gusset plate and longitudinal stiffener are not welded to the transverse stiffener.

The CIF retrofit shown in Figure 3.29 for a longitudinal stiffener splice is intended to be applied only where these elements are in tension or experience stress reversal, not in a compression zone. As such, there is typically not a need to stiffen the web in the vicinity of the cored hole.

Figure 3.30, Figure 3.31, and Figure 3.32 show these repair concepts being applied in the field.

\section{Field Directions for Repair of Details Susceptible to CIF}

1. Obtain guidance from the Engineer as to the appropriate repair approach at each location. For a given structure, more than one approach may be required.

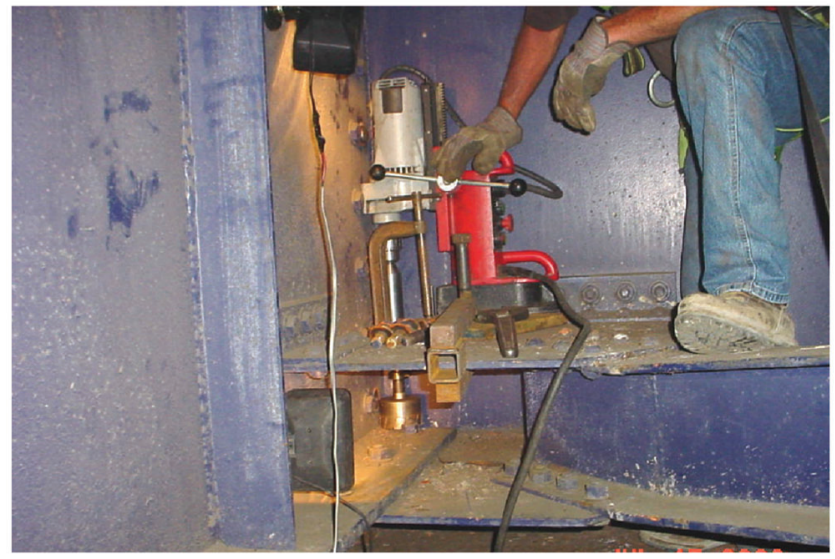

Figure 3.30 Hole-drilling process at gusset detail with difficult access. 


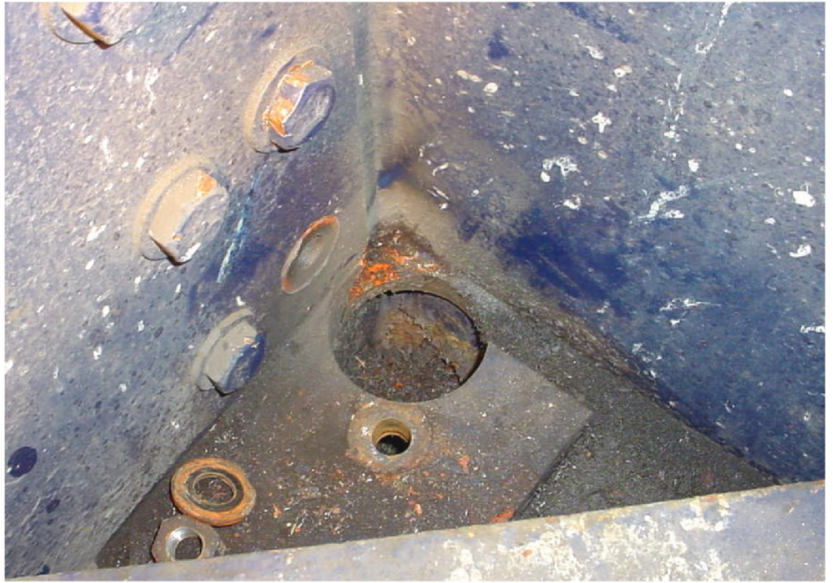

Figure 3.31 Retrofit hole (prior to finish grinding). (Note guide plate used as template to ensure core barrel does not "wobble".)

2. CAUTION: All parties involved must understand that these details cannot be "inspected" to determine likelihood of failure; once identified, they need to be repaired immediately.

3. Where hole-drilling is recommended by the Engineer, follow Section 3-6.b (see also Section 3-2.d: Field Directions for Repair of Surface Discontinuities with respect to grinding guidelines).

4. Some considerations for retrofits which utilize holedrilling are as follows:

a. Drill a vertical hole in the corner of the gusset plate and clean up weld toes of vertical weld so that the original profile of the fillet weld is kept consistent throughout.

b. Grind the edges of the hole along the web gap region to remove any remaining weld metal.

c. The gusset plate to web weld toes at the edge of the drilled hole should be transitioned by grinding and chiseling in order to provide a profile similar to the termination of typical fillet welds.

d. During drilling and grinding of the intersecting weld locations, internal discontinuities may be uncovered which should be completely removed through further

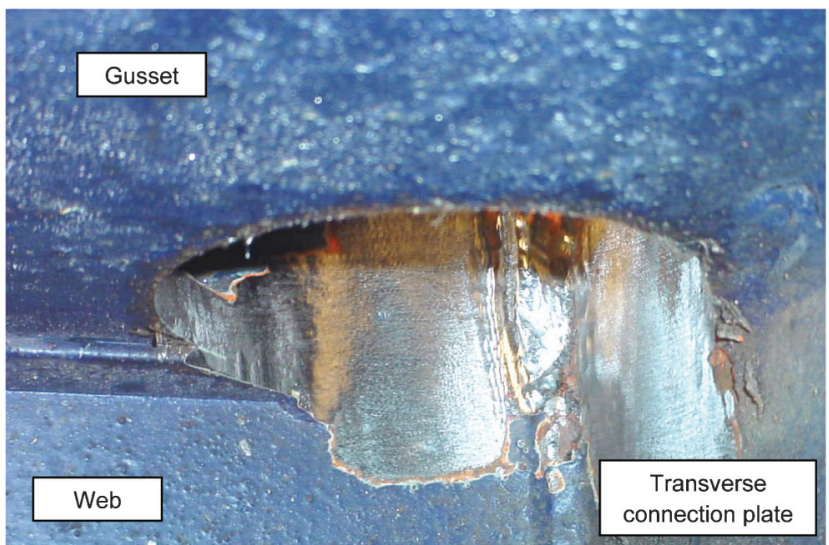

Figure 3.32 Close-up of retrofit hole with finished ground surface.

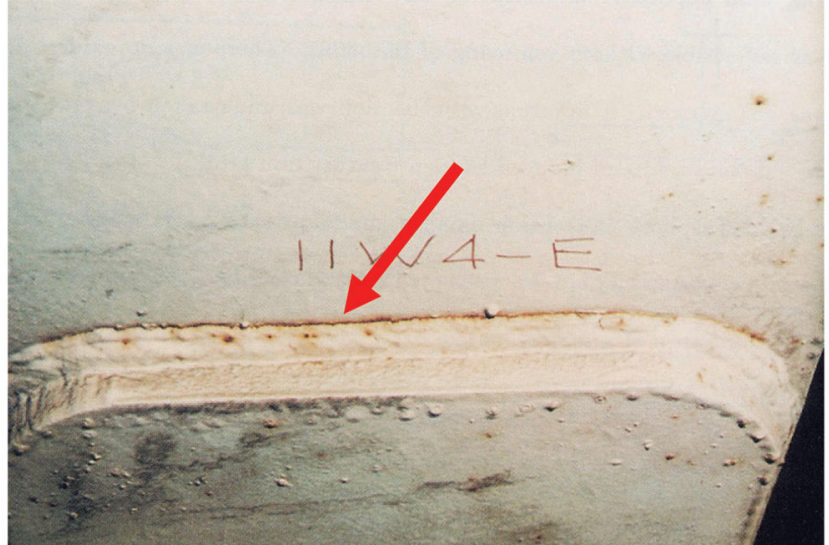

Figure 3.33 Cover plate with weld at termination.

grinding. These locations should be transitioned on a 5:1 minimum slope.

\subsection{Cover Plate Repair}

\section{A. Introduction}

Cover plates are commonly used on bridges in order to increase the capacity of a member in high stress locations. Although built-up riveted girders utilized details similar to cover plates, cover plates have historically been used on rolled shapes but they may also be found on plate girders. Cover plates are almost always welded to the outside of the flange using fillet welds. The fillet welds may extend completely around the cover plate as shown in Figure 3.33 or be terminated before the end of the cover plate as shown in Figure 3.34. Both of these details have very poor fatigue resistance and cracking often occurs at the weld toes at the termination of the cover plate due to a high stress concentration. Because of the poor fatigue resistance, these details are classified by AASHTO as either Category $\mathrm{E}$ or $\mathrm{E}^{\prime}$ depending on cover plate thickness, width, and the termination weld.

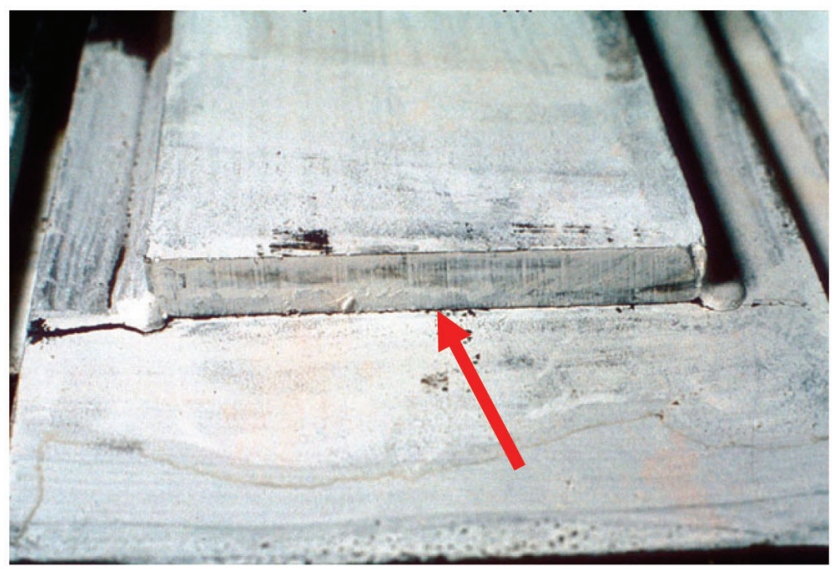

Figure 3.34 Cover plate without weld at termination. 


\section{B. Evaluation Techniques}

A hands-on visual inspection of cover plates is required by some owners during every routine inspection. Dye penetrant testing (PT) and/or magnetic particle testing (MT) should be used if cracks are suspected based on the visual inspection. The inspection should be concentrated on the welds at the termination of the cover plates. This region undergoes the largest stress concentration since the load in the cover plate is transferred to the flange through the fillet welds. Hence, cracks often develop on the flange of the primary member along the toe of the fillet weld at the termination of the cover plate. It is critical that NDT is performed in this location to determine if damage is present. The extents of the damage should be determined as it will be important in the repair strategy.

An engineering analysis of the fatigue life at the detail may be performed using an estimation of the stresses or, preferably, live load strain gage data. If it is found that the stresses are below the Constant Amplitude Fatigue Limit (CAFL) of the detail category, the detail may not require hands-on inspection at such a high frequency. As a precautionary measure, UIT can be performed along the toe of the fillet weld to increase the fatigue resistance. The history of cracking on similar details elsewhere in the bridge should be considered before taking remedial action.

If any damage is found, a repair strategy should be developed depending on the extents of the damage and the criticality of the member. An engineering analysis of the critical crack size that the member can tolerate can be used to decide on the necessary corrective action. The repair action may include grinding out the crack or damage, performing UIT along the toe of the fillet weld, and/or constructing a bolted retrofit. UT may be used to estimate the depth of the discontinuity to determine if it extends into the primary member. Due to the difficulties in determining the crack tip, UT should not be used exclusively to define the extents of the damage. Advanced UT methods have been developed which have increased sensitivity and crack depth measuring capabilities. Two of these methods are phased array UT (PAUT) and time of flight diffraction (TOFD). PAUT uses multiple element transducers to send sound into the member over a range of angles which increases the coverage greatly over conventional UT. TOFD uses a pair of ultrasonic probes on opposite sides of the tested location with one prove emitted ultrasonic pulses and the other probe receiving them. Instead of measuring the amplitude of the response like conventional UT and PAUT, TOFD uses the time of flight of the diffraction from the tip of the crack to determine its depth.

\section{Repair Considerations}

If the damage does not extend into the primary member or is very shallow, the first step in the repair may include removing the crack through surface grinding. Although this is important to limit the chance for the propagation of further damage, grinding out the crack will not remove the stress concentration and shear lag effects which caused the initiation of damage. Removing the damage by grinding will also not increase the fatigue resistance or fatigue category of the detail. For cover plates wider than the flange and less than $0.8^{\prime \prime}$ thickness, excessive grinding without any other repair procedure may, in fact, lower the fatigue resistance by eliminating part of the fillet weld on the termination of the cover plate which will reduce AASHTO Category E details to AASHTO Category $\mathrm{E}^{\prime}$. Hence, it is important that removal of the damage by grinding is paired with either UIT or a bolted retrofit. The procedure for grinding should follow the guidelines in Section 3-2.d: Field Directions for Repair of Surface Discontinuities and the surface should be smooth and without any sharp transitions.

UIT may be used if, after grinding, it is found that the damage does not extend into the primary member and the fillet weld at the termination of the cover plate has not been removed. As explained in Section 3-5.b, UIT will induce compressive residual stresses into the weld toe and can increase the fatigue performance of a cover plate weld from AASHTO Category $\mathrm{E}^{\prime}$ to Category C (Fisher, Statnikov, \& Tehini, 2001). The UIT procedure should meet the guidelines in Section 35.d. If it is desired to have added safety due to the criticality of the member, a bolted retrofit may be used instead of or in combination with UIT. UIT will not repair any damage that was initiated previously, and micro-cracking may still be present along the weld toe. Although the compressive residual stresses induced by UIT will help to limit the propagation of the cracks, cracking may still occur in this location if placed under large stress ranges due to the application of live load.

A bolted retrofit should be used if, after grinding, it is found that the damage has extended into the primary member. A bolted retrofit will not be as economical as UIT but will add internal redundancy to the member. This redundancy may be important if the member is a FCM. The splice plates added in this retrofit will be able to carry the load transferred from the flange if it would crack at the end of the cover plate. The plan view of the bolted retrofit is shown in Figure 3.35 and a cross section view of the bolted retrofit is shown in Figure 3.36.

A fill plate is placed at the end of the cover plate while leaving a small gap between these plates to allow for the cover plate fillet weld. Splice plates are then attached to the top of the fill plate and the cover plate along with the other side of the flange plate. High strength ASTM A325 or A490 bolts should be used in the retrofit and should be fully pretensioned. Although this retrofit is mainly precautionary, it should be designed with adequate resistance to carry the load for the flange and should not slip when initially loaded.

If an engineering analysis shows that there is a need for a retrofit at a cover plate termination due to the high probability of cracking or there is a history of 


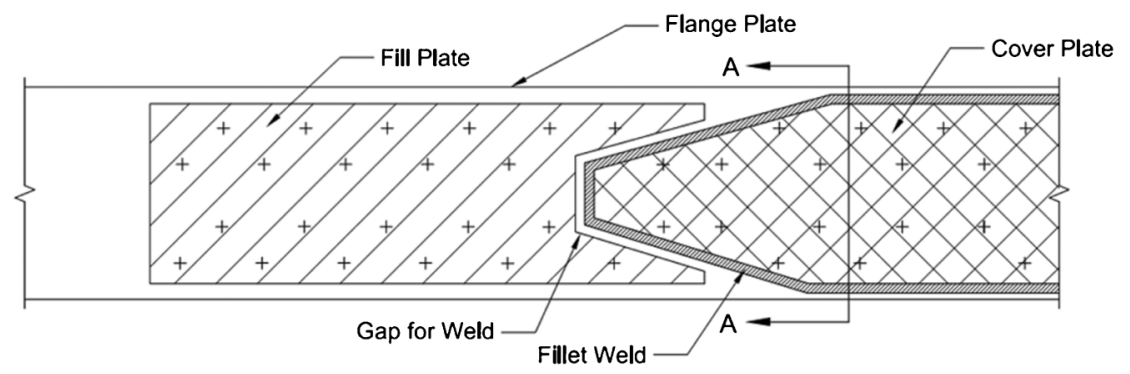

Figure 3.35 Plan view of bolted cover plate retrofit (without splice plate).

cracking at similar details, either a bolted retrofit or UIT on the weld toe could be utilized as a precautionary measure to provide internal redundancy or add fatigue resistance to the detail. Although the added safety provided by these retrofits and repairs may outweigh the cost of repairing future fatigue damage, there are examples of cover plate terminations which have not had service issues due to low live load stresses.

\section{Field Directions for Repair of Cover Plates}

1. Locate cover plate ends with stress ranges that may lead to fatigue problems.

2. Perform visual inspection along with PT and/or MT to determine if any damage is present.

3. Check for depth of damage using UT and determine if damage has propagated into primary member.

4. Attempt to grind out the damage unless it is known that it has propagated into the primary member.

5. Take care not to remove excessive amounts of material.

6. Grind smooth and parallel to primary stresses.

7. If damage is removed and fillet weld still remains (or for precautionary measures), perform UIT along toe of fillet weld.

8. If damage is located in primary member and/or weld toe has been removed (or for precautionary measures), design a bolted splice and construct over cover plate termination. The bolted retrofit will provide the greatest safety against fracture due to fatigue growth and may be desired for FCMs.

\subsection{Rivet and Bolt Removal and Replacement}

\section{A. Introduction}

Rivets and bolts may require removal and replacement due to local corrosion of the mechanical fastener or pack rust between plates in a connection. Because these issues may occur on almost every steel bridge, removal of rivets and bolts may be a common procedure for bridge maintenance personnel. Although this guide concentrates on the evaluation of the condition of the localized region around the mechanical fasteners, the removal of rivets and bolts are not only limited due to the deterioration of this region. Rather, removal of rivets and bolts may also be required due to a repair or retrofit elsewhere on the bridge elements. A video showing the process of rivet removal using an air hammer chisel on an in-service bridge can be viewed at http://dx.doi.org/10.4231/R7RJ4GC7.

If done properly, the replacement of rivets with pretensioned high strength bolts should increase the fatigue resistance of the connection due to the localized compression from the pretension in the bolts. Although added fatigue resistance should occur, it should not be counted on as it requires that the connection perform as slipcritical and that all surface discontinuities have been removed, conditions not typically achieved in these repairs.

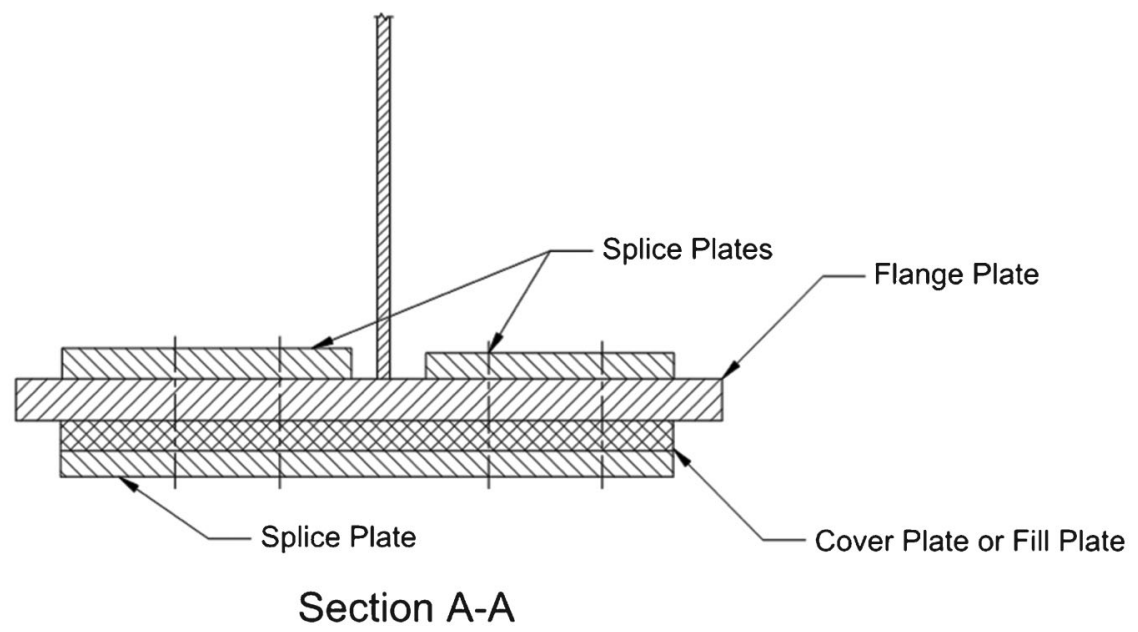

Figure 3.36 Elevation view of bolted cover plate retrofit. 

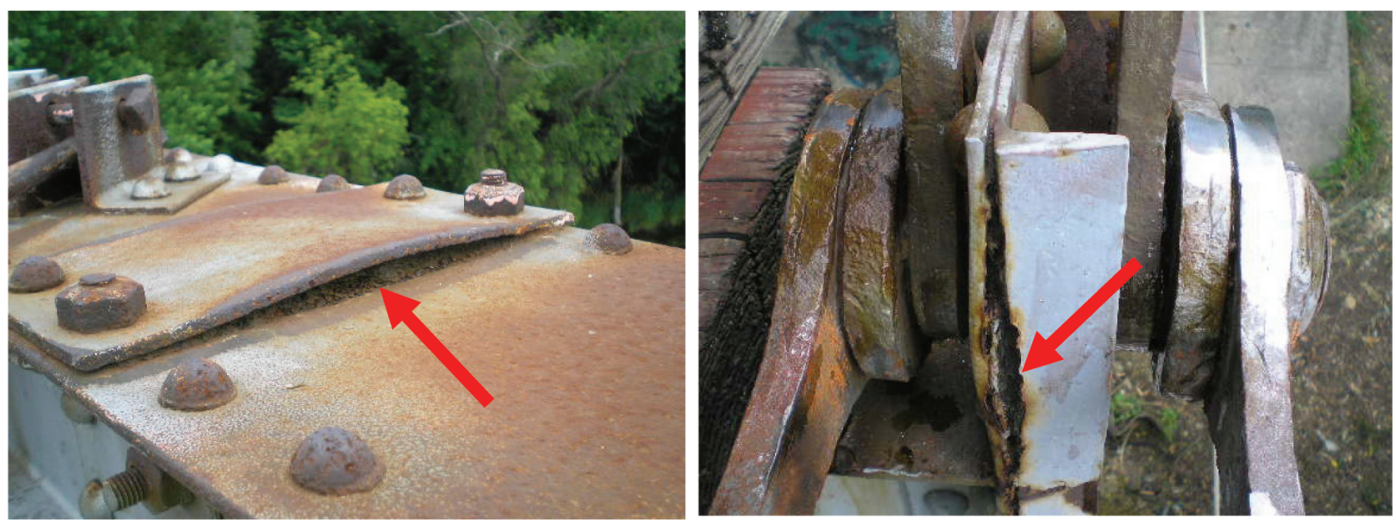

Figure 3.37 Pack rust in mechanically fastened connections.

\section{B. Evaluation Techniques}

Mechanically fastened connections may be inspected visually for corrosion of the connection plates, section loss on the head of the rivet or bolt, and pack rust. Rivets may be sounded with a hammer to determine if enough section loss has occurred that the rivet has become loose or has weakened enough that the head may fracture. A wrench may be used to check for adequate pretension in a bolted connection. Pack rust, if left unchecked, will grow and induce large stresses into the connection plates. Pack rust can deform the connecting plates and can load a mechanical fastener to ultimate capacity leading to fracture of the fastener. Figure 3.37 shows two connections with a large amount of pack rust. Remedial action should be undertaken before the condition of the connection deteriorates to the condition shown in this figure.

If the deterioration of the bolted or riveted connection can be estimated, the remaining capacity of the connection can be evaluated. Accurately estimating the section loss along the shaft of a bolt or rivet can be very difficult using current NDT techniques due to the presence of corrosion products.
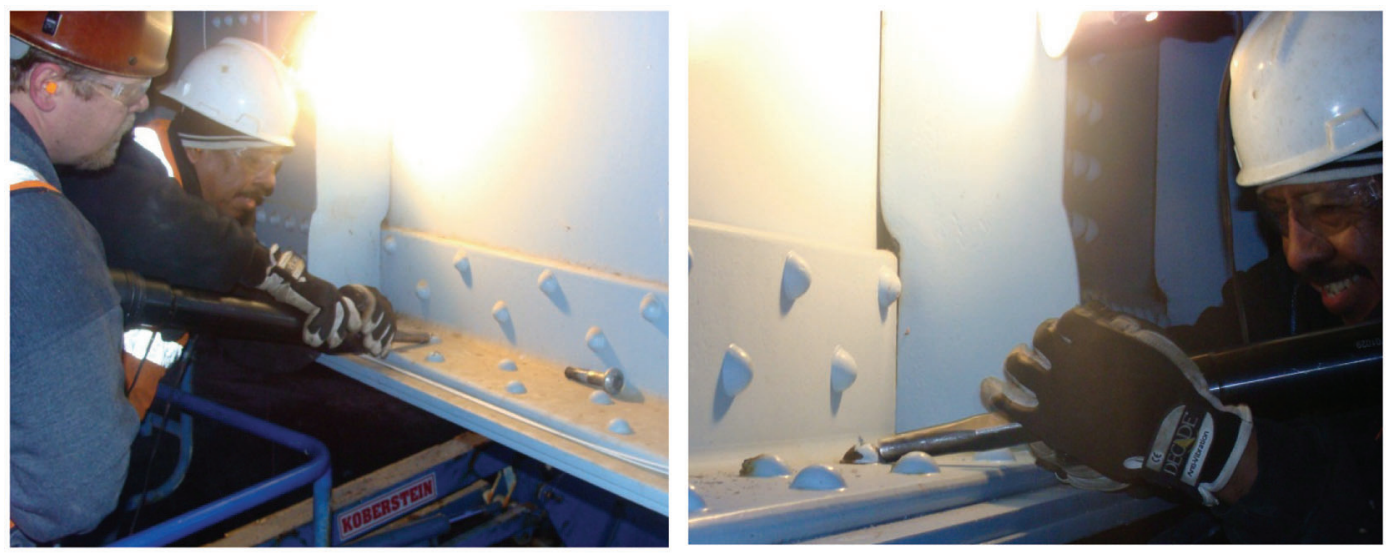

Figure 3.38 Rivet head removal using rivet buster (courtesy of Purdue University). 


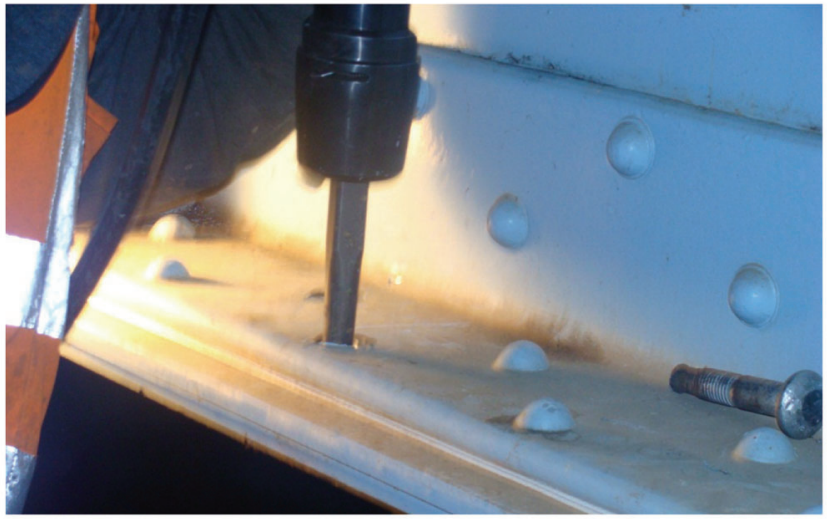

Figure 3.39 Driving rivet out of connection plates using Rivet Buster (courtesy of Purdue University).

Once the rivet head is removed, the rivet buster may be positioned vertically over the sheared rivet and the rivet may be driven out of the connection plates. Figure 3.39 shows the removal of a rivet by driving it out using a rivet buster in a vertical position.

Sometimes the rivet cannot be removed from the plates with the rivet buster. In these cases, the center of the rivet may need to be removed by drilling before the rest of the rivet can be driven out of the plate. A drill with a magnetic base to attach to the steel plate is often used. The drill can then be centered over the rivet and used to drill out most of the remaining material. This process is shown in Figure 3.40. Once the center of the rivet has been removed, the rest of the rivet can be removed with the rivet buster in the vertical position as shown in Figure 3.39.

Once the rivet is removed, the surface of the plate around the hole will be gouged and damaged as seen in Figure 3.41. The surface of the plate around the hole should be ground smooth using an abrasive sanding

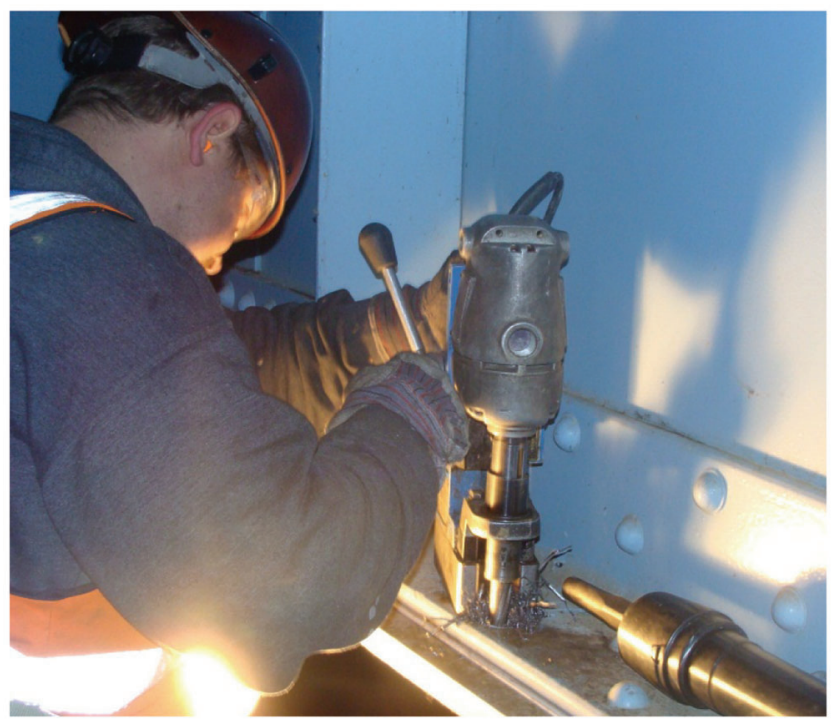

Figure 3.40 Drilling out center of rivet (courtesy of Purdue University)

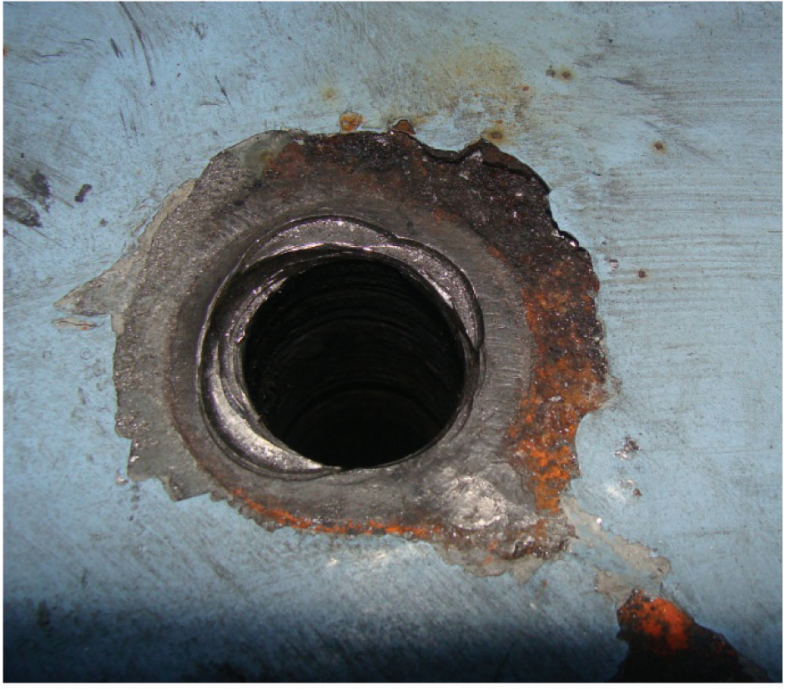

Figure 3.41 Damaged surface after rivet removal around hole (courtesy of Purdue University).

disc and the inside of the hole should be inspected for any rough surfaces or damage. The procedure should follow the guidelines in Section 3-2.d: Field Directions for Repair of Surface Discontinuities. A die grinder with a flapper wheel may be used to remove any rough surfaces on the inside of the hole. Once the surfaces on the hole have been cleaned and prepared, a visual inspection and MT should be completed to check for any cracks in the plates around the holes. If no damage is found, a bolt should be inserted into the hole and snug tightened.

If considerable damage to the plate is found that cannot be easily removed by surface grinding, an engineering analysis should be conducted on the remaining capacity and fatigue and fracture resistance. If replacement of the plate is required, the capacity of the remaining section when the plate is removed should be checked against the total load on the bridge. If pack rust is found, the plate should be removed and all corrosion should be cleaned from the connection. If after removal of the corrosion it is found that the plate did not experience significant section loss, the plate may be cleaned, painted, and reinstalled. Sealing putty such as titanium putty may be added between plates in the connection to decrease the likelihood for a corrosion issue in the future, but the bolted joint should be evaluated for loss of slip resistance at slip-critical connections due to loss of compression and friction resistance between faying surfaces.

If remaining fatigue life is a controlling limit state, the rivet holes should be reamed before installation of high strength bolts. This may require bolts one size larger in diameter unless a similar diameter meets the requirements of an oversized hole. Reaming may also be required for holes with a lot of damage that cannot be removed by grinding with a flapper wheel. The reamed hole should meet the requirements of AASHTO fatigue Category B when installed properly. 
The replacement of rivets with high strength bolts shall be on a one-to-one basis with the replacement bolts of equal or greater diameter as the rivets. Locations which are under high dead load stress may require pretensioning of the bolts before additional rivets are removed, but care should be taken to ensure that the plates remain in contact and that the bolts do not bind in the plates. For locations which are not under high dead load stress, the bolts may be installed snug tightened. Once all locations of removed rivets and bolts have been replaced with snug tightened bolts, the bolts may be further tightened to a fully pretensioned load. The bolts should be installed according to the requirements of the RCSC Specification for Structural Joints Using High-Strength Bolts (2009) for either the snug-tightened joints, pretensioned joints, or slip-critical joints. Calibration procedures including pre-installation verification and rotational capacity testing should be performed to ensure that the bolt assembly and tightening procedures will meet the pretensioned load requirements.

\section{Field Directions for Rivet and Bolt Repair and Replacement}

1. Identify locations of corrosion and pack rust and visually inspect.

2. Sound rivet heads with a hammer to determine if loose or close to fracture.

3. Remove the required bolts or rivets.

a. Use wrench to remove bolts.

b. Use pneumatic impact gun or rivet buster to knock off the rivet head and then drive out rivet.

c. If rivet or bolt cannot mechanically be removed, airarc cutting can be considered with guidance to ensure that damage to the primary member does not occur.

d. If rivet cannot be easily driven out of plates, center of rivet may need to be drilled out before being driven out, care should be taken to not penetrate surface of rivet shank.

4. The plate surface and existing hole should be ground smooth and visually inspected along with MT. Layered plates should be inspected for pack rust and repaired considering the following points.

a. Take care not to remove excessive amounts of material.

b. Grind smooth and parallel to primary stresses.

c. The existing hole may need to be reamed if damage is not removed after surface grinding.

5. If pack rust is an issue and the capacity under current loading of the bridge is adequate if the connection is fully disassembled and one of the plates is removed, the connection may be opened up and corrosion products should be removed by grinding.

a. If the plate is to be reused, a protective coating should be applied after removal of corrosion.

b. A sealant such as titanium putty may be placed in the joint before reinstallation of plates to protect against future corrosion.
6. The rivets and bolts should be replaced on a one to one basis with a high-strength bolt of equal or larger diameter.

a. If hole is reamed, a larger diameter bolt may be needed if original diameter does not meet the oversize hole requirements.

b. New bolts should be installed snug tightened until the final bolt is installed unless in a region of high dead load stress where the plates may slip into bearing if not initially pretensioned on one-to-one basis with the removal of rivets. The bolts should be pretensioned following procedures defined in RCSC or AASHTO Construction Specification.

\subsection{Welded Gusset Plate Repair}

\section{A. Introduction}

Lateral gusset plates are used to connect secondary members to primary members and can be welded to either the web or the flange of the primary member. Both of these connection types contain fatigue and fracture prone details. One of the fracture prone details that are commonly found on gusset plates is intersecting welds. Intersecting welds can lead to high amounts of constraint which may lead to CIF as seen in Figure 3.42. The guidelines in Section $G$ should be followed to remove CIF conditions in gusset plate connections.

Historically, gusset plates did not utilize smooth transitions in the connection with the web or the flange. Accordingly, high stress concentrations occur at the ends of the gusset plates. These stress concentrations, coupled with the residual stresses from the weld, increase the likelihood of cracking. Without any transition at the termination of the gusset plates, these details have very low fatigue resistance and may fall under AASHTO fatigue Category E or E'.

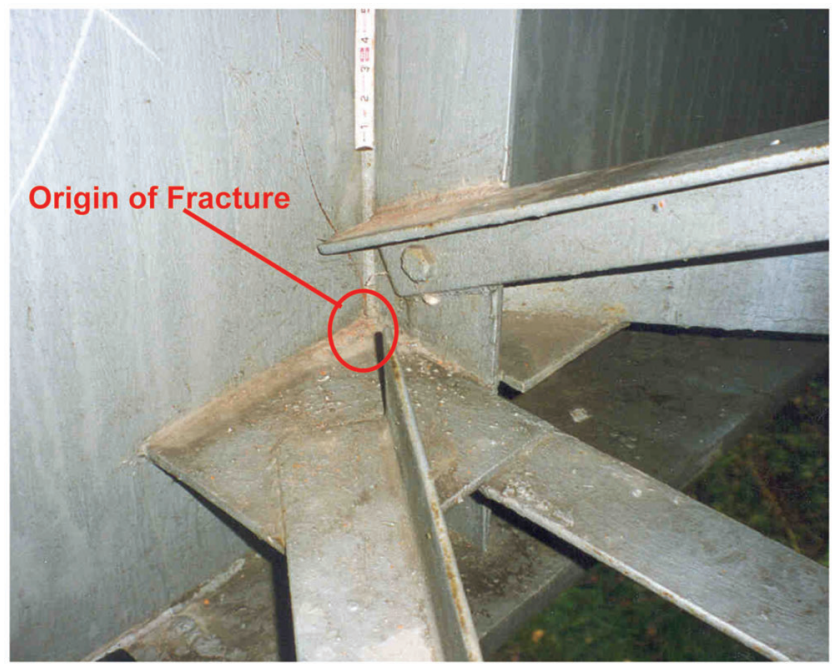

Figure 3.42 Constraint-induced fracture in gusset plate connection. 


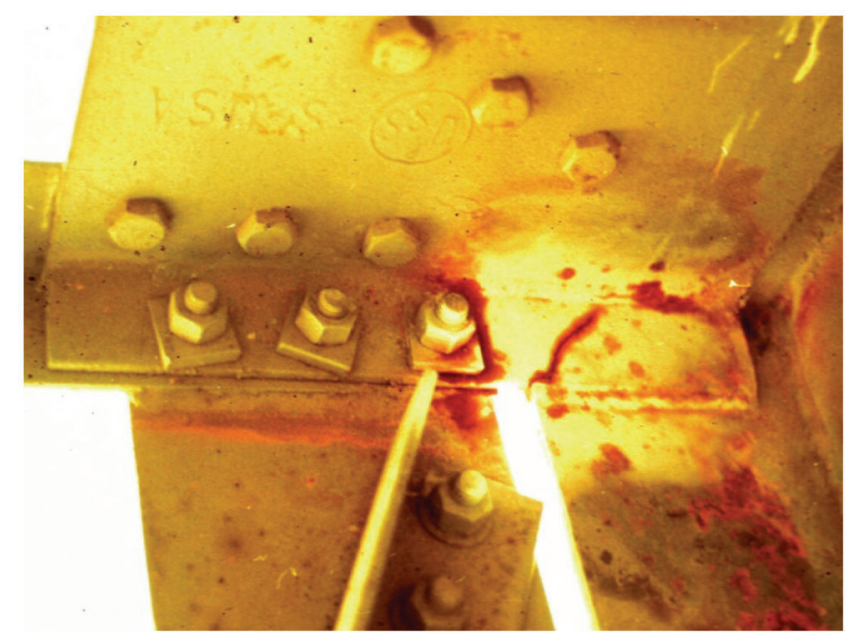

Figure 3.43 Cracking in flange of channel (gusset plate) and girder.

Gusset plates are likely to have fatigue issues when connected directly to the flange due to the high stresses, high stress concentration due to poor connection details, and biaxial stresses in the gusset plate. The gusset plate is not only transversely loaded but will also pick up longitudinal load from the flange of the girder. Figure 3.43 and Figure 3.44 show cracks that have propagated into the flange due to the stresses imposed on this connection.

Figure 3.43 shows a channel used as a gusset plate and welded to the bottom flange of the girder using a fillet weld perpendicular to the primary stresses. A crack initiated at the toe of this weld due to the high stress concentration at this detail. Figure 3.44 shows a lateral gusset plate welded to the bottom flange of a girder using a fillet weld parallel to the primary stresses. A crack initiated at the termination of this weld and propagated into the bottom flange. In both cases, the cracking originated due to the gusset plate picking up longitudinal load from the primary member through the "shear lag" effect, which caused a stress concentration at the toe or termination of the weld.

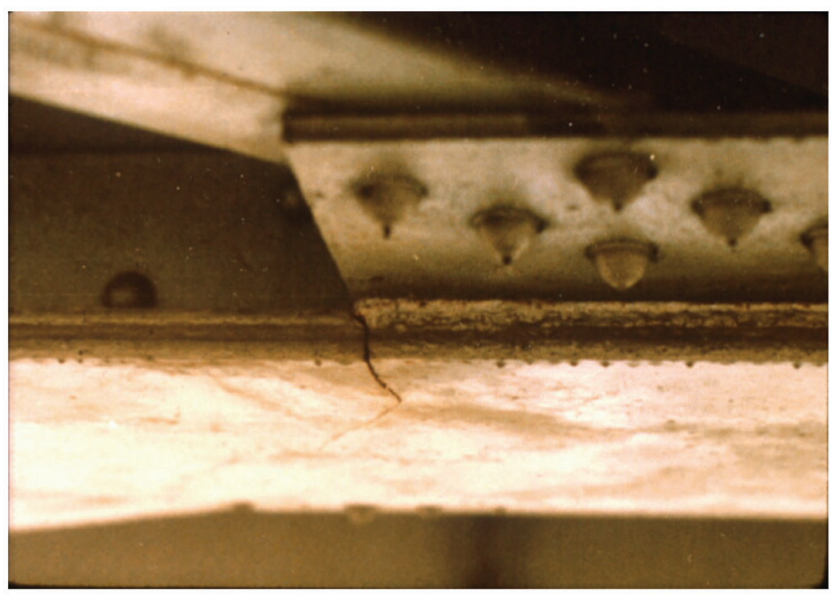

Figure 3.44 Cracking in girder flange.

\section{B. Evaluation Techniques}

Welded lateral gusset plates that may require an engineering analysis include the following:

- Plates welded to the web and not incorporating a significant transition radius at the termination of the gusset plate.

- Plates connected to the web when the members connected to the gusset plates introduce moment and cause out-of-plane distortion at the plate ends.

- Any gusset plate welded to the top or bottom girder flange. A gusset plate welded to the top or bottom of the flange will always have a stress concentration at the toe or termination of the fillet weld.

- Plates welded to the side of the flange without a significant transition radius at the termination of the gusset plate.

An engineering analysis of the fatigue life at the detail may be performed using an estimation of the stresses or, preferably, live load strain gage data. If it is found that the stresses are below the Constant Amplitude Fatigue Limit (CAFL) of the detail category, the detail may not require a hands-on inspection during every routine inspection. As a precautionary measure, UIT can be performed along the toe of the fillet weld to increase the fatigue resistance, but the history of cracking on similar details elsewhere in the bridge should be considered before taking remedial action. Details which are susceptible to out-of-plane cracking may still warrant a closer look since this type of loading is not represented during engineering analysis.

A hands-on inspection of the connection, when possible, should be completed during every routine inspection if there is a high potential for cracking due to the findings of an engineering analysis or if the member is an FCM. The welded connection of the gusset plate to the primary member should be visually inspected along with PT and/or MT. The inspection should be concentrated on the region of the termination of the gusset plates or fillet welds. This region undergoes the largest stress concentration due to the geometric discontinuity and "shear lag" of the longitudinal load. It is critical that NDT is performed in this location if a problem is expected to determine if damage is present. The extents of the damage should be determined, as it will be a key factor in the repair strategy.

If any damage is found, a repair strategy should be developed which considers the extent of the damage and the "criticality" of the member. The repair action may include removing a surface crack or damage by grinding, along with performing UIT along the toe of the fillet weld and/or constructing a bolted retrofit. UT may be used to estimate the depth of the discontinuity and to determine if it extends into the primary member. Due to the difficulties in determining the crack tip, UT should not be used exclusively to define the extent of the damage.

\section{Repair Considerations}

If no damage was found but an engineering analysis of the remaining theoretical fatigue life determines that 
the remaining fatigue life may be exceeded, a field instrumentation study to refine the input loading or a repair could be performed to ensure that the location will not fail due to fatigue. It is important that the history of cracking in similar details and locations is considered as additional action may not be warranted at low stress regions. If it is determined that a repair should be performed, the most economical repair may be to perform UIT along the toe of the fillet weld. For FCMs, a bolted retrofit may be preferred since the added internal redundancy will support the section in the event of a fracture.

If damage has been found which has not propagated into the primary member, it should be removed through grinding according to the recommendations in Section 3-2.d: Field Directions for Repair of Surface Discontinuities. A decision will need to be made whether to increase the future fatigue resistance through UIT as discussed in Section 3-5.d or construct a bolted retrofit.

There are two strategies to improving the fatigue resistance through bolted retrofits and either may be used separately or in conjunction with one another. These strategies are:

1. Provide alternate load paths around the critical detail which will improve its fatigue resistance by decreasing the stress in the weld toe and supporting the primary member if a fracture would occur.

2. Completely remove the lateral gusset plate, grind smooth all remaining weld metal, and reattach the gusset plate back to the primary member through a bolted connection. This strategy will remove all the Category $\mathrm{E}$ or $\mathrm{E}^{\prime}$ details and replace them with Category $B$ details, which will significantly increase the fatigue resistance. If it can be proven through analysis that the secondary members are not necessary, the secondary members and gusset plate could be removed and all remaining weld metal could be ground smooth to establish Category A base metal.

The first strategy, which includes bolting a splice plate over the critical detail, is more effective for lateral gusset plates which are welded to the flange of the primary member than to the web. The most efficient bolted splice plate repair will be to install the splice plate on the opposite side of the flange as the lateral gusset plate. This retrofit utilizes a single splice plate which extends beyond the ends of the gusset plate on both sides and is bolted through both the flange and the gusset plate. The dimension of the plate (i.e., thickness, width, and length) should be determined by analysis of the Engineer. An illustrative sample retrofit is shown in Figure 3.45.

The second strategy, which includes removing the existing weld and replacing with a bolted connection, should have greater potential of alleviating future fatigue problems than the first strategy since the stress concentration at the weld toe is removed.

For gusset plates on the web, the gusset plate may be cut directly off of the web using a cutting wheel, air-arc, or plasma torch. Flame cutting (including plasma and air-arc) should not be used since there is a chance that the primary member could get gouged. Once the gusset plate has been removed, the remaining weld metal should be ground smooth parallel to the primary stresses. The area should then be inspected visually and using PT or MT to determine if any damage is present. Holes should be drilled in the web and connection angles should be used to reattach the gusset plate to the web. A protective coating should be applied to all bare metal before final bolting to protect against pack rust from the infiltration of water into the connection. Figure 3.46 shows an illustrative example of a bolted retrofit using connection angles for a gusset plate welded to the web of the primary member.

For gusset plates on the flange, the weld connecting the gusset plate to the flange will need to be removed using a cutting wheel or air-arc. Care should be taken not to cut into the flange. Flame cutting or a plasma torch should not be used since it is likely that the flange will be gouged. Once the gusset plate has been removed,

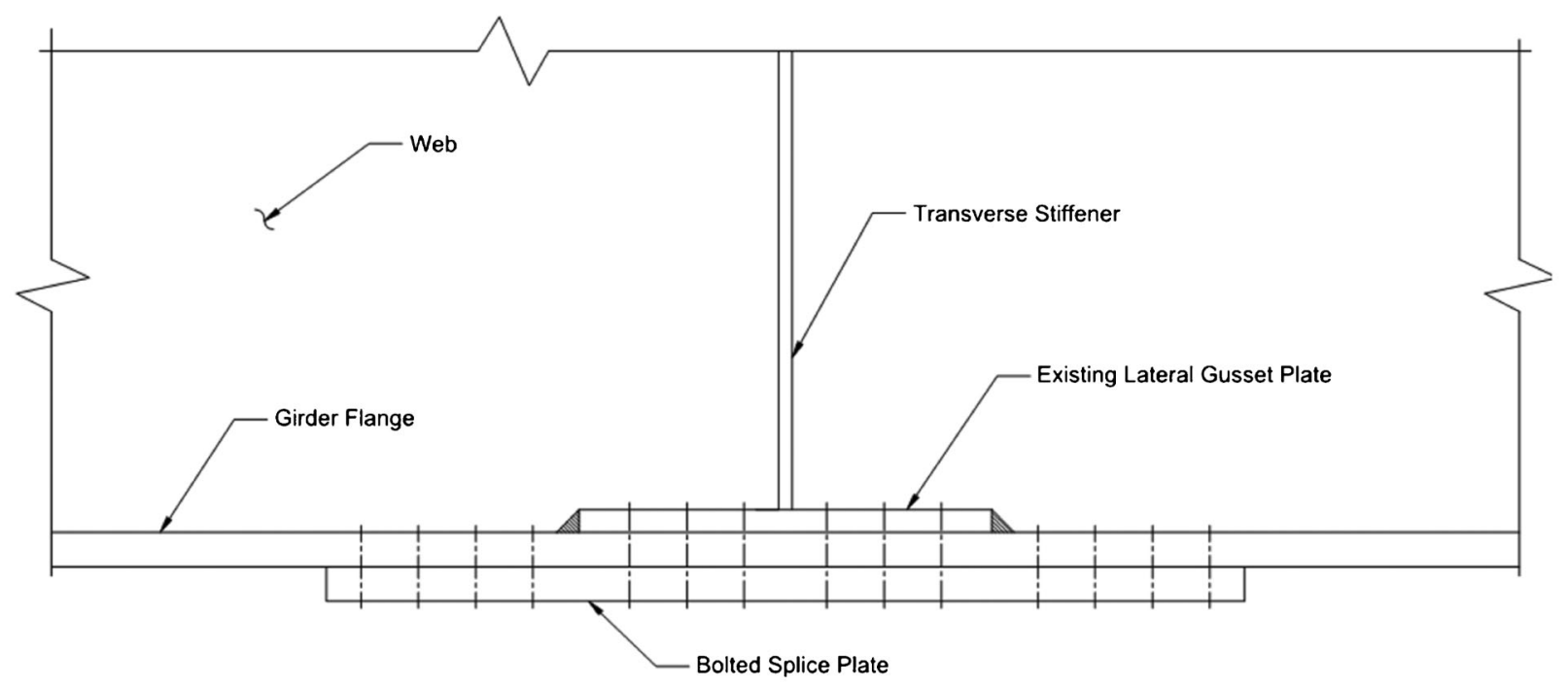

Figure 3.45 Bolted splice gusset plate repair. 


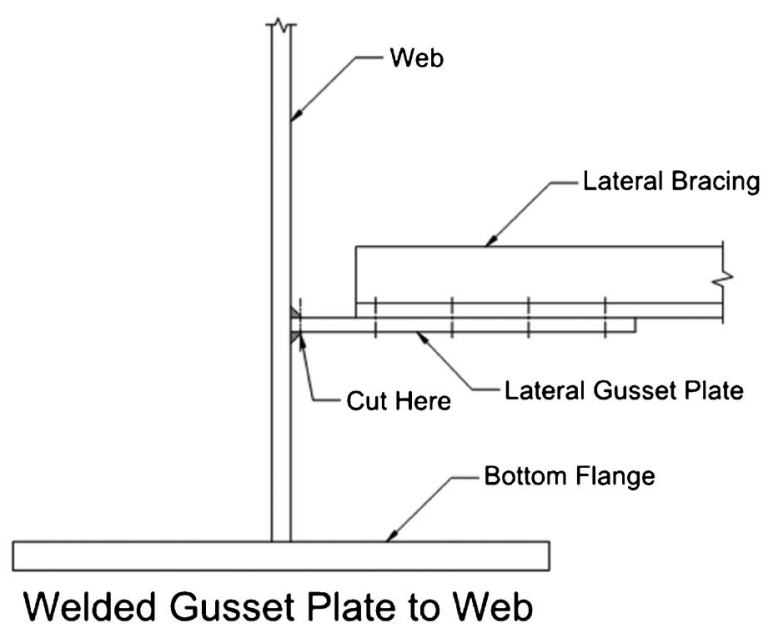

Figure 3.46 Bolted connection angle gusset plate repair.

the remaining weld metal should be ground smooth parallel to the primary stresses. The area should then be inspected visually along with PT or MT to determine if any damage is present. Holes should be drilled in the flange and gusset plate and the gusset plate should be reattached to the flange. Again, a protective coating should be applied to all bare metal before final bolting to protect against pack rust from the infiltration of water into the connection. Figure 3.47 shows an illustrative example of a bolted retrofit for a gusset plate welded to the flange of the primary member. An engineering analysis of the capacity of the section during construction, from the section loss at the bolt holes in the flange, should be conducted prior to installation.

It is important to note that removal of the gusset plate by cutting the plate off without grinding off the remaining weld material will not improve the fatigue resistance of the connection. The poor fatigue detail is the weld toe connecting to the flange and crack growth will normally be driven by the primary longitudinal stresses, not the secondary stresses from the lateral bracing. Even a gusset plate, which is not connected to anything but the primary member, will still be a primary location for crack growth and is still a Category $\mathrm{E}$ or $\mathrm{E}^{\prime}$ detail.

\section{Field Directions for Welded Gusset Plate Repair}

1. Identification of Damage

a. Identify primary locations where gusset plates may have fatigue issues, including the following:

i. Gusset plates welded to the top and bottom of the flange

ii. Gusset plates welded to the web or side of the flange of the primary member and that do not contain an adequate radius

b. Conduct a hands-on inspection of the connection, with testing concentrated near the termination of the gusset plate or fillet welds, including:

i. Visual inspection

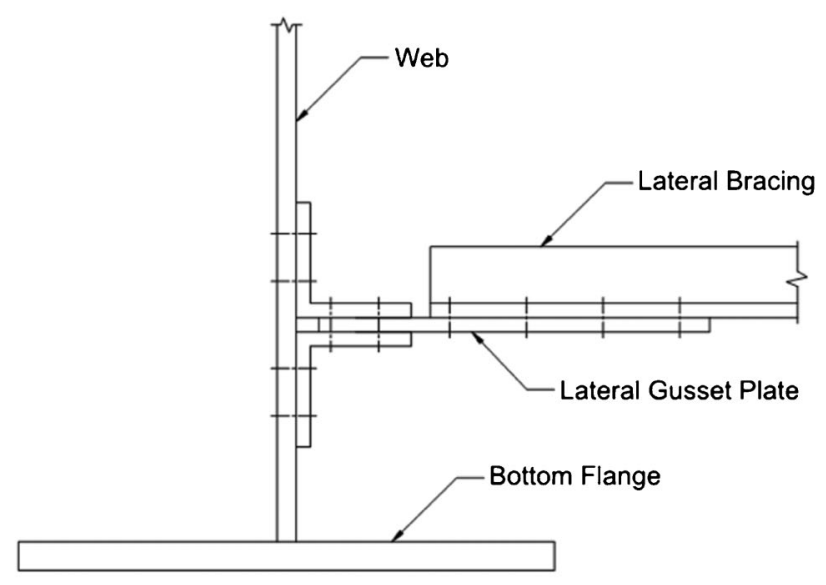

Bolted Retrofit to Web

ii. Dye penetrant and/or magnetic particle testing

iii. Ultrasonic testing may be used to estimate the depth of any damage

c. If no damage is found, an engineering analysis of the remaining fatigue life should be conducted.

i. May require live load strain gage data

ii. UIT or bolted splice may be used as a precautionary measure

d. If damage is found and has not propagated into the primary member, the damage should be removed through grinding and a retrofit strategy should be developed.

e. If damage is found, an evaluation should be performed by an Engineer to decide on the necessary repair strategy and to determine the required capacity of the retrofit.

2. Splice Plate Retrofit

a. Remove damage by grinding if located on the surface.

b. Apply protective coating to the splice plate(s).

c. Drill bolt holes and assemble splice.

d. Pretension bolts once all have been snug tightened.

3. Removing Existing Welds and Replacing with Bolted Connection

a. The gusset plate should be verified through engineering analysis that it can be removed from the primary member without affecting the load-carrying capacity of the bridge. Most lateral gusset plates likely can be safely removed, but engineering review should be performed before the gusset plate is removed.

b. Remove gusset plate from primary member.

i. For gusset plates on the web, cut through the throat of the weld at a safe distance from the web itself. A cutting wheel, air-arc, or plasma torch may be used, but do not use a flame torch.

ii. For gusset plates on the flange, cut through the throat of the weld while making sure not to gouge the flange. A cutting wheel or air-arc may be used, but do not use plasma cutter or flame torch. 


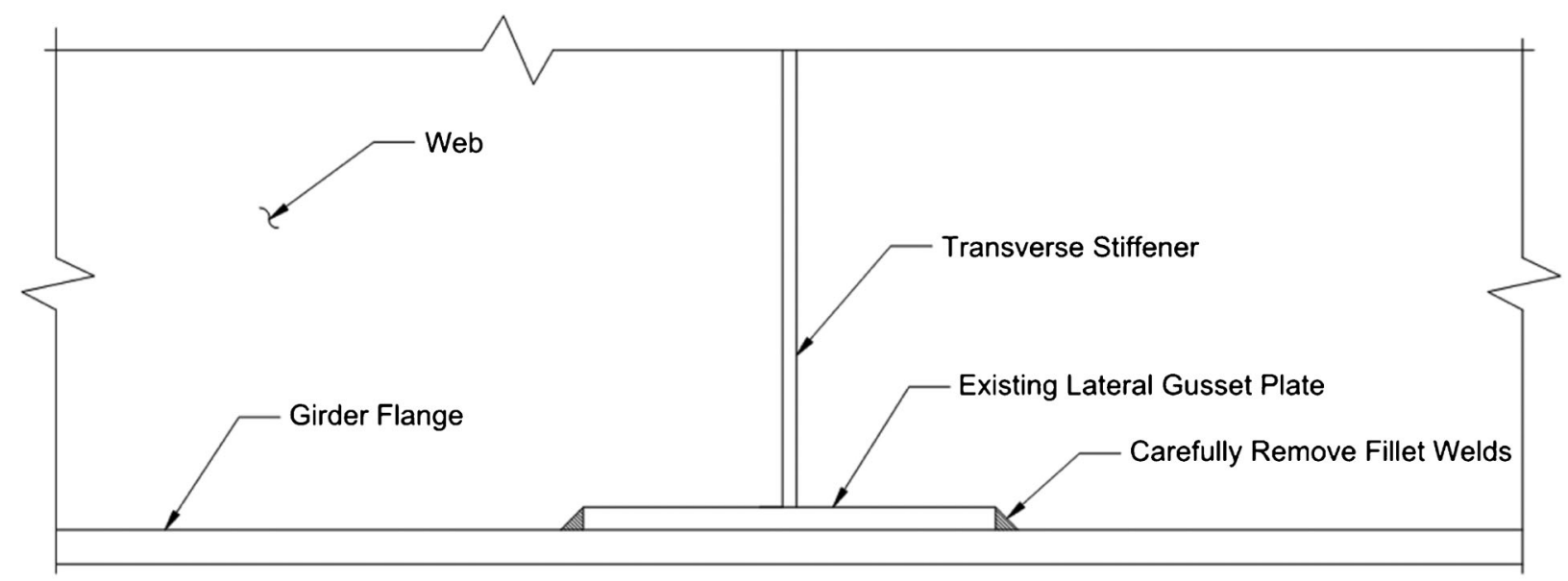

Welded Gusset Plate to Flange

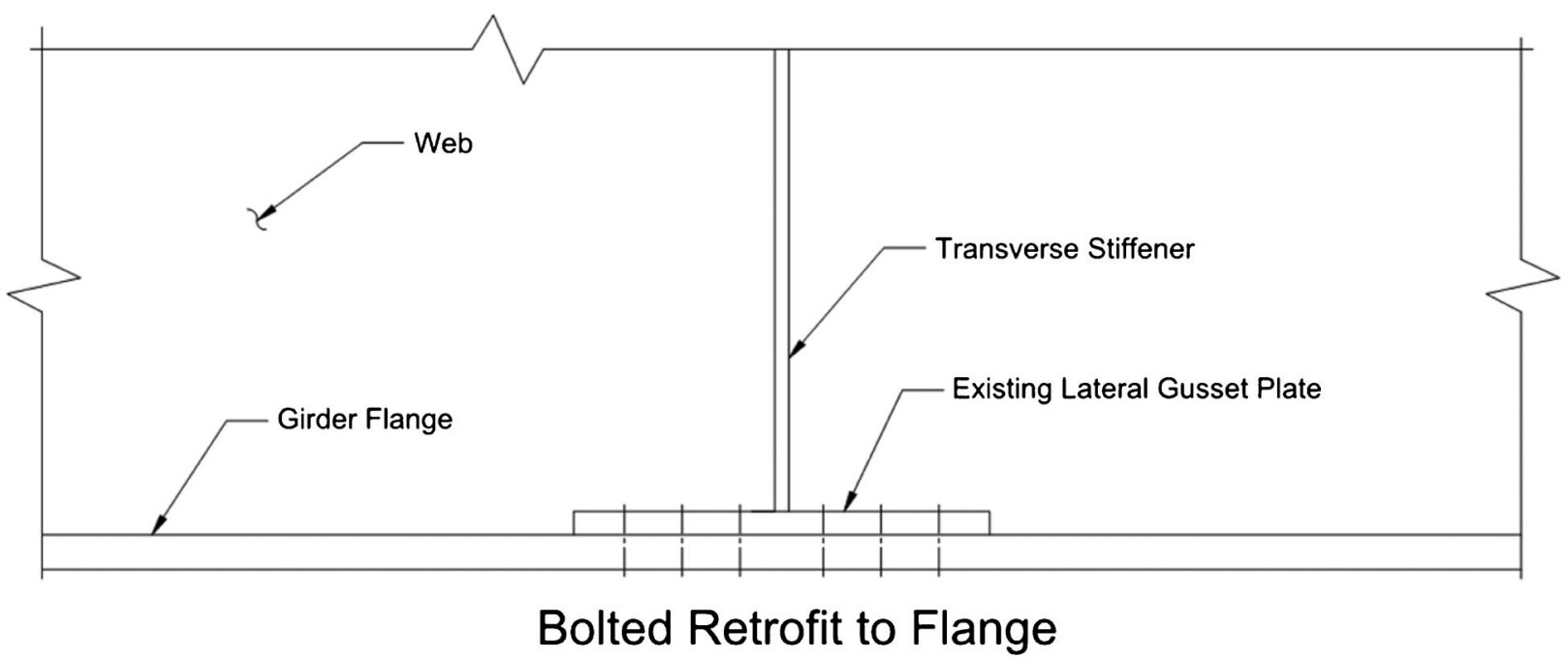

Figure 3.47 Bolted gusset plate repair to flange.

c. Grind remaining weld metal smooth and inspect for any prior damage.

i. Completely remove gusset and weld and grind smooth. Do not leave any portion(s) of a disconnected gusset plate attached to the primary member.

d. Apply protective coating to connection and bolt component(s) in place.

i. Use connection angles for gusset plate to web connections.

ii. May bolt directly to the flange for gusset plate to flange connections.

\section{REFERENCES}

American Association of State Highway and Transportation Officials (AASHTO). (2011). AASHTO Manual for Bridge Evaluation (2nd ed.). Washington, DC: Author.
American Association of State Highway and Transportation Officials (AASHTO). (2012). AASHTO LRFD Bridge Design Specifications (6th ed.). Washington, DC: Author.

American Institute of Steel Construction (AISC). (2012). AISC Steel Construction Manual (14th ed.). Chicago, IL: Author.

American Railway Engineering and Maintenance-of-Way Association (AREMA). (2014). "Steel Structures." In 2014 Manual for Railway Engineering, Vol. 2. Lanham, MD: Author.

Barth (Grider), A. S., \& Bowman, M. D. (Oct. 2001). Fatigue behavior of welded diaphragm-to-beam connections. Journal of Structural Engineering, 127, 1145-1152.

Barsom, J., \& Rolfe, S. (1999). Fracture and Fatigue Control in Structures. West Conshohocken, PA: ASTM International. Bowman, M. D., Fu, Gongkang, Zhou, Y. E., Connor, R. J., \& Godbole, A. A. (2012). Fatigue evaluation of steel bridges (NCHRP Report 721). Washington, DC: Transportation Research Board.

Connor, R. J., Dexter, R. J., \& Mahmoud, H. (2005). Inspection and management of bridges with fracture-critical details (NCHRP Report 354). Washington, DC: Transportation Research Board. 
Connor, R. J., \& Fisher, J. W. (2001). Report on field measurements and assessment of the I-64 Kanawha River bridge at Dunbar, West Virginia (ATLSS Report 01-14). Bethlehem, PA: Lehigh University.

Connor, R. J., \& Fisher, J. W. (2006). Identifying effective and ineffective retrofits for distortion fatigue cracking in steel bridges using field instrumentation. Journal of Bridge Engineering, ASCE, 11(6), 745-752.

Connor, R. J., Hodgson, I. C., Mahmoud, H. N., \& Bowman, C. (2005). Field testing and fatigue evaluation of the I-79 Neville Island bridge over the Ohio River-final report (ATLSS Report No. 05-02). Bethlehem, PA: Lehigh University.

Connor, R. J., Kaufmann, E., Fisher, J. W., \& Wright, W. (2007). Prevention and mitigation strategies to address recent brittle fractures in steel bridges. Journal of Bridge Engineering, ASCE, 12(2), 164-173.

Dexter, R., Fitzpatrick, R., \& St. Peter, D. (May 2003). Fatigue strength and adequacy of fatigue crack repairs (Report SSC-425). Washington, DC: Ship Structure Committee.

FHWA. (1989). Technical advisory on uncoated weathering steel in structures. Washington, DC: Federal Highway Administration, U.S. Department of Transportation.

Fisher, J. W. (1984). Fatigue and fracture in steel bridges. New York, NY: John Wiley and Sons.

Fisher, J. W., Albrecht, P. A., Yen, B. T., Klingerman, D. J., \& McNamee, B. M. (1974). Fatigue strength of steel beams with welded stiffeners and attachments (NCHRP Report 147). Washington, DC: Transportation Research Board.

Fisher, J. W., Barthelemy, B. M., Mertz, D. R., \& Edinger, J. A. (1980). Fatigue behavior of full-scale welded bridge attachments (NCHRP Report 227). Washington, DC: Transportation Research Board.

Fisher, J. W., Frank, K. H., Hirt, M. A., \& McNamee, B. M. (1970). Effect of weldments on the fatigue strength of steel beams (NCHRP Report 102). Washington, DC: Transportation Research Board.

Fisher, J. W., Hausammann, H., Sullivan, M. D., \& Pense, A. W. (1979). Detection and repair of fatigue damage in welded highway bridges (NCHRP Report 206). Washington, DC: Transportation Research Board.

Fisher, J. W., Jim, J., Wagner, D. C., \& Yen, B. T. (1990). Distortion induced fatigue cracking in steel bridges (NCHRP Rep. 336). Washington, DC: Transportation Research Board.
Fisher, J. W., Kaufmann, E. J., Wright, W. J., Xi, Z., Tjiang, H., Sivakumar, B., \& Edberg, W. (June 2001). Hoan bridge forensic investigation failure analysis final report (FHWA Report). Madison, WI: Wisconsin Department of Transportation.

Fisher, J. W., Statnikov, E., \& Tehini, L. (2001). Fatigue strength enhancement by means of weld design change and the application of ultrasonic impact treatment. In Proceedings of the 2001 World Steel Bridge Symposium, October 2-5, Chicago, IL. Golden Valley, MN: National Steel Bridge Alliance.

Gregory, E. N., Slater, G., \& Woodley, C. C. (1989). Welded repair of cracks in steel bridge members (NCHRP Report 321). Washington, DC: Transportation Research Board.

Hobbacher, A. (May 2007). Recommendations for fatigue design of welded joints and components (Document XIII2151-07/XV-1254-07). Paris, France: International Institute of Welding (IIW).

Kaufmann, E. J., Connor, R. J., \& Fisher, J. W. (2004). Failure analysis of the US 422 girder fracture-final report (ATLSS Report No. 04-21). Bethlehem, PA: Lehigh University.

Keating, P. B., \& Fisher, J. W. (1986). Evaluation of fatigue tests and design criteria on welded details (NCHRP Report 286.) Washington, DC: Transportation Research Board.

Koob, M. J., Frey, P. D., \& Hanson, J. M. (Sept. 1985). Evaluation of web cracking at floor beam to stiffener connection of the poplar street approaches, FAI Route 70, East St. Louis, St. Clair County, Illinois. Northbrook, IL: Wiss, Janney, Elstner Associates, Inc.

Mahmoud, H. N., Connor, R. J., \& Fisher, J. W. (2005). Finite element investigation of the fracture potential of highly constrained details. Journal of Computer-Aided Civil and Infrastructure Engineering, 20(5), 383-392.

Mueller, J. A., \& Yen, B. T. (1968). Girder web boundary stresses and fatigue (Fritz Engineering Laboratory Report No. 327.2), Welding Research Council Bulletin No. 127. Bethlehem, PA: Lehigh University.

Research Council on Structural Connections (RCSC). (2009). Specification for structural joints using high-strength bolts. Chicago, IL: Author.

Schilling, C. G., Klippstein, K. H., Barsom, J. M., \& Blake, G. T. (1978). Fatigue of welded steel bridge members under variable-amplitude loadings (NCHRP Report 188). Washington, DC: Transportation Research Board. 


\section{S-BRITE Center}

As infrastructure continues to age, the engineers who designed and had first-hand knowledge of the then new structures (e.g., the Interstate era) eventually exit the workforce. Further, the vast majority of the infrastructure comprises structures built with older materials, design philosophies, and construction practices that are no longer discussed in the classroom. To successfully maintain the existing steel bridge inventory, expertise is needed in the areas of deterioration, fatigue, fracture, corrosion, repair/ retrofit, coatings, materials, NDE, riveting, welding, and fabrication. Using Purdue's existing strengths in education and research, the Steel Bridge Research, Inspection, Training, and Engineering (S-BRITE) Center fills a growing need in the transportation industry as it relates to existing and aging steel bridges.

Additional information about the S-BRITE Center is available at https://engineering.purdue.edu/CAI/ SBRITE.

\section{Publication}

This report was published in collaboration with the S-BRITE Center, Fish and Associates, and the US Army Corps of Engineers. The full content of this technical report (in pdf and e-book formats) is available for download at http://dx.doi.org/10.5703/1288284315520. In addition, a print-on-demand bound version of this report can be purchased at that location.

\section{Open Access and Collaboration with Purdue University}

The Indiana legislature established the Joint Highway Research Project in 1937. In 1997, this collaborative venture between the Indiana Department of Transportation and Purdue University was renamed as the Joint Transportation Research Program (JTRP) to reflect state and national efforts to integrate the management and operation of various transportation modes. Since 1937, the JTRP program has published more than 1500 technical reports. In 2010, the JTRP partnered with the Purdue University Libraries to incorporate these technical reports in the University's open access digital repository and to develop production processes for rapidly disseminating new research reports via this repository. Affiliated publications have since been added to the JTRP collection, which as of 2015 has exceeded 1,000,000 downloads. 